\title{
NLT
}

United States Department of Commerce National Institute of Standards and Technology

NISTIR 3971

REVIEW OF CRYOGENIC MECHANICAL AND THERMAL PROPERTIES OF AI-Li ALLOYS AND ALLOY 2219
N.J. Simon
E.S. Drexler
R.P. Reed

QC

100

.056

\#3971

1991

C. 2 
NATIONAL INSTITUTE OF STANDARDS \&

TECHNOLOGY

Research Information Center

Gaithersburg, MD 20899

DATE DUE

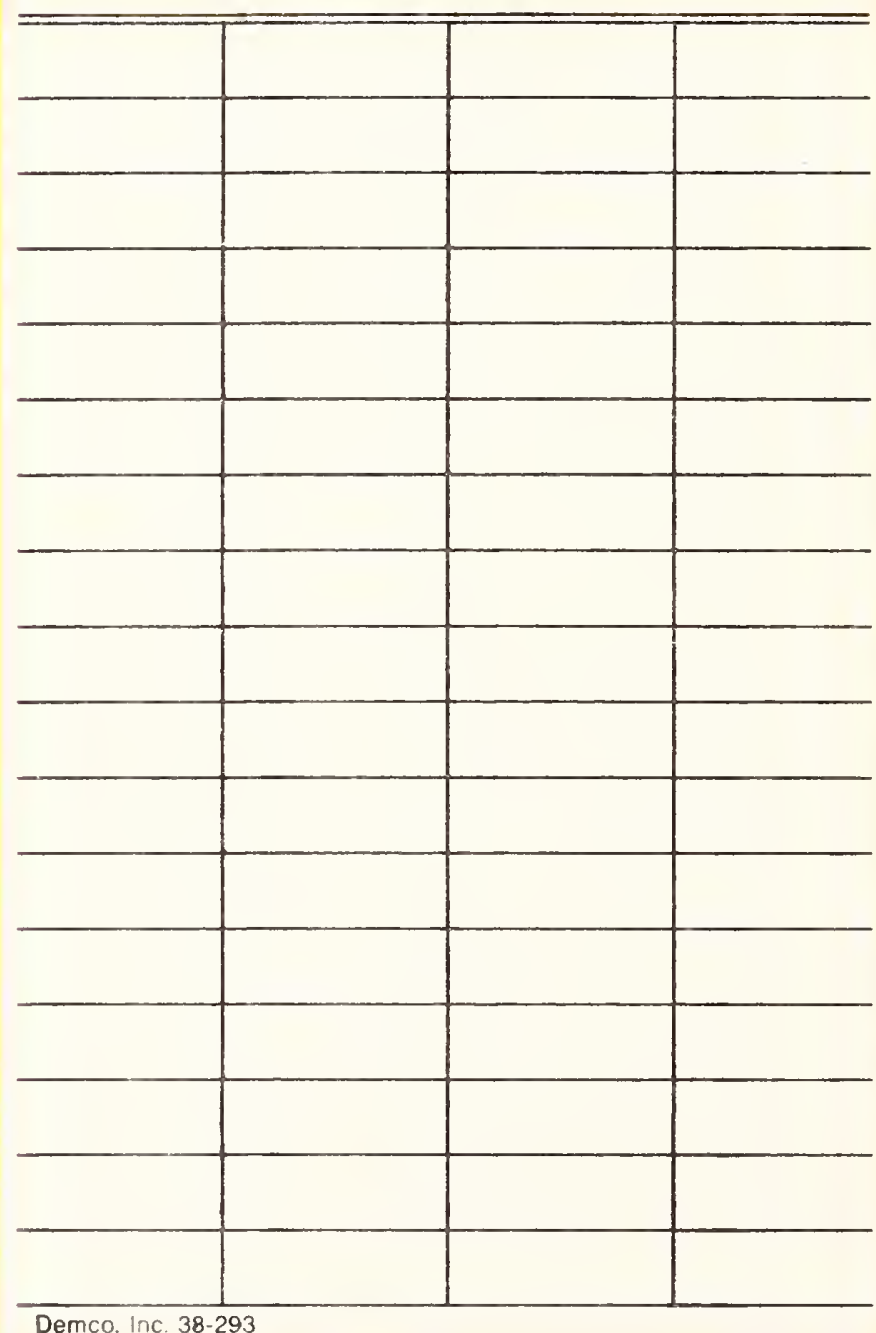


NISTIR 3971

\section{REVIEW OF CRYOGENIC MECHANICAL AND THERMAL PROPERTIES OF AI-Li ALLOYS AND ALLOY 2219}
N.J. Simon
E.S. Drexler
R.P. Reed

\section{Materials Reliability Division}

Materials Science and Engineering Laboratory

National Institute of Standards and Technology

Boulder, Colorado 80303

December 1991
Prepared for:

Astronautics Laboratory (AFSC)

Air Force Space Technology Center

Space Systems Division

Air Force Systems Command

Edwards AFB, California 93523-5000

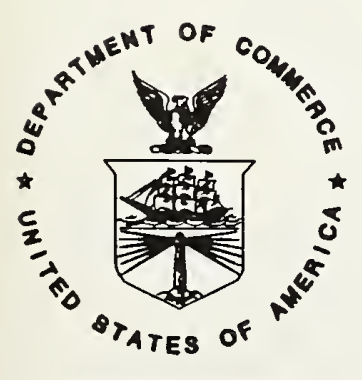

U.S. DEPARTMENT OF COMMERCE, Robert A. Mosbacher, Secretary NATIONAL INSTITUTE OF STANDARDS AND TECHNOLOGY, John W. Lyons, Director 
Executive Summary

Composition Limits for Al-Li Alloys and Alloy 2219

1. Tensile Properties

1.1. Introduction to Graphs

1.2. Alloy 8090

1.2.1. I8 (8771, 8151) Tempers

1.2.1.1. L Orientation Graphs

1.2.1.1.1. Ultimate Tenslle Strength 3

1.2.1.1.2. Tensile Yield Stength

1.2.1.1.3. Elongation

1.2.1.2. T Orientation Graphs

1.2.1.2.1. Ultimate Tensile strength 6

1.2.1.2.2. Tensile Yield Strength

1.2.1.2.3. Elongation

1.2.1.3. $45^{\circ}$ Erom L Orientation Graphs

1.2.1.3.1. Ultimate Tensile Strength 9

1.2.1.3.2. Tensile Yleld Strength 10

1.2.1.3.3. Elongation 11

1.2.1.4. S Orientation Graphs

1.2.1.4.1. Ultimate Tensile Strength 12

1.2.1.4.2. Tensile Yield Strength 13

1.2.1.4.3. Elongation 14

1.2.2. T3 Temper

1.2.2.1. L Orientation Graphs

1.2.2.1.1. Ultimate Tensile strength 15

1.2.2.1.2. Tens1le Yleld Strength 16

1.2.2.1.3. Elongation 17

1.2.2.2. T Orientation Graphs

1.2.2.2.1. Ultimate Tens1le Strength 18

1.2.2.2.2. Tensile Yield Strength 19

1.2.2.2.3. Elongation 20

1.2.3. Data Table 21

1.2.3.1. Comments from the Data Table 32

1.2.4. Test Parameter Table 33

1.2.4.1. Comments from the Test Parameter Table 35

1.3. Alloy 2090

1.3.1. T8 (81,8E41, 8E50) Tempers

1.3.1.1. L Orientation Graphs

1.3.1.1.1. Ultimate Tensile Strength 36

1.3.1.1.2. Tensile Yield Strength 37

1.3.1.1.3. Elongation 38

1.3.1.2. T Orientation Graphs

1.3.1.2.1. Ultimate Tensile Strength 39.

1.3.1.2.2. Tensile Yield Strength. 40

1.3.1.2.3. Elongation 41

1.3.1.3. $45^{\circ}$ from L Orlentation Graphs

1.3.1.3.1. Ultimate Tensile Strength 42

1.3.1.3.2. Tensile Yield Strength 43

1.3.1.3.3. Elongation 44

1.3.1.4. S Orientation Graphs

1.3.1.4.1. Ultimate Tensile Strength 45 
1.3.2. Data Table

$$
\text { 1.3.1.4.3. Elongation }
$$

1.3.2.1. Comments from the Data Table 53

1.3.3. Test Parameter Table 54

- 1.3.3.1. Comments from the Test Parameter Table 55

1.4. Alloy WL049

1.4.1. T8 (851, 8) Tempers

1.4.1.1. L Orientation Graphs

1.4.1.1.1. Ultimate Tensile Strength 56

1.4.1.1.2. Tensile Yield Strength 57

1.4.1.1.3. Elongation 58

1.4.1.2. T Orientation Graphs

1.4.1.2.1. Ultimate Tensile strength 59

1.4.1.2.2. Tens1le Yleld Strength 60

1.4.1.2.3. Elongation

1.4.1.3. $45^{\circ}$ from L Orientation Graphs

1.4.1.3.1. Ultimate Tensile Strength 62

1.4.1.3.2. Tensile Yield Strength 63

1.4.1.3.3. Elongation

1.4.1.4. S Orientation Graph

1.4.1.4.1. Ultimate Tensile Strength 65

1.4.2. T6 (651,64,68,620) Tempers

1.4.2.1. L Orientation Graphs

1.4.2.1.1. Ultimate Tensile Strength 66

1.4.2.1.2. Tensile Yield Strength 67

1.4.2.1.3. Elongation

1.4.2.2. T Orientation Graphs

1.4.2.2.1. Ultimate Tensile Strength 69

1.4.2.2.2. Tensile Yleld Strength 70

1.4.2.2.3. Elongation

1.4.2.3. $45^{\circ}$ Erom L Orientation Graphs

1.4.2.3.1. Ultimate Tensile Strength 72

1.4.2.3.2. Tensile Yield Strength 73

1.4.2.3.3. Elongation 74

1.4.2.4. S Orientation Graph

1.4.2.4.1. Ultimate Tensile strength 75

1.4.3. T3 (351, 3) Tempers

1.4.3.1. L Orientation Graphs

1.4.3.1.1. Ultimate Tensile Strength 76

1.4.3.1.2. Tensile Yleld Strength 77

1.4.3.1.3. Elongation 78

1.4.3.2. T Orientation Graphs

1.4.3.2.1. Ultimate Tensile Strength 79

1.4.3.2.2. Tensile Yield Strength 80

1.4.3.2.3. Elongation 81

1.4.3.3. S Orientation Graph

1.4.3.3.1. Ultimate Tensile Strength 82

1.4.4. Data Table

1.4.5. Test Parameter Table

1.5. Alloy 2219

1.4.5.1. Comments from the Test Parameter Table 93

1.5.1. T8 (87, 851) Tempers

1.5.1.1. L Orientation Graphs 
1.5.1.1.1. Ultimate Tensile Strength 94

1.5.1.1.2. Tensile Yield Strength 95

1.5.1.1.3. Elongation 96

1.5.1.2. T Orientation Graphs

1.5.1.2.1. Ultimate Tensile Strength 97

1.5.1.2.2. Tensile Yield Strength 98

1.5.1.2.3. Elongation

99

1.5.1.3. $45^{\circ}$ from L Orientation Graphs

1.5.1.3.1. Ultimate Tensile Strength 100

1.5.1.3.2. Tenslle Yleld Strength 101

1.5.1.3.3. Elongation

102

1.5.1.4. S Orientation Graph

1.5.1.4.1. Ultimate Tensile Strength 103

1.5.2. T3 Temper

1.5.2.1. L Orientation Graphs

1.5.2.1.1. Ultimate Tensile Strength 104

1.5.2.1.2. Tensile Yield Strength 105

1.5.2.1.3. Elongation

106

1.5.2.2. T Orientation Graphs

1.5.2.2.1. Ultimate Tensile Strength 107

1.5.2.2.2. Tensile Yield Strength 108

1.5.2.2.3. Elongation

109

1.5.2.3. S Orientation Graph

1.5.2.3.1. Ultimate Tensile Strength 110

1.5.3. Data Table

1.5.4. Test Parameter Table 125

2. Fracture Properties

2.1.1. Figure of CT Orlentations 128

2.2. Alloy 8090

2.2.1. Fracture Toughness vs. Temperature Graph

129

2.2.2. Fracture Toughness vs. Tensile Yleld Strength Graphs

2.2.2.1. $295 \mathrm{~K}$

2.2.2.2. $77 \mathrm{~K}$

130

2.2.2.3. $4 \mathrm{~K}$

2.2.3. Data Table

133

2.2.3.1. Comments from the Data Table

135

2.2.4. Test Conditions Table

2.2.4.1. Comments from the Test Conditions Table 137

2.3. Alloy 2090

2.3.1. Fracture Toughness vs. Temperature Graph

138

2.3.2. Fracture Toughness vs. Tensile Yleld Strength Graphs

2.3.2.1. $295 \mathrm{~K}$

2.3.2.2. $77 \mathrm{~K}$

2.3.2.3. $4 \mathrm{~K}$

139

140

141

2.3.3. Data Table

142

2.3.3.1. Comments from the Data Table

144

145

2.3.4. Test Conditions Table

146

2.4. Alloy WL049

2.3.4.1. Comments from the Test Conditions Table

2.4.2. Fracture Toughness vs. Tensile Yield Strength Graphs

2.4.2.1. $295 \mathrm{~K}$

2.4.2.2. $77 \mathrm{~K}$ 


$$
\text { 2.4.2.3. } 4 \mathrm{~K}
$$

2.4.3. Data Table

2.4.3.1. Comments from the Data Table 155

2.4.4. Test Conditions Table

2.5. Alloy 2219

2.5.1. Fracture Toughness vs. Temperature Graph . 157

2.5.2. Fracture Toughness vs. Tensile Yield Strength Graphs 2.5.2.1. $295 \mathrm{~K}$

2.5.3. Data Table

2.5.4. Test Conditions Table 164

3. Elastic Propertes 165

3.1. Introduction to Graphs 165

3.1.1. Temperature Dependence 165

3.1.2. Effects of Alloying Elements, Cold Work, and Other Factors

3.2. Young's Modulus Graph, Alloys 2090 and 2219

3.3. Shear Modulus Graph, Alloys 2090 and 2219

3.4. Bulk Modulus Graph, Alloys 2090 and 2219

3.5. Poisson's Ratio, Alloys 2090 and 2219

3.6. Density and Elastic Constants of Al-Li Alloys and Alloy
2219 at Ambient Temperature

3.7. Elastic Constants of Al-LI Alloys and Alloy 2219 at Low
Temperatures

$\begin{array}{ll}\text { Temperatures } & 172 \\ \text { al Properties } & 173\end{array}$

$\begin{array}{ll}\text { 4. Thermal Properties } & 173 \\ \text { 4.1. Specific Heat } & 173\end{array}$

$\begin{array}{ll}\text { 4.1. Specific Heat } & 173 \\ \text { 4.1.1. Introduction to Graph } & 173\end{array}$

4.1.2. Graph for Alloys 8090, 2090, 2024(2219) 174

4.1.3. Specific Heat of Al-Li Alloys and Alloy 2219

4.2. Thermal Conductivity 176

4.2.1. Introduction to Graph 176

4.2.2. Graph for Alloys 8090, 2090, 2219

4.2.3. Thermal Conductivity of Al-Li Alloys and Alloy $2219 \quad 178$

4.3. Mean Thermal Expansion 179

4.3.1. Introduction to Graph 179

4.3.2. Graph for Alloys 8090, 2090, 2219

4.3.3. Mean Thermal Expansion of Al-Li Alloys and Alloy
2219

5. Acknowledgements 182

6. References 183 


\section{EXECUTIVE SUMMARY}

The review of cryogenic mechanical and thermal properties presented here is part of a broader National Institute of Standards and Technology (NIST) program to assess new high-strength Al-Li alloys for use in the cryogenic tankage of the Advanced Launch System (ALS). The purpose of the NIST program has been to assess the relative suitability of high-strength Al-Li alloys and alloy 2219 for use in ALS cryogenic tanks. In this report, the cryogenic data on Al-Li alloys 8090, 2090, WL049," and Al alloy 2219 have been summarized. Properties covered in this survey are tensile strength, yield strength, elongation, fracture toughness, elastic constants, specific heat, thermal conductivity, and thermal expansion.

Composition Limits for Al-Li Alloys and Alloy 2219 in wtz.

\begin{tabular}{|c|c|c|c|c|}
\hline \multirow[b]{2}{*}{ Elements } & \multicolumn{4}{|c|}{ ALLOY } \\
\hline & 8090 & 2090 & WL049 & .2219 \\
\hline $\mathrm{Cu}$ & $1.0-1.6$ & $2.4-3.0$ & $4.0-6.3$ & $5.8-6.8$ \\
\hline LI & $2.2-2.7$ & $1.9-2.6$ & 1.3 & $\ldots$ \\
\hline $\mathrm{Mg}$ & $0.6-1.3$ & 0.25 & 0.4 & 0.02 \\
\hline 25 & $0.04-0.16$ & $0.08-0.15$ & 0.14 & $0.10-0.25$ \\
\hline Si & 0.20 & 0.10 & $\ldots$ & 0.20 \\
\hline $\mathrm{Fe}$ & 0.30 & 0.12 & . & 0.30 \\
\hline TI & 0.10 & 0.15 & 0.03 & $0.02-0.10$ \\
\hline $\mathrm{Cr}$ & 0.10 & 0.05 & $\ldots$ & .. \\
\hline $\mathrm{Z} \Omega$ & 0.25 & 0.10 & . & 0.10 \\
\hline $\mathrm{Ag}$ & -. & $\ldots$ & 0.4 & - \\
\hline Mn & 0.10 & 0.05 & $\ldots$ & $0.20-0.40$ \\
\hline Others, each & 0.05 & 0.05 & $\ldots$ & .. \\
\hline Others, total & 0.15 & 0.15 & $\ldots$ & $\ldots$ \\
\hline Al & Remainder & Remainder & Remainder & Remainder \\
\hline
\end{tabular}

* The WL049 alloy does not have a generic specification at this time and is commonly termed WELDALITE 049. Trade names are furnished to identify the material adequately. Such identification does not imply recommendation or endorsements by NIST, nor does it imply that the materials identified are necessarily the best available for the purpose. 



\section{TENSILE PROPERTIES}

\subsection{Introduction to Graphs}

In general, only measurement sets that included cryogenic data were included in the graphs and tables. However, some ambient temperature values, such as the producers' typical values, are presented. The horizontal scale of the graphs was extended to $600 \mathrm{~K}$ because some cryogenic data sets also included measurements above ambient temperatures and it was considered useful to present the additional information. When available, data are provided for longitudinal (L), transverse (T), $45^{\circ}$ from the rolling direction, and through-thickness (S) orientations. The graphs show data for the T8 temper for all the alloys. Additional graphs are provided for the T3 temper for alloys 8090, WL049, and 2219, and the T6 temper for alloy WL049. The graphs are organized in decending order by temper for each alloy.

All tensile property data points shown graphically are listed and referenced in the tables following the graphs. A reference number is provided in the legend of each graph. Two formats are used in the tensile property tables: (1) data, and (2) test parameters, including further documentation. The data tables present temperature and tensile properties, including reduction of area (not presented in the graphs). This is followed by information on orientation, temper, product form and thickness, thermomechanical processing, grain size, hardness, number of tests per data point, and a reference and note number. The reference and note number (which corresponds to the reference number on the graphs) is a guide to the accompanying test parameter table. The test parameter table gives information on the strain rate during testing; specimen type, dimensions, and location; exposure time at test temperature (available chiefly for data above ambient temperature); supplier; year produced; lot number; product dimensions; and chemistry. The tables are ordered by temper, starting with T8 tempers and ending with T3 or annealed (0) tempers. Some cryogenic data is presented in the tables but not in the graphs; for example, data on the T4 temper of alloy 2090.

Much of the cryogenic data, especially on current production vintages and tempers, are from recent measurements at the National Institite of Standards and Technology (NIST), under sponsorship of the Advanced Launch System (ALS) program. For more detailed information on measurement techniques, stress strain curves, and microstructure, see ref. 1. The NIST data are denoted by solid square and solid diamond symbols on the graphs. A smoothed line connects the NIST data points corresponding to tempers under consideration for use in the ALS program. The position of the line and the indicated temperature dependence generally are based on measurements made on two specimens at 4,20 , 76 , and $295 \mathrm{~K}$. The material in the NIST program was usually $12.7-\mathrm{mm}(0.5-\mathrm{in})$ plate; and only ultimate tensile strength measurements were obtained from tests in the $S$ orientation.

The four graphs of alloy 2219-T8 data in the $\mathrm{L}$ and $\mathrm{T}$ orientations for tensile yield strength and ultimate tensile strength include dashed lines. These lines, labeled MIL-HNBK-5E, ${ }^{2}$ were derived from curves presented in 
Figures 3.2.6.41(a) and (b) of that handbook ${ }^{2}$ which give cryogenic values as a percentage of the room temperature value for ultimate and yield strengths, respectively. The room temperature values used to obtain the curves on our graphs for ultimate and yield strengths came from Table 3.2.6.0(b) from the MIL-HNBK-5E handbook. These values are "A basis" minimums and indicate that 998 of the data should fall on or above the curve, with a confidence level of 958. (Please note that this information is provided on the graphs by the asterisked footnote.)

Most of the cryogenic data do not fall on or above the handbook-derived minimum line for temper T87. We do not have a complete explanation for why this occurred. It is to be expected that the solid squares, temper T851, consistantly would fall below the line. Very thick plate results frequently fall below the line. The "A basis" value does not pertain to plates of these thicknesses. At thicknesses of 100-125 mm the "A basis" line would fall 21 and $14 \mathrm{MPa}$ lower for ultimate and yield strengths, respectively, in the $\mathrm{T}$ orientation. No value is provided for thicker plate in the $L$ orientation. 
ULTIMATE TENSILE STRENGTH, $k s i$

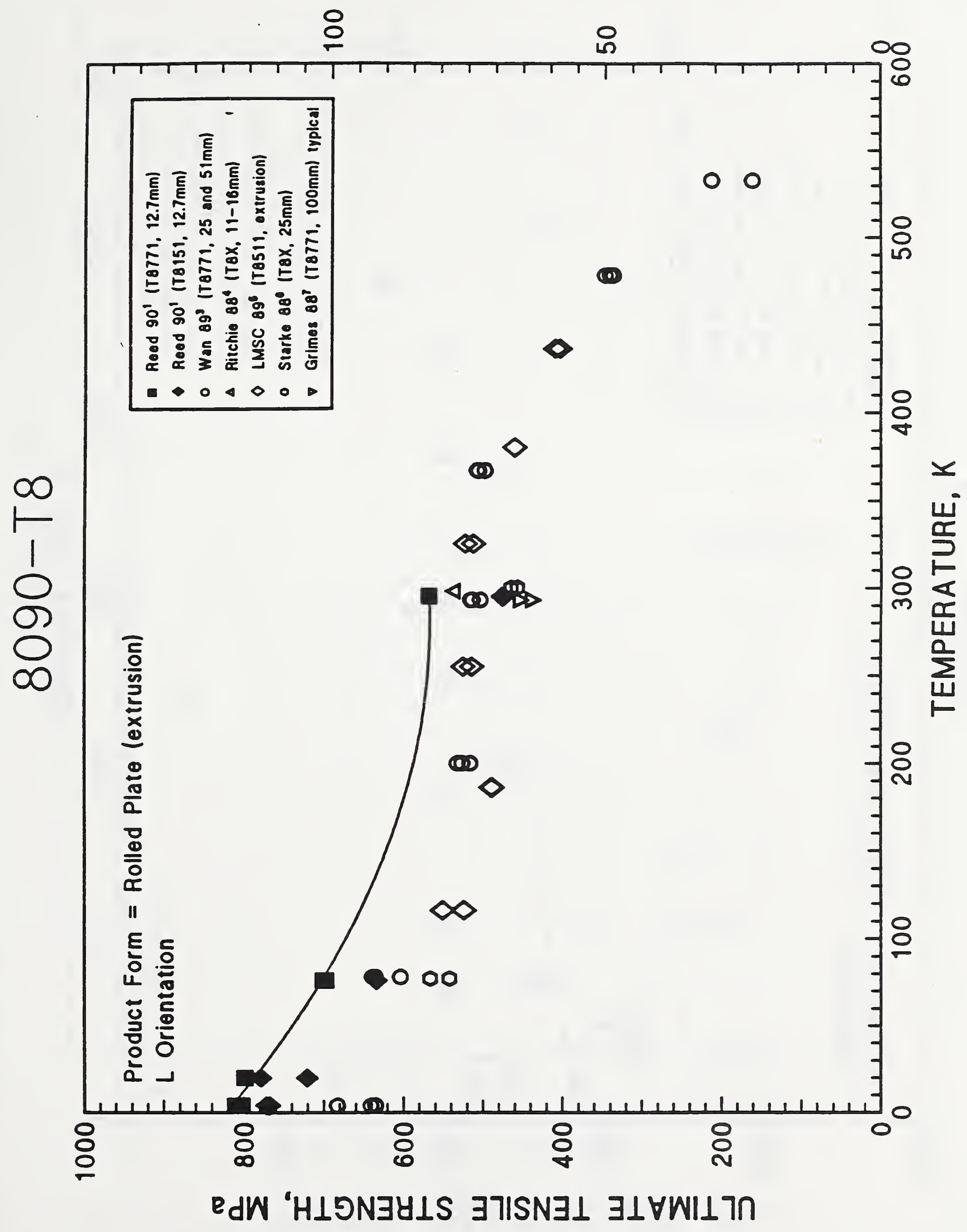


TENSILE YIELD STRENGTH, ksi

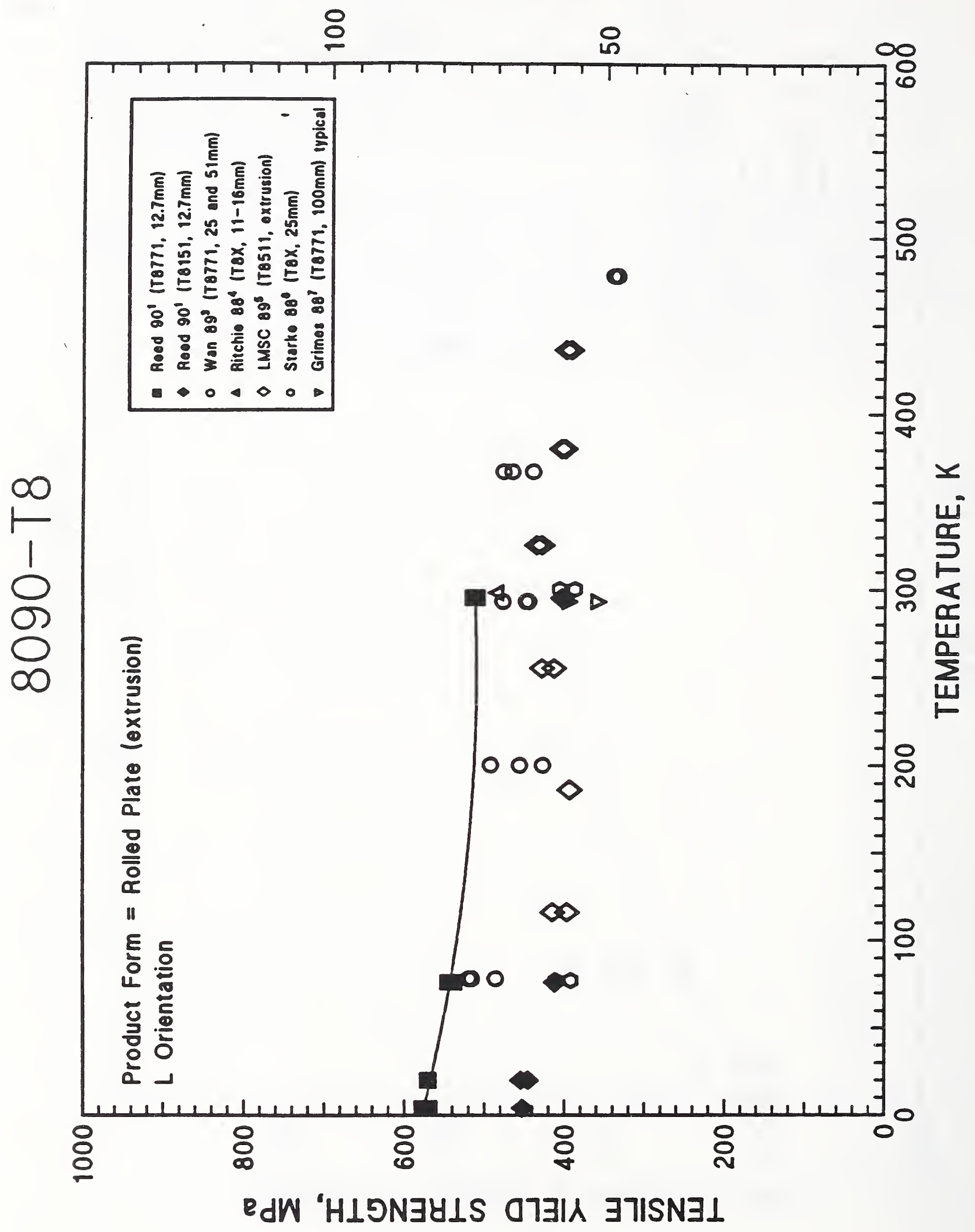




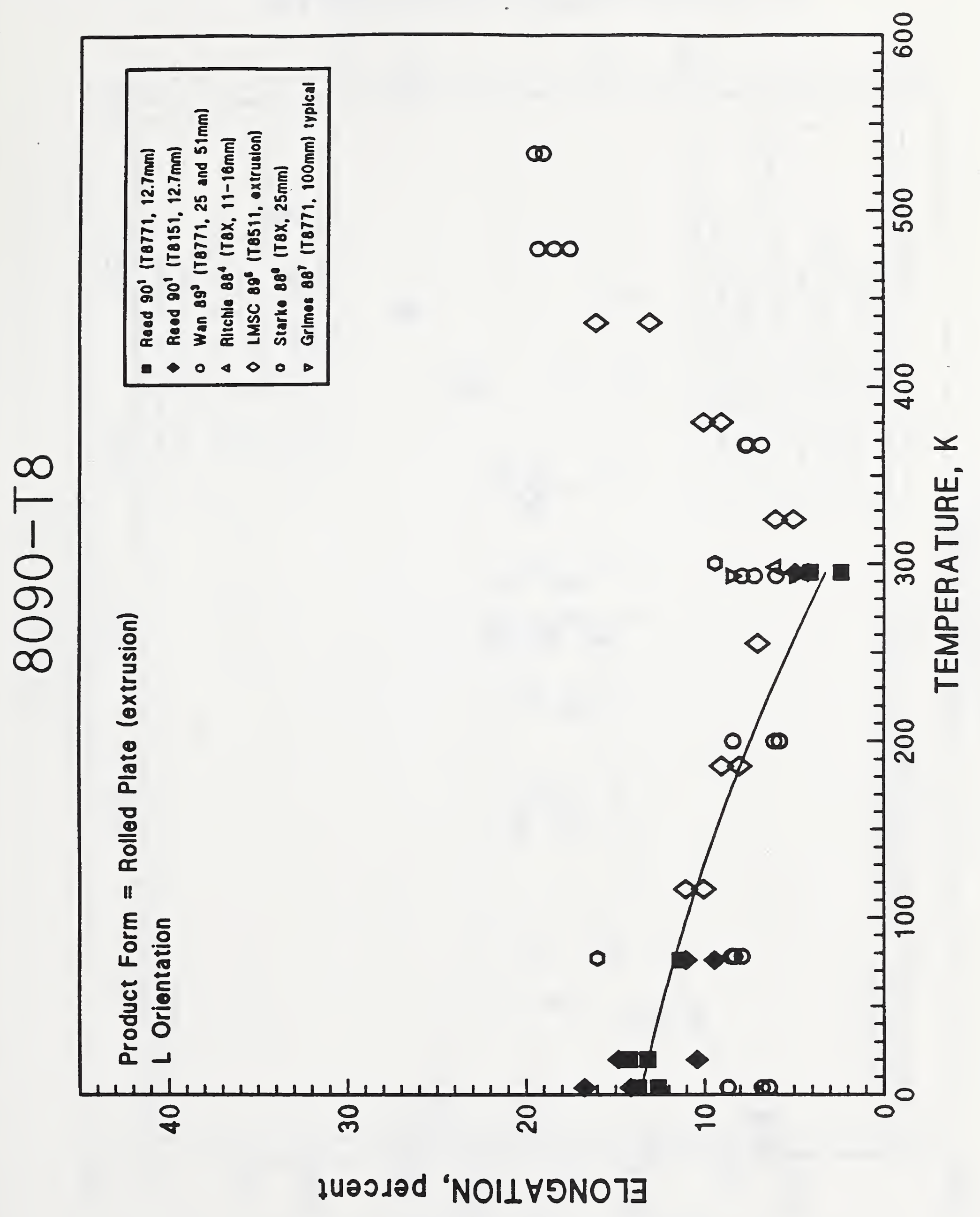


ULTIMATE TENSILE STRENGTH, ksi

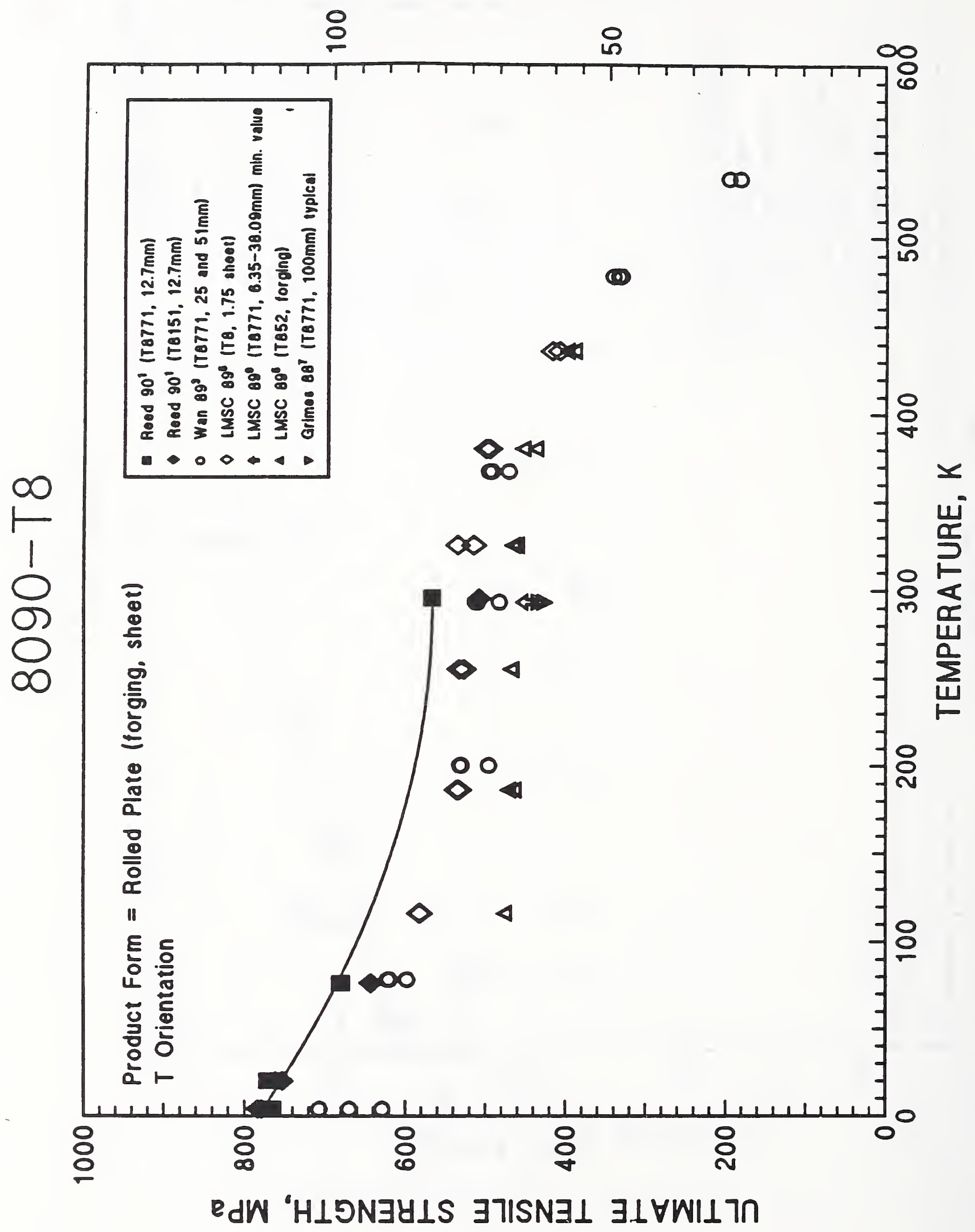


TENSILE YIELD STRENGTH, ksi

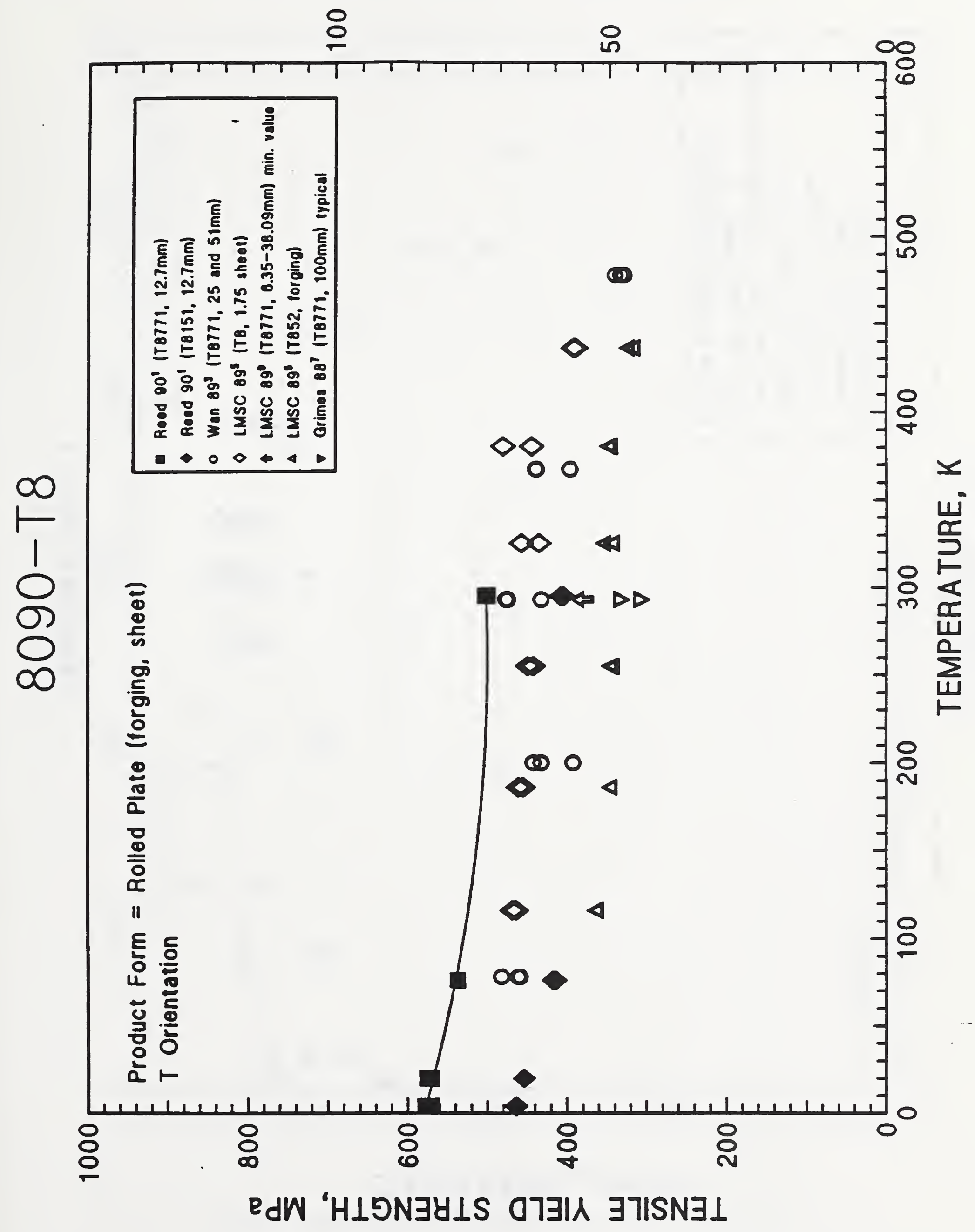




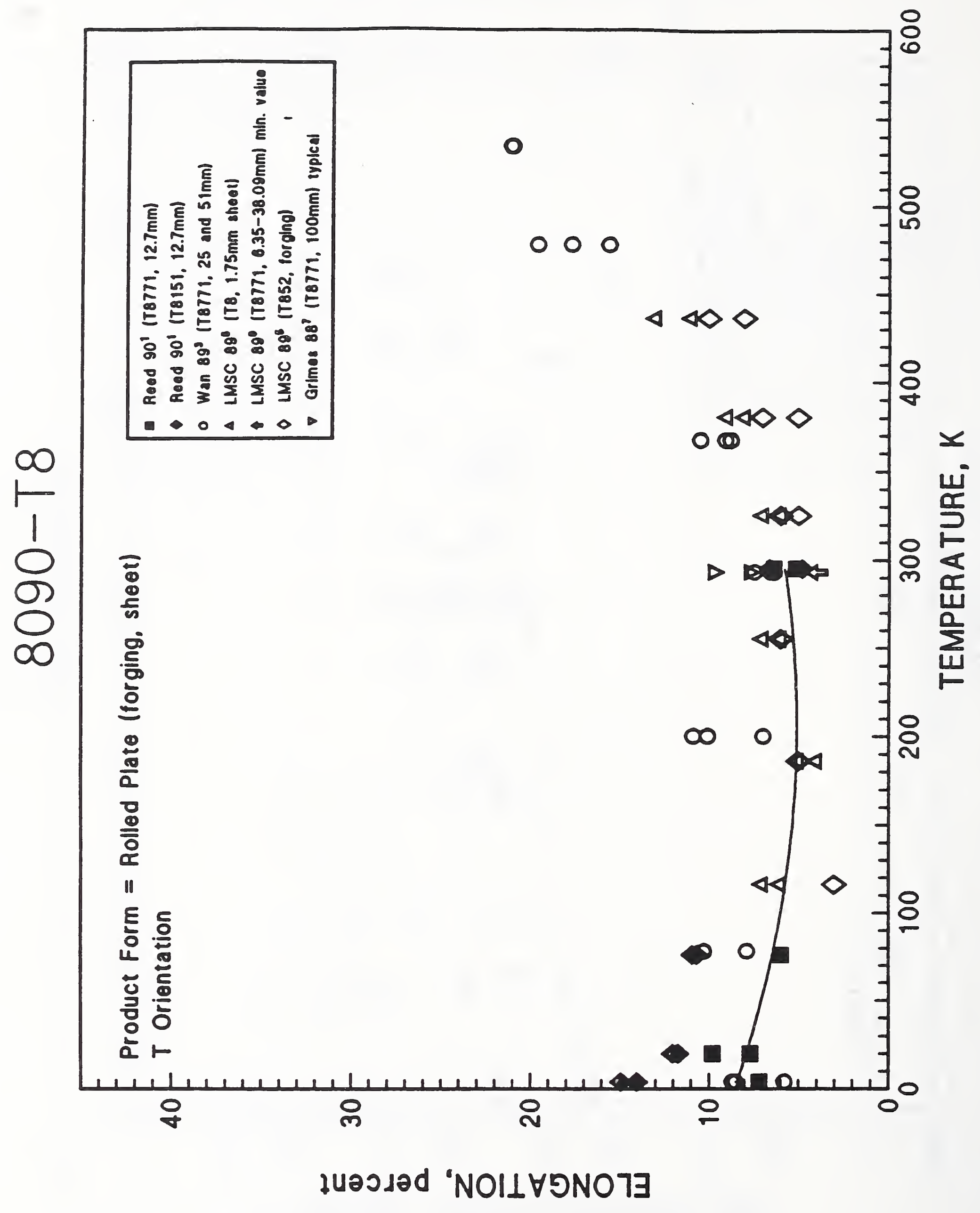


ULTIMATE TENSILE STRENGTH, ksi

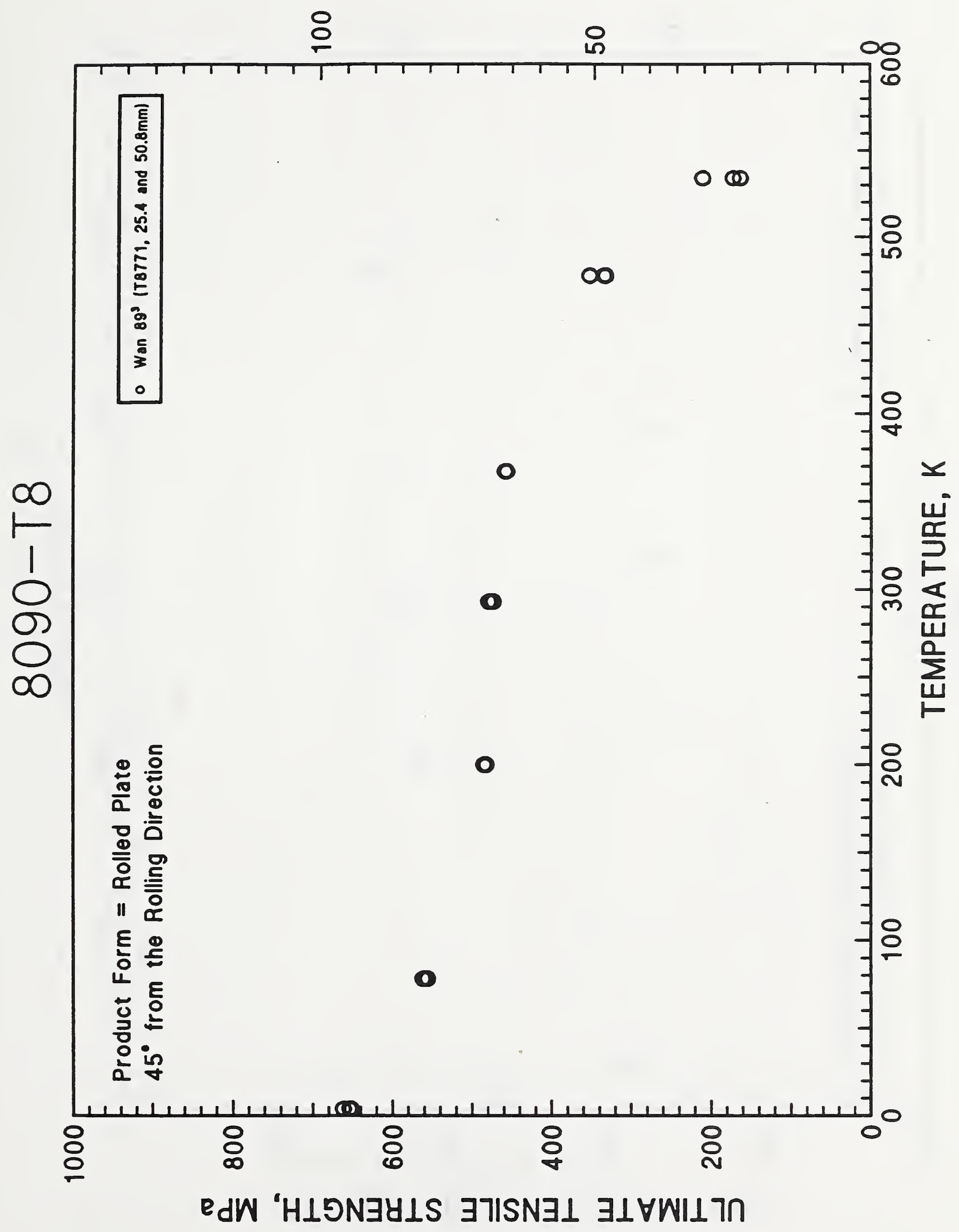


TENSILE YIELD STRENGTH, ksi

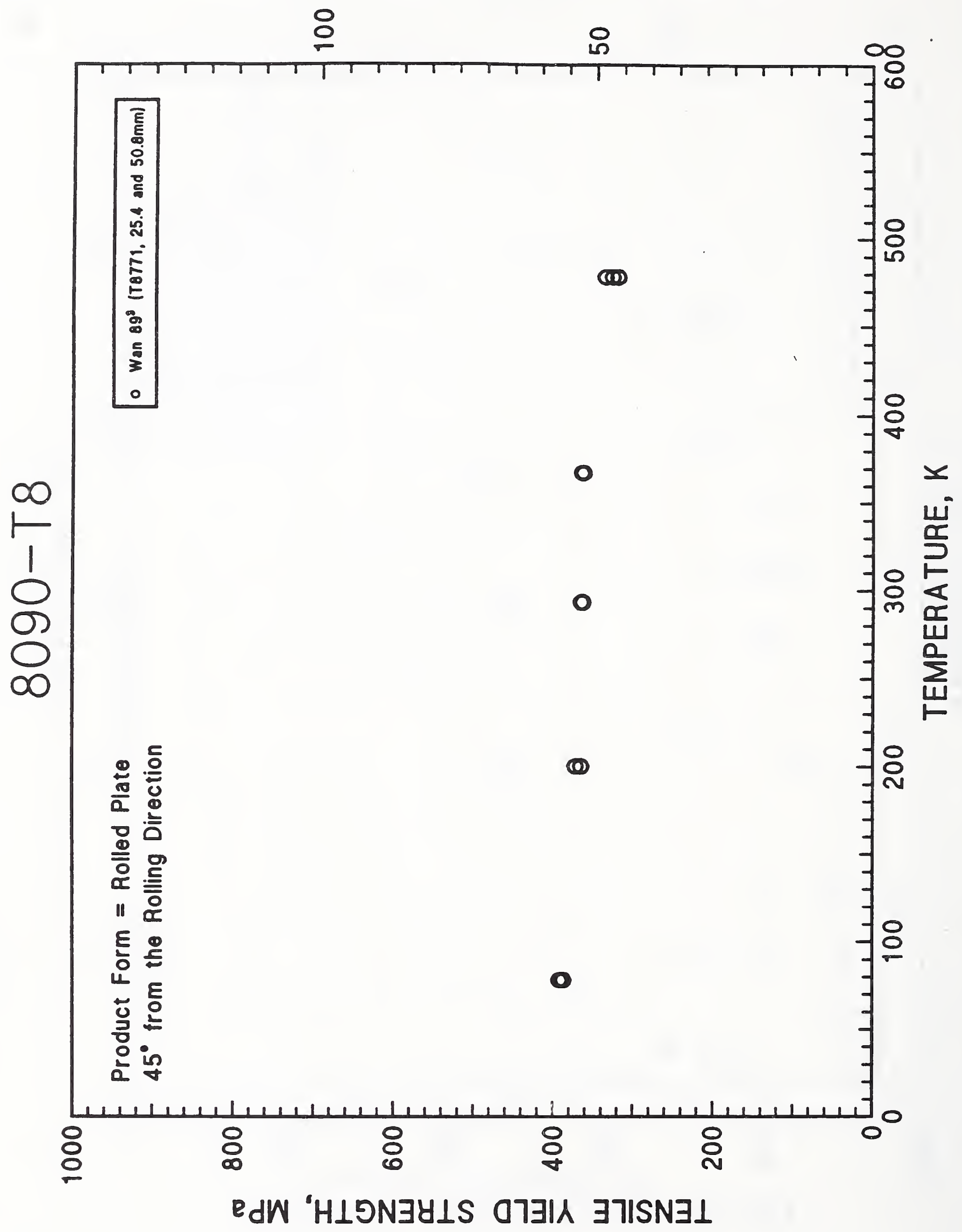




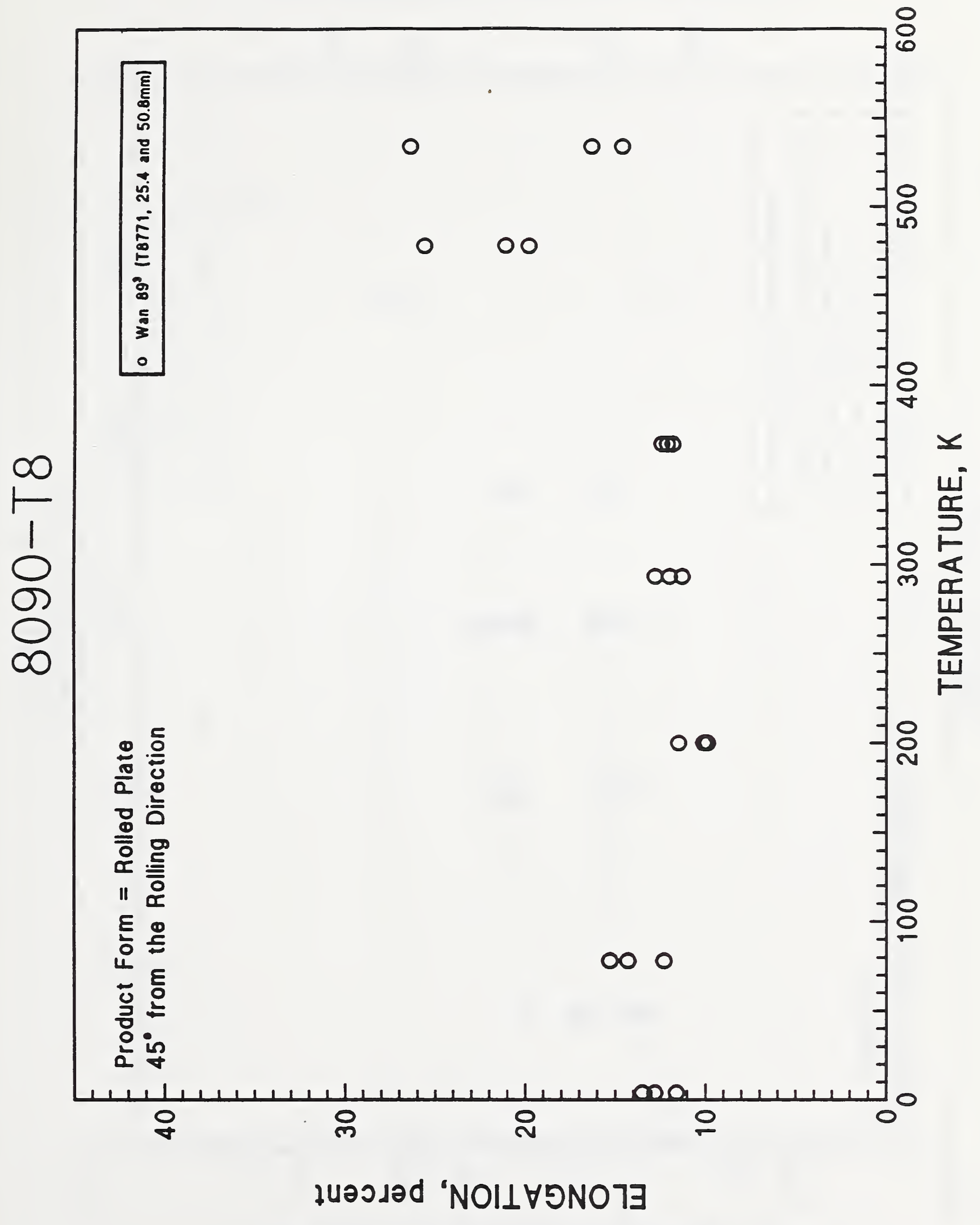


ULTIMATE TENSILE STRENGTH, ksi

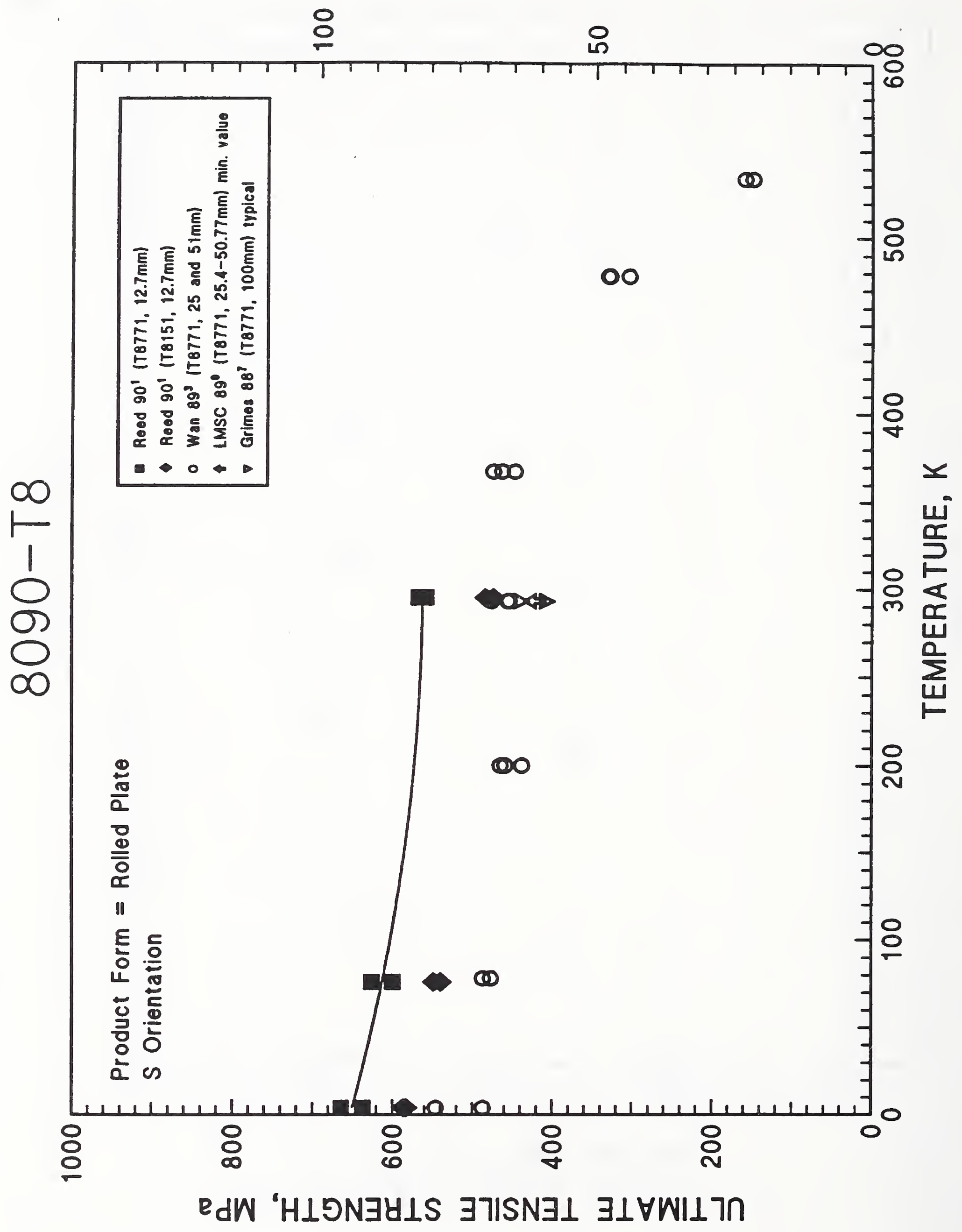


TENSILE YIELD STRENGTH, ksi

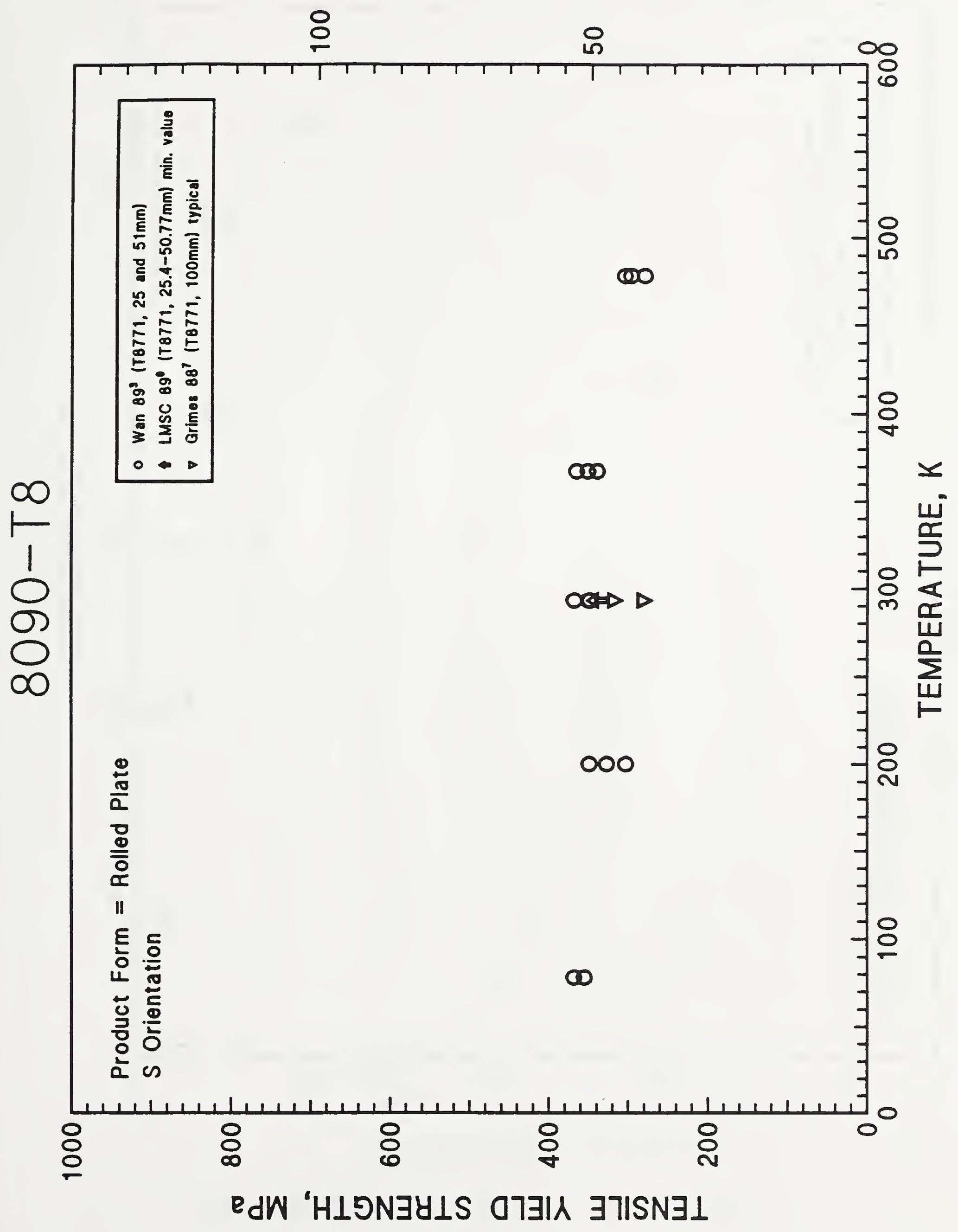




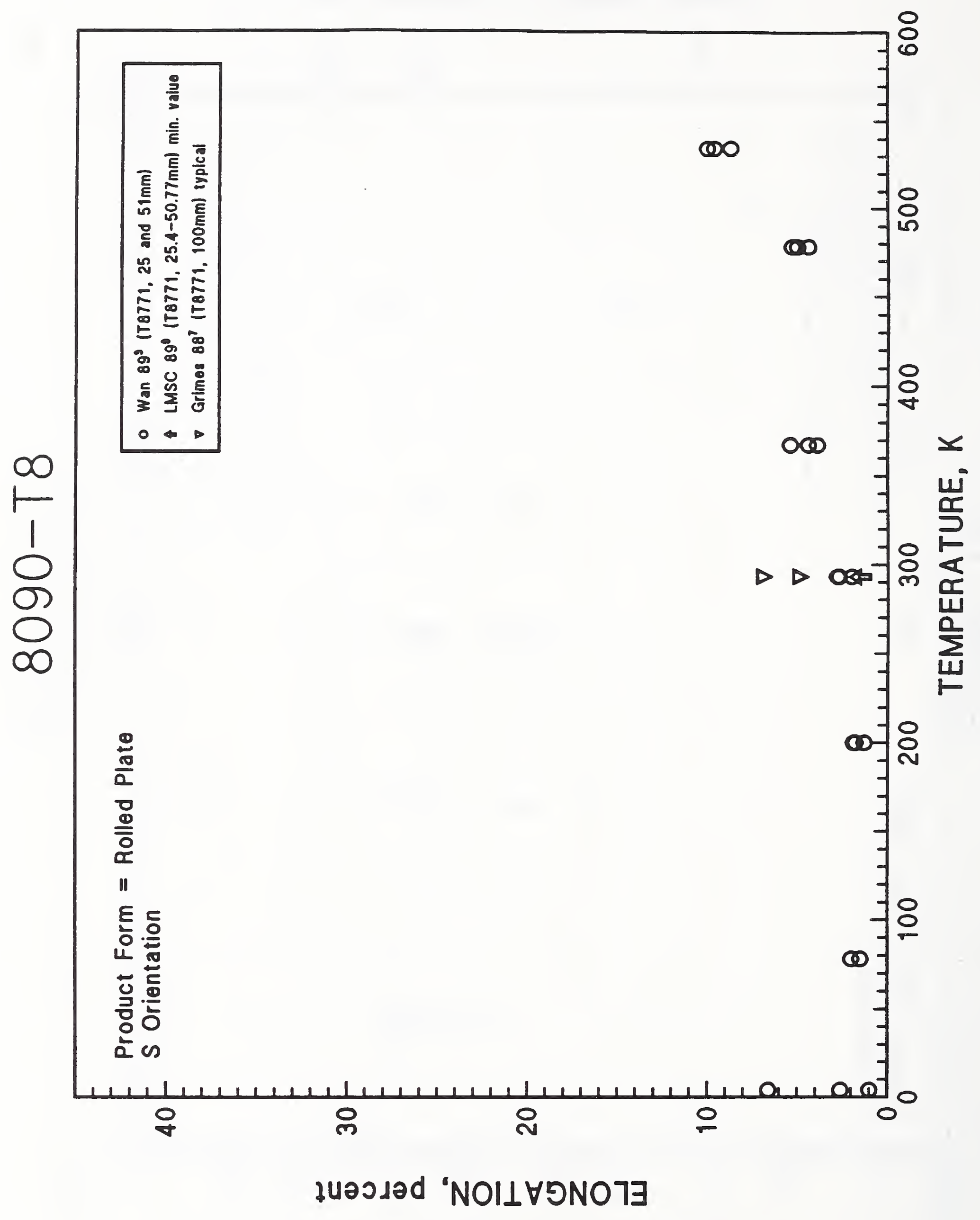


ULTIMATE TENSILE STRENGTH, ksi

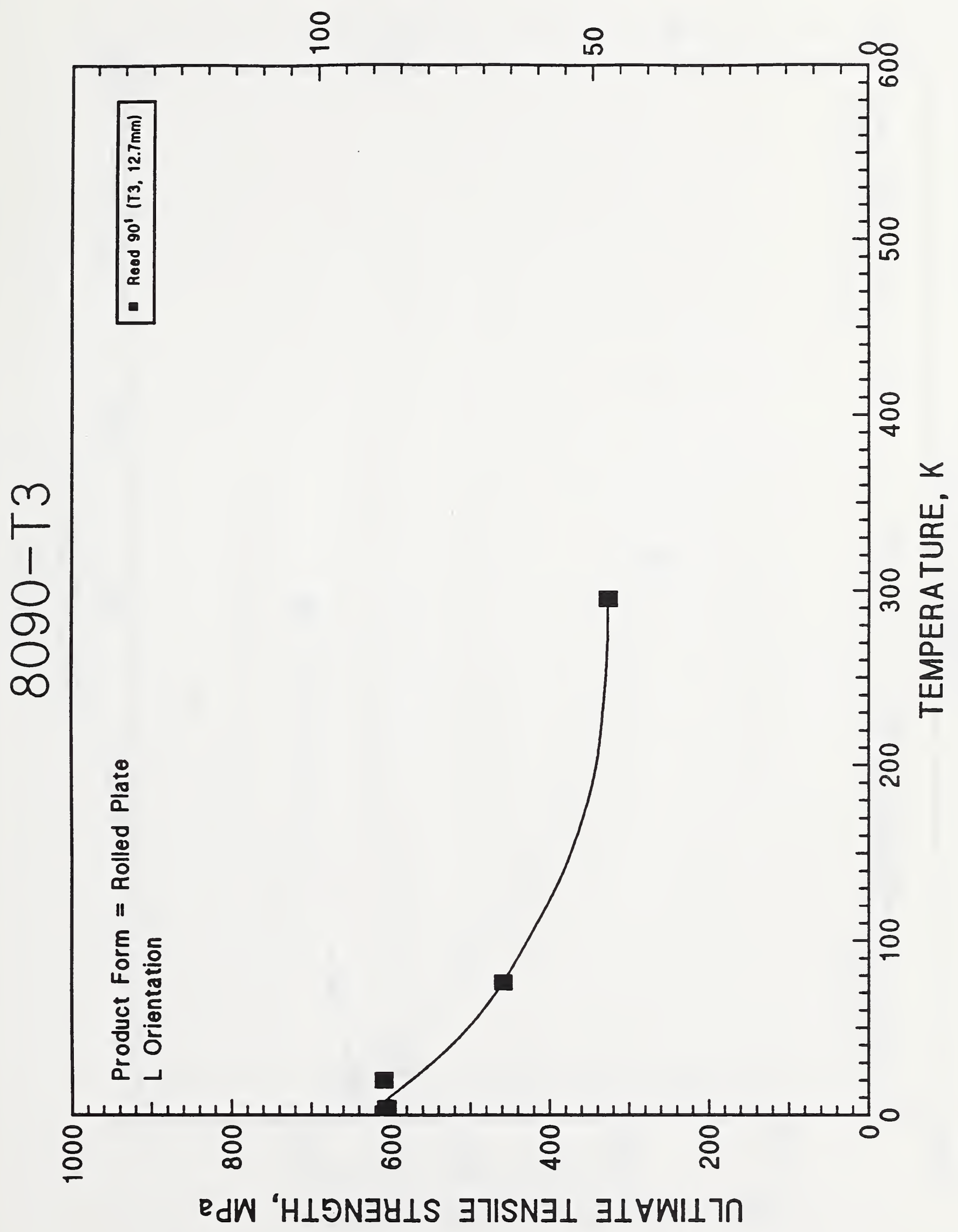


TENSILE YIELD STRENGTH, ksi

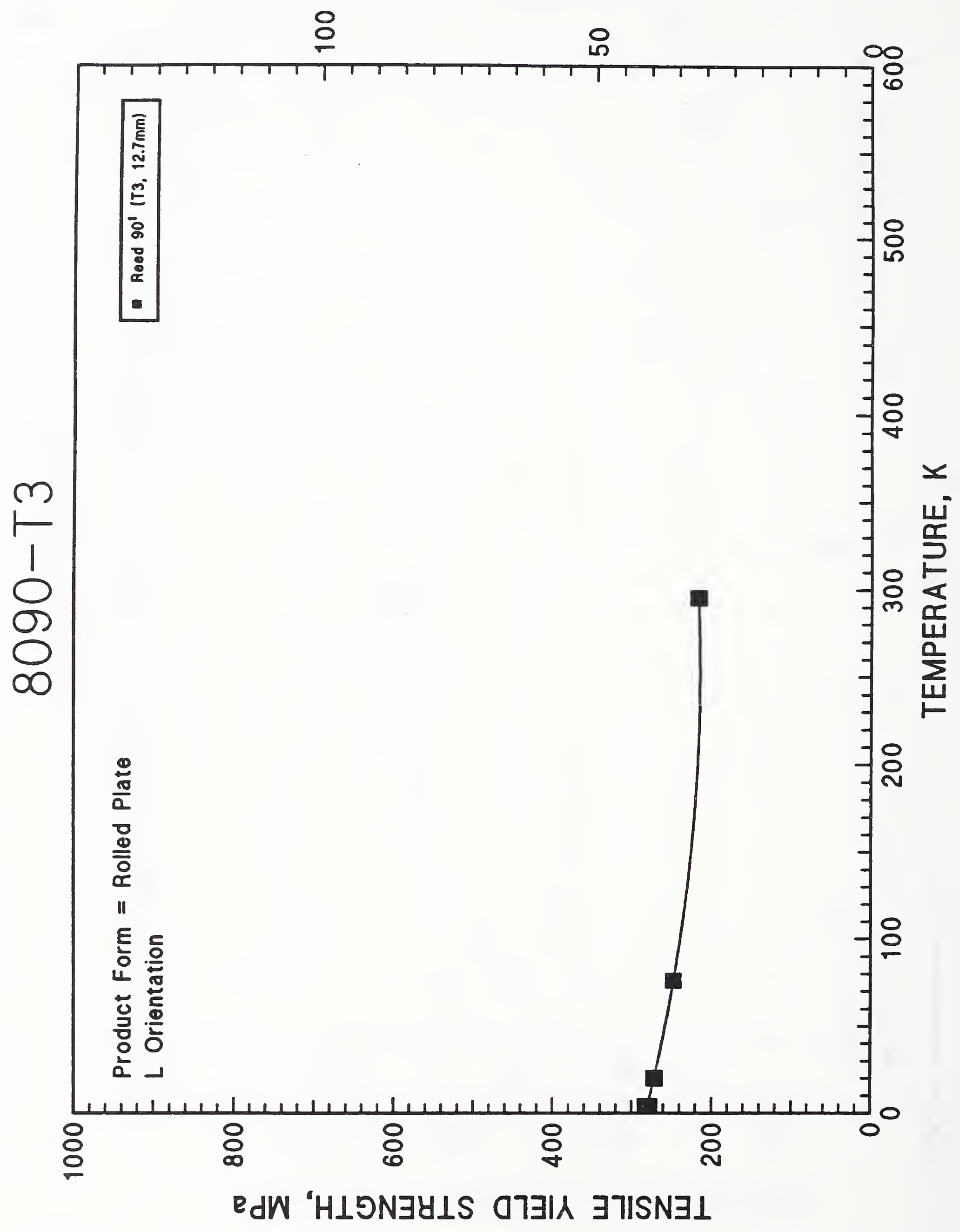




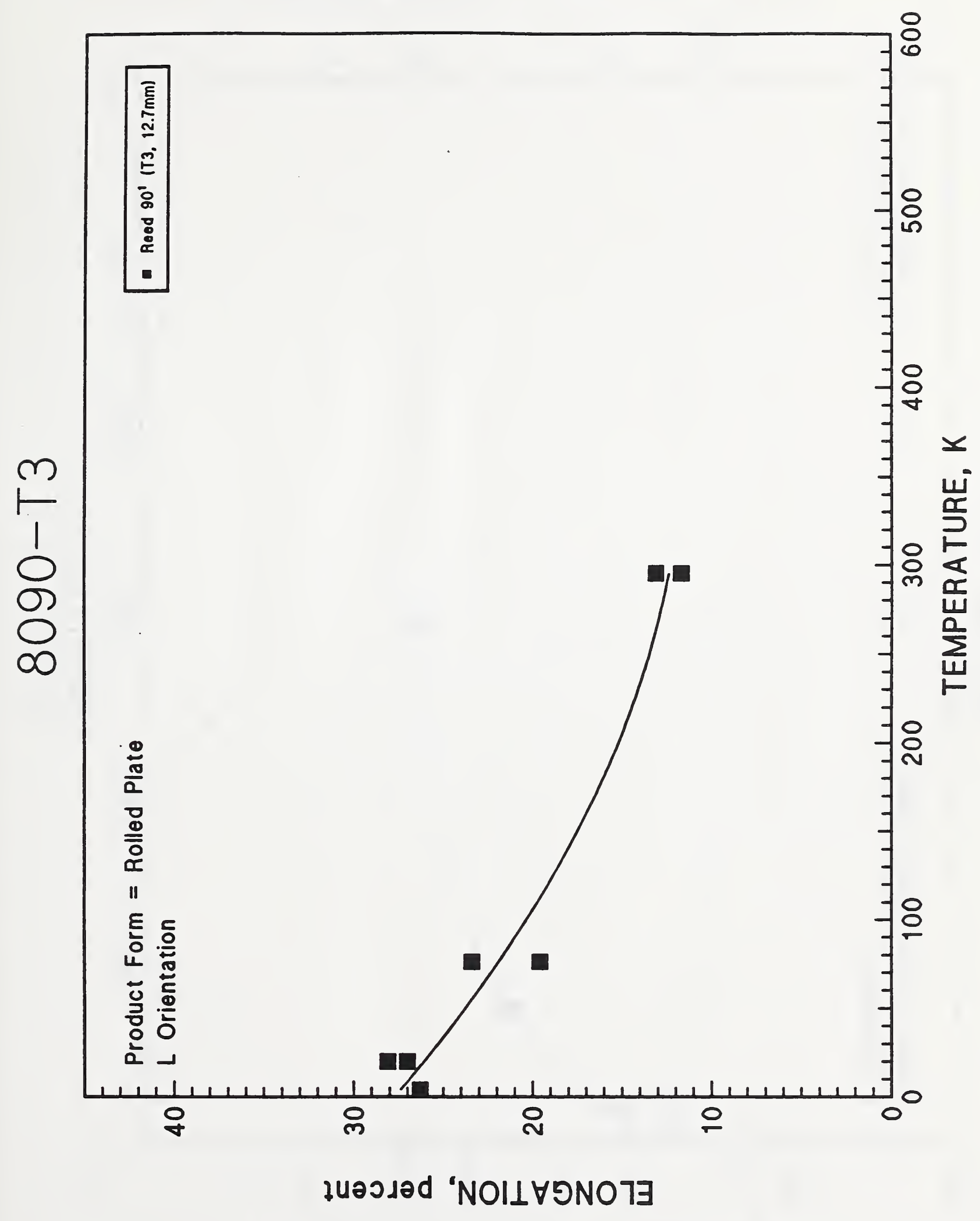


ULTIMATE TENSILE STRENGTH, ksi

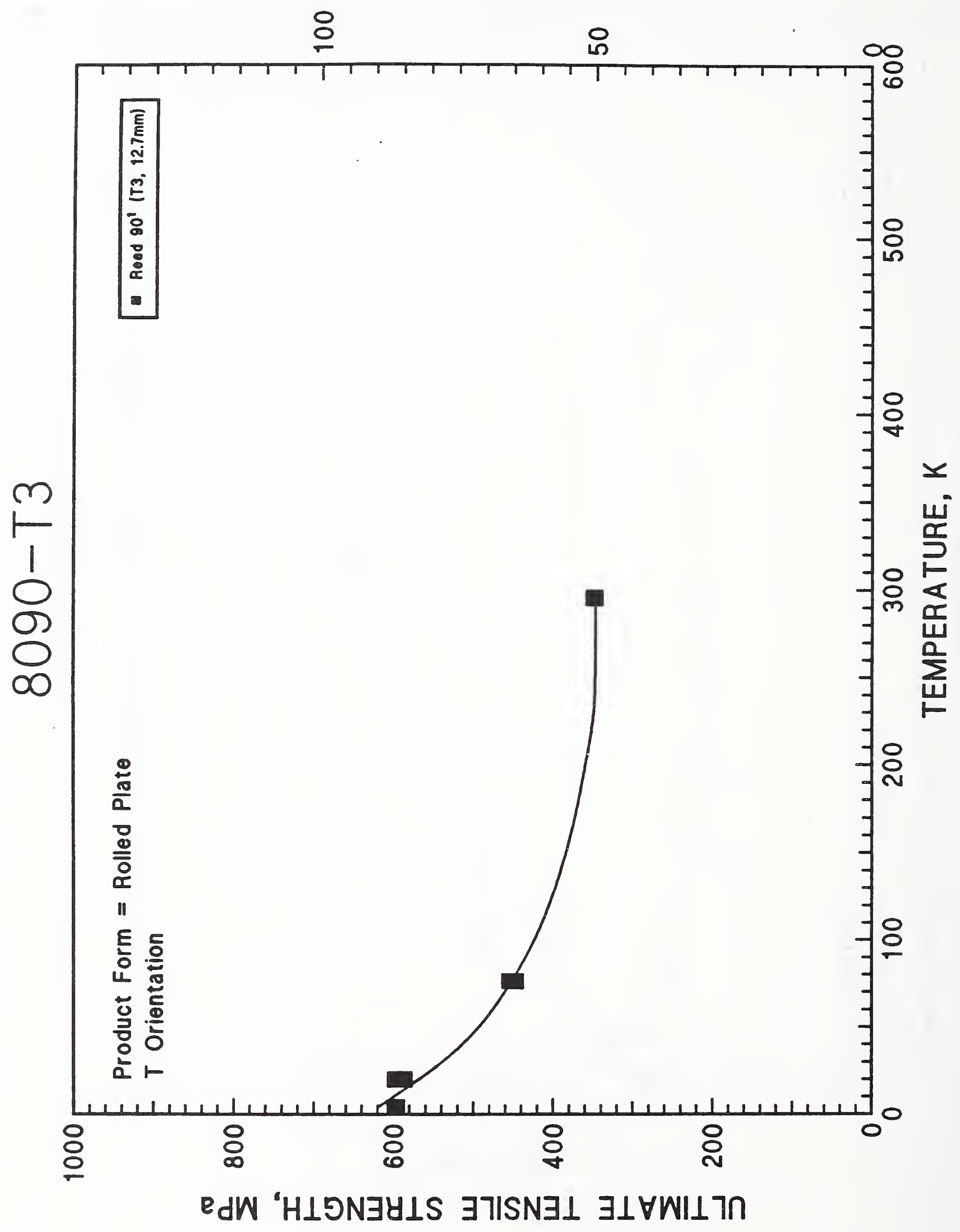


TENSILE YIELD STRENGTH, ksi

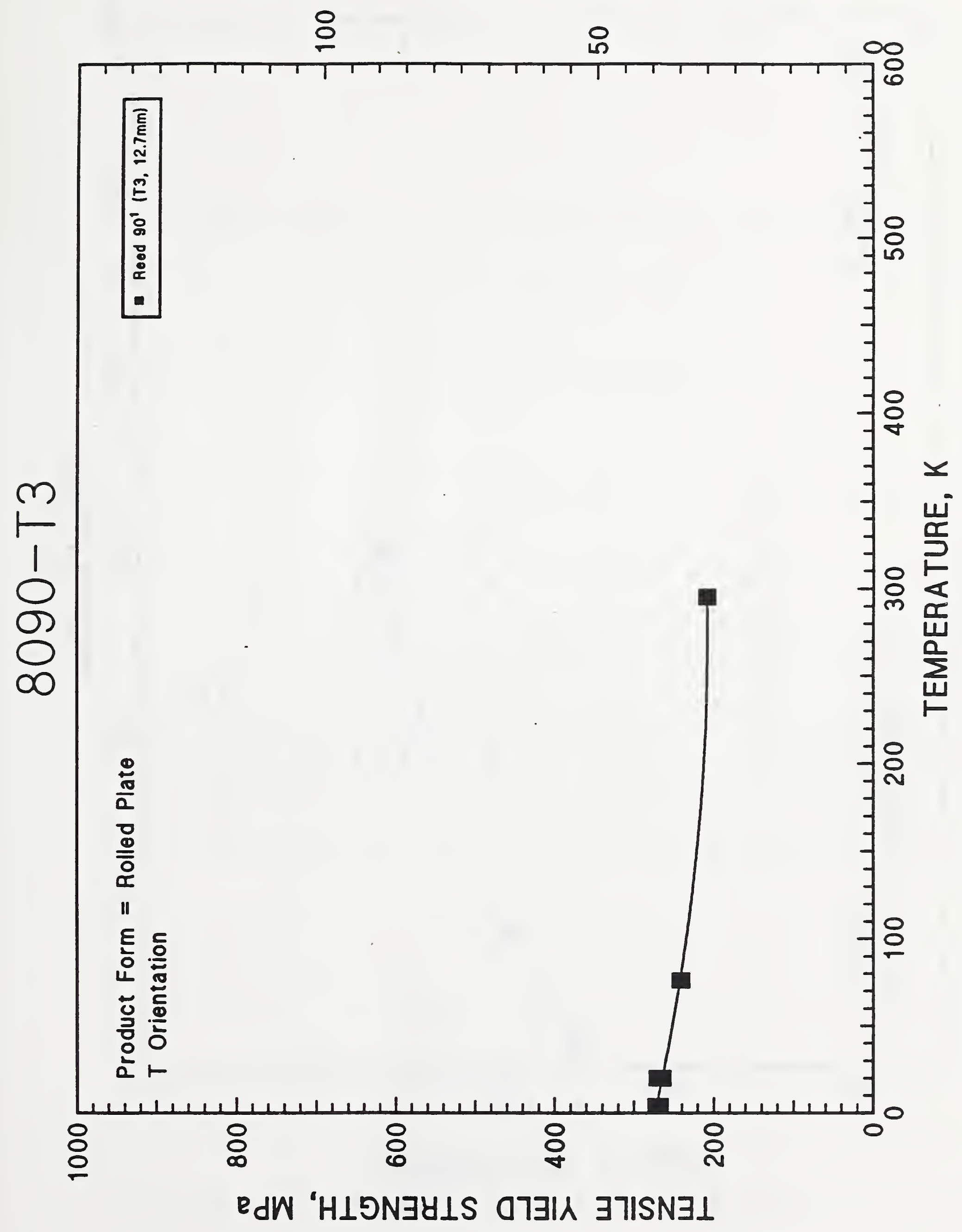




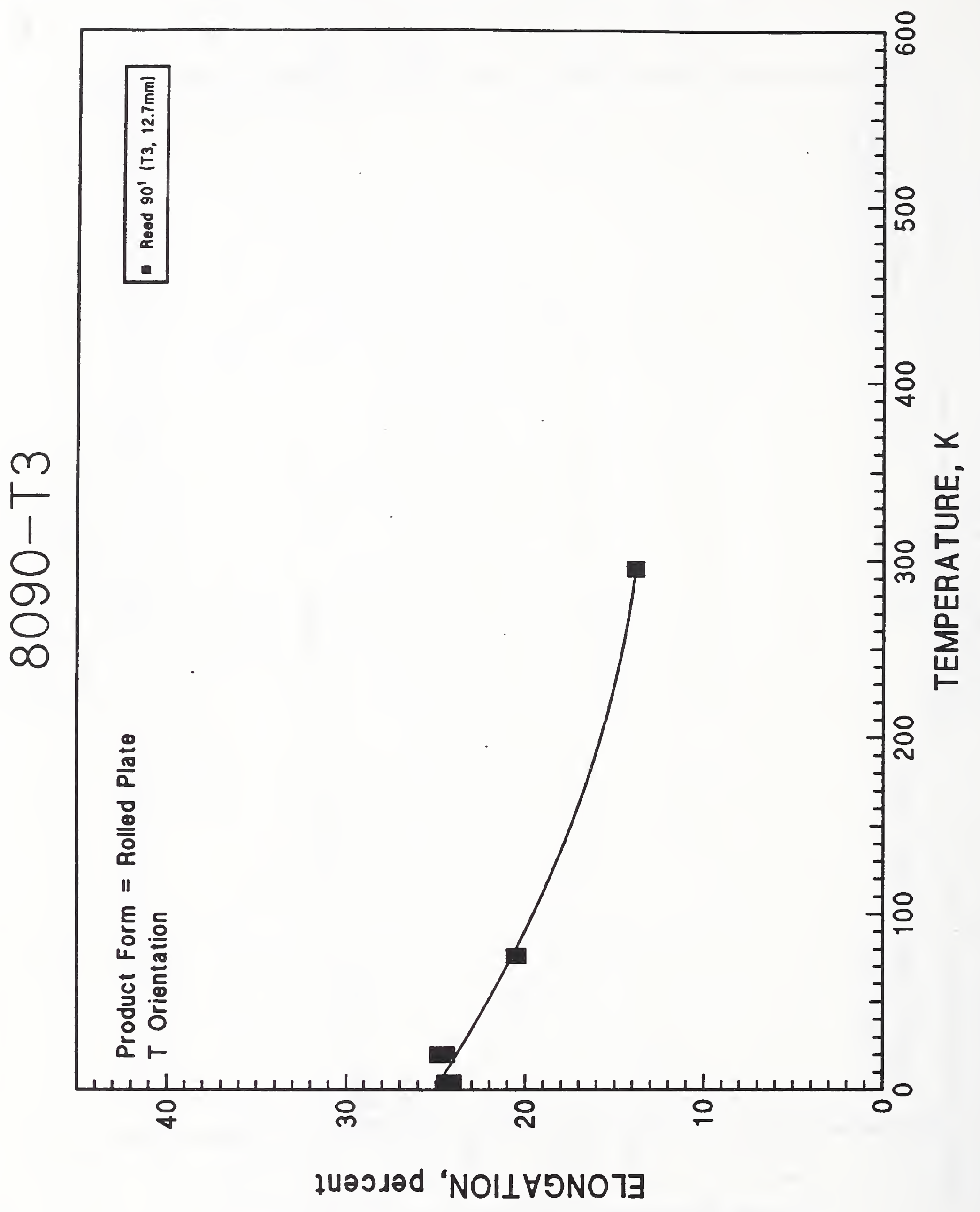




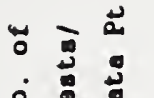

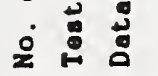

:

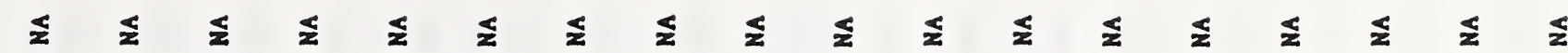

的

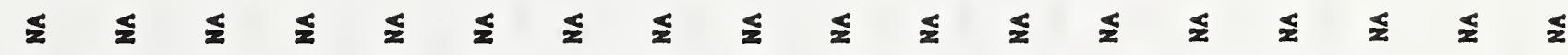

竞

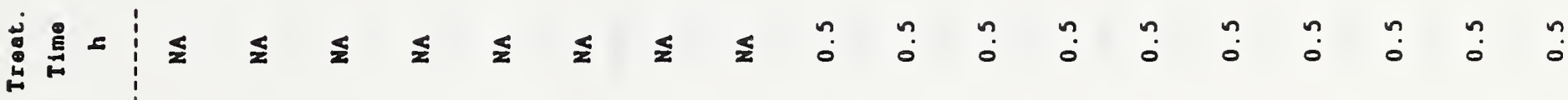

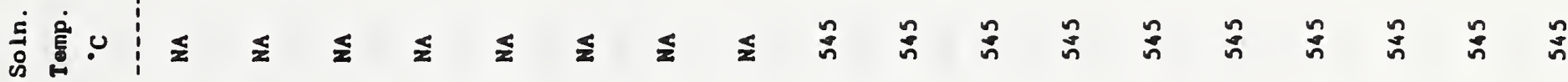

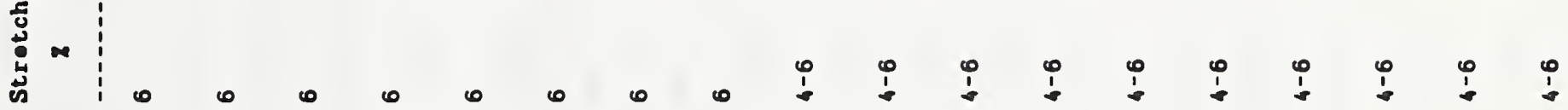

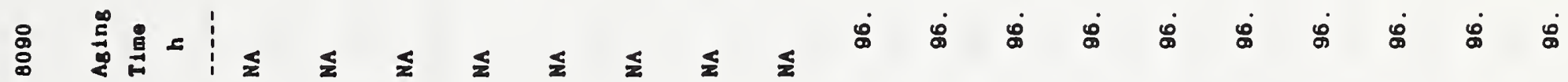

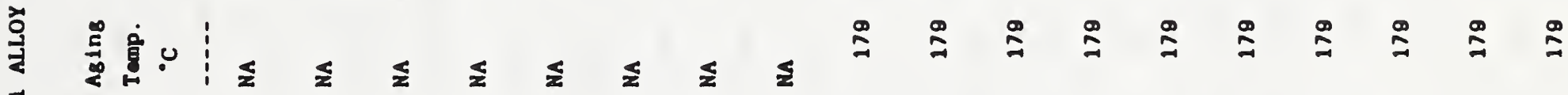
$\stackrel{1}{\frac{1}{2}}$

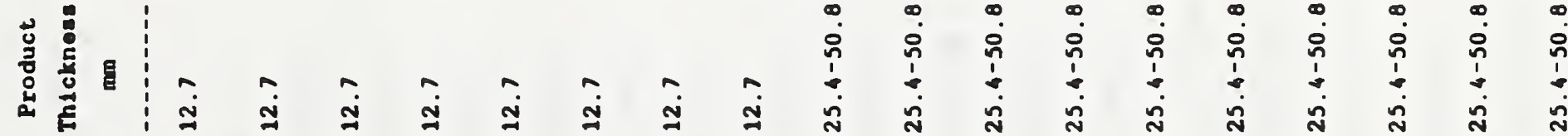

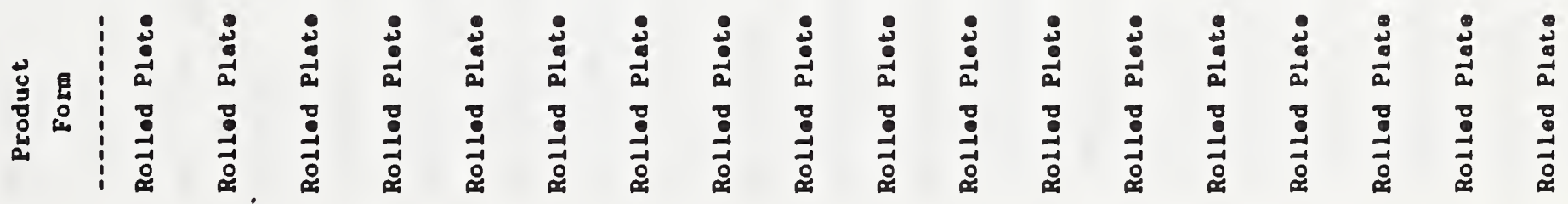

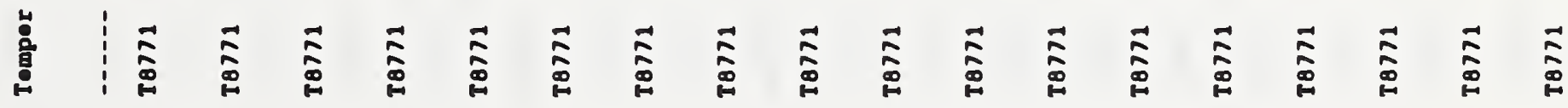
蓆

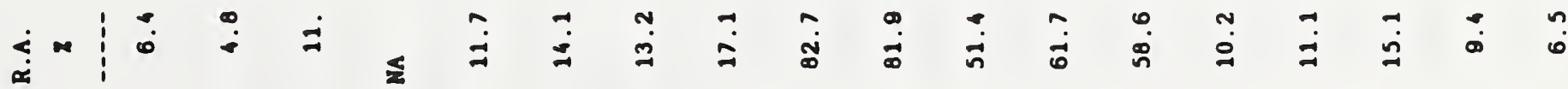

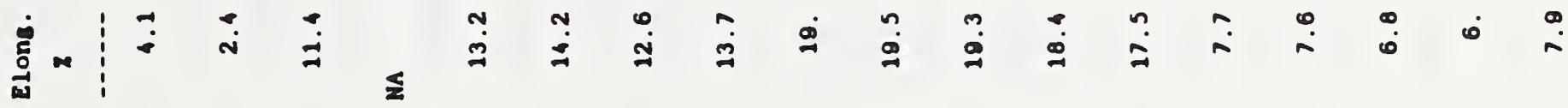
边 ஸ்

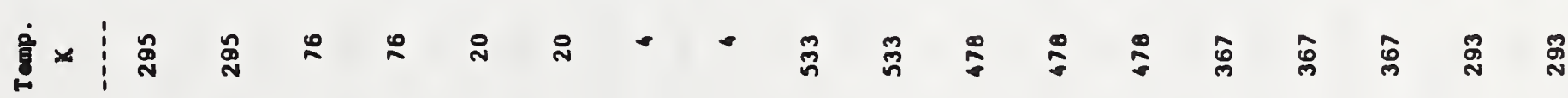

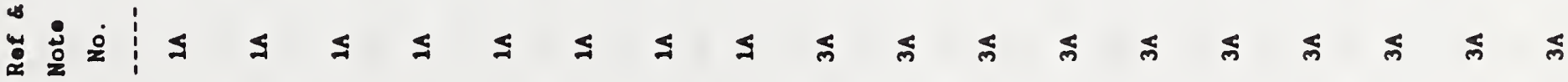




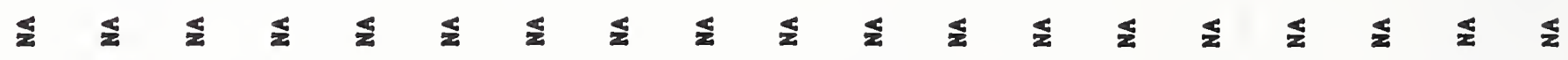

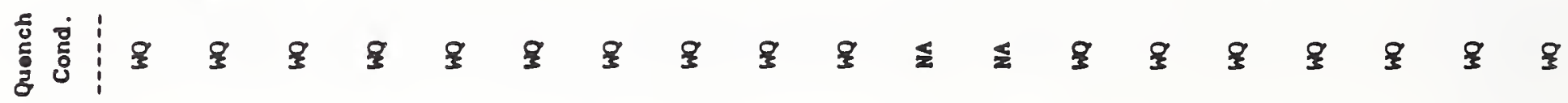

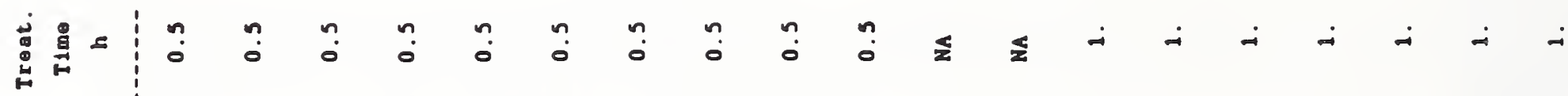

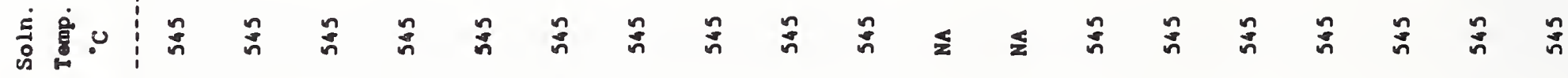
竎

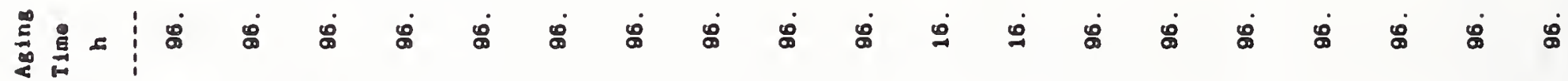
题

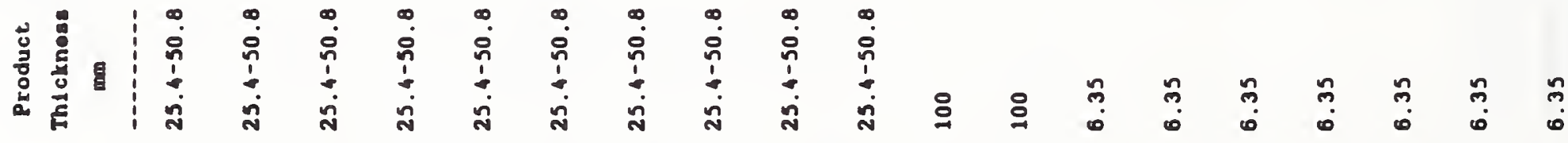

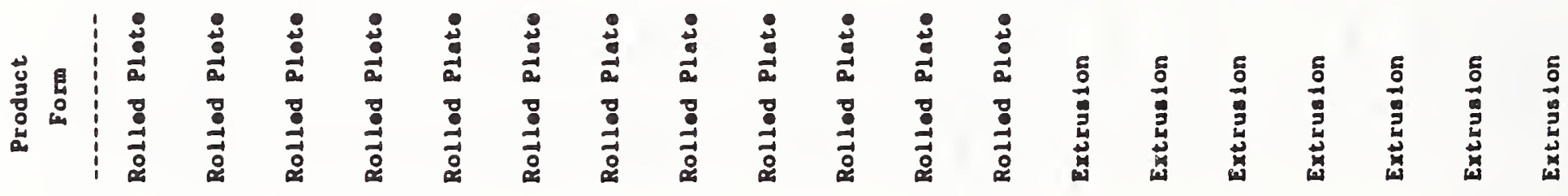

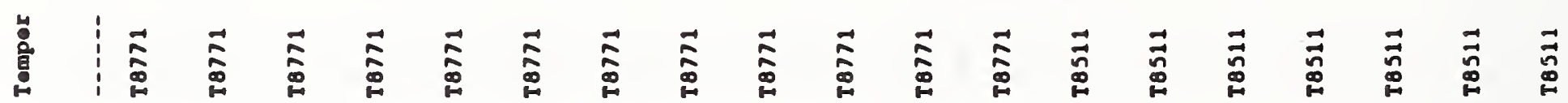

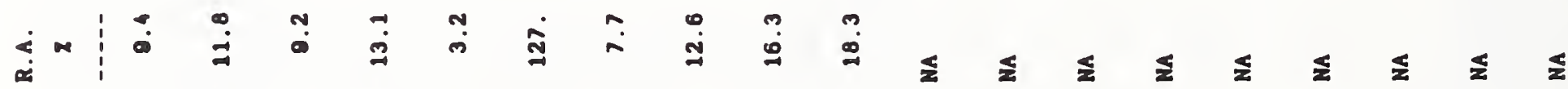

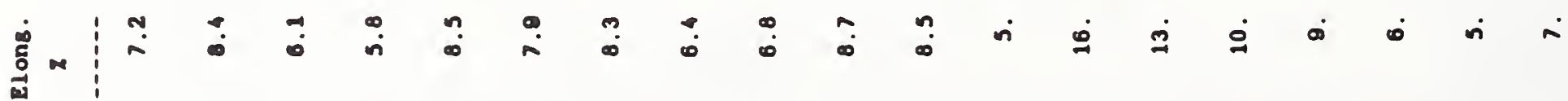

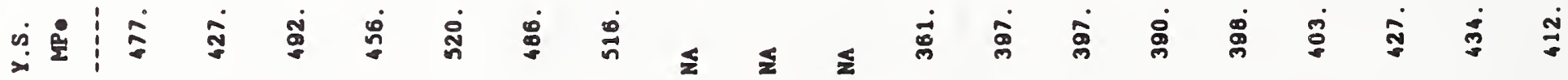

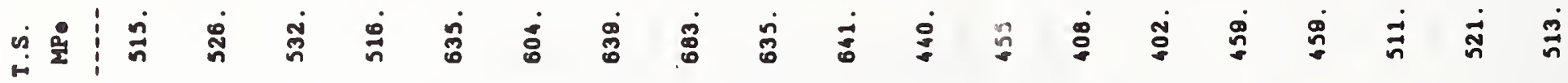

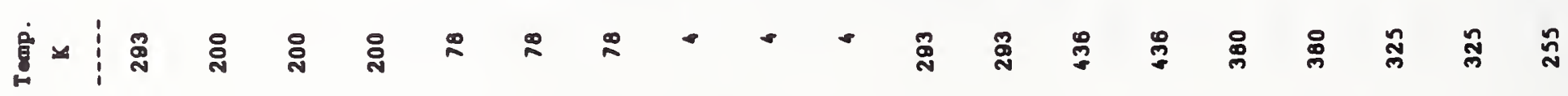

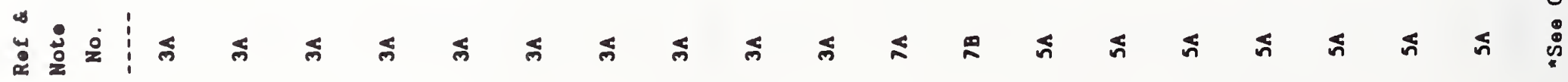




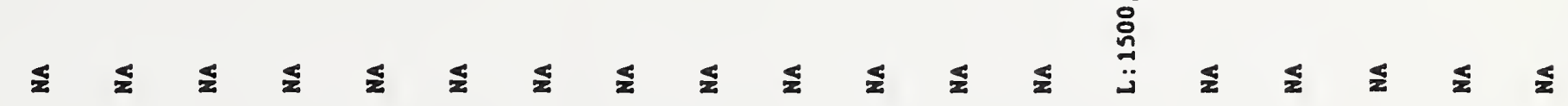

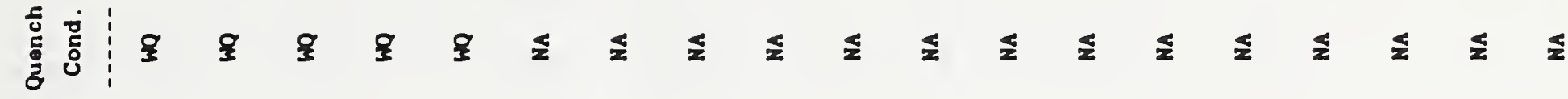

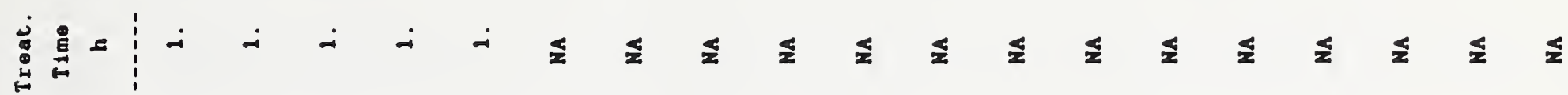

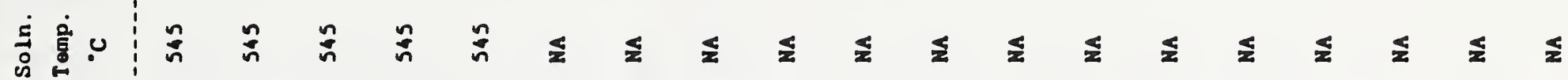

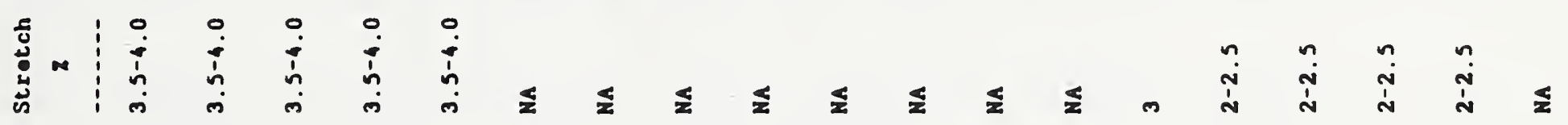

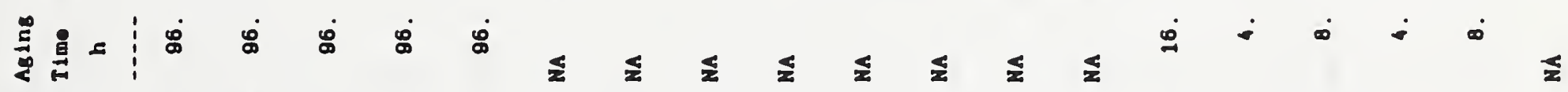
递官

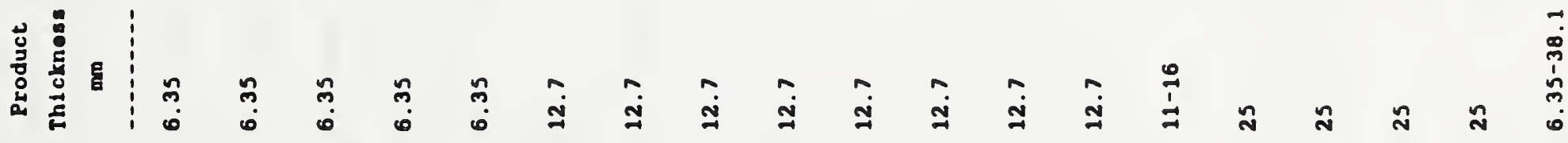

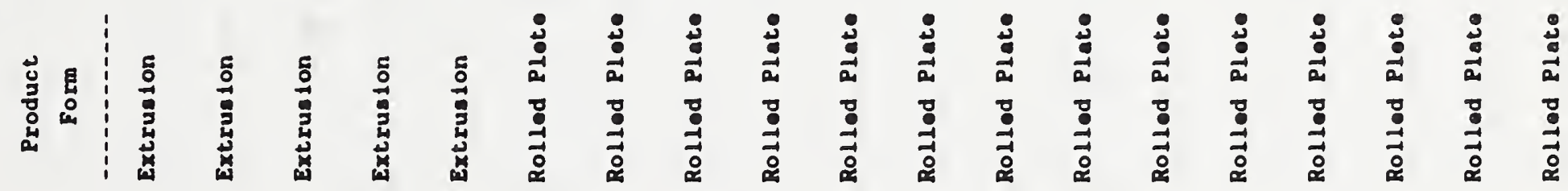
兽

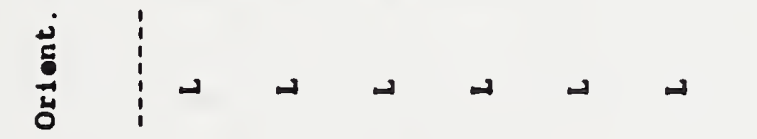

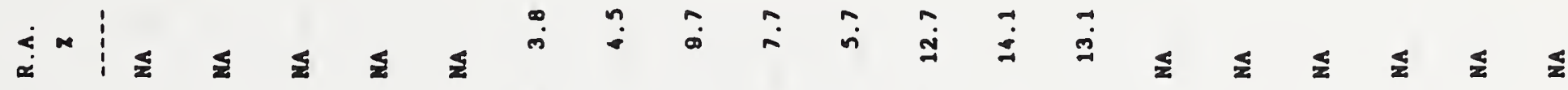

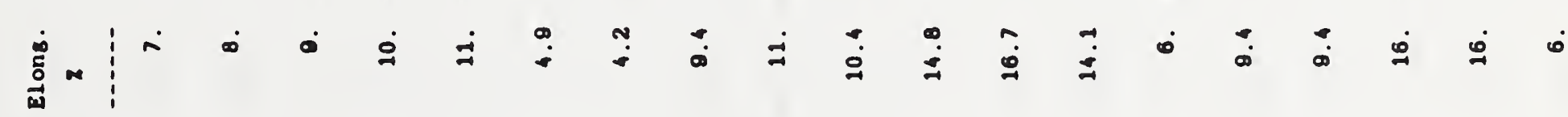
ن்

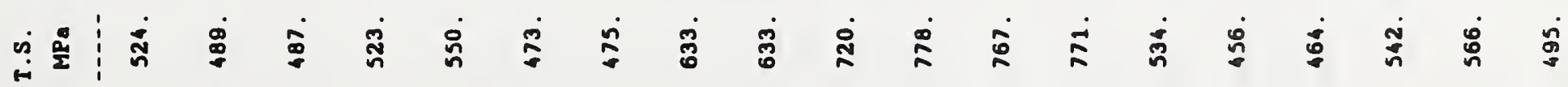
富ะ

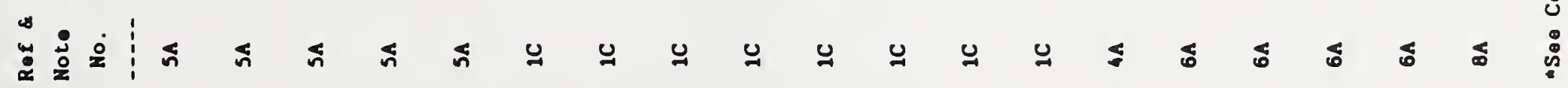




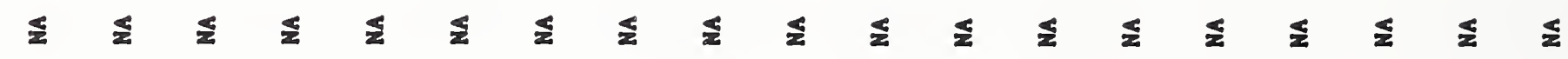

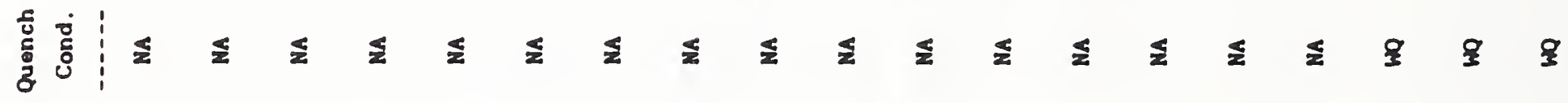

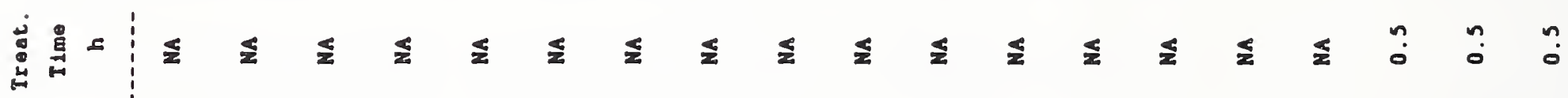

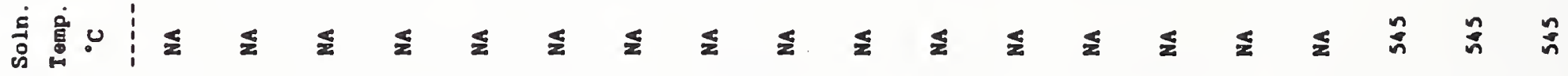

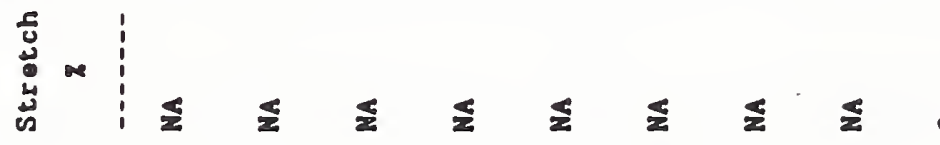

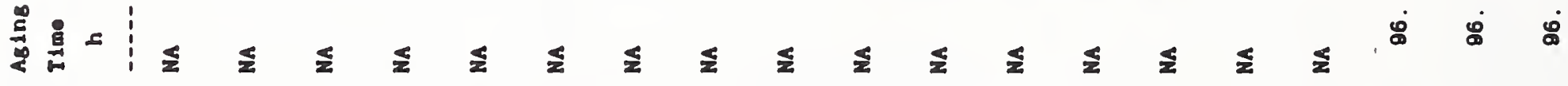

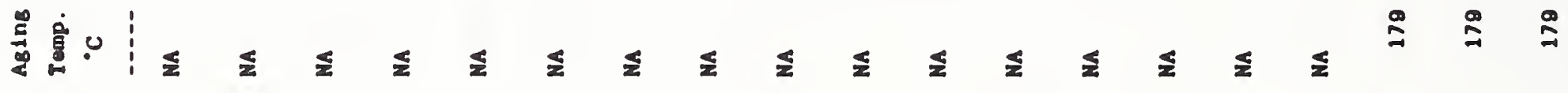
总泀

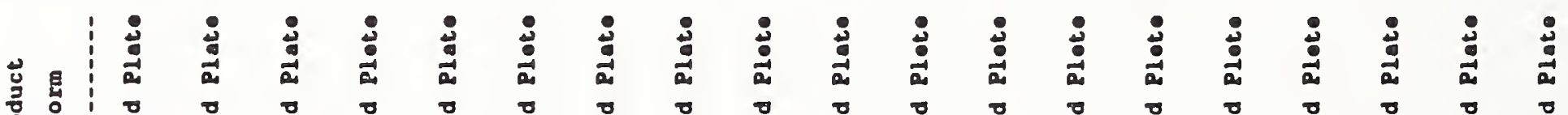

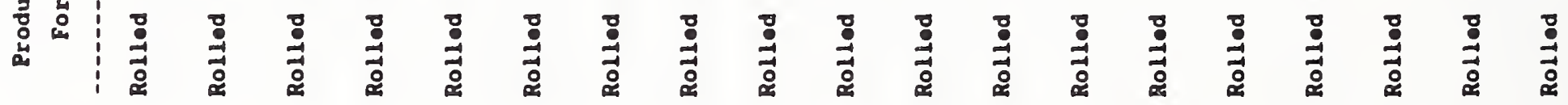
兽 总

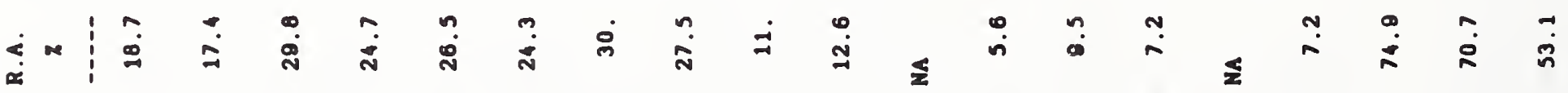

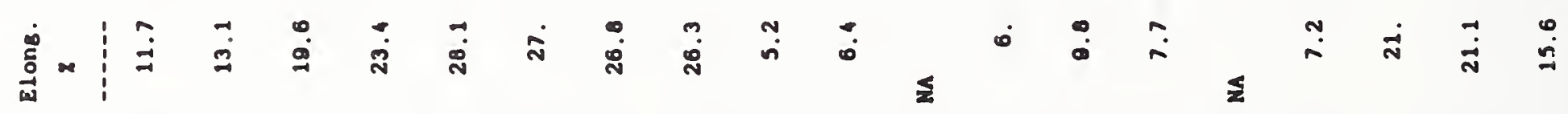
ن ن

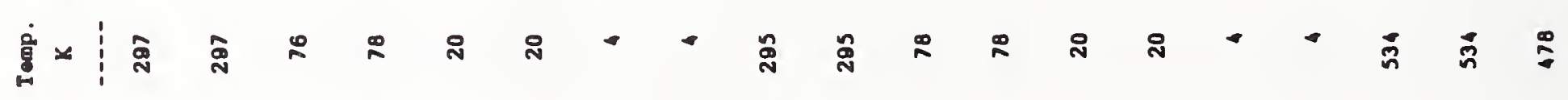

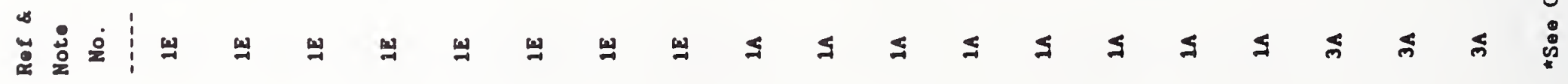




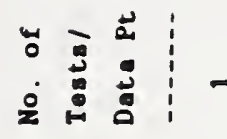

1

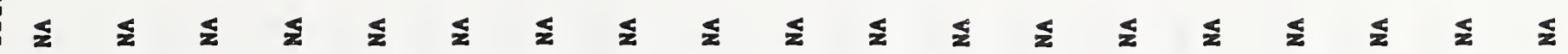

离

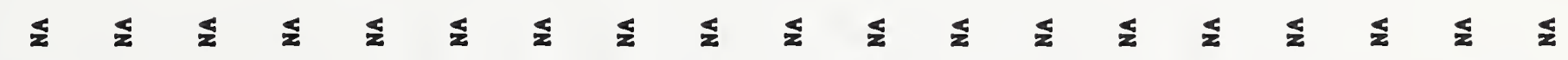

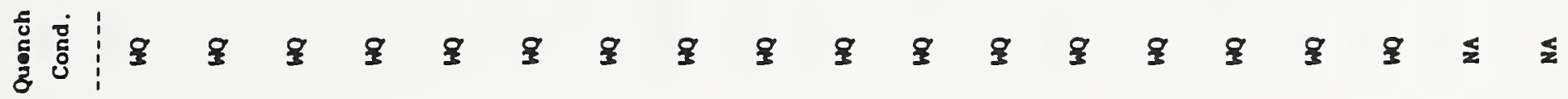

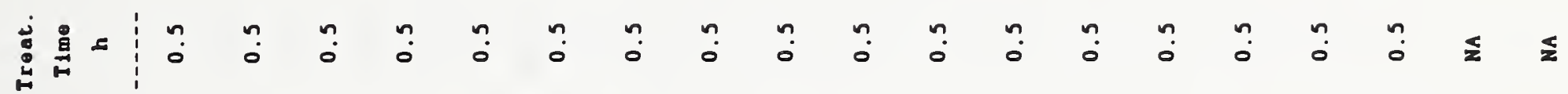

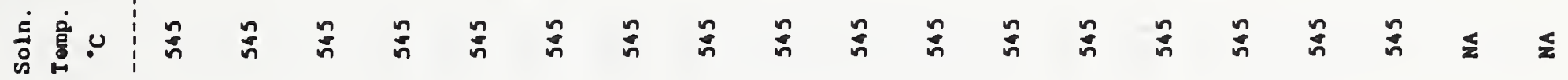

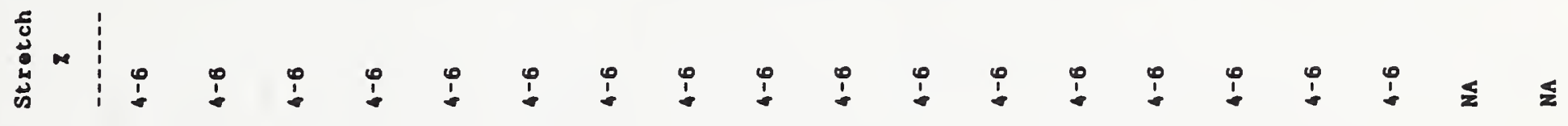
旁息 童

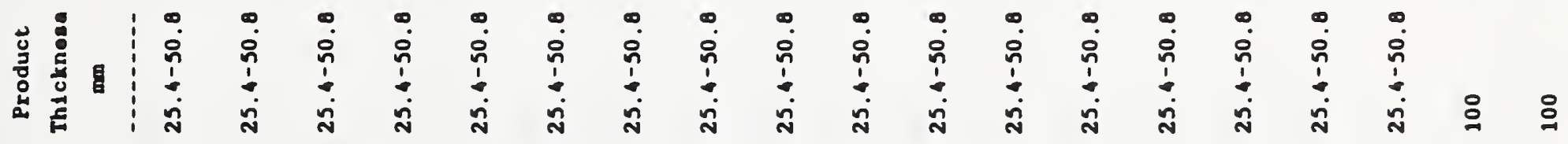

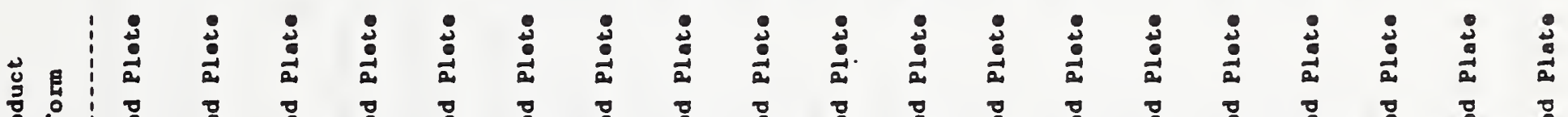

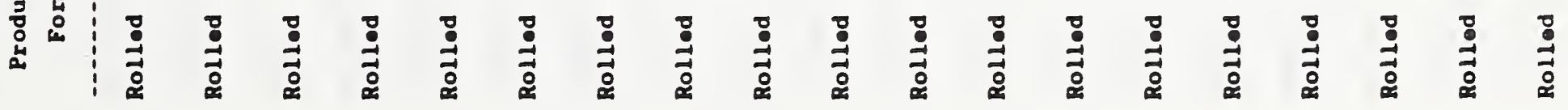

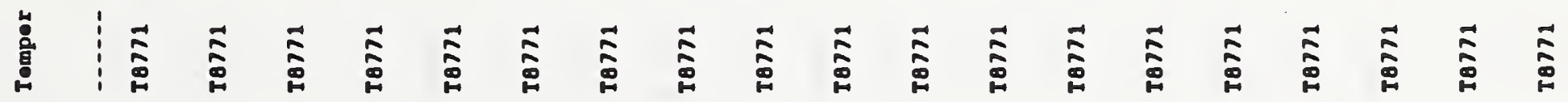
蓆

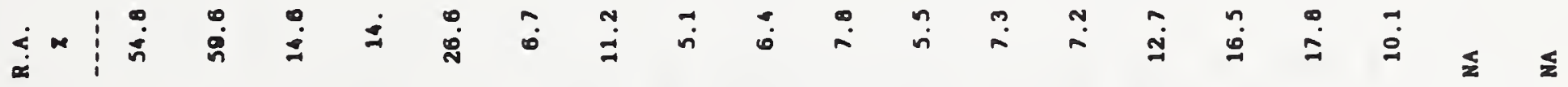

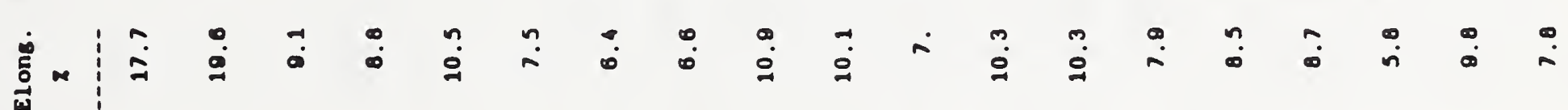

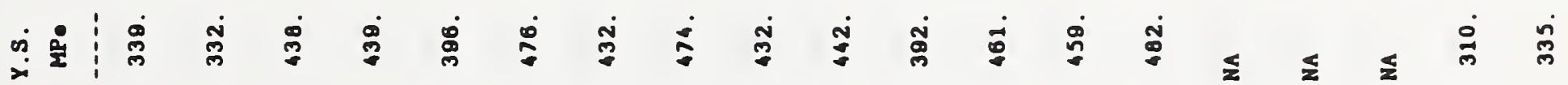
نั 密

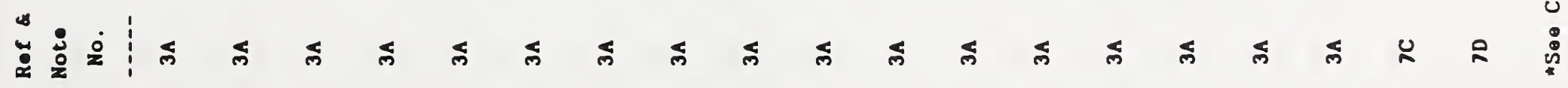


䒘矛

:

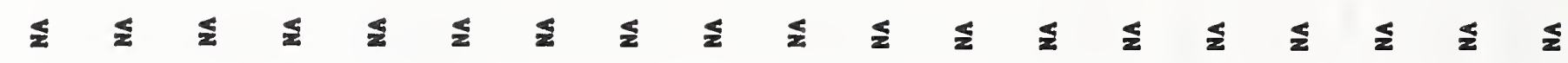

施

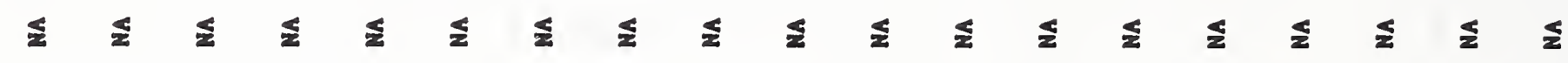

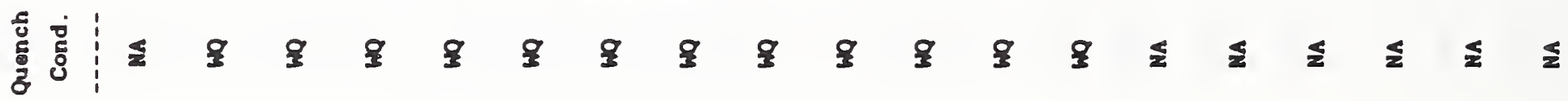
总曷

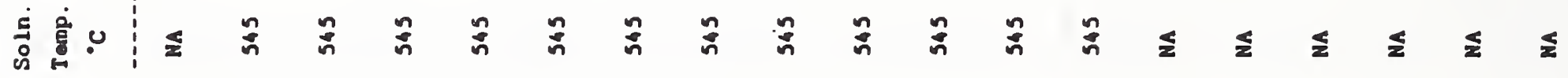

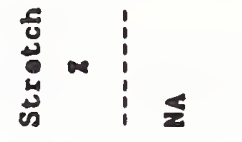

送息 造愠

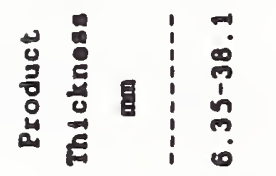

มิำ

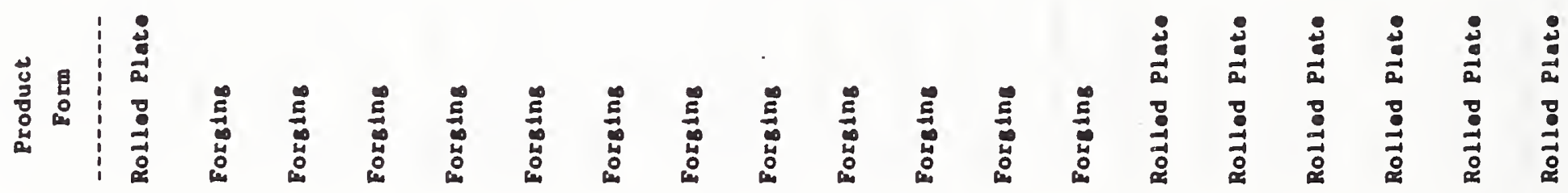
兽 泀

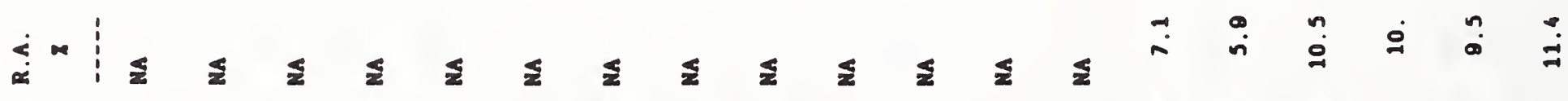
这 i் ம்

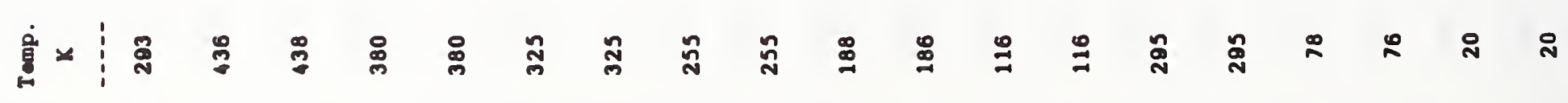

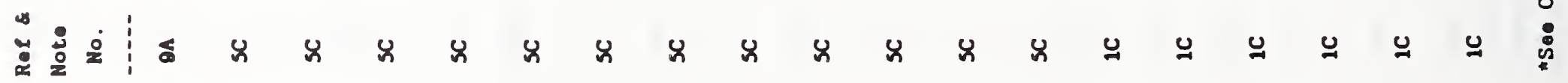




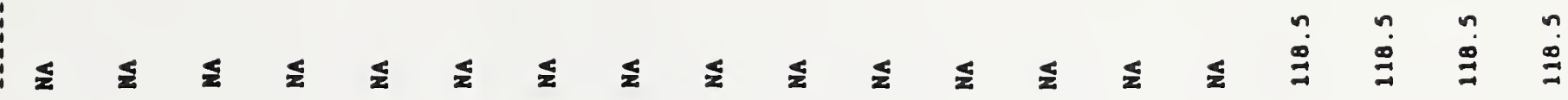

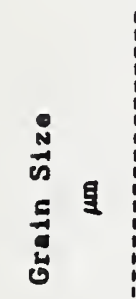

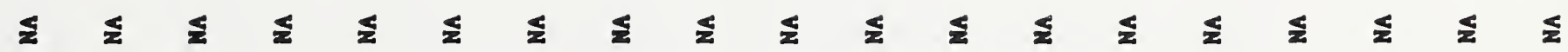
总

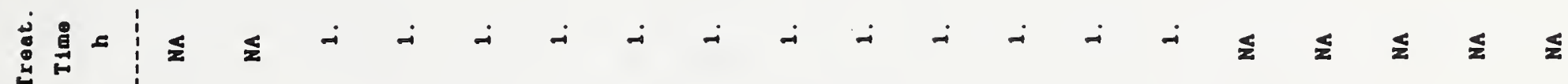

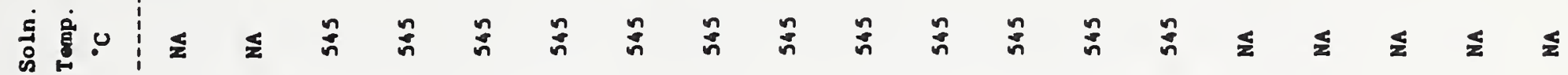

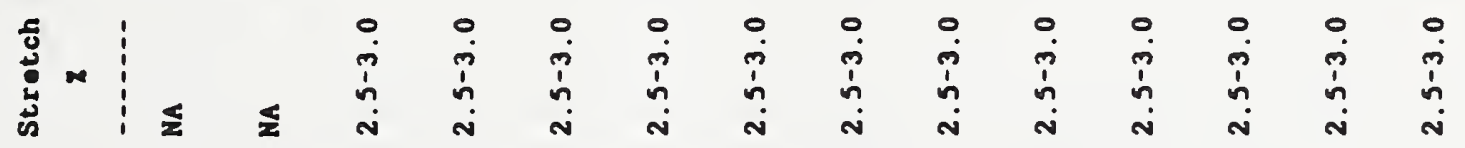
递息 兽富 总总

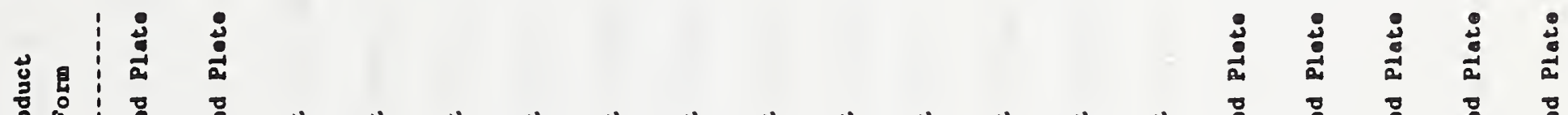

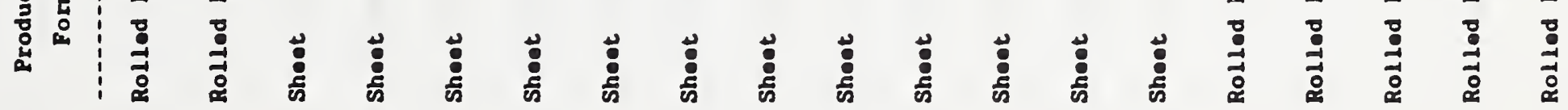

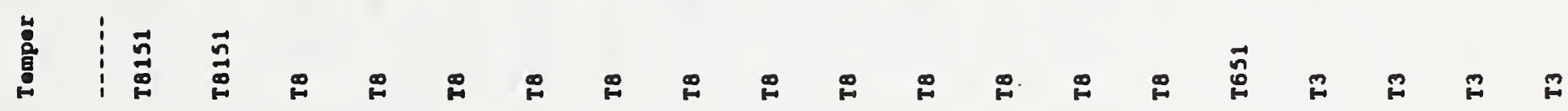

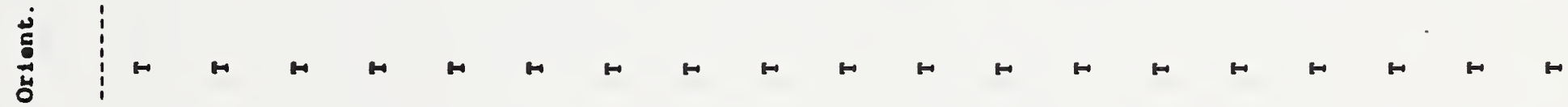

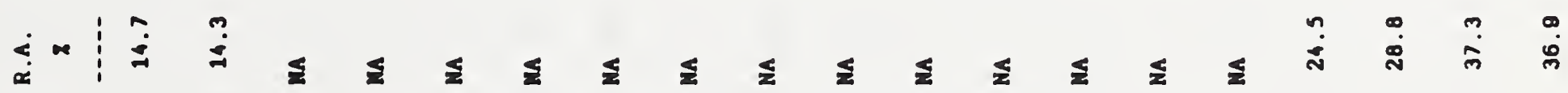

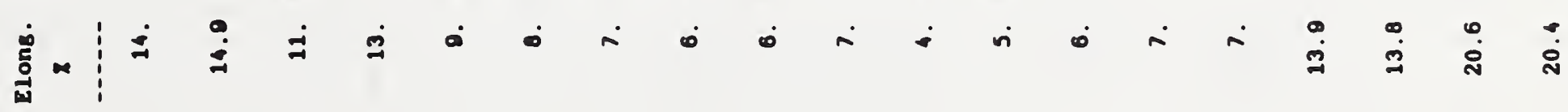
ن்

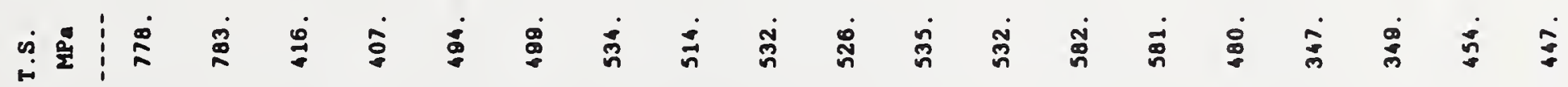

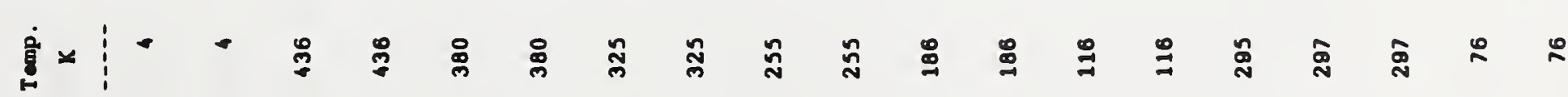
旁完 


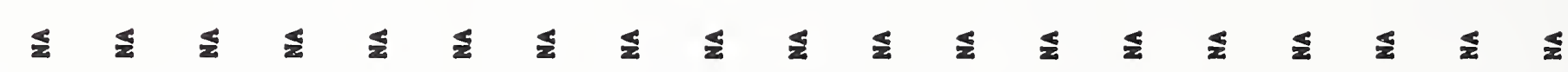
总苛 造曾

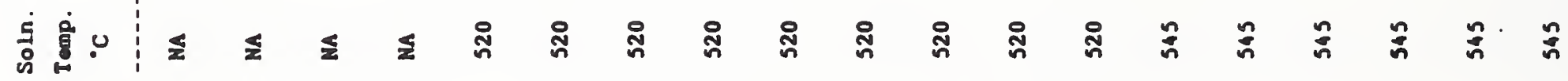
竞

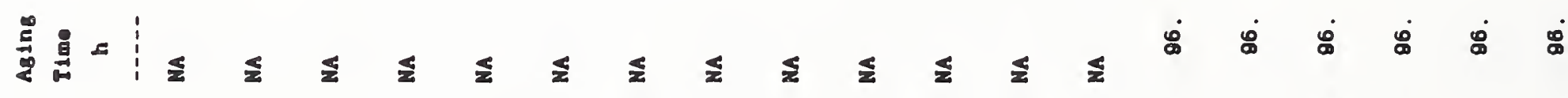
递富

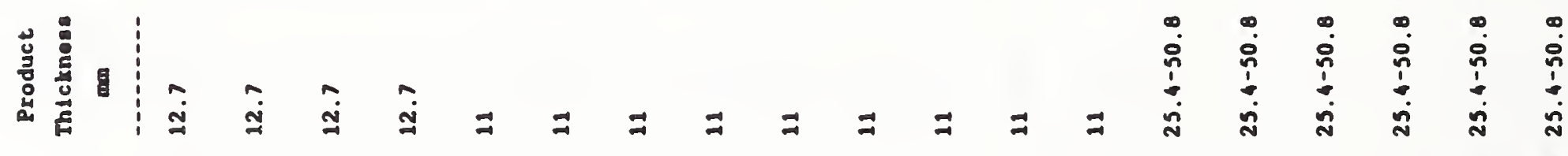

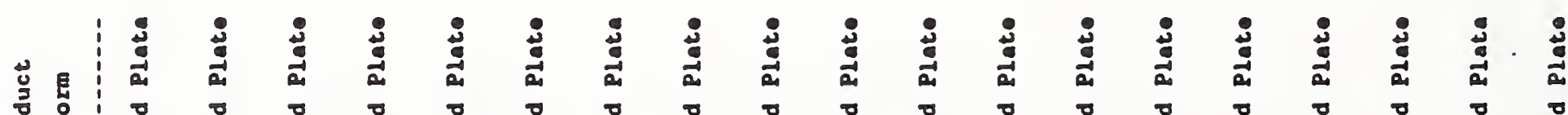

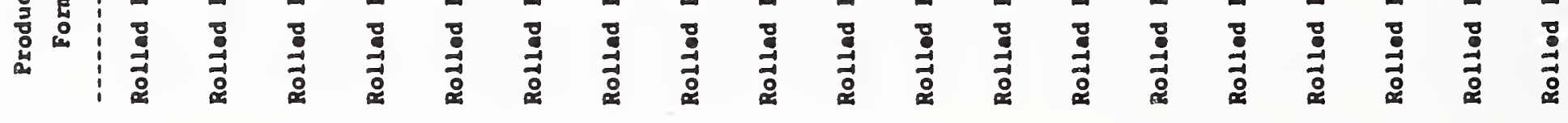

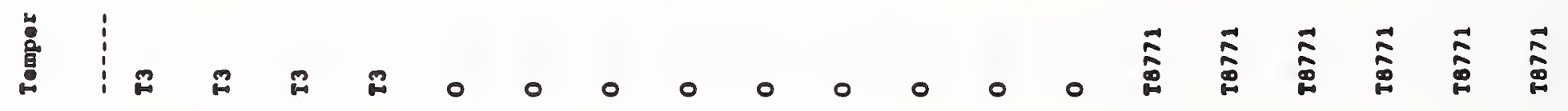
泀

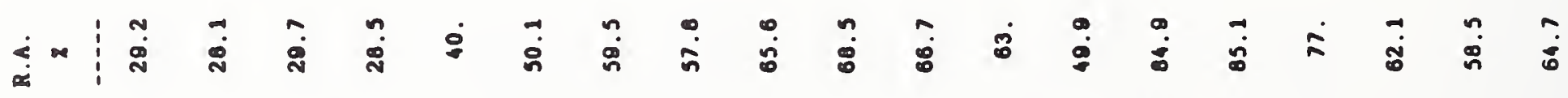

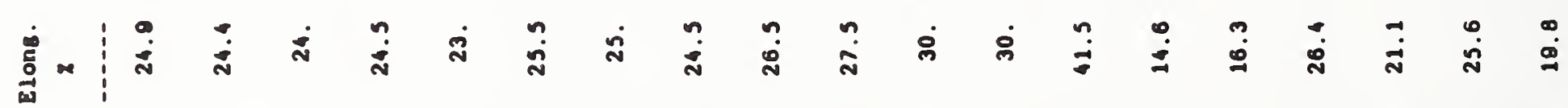
ن

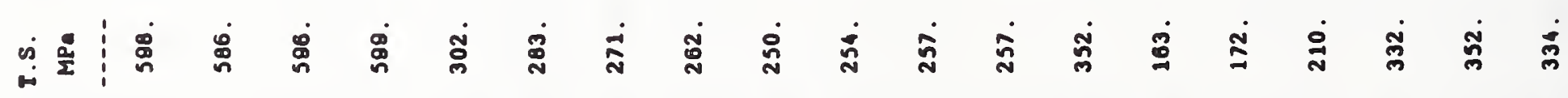
苗

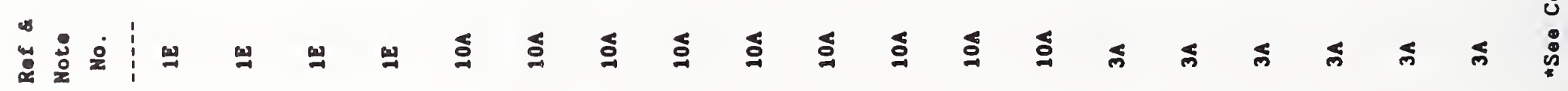




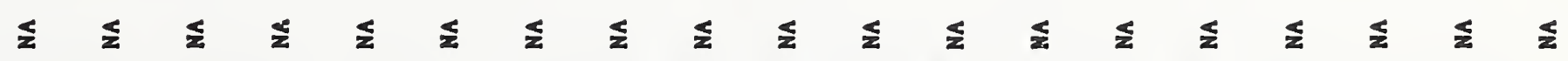

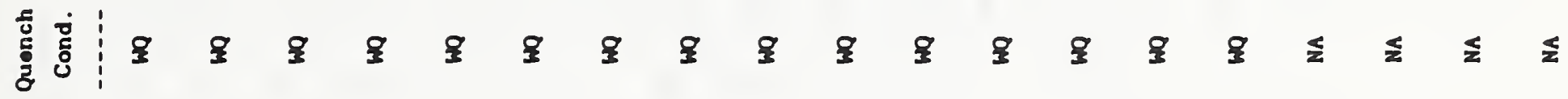

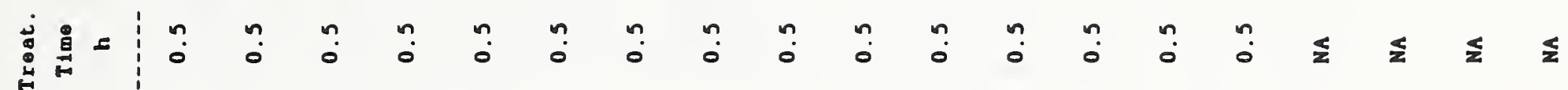

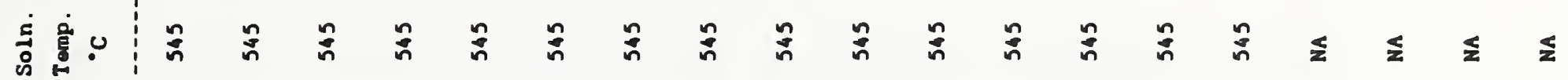

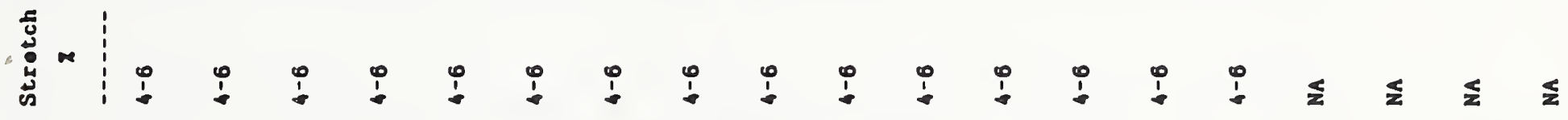
送息 逼

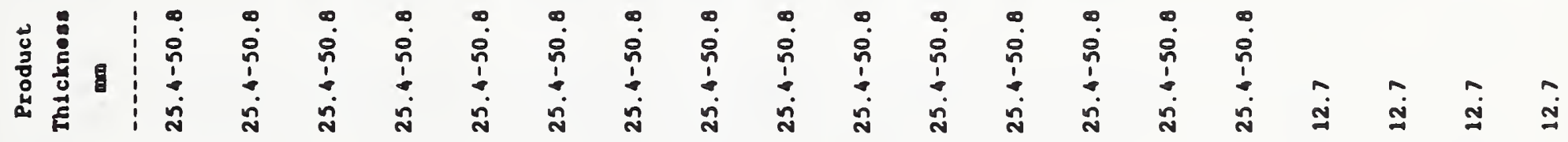

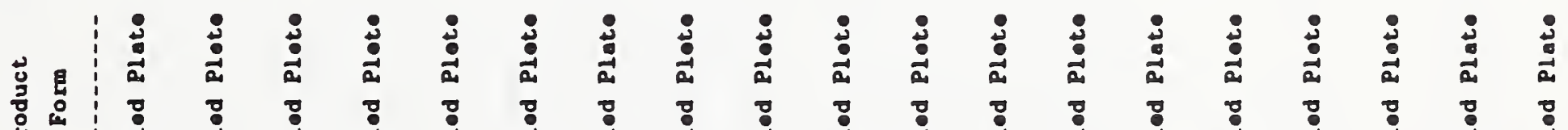
总

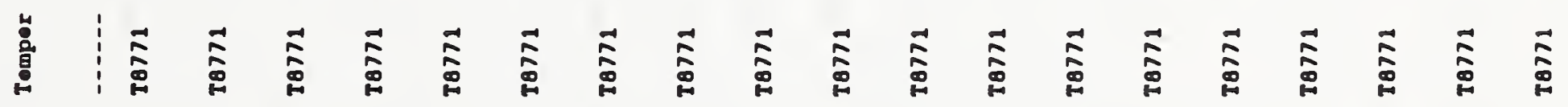

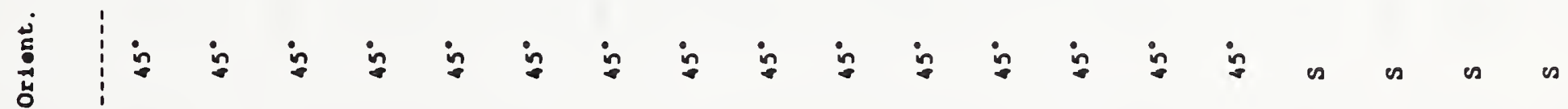

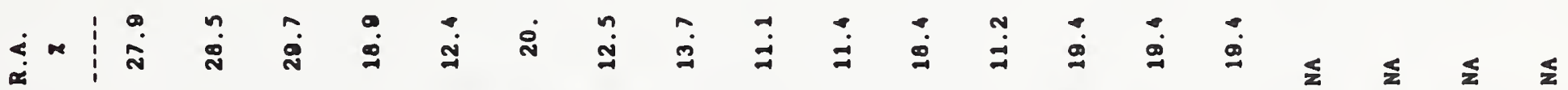

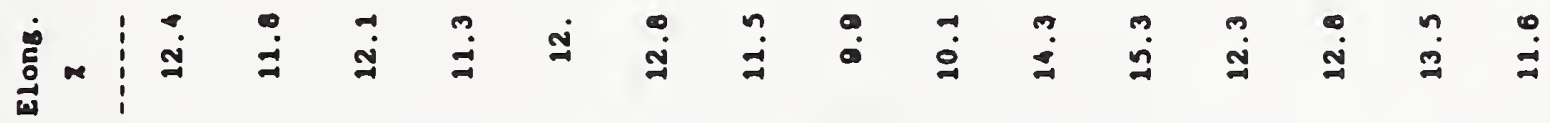

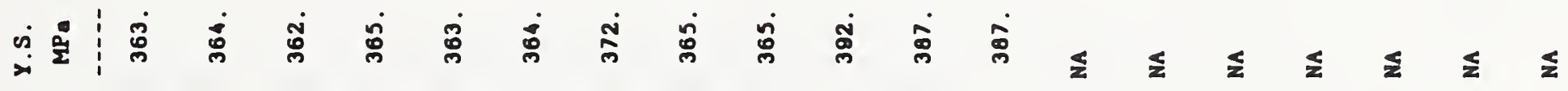

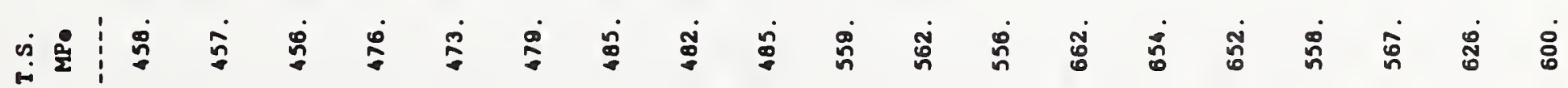

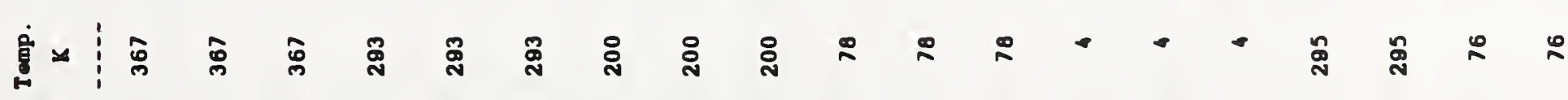

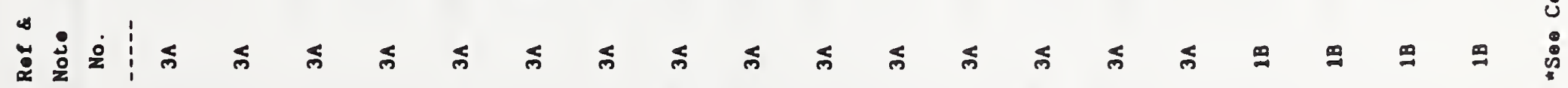




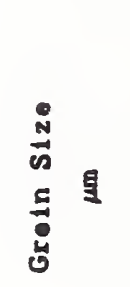

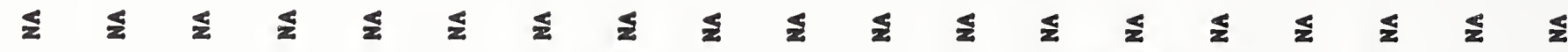
息

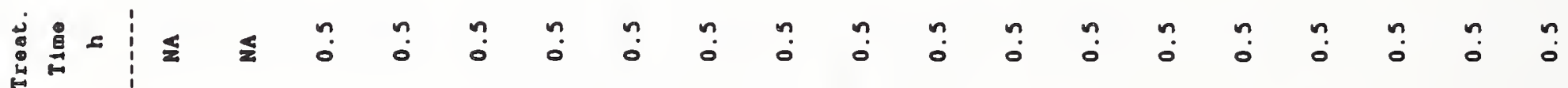

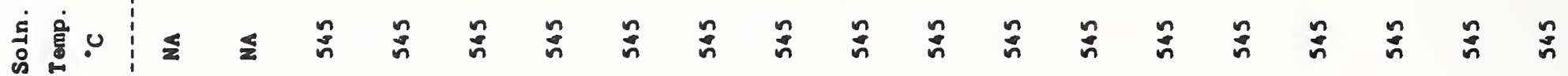

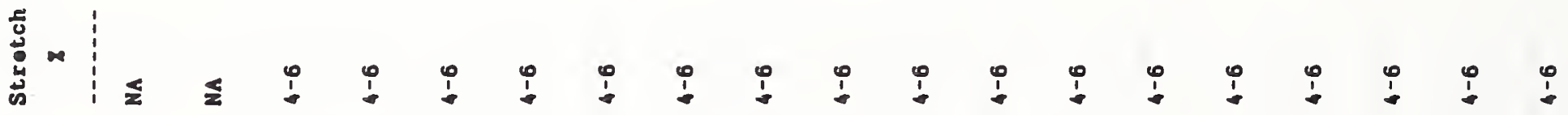
进息 帛

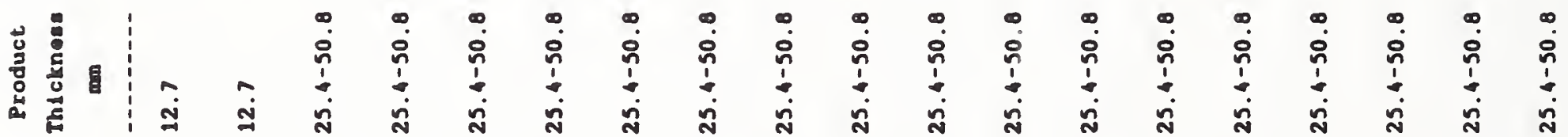

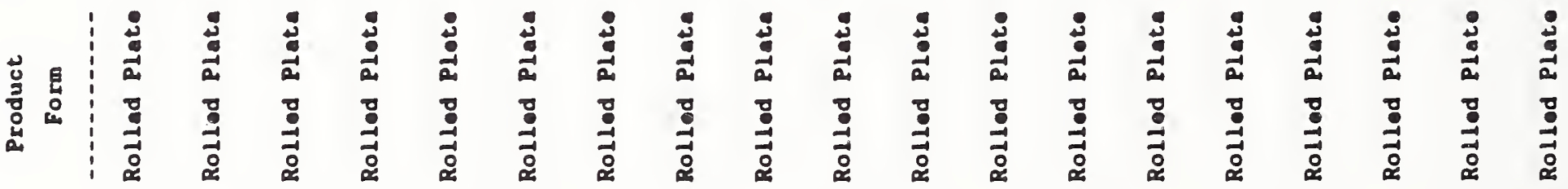

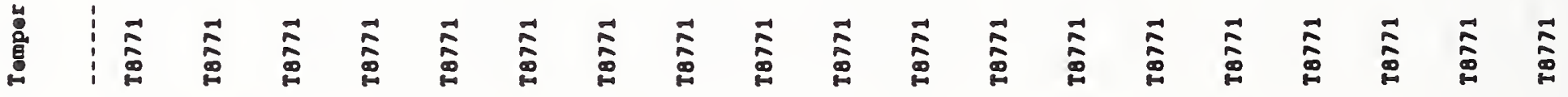

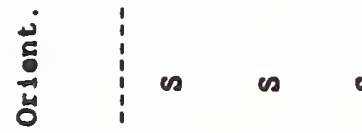

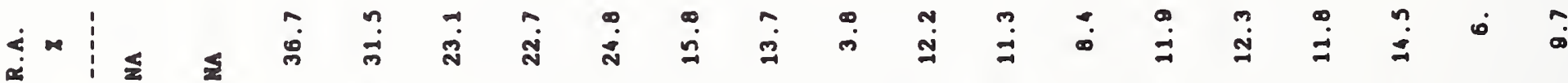
远 ๖ ம்

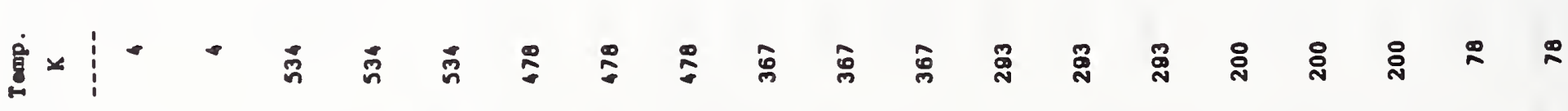

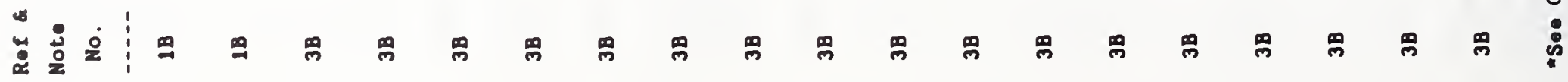




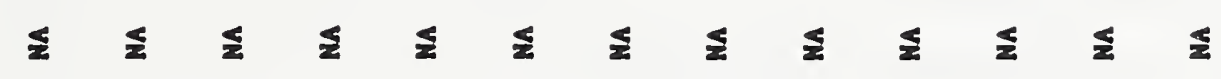

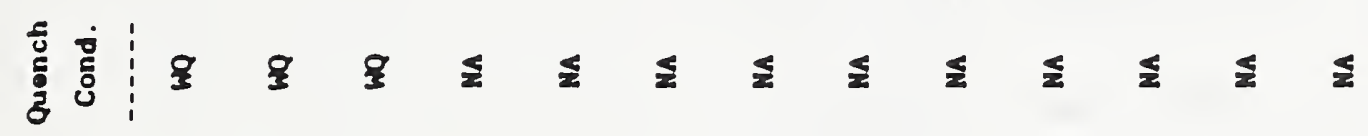

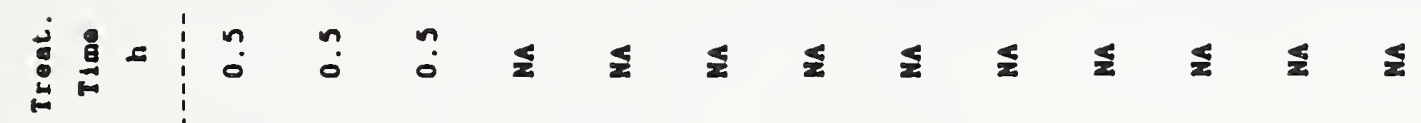

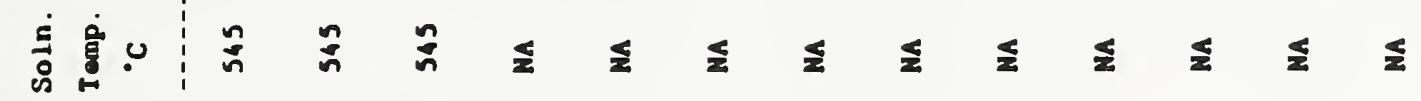
站以 递息 递菑

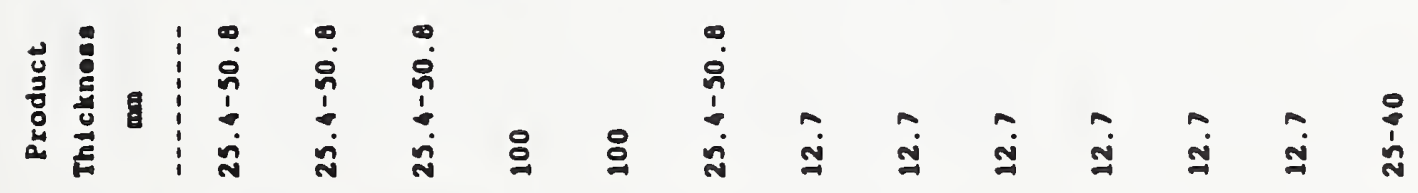

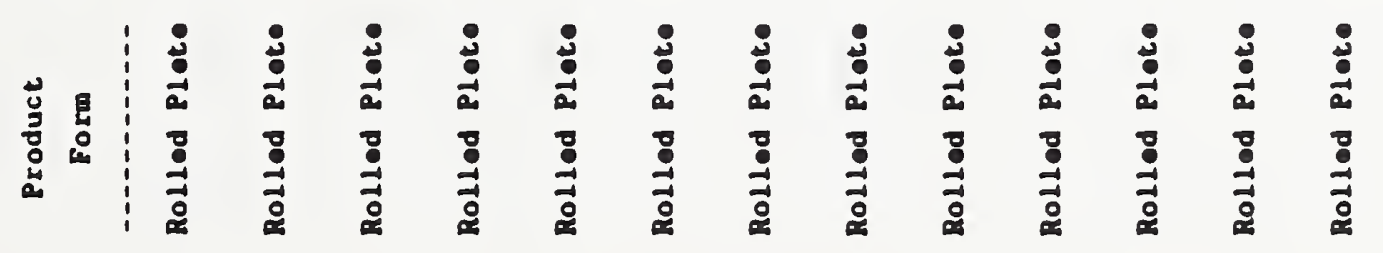
兽

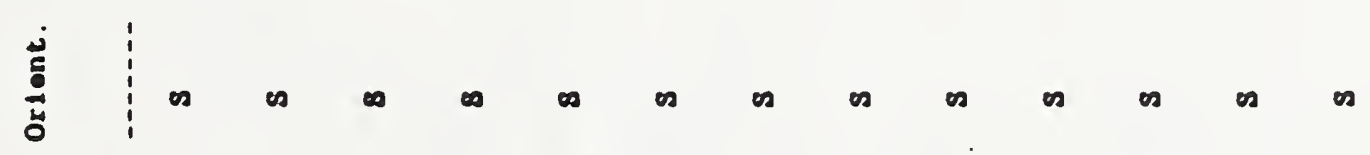

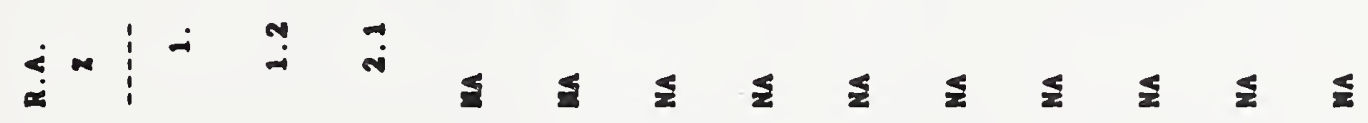

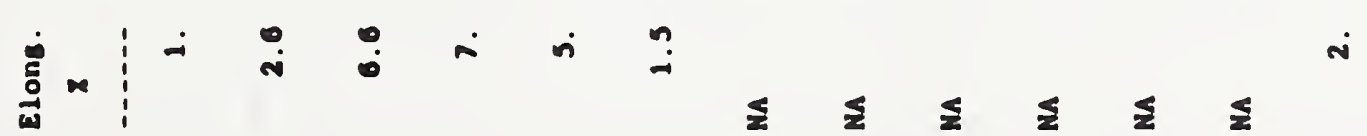
ம்

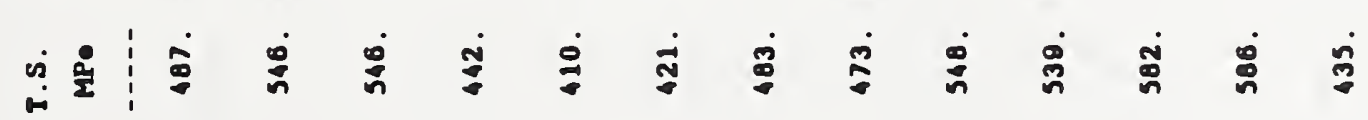

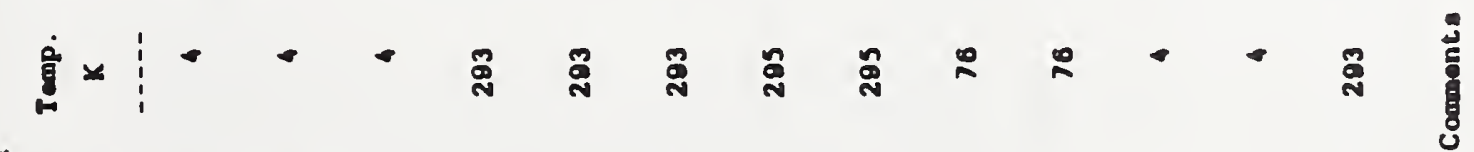

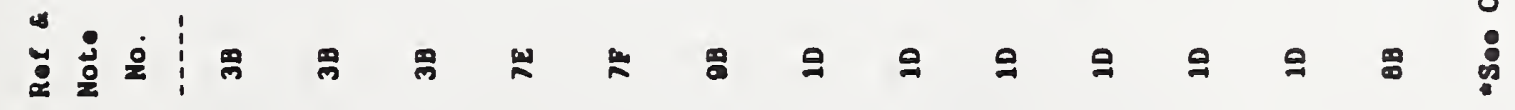




\section{Comments from the Al-Li Alloy 8090 Data Table}

\section{Reference and}

Note Number

3A-B--Temper T851 appears to be T8771, and is reported here as such. 5C--Cold work is in compression.

$8 \mathrm{~A}$--Values reported are "typical" properties.

9A--Values reported are "minimum" properties. 


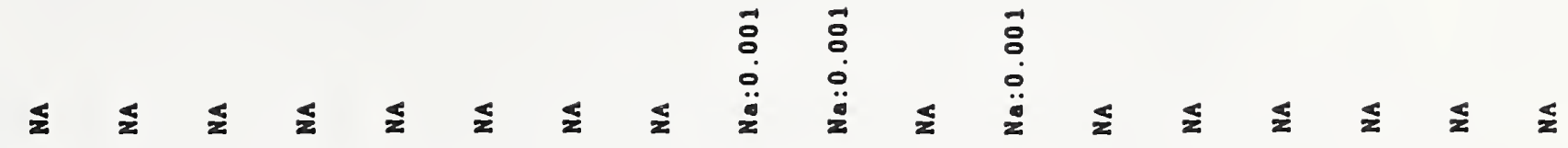

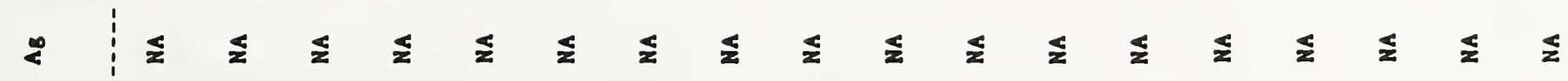

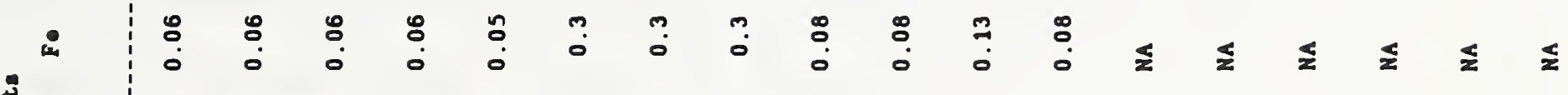

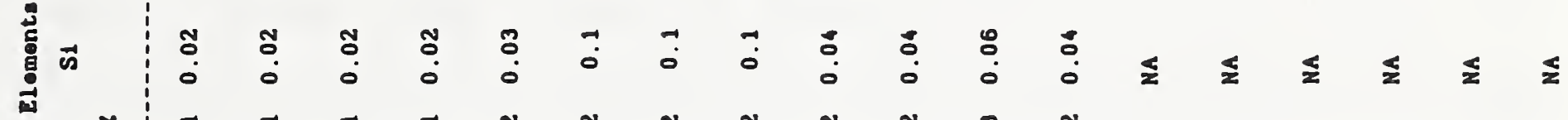

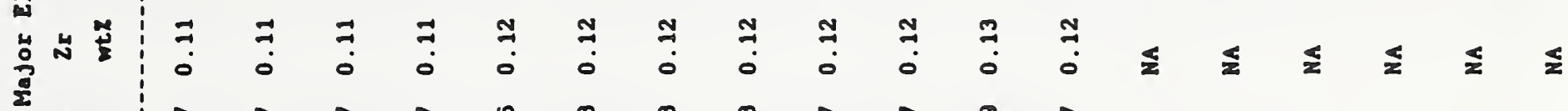

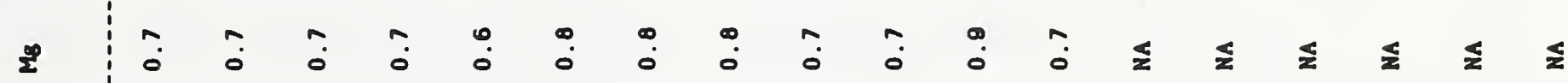

ช

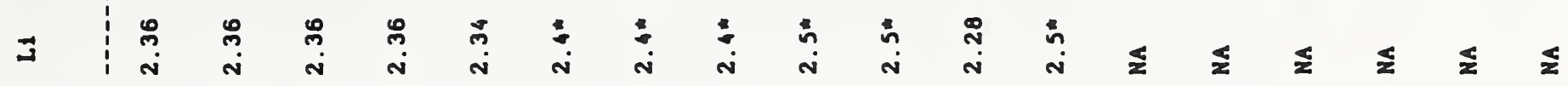

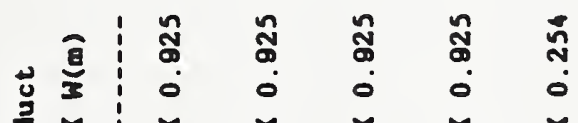

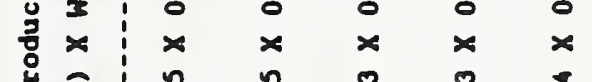

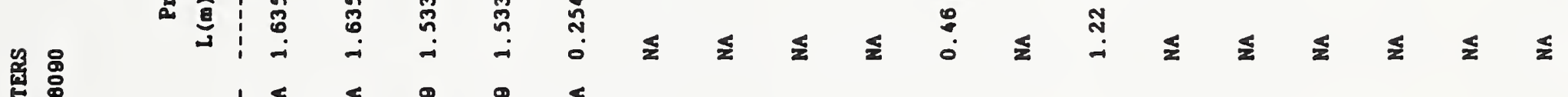

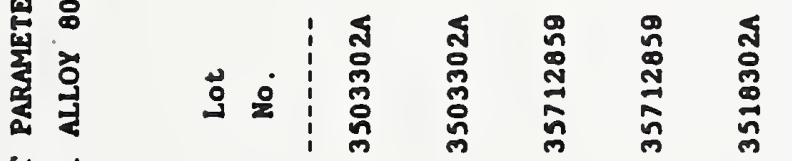

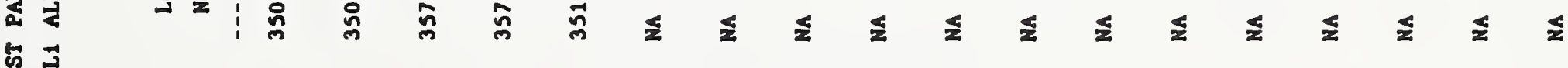
运㻤

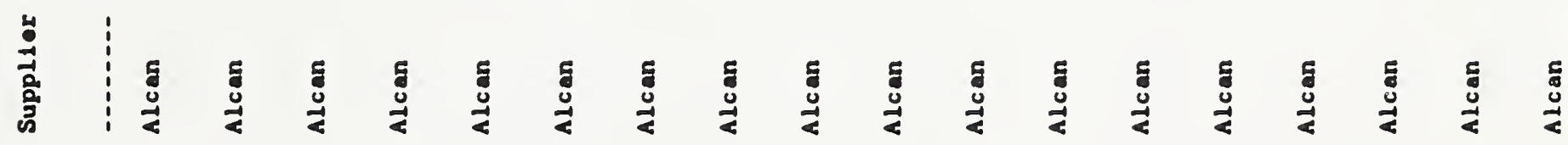

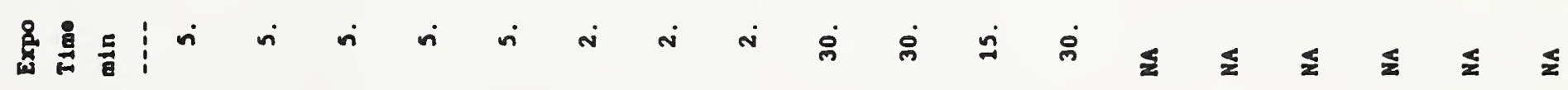

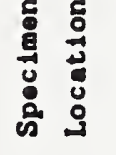

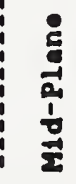

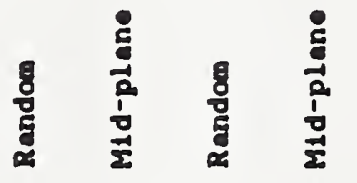

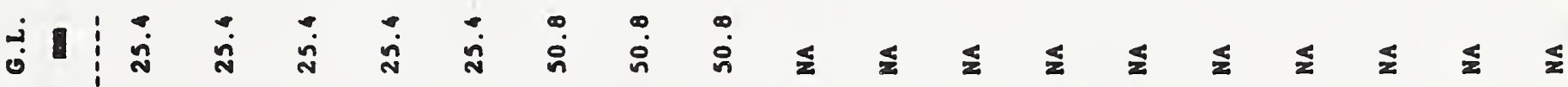

兽苛 总青冒 运

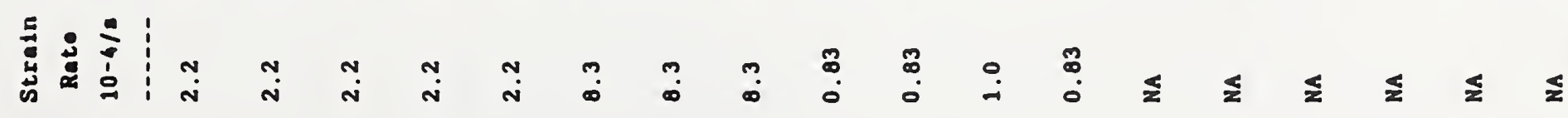

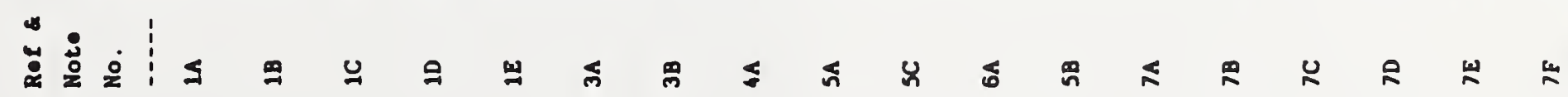




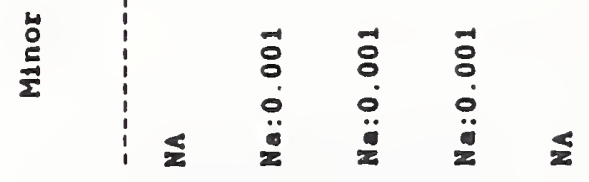

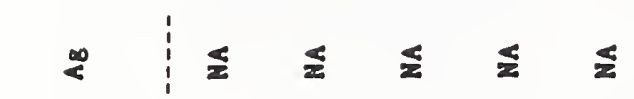

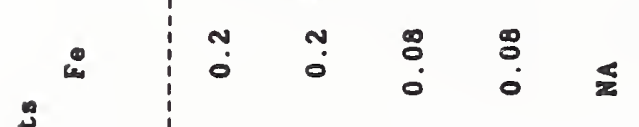

产

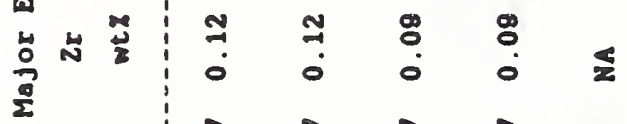

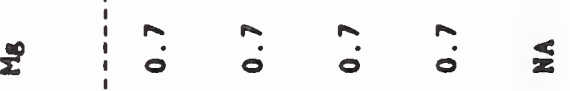

उ

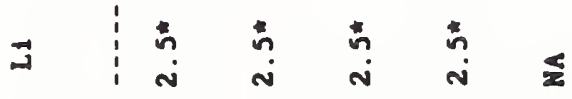

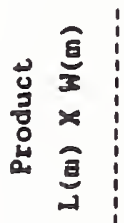

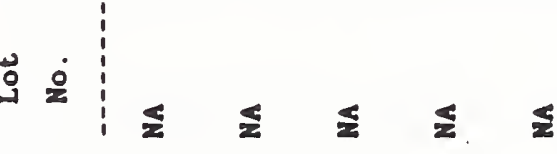

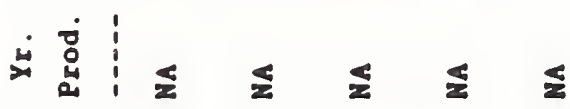

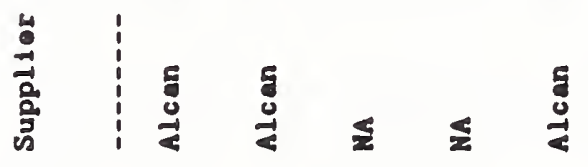

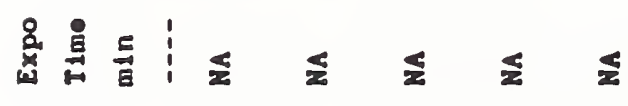

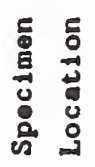

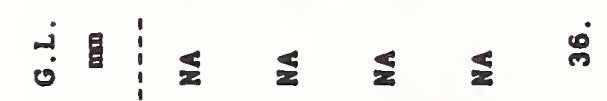

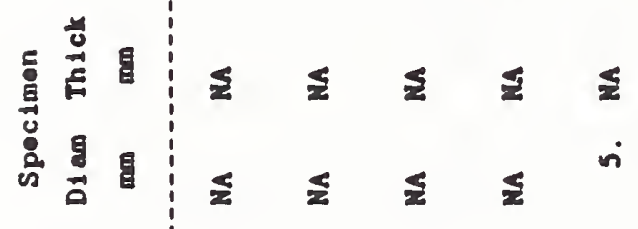
总

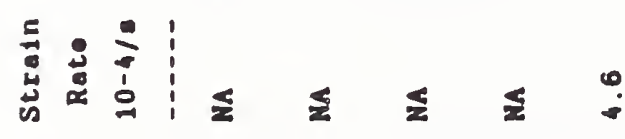

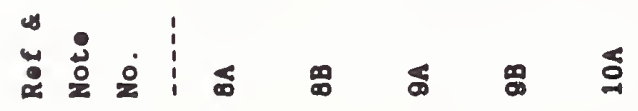




\section{Comments from the Al-Li Alloy 8090 Test Parameter Table}

\section{Refertace and}

Note Number

3A-B--Reported composition is based on typical values.

4A--Reported composition is based on nominal values.

5A-C--Reported composition is the average of the range provided for in the Lockheed requirements.

8A--Reported composition is based on nominal values.

$9 A-B-$-Reported composition is the average of the range provided for in the Lockheed requirements. 
ULTIMATE TENSILE STRENGTH, ksi

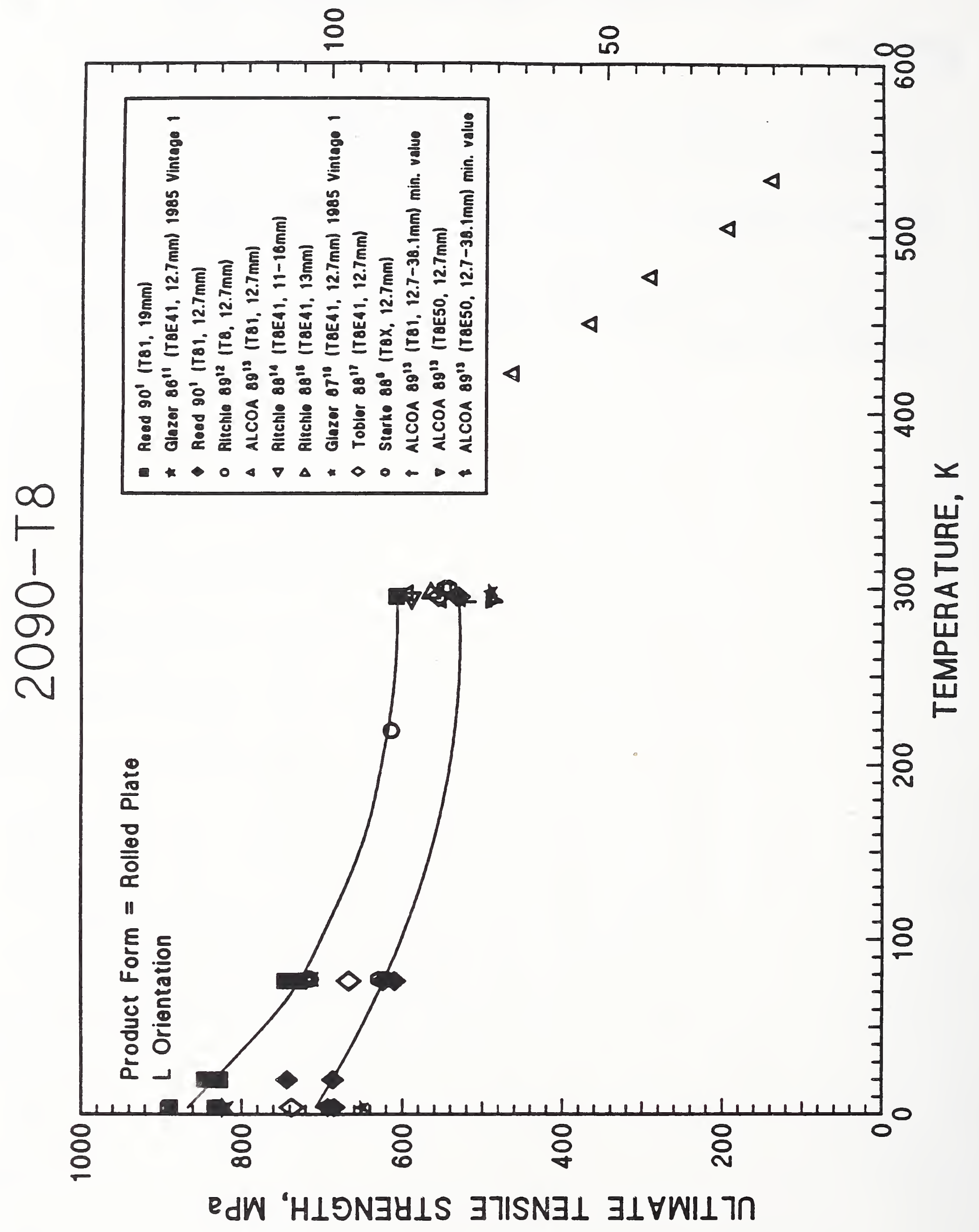


TENSILE YIELD STRENGTH, ksi

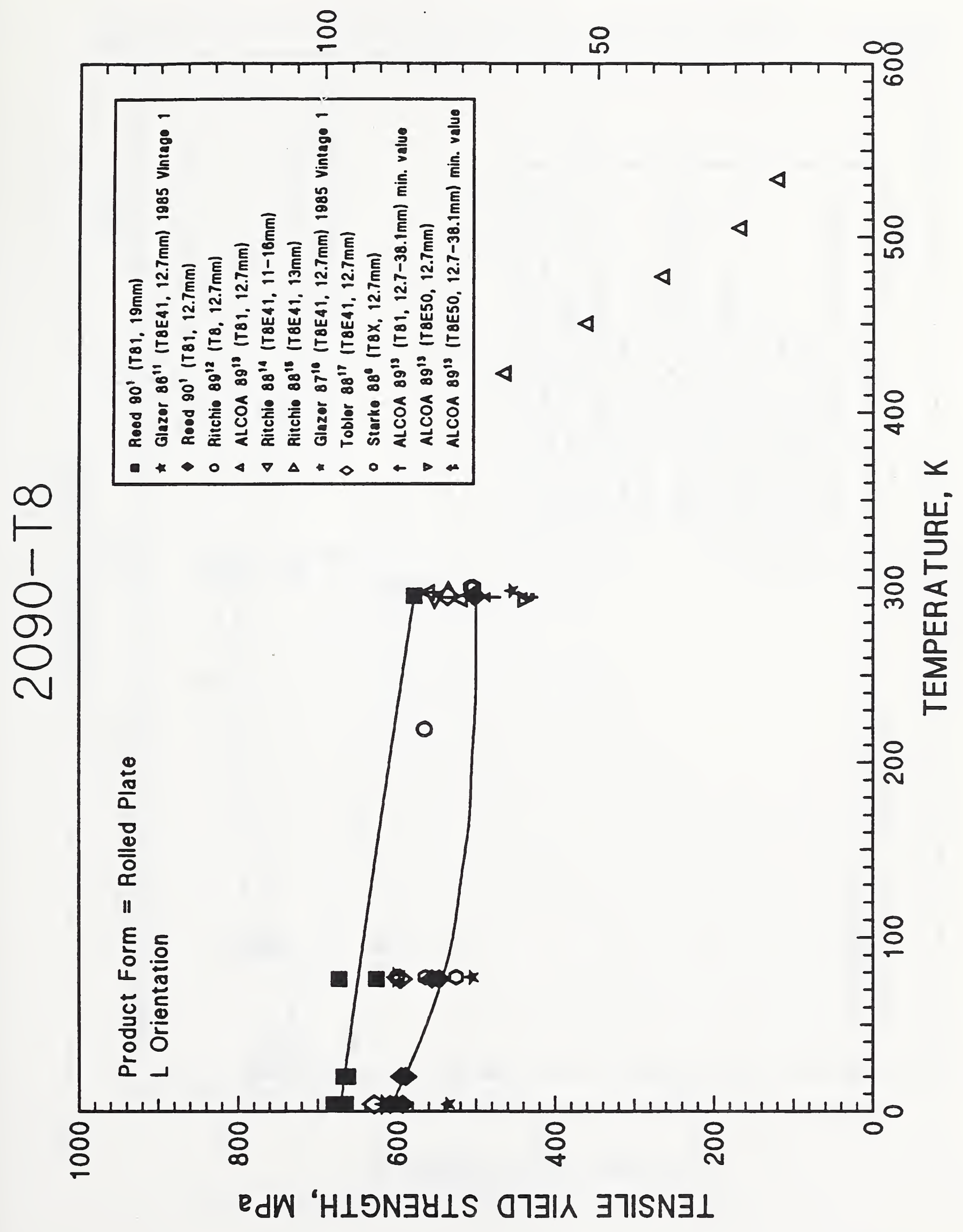




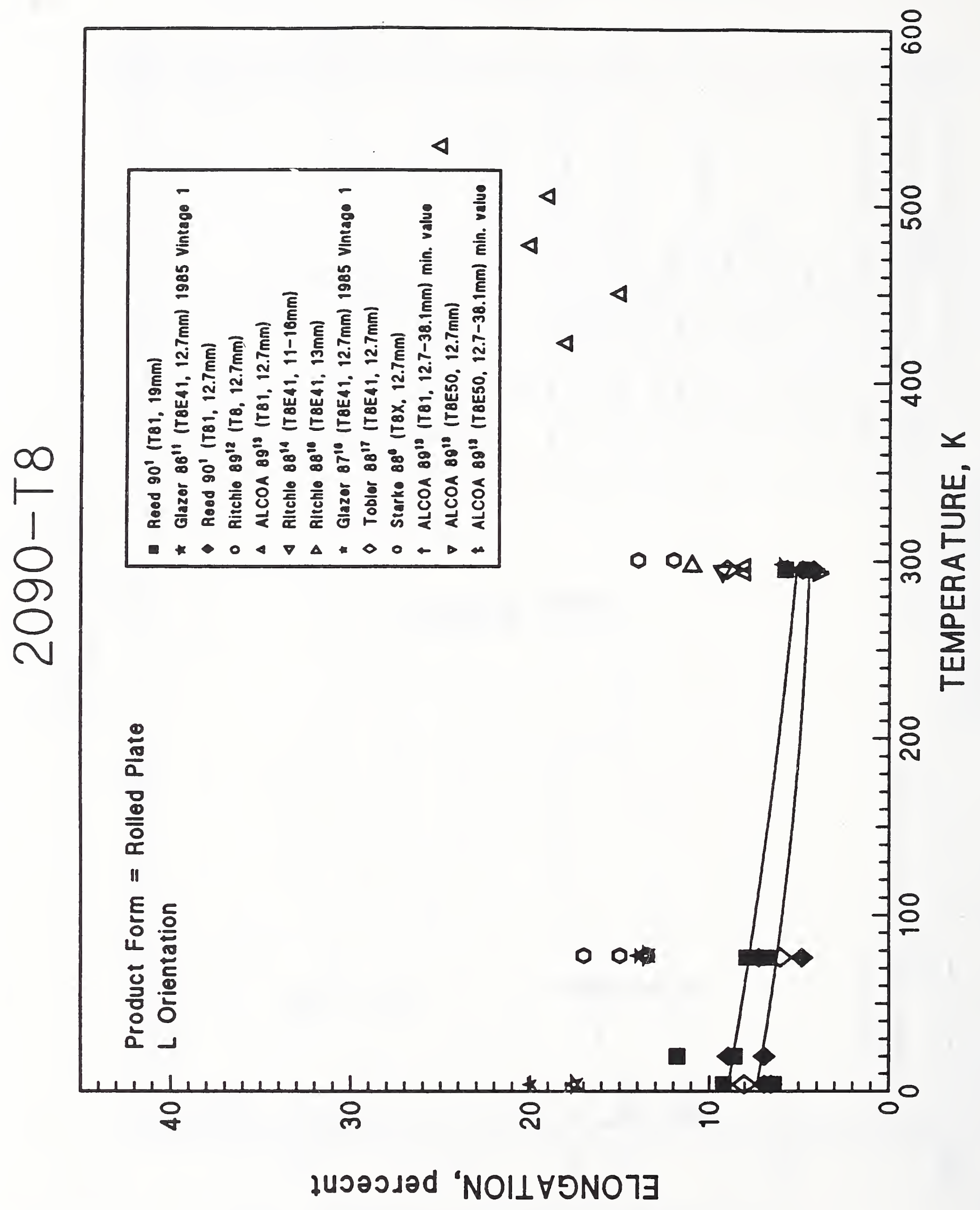


ULTIMATE TENSILE STRENGTH, ksi

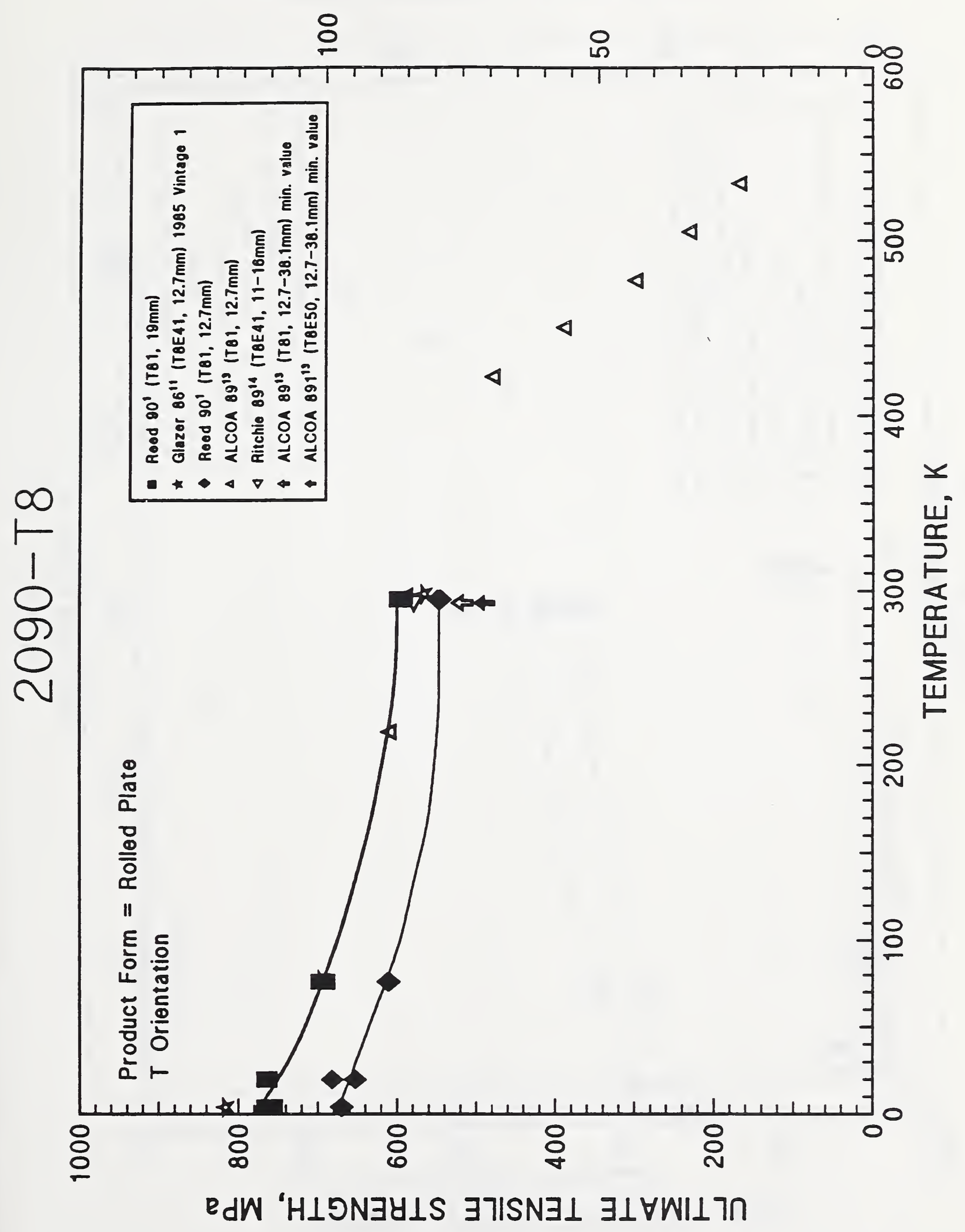


TENSILE YIELD STRENGTH, ksi

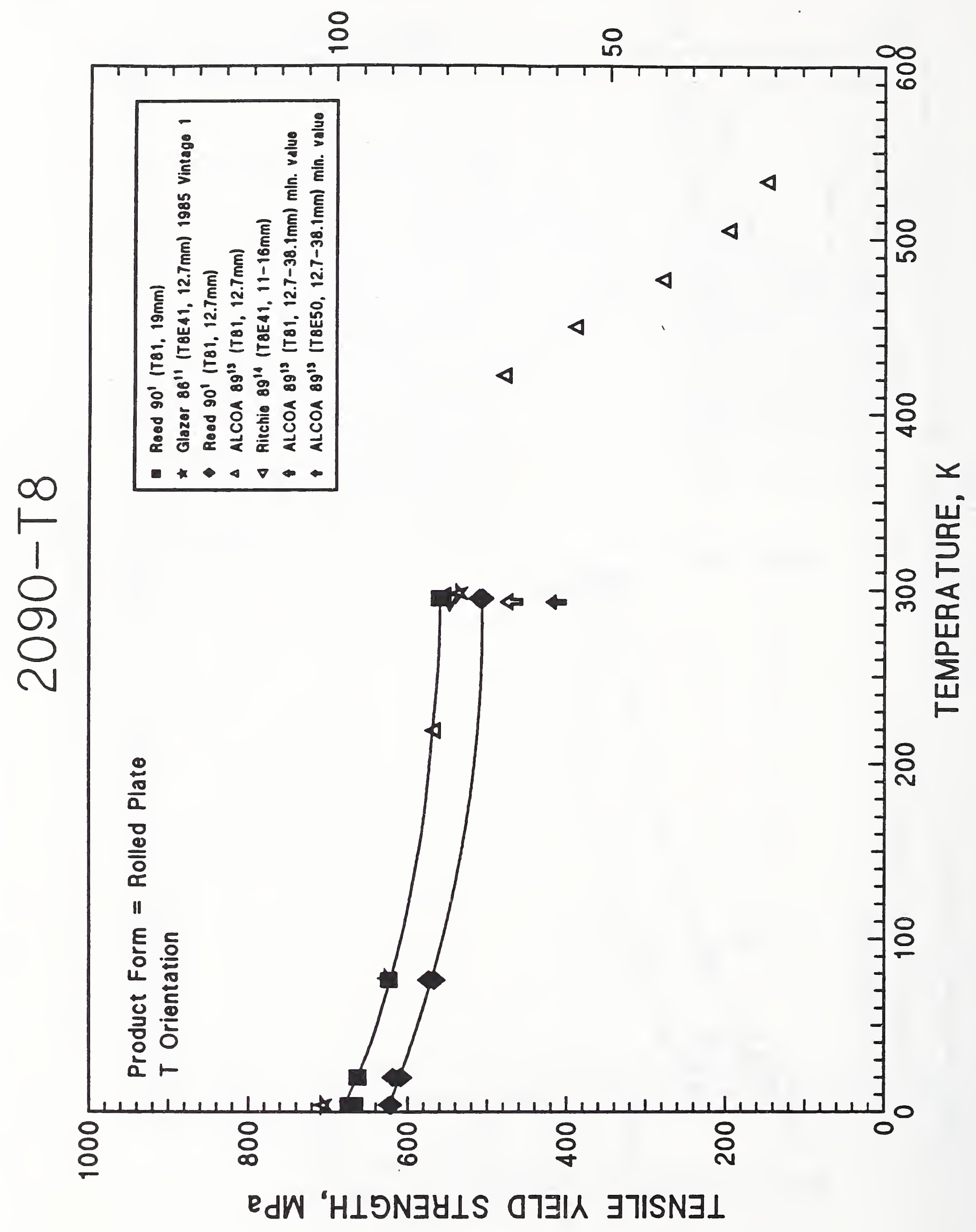




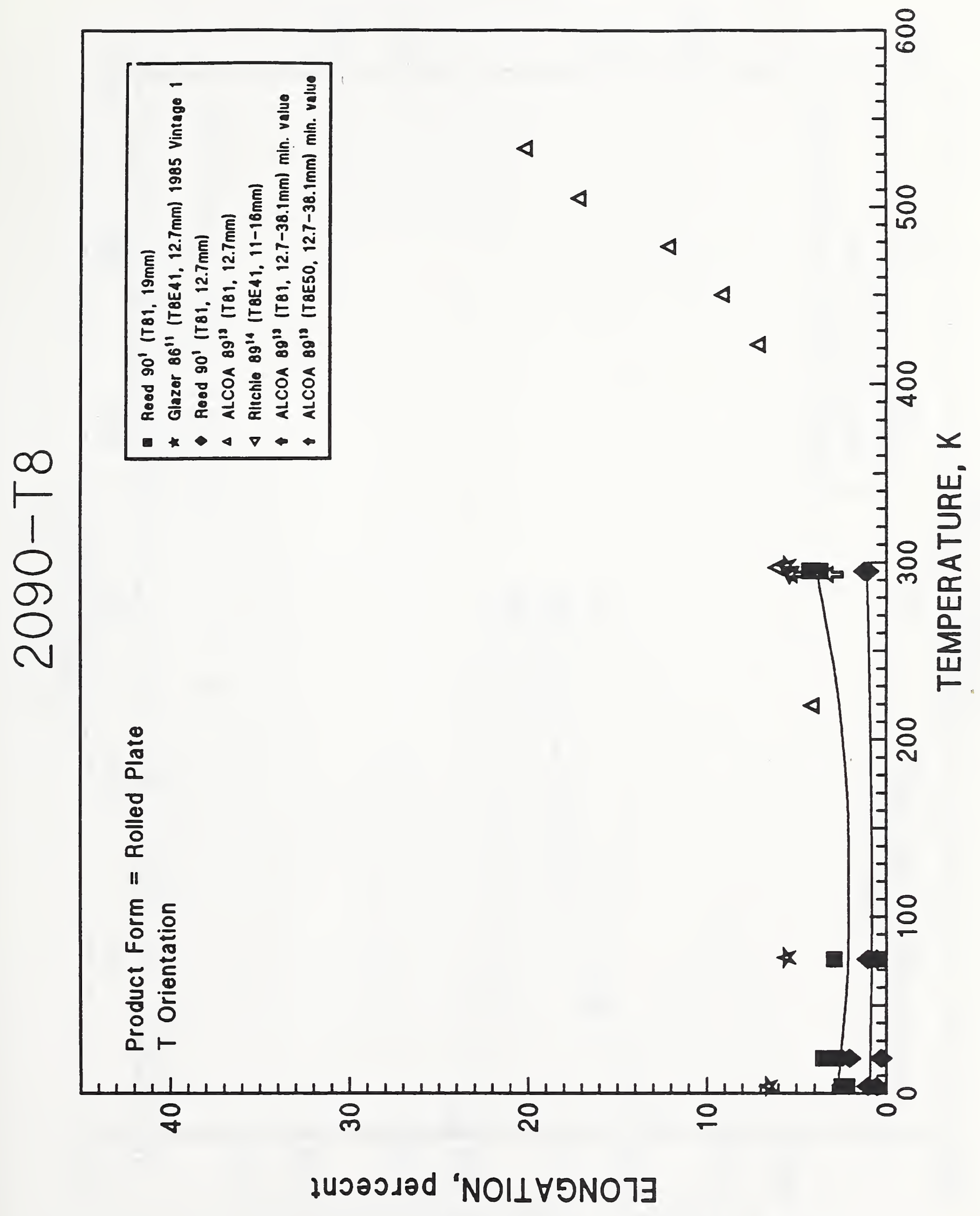


ULTIMATE TENSILE STRENGTH, ksi

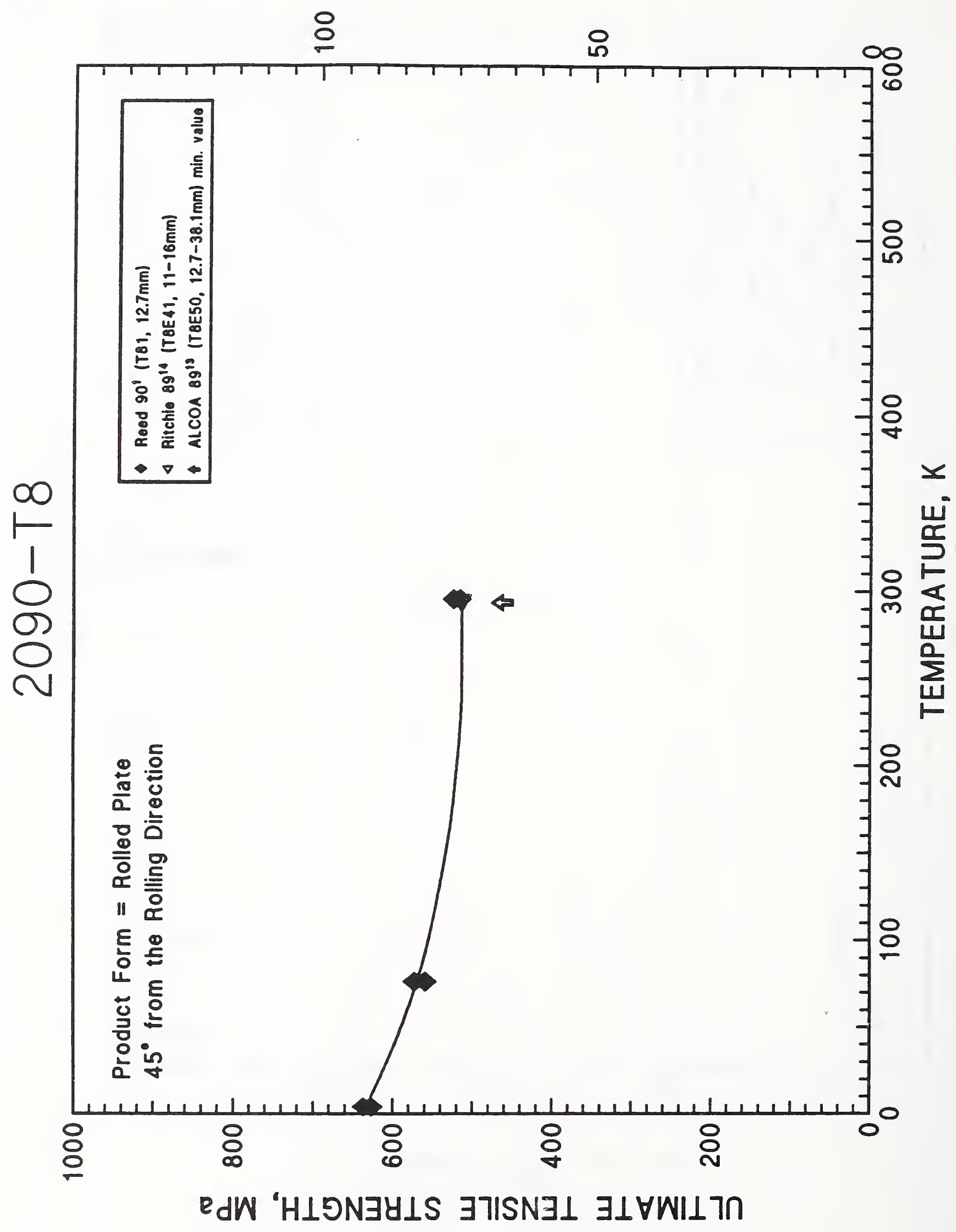


TENSILE YIELD STRENGTH, ksi

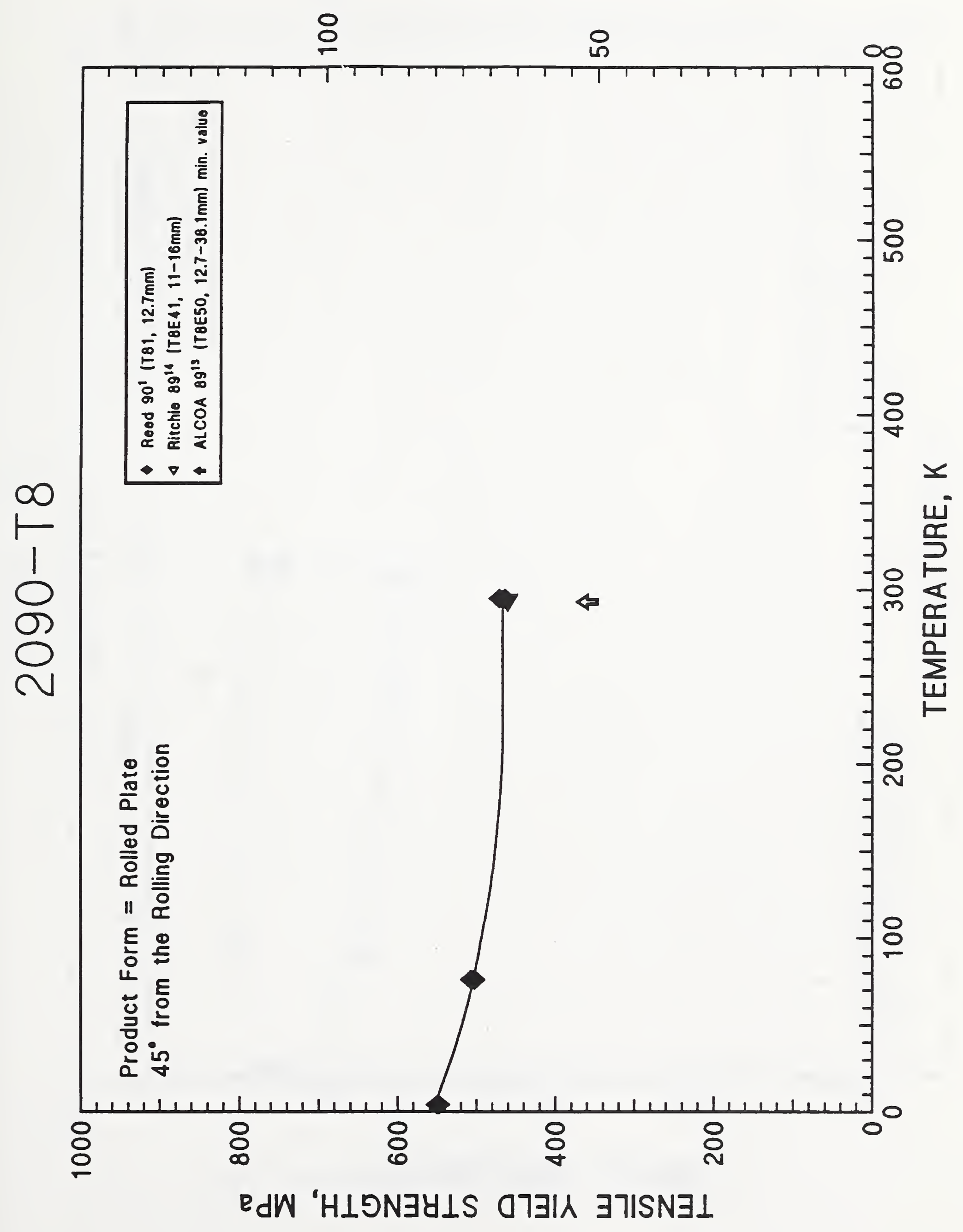




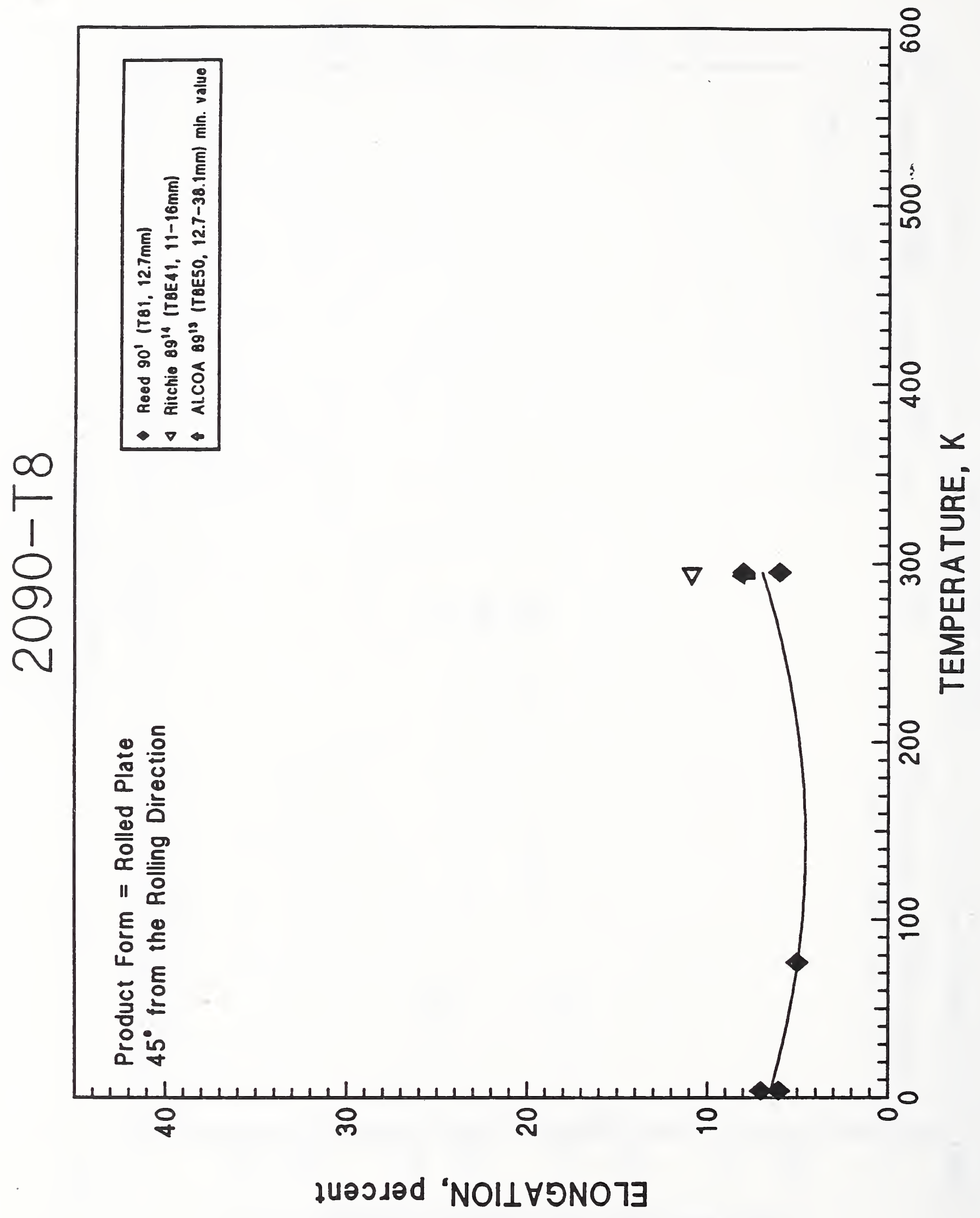


ULTIMATE TENSILE STRENGTH, ksi

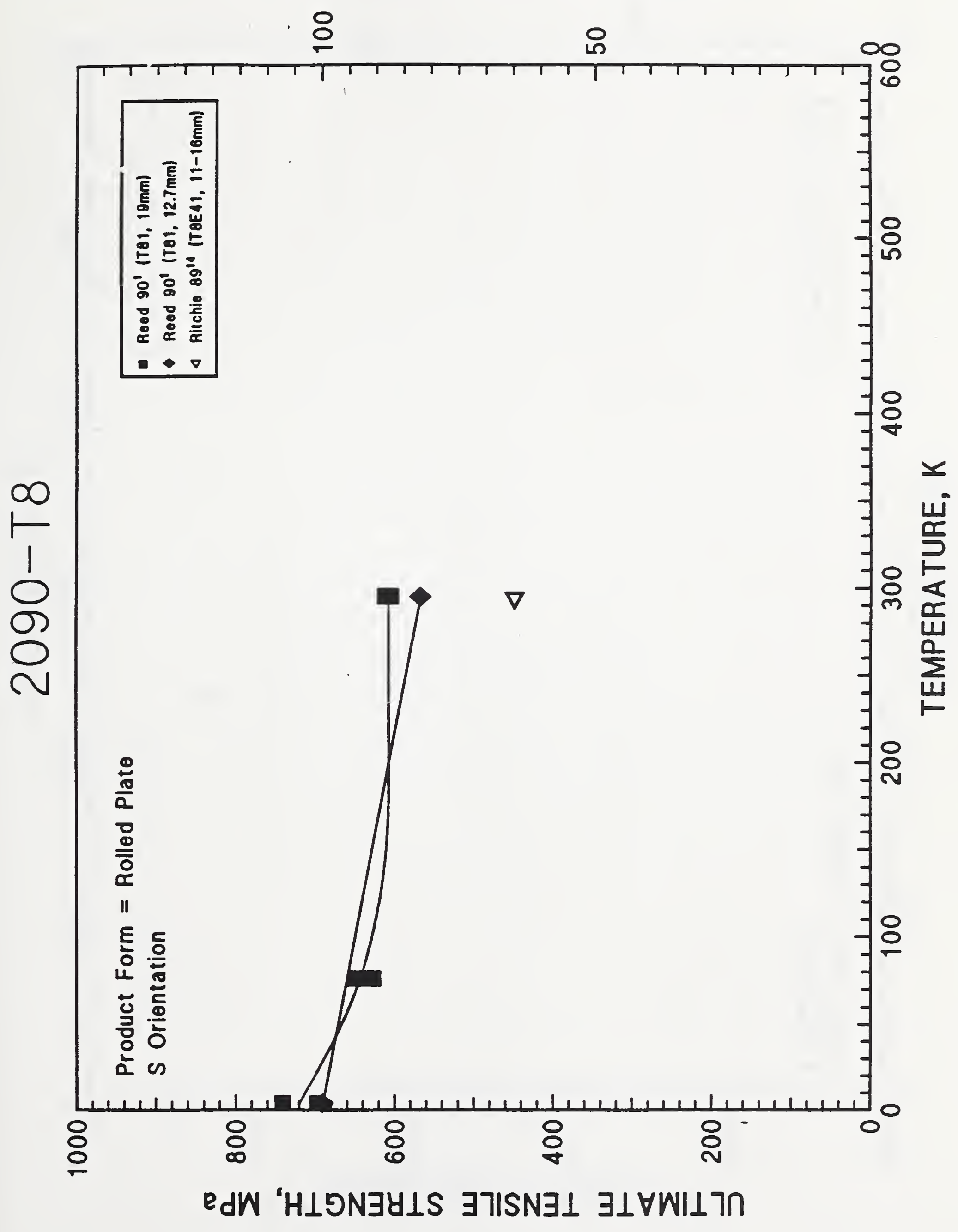


TENSILE YIELD STRENGTH, ksi

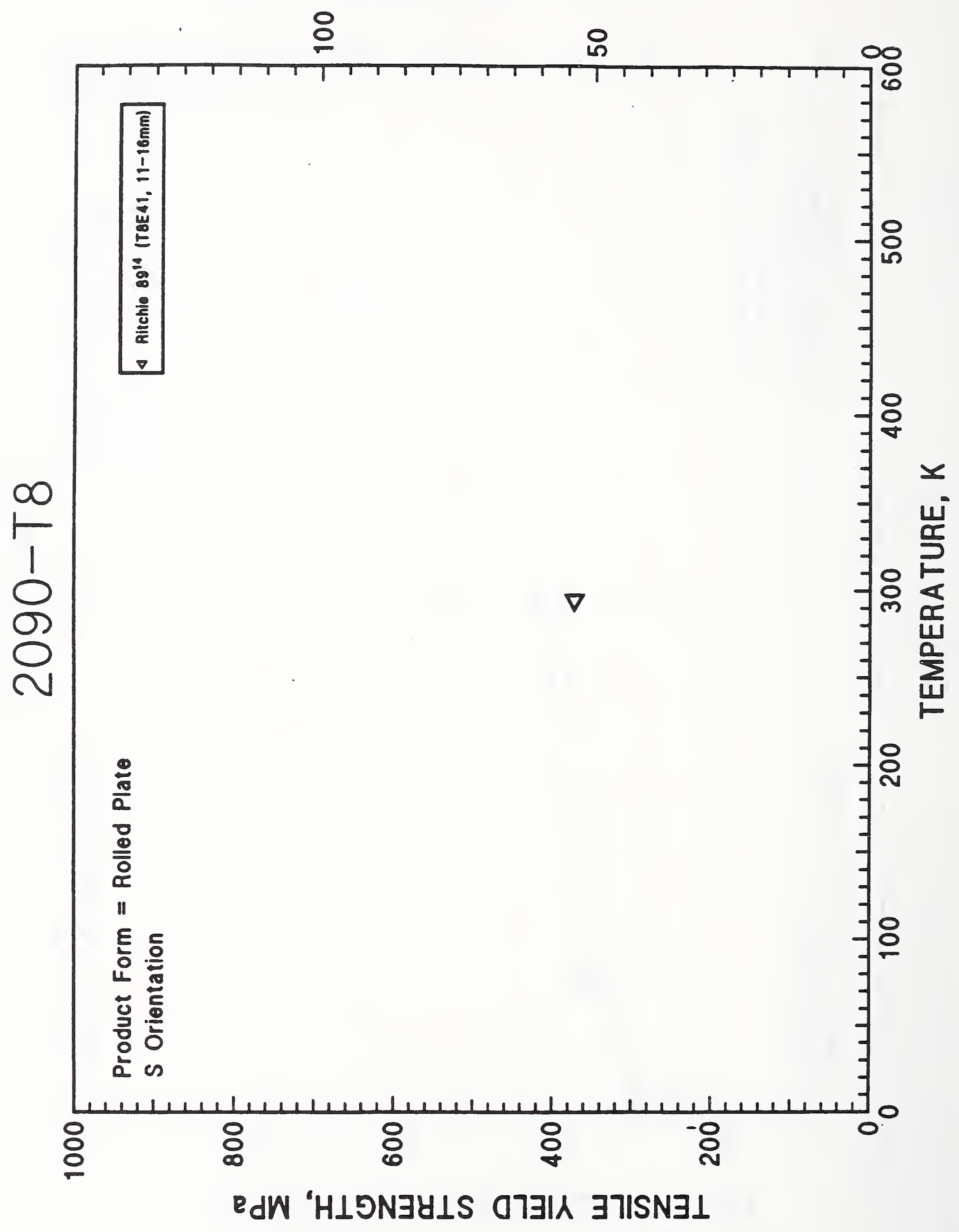




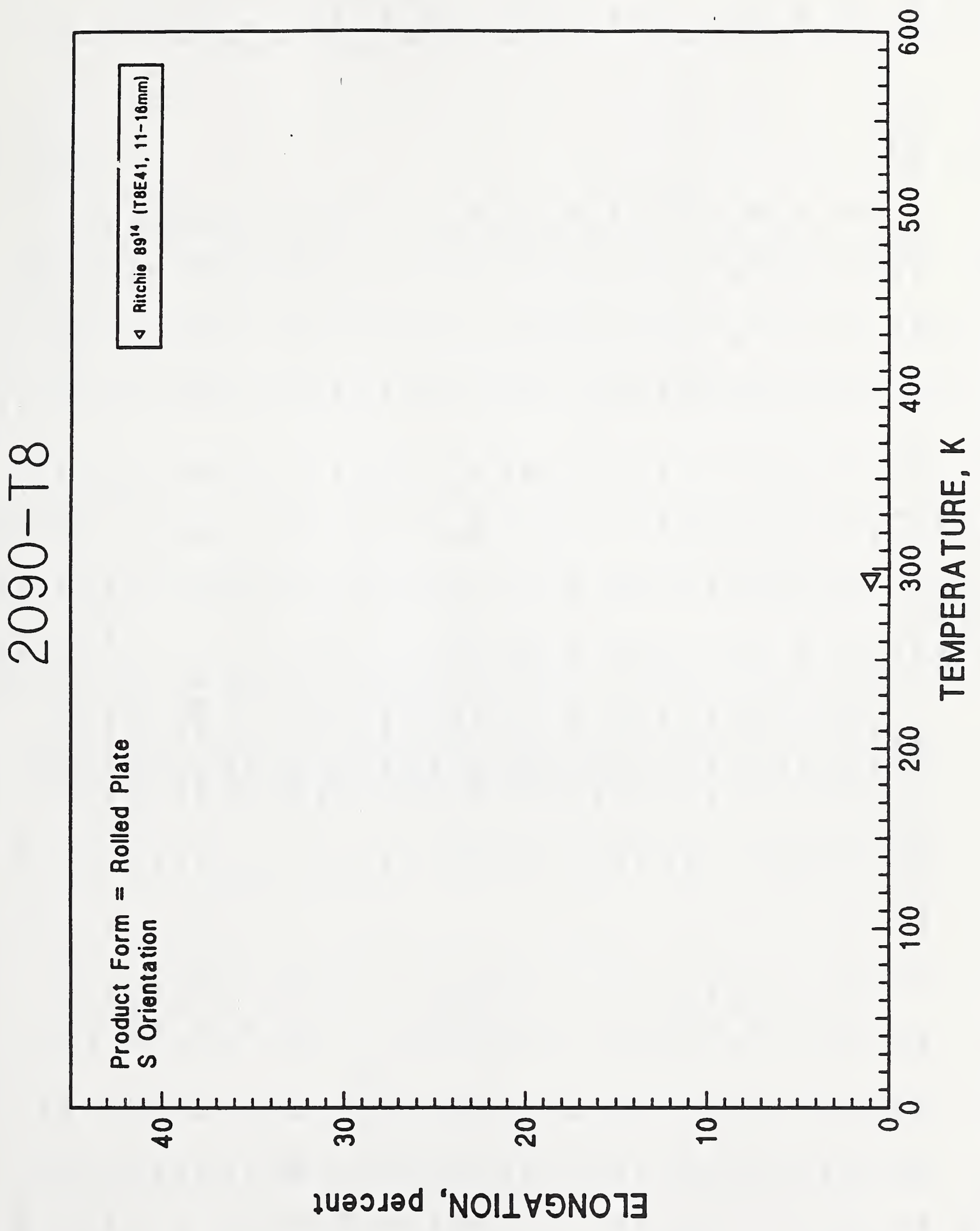




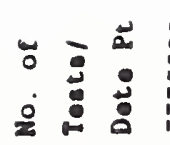

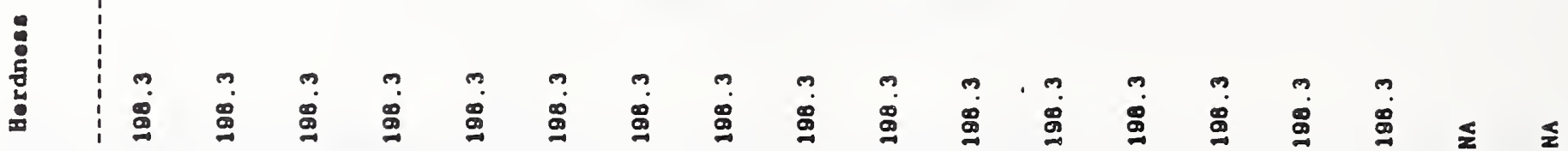
竎

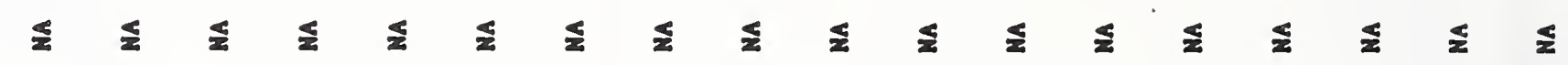
吾

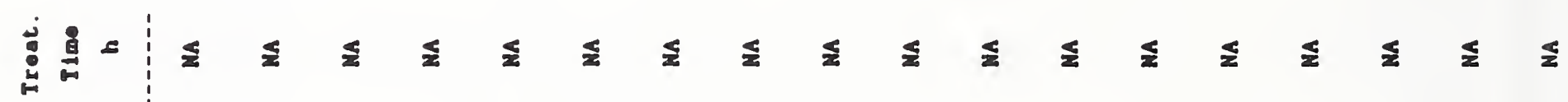

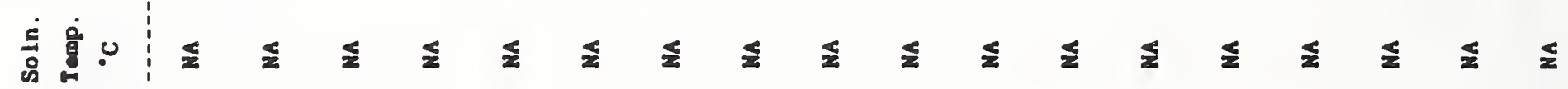

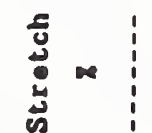

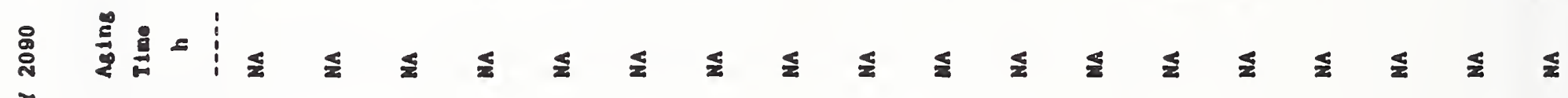

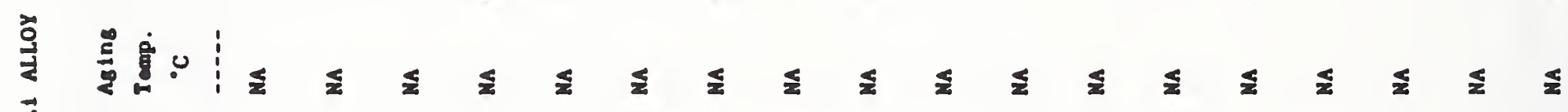
$\overrightarrow{\vec{i}}$

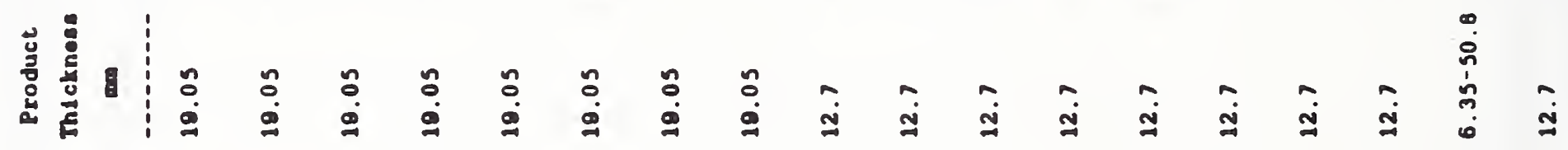

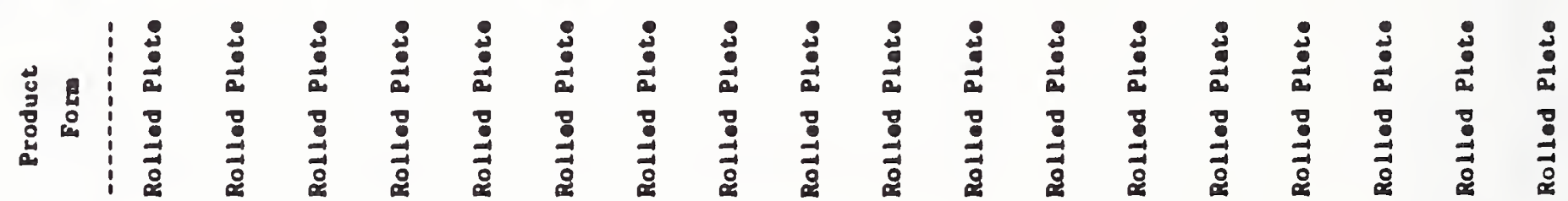

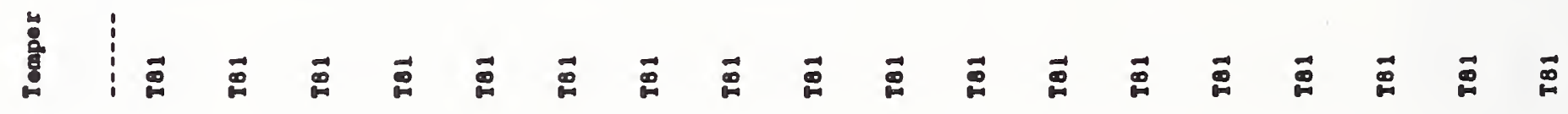

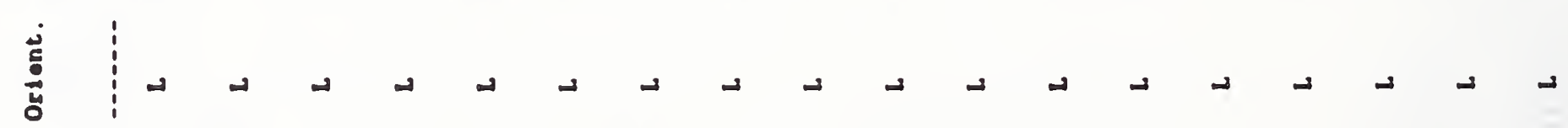

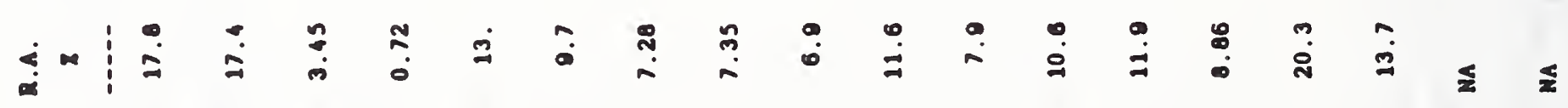
㻤ஸ்

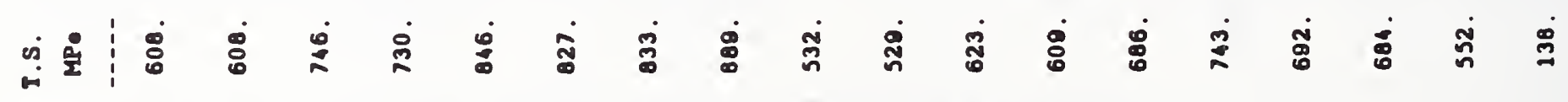
율

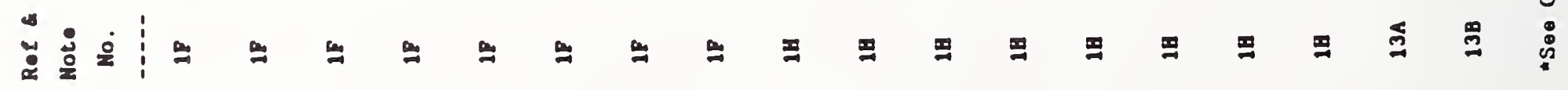




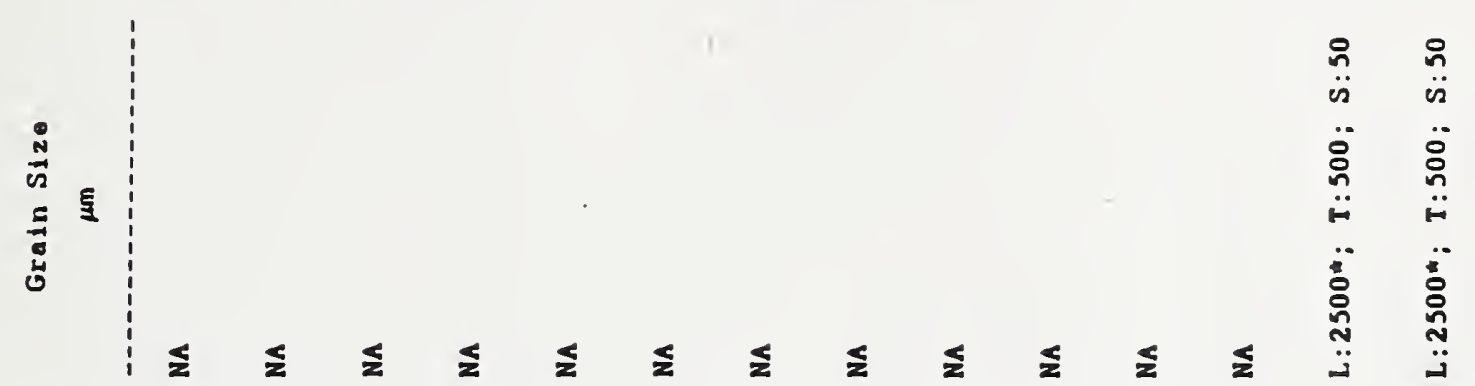

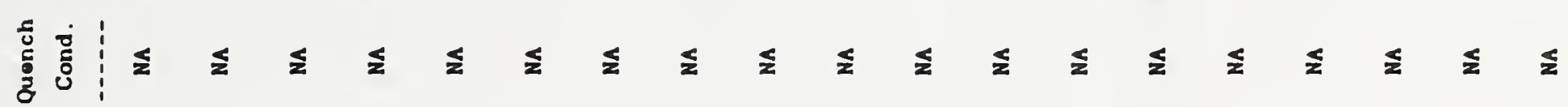
离曾

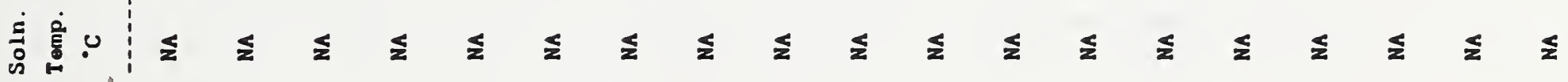

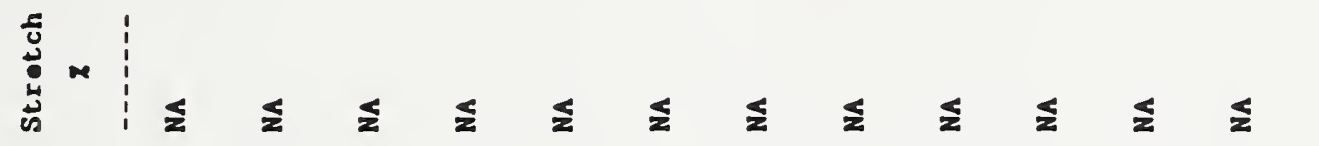

道兽 苛高0

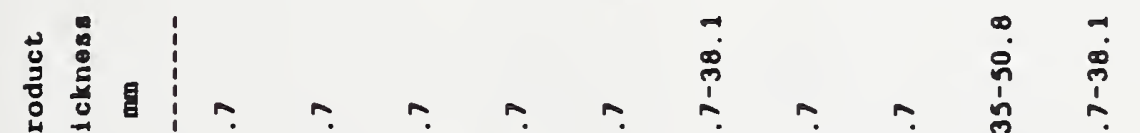

䓪

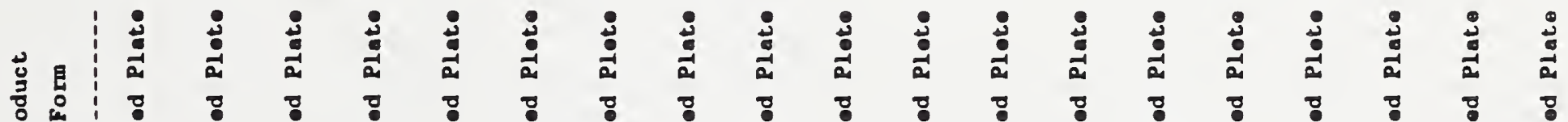

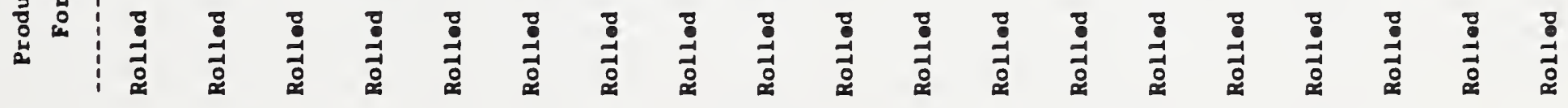
总

غं

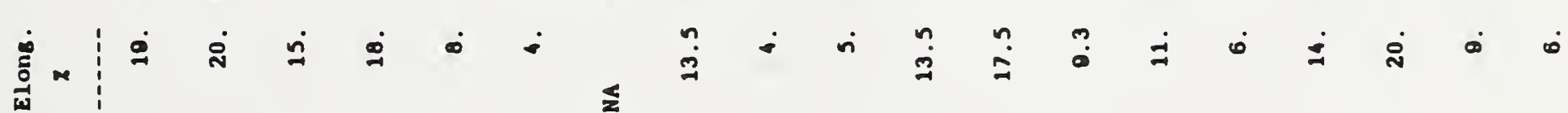
ن் ن 棉ะ

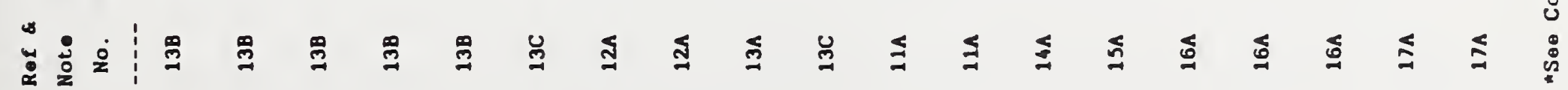




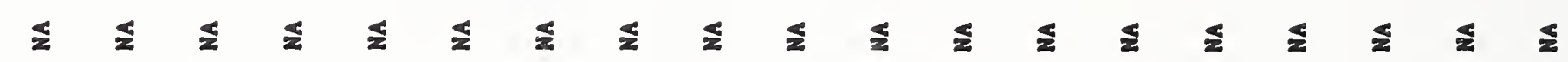

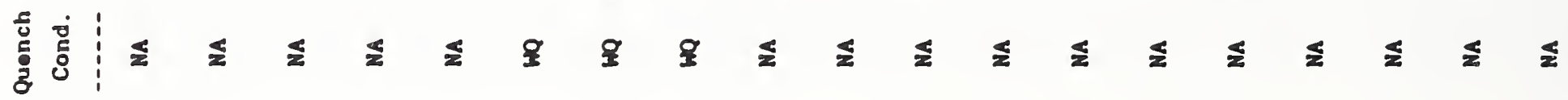

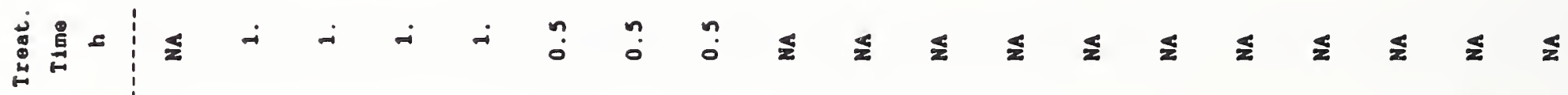

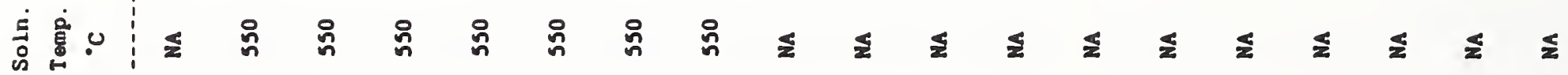
:

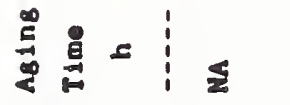

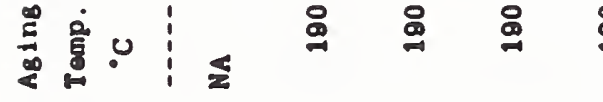

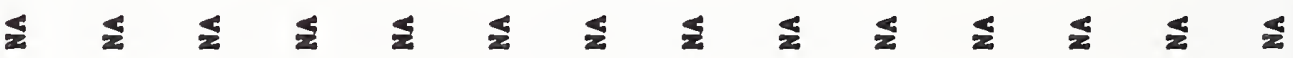

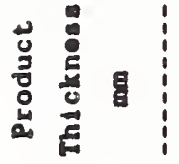

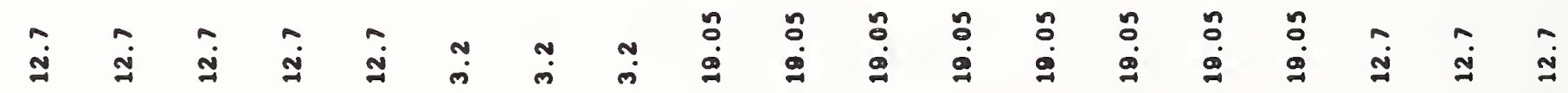

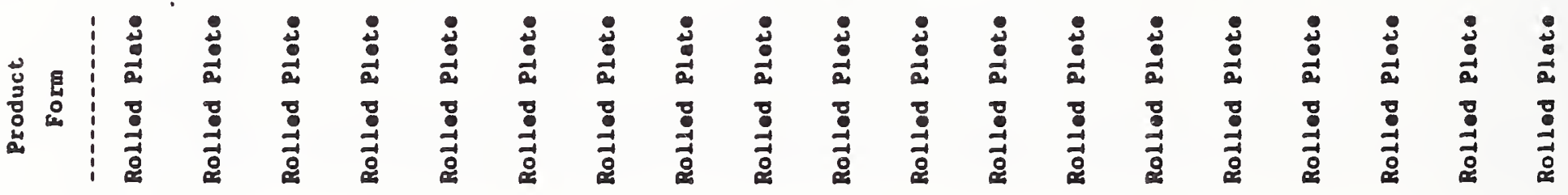

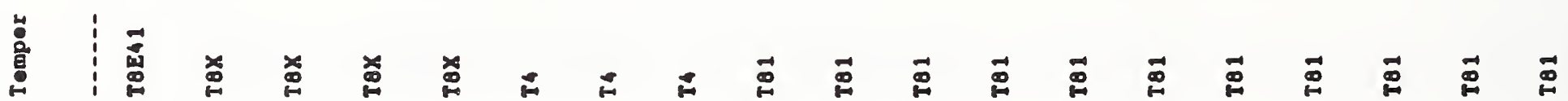

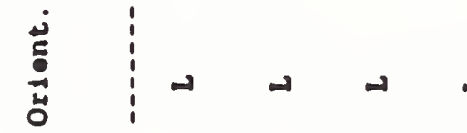

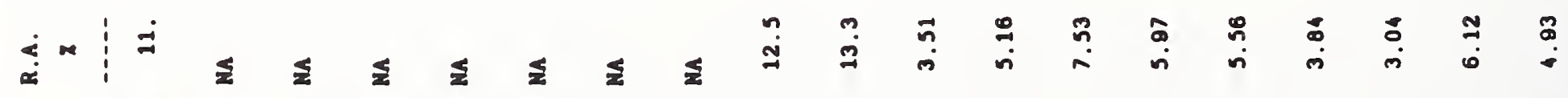

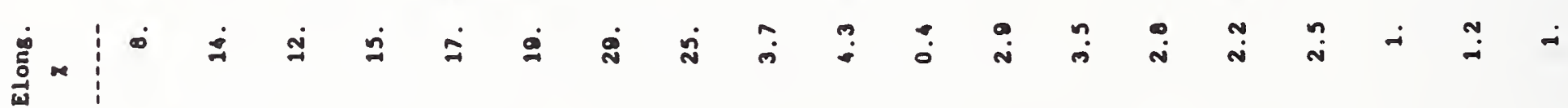

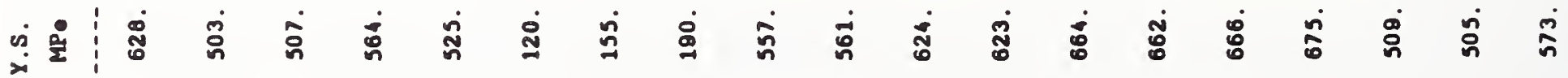

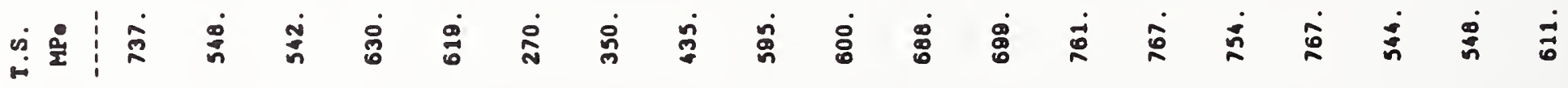

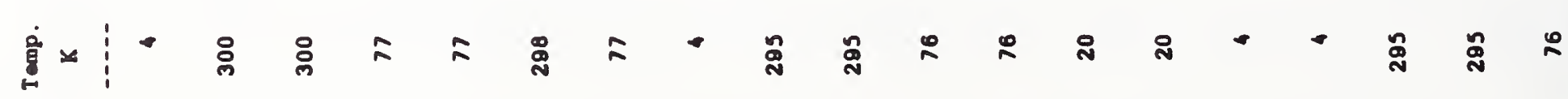

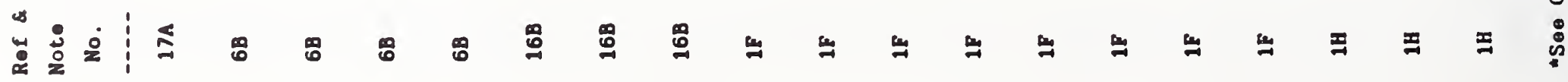




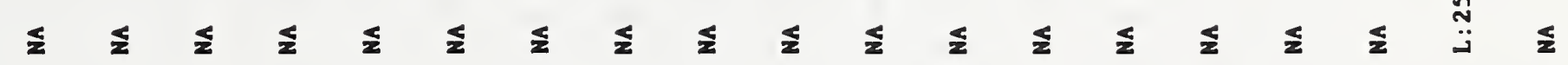

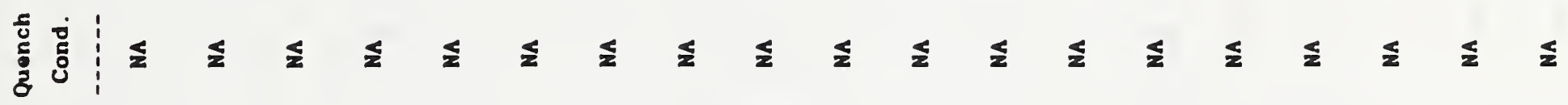

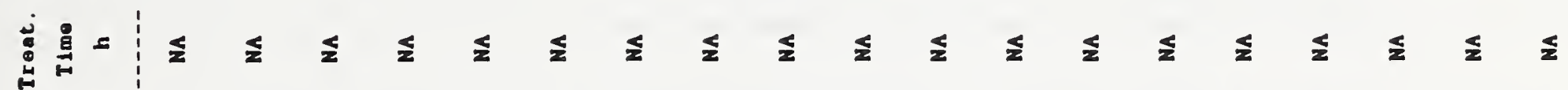

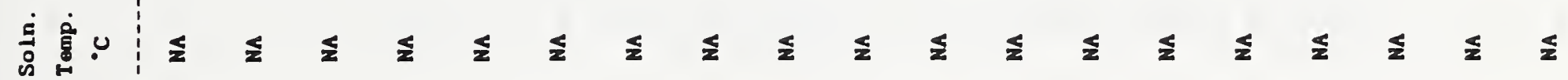

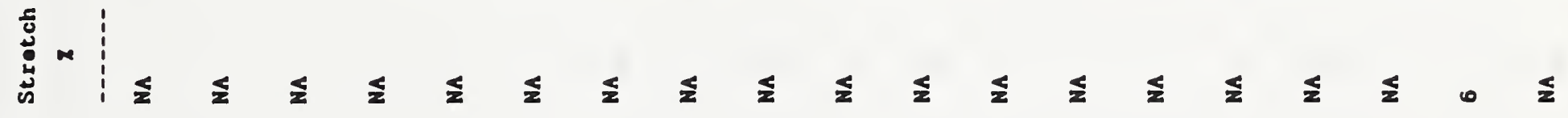

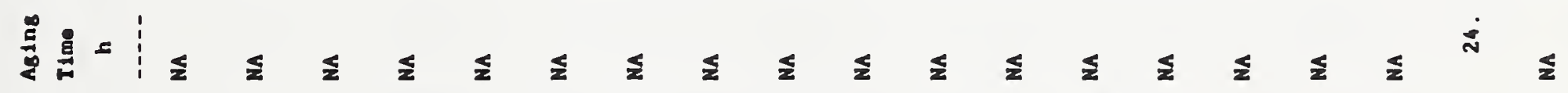
总富:

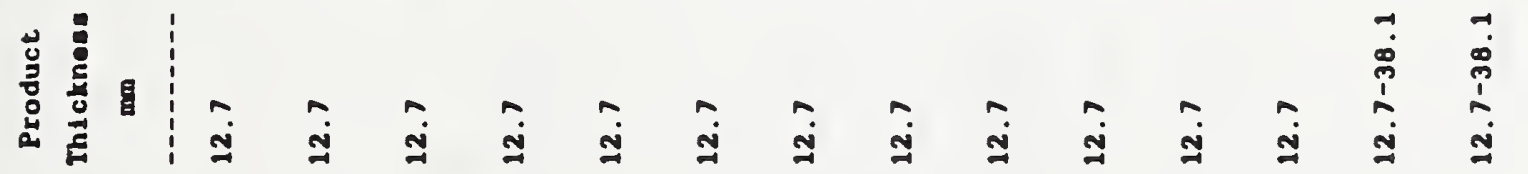

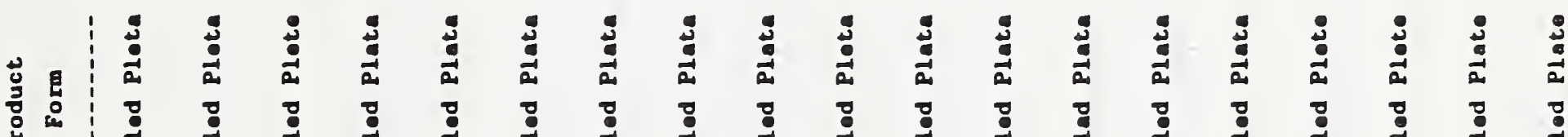

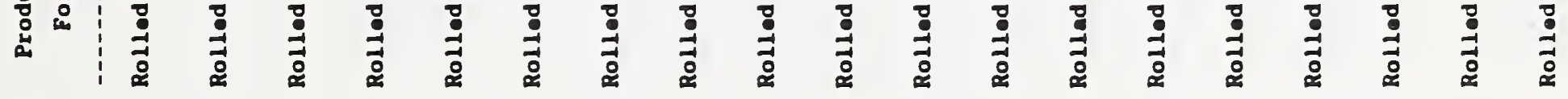

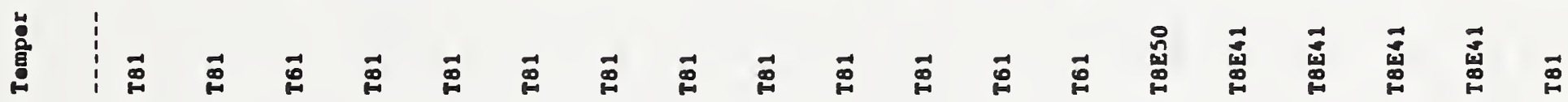
$\frac{5}{5}$

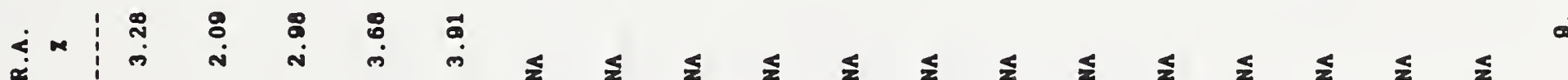
递 ஸ் ஸ் 菑ะ

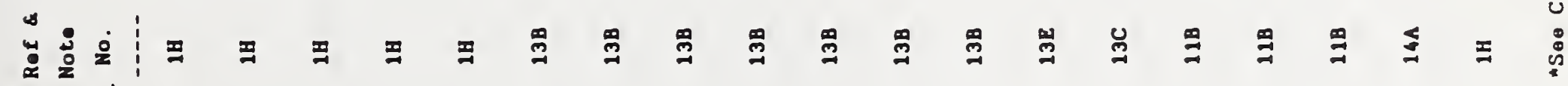




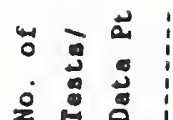

:

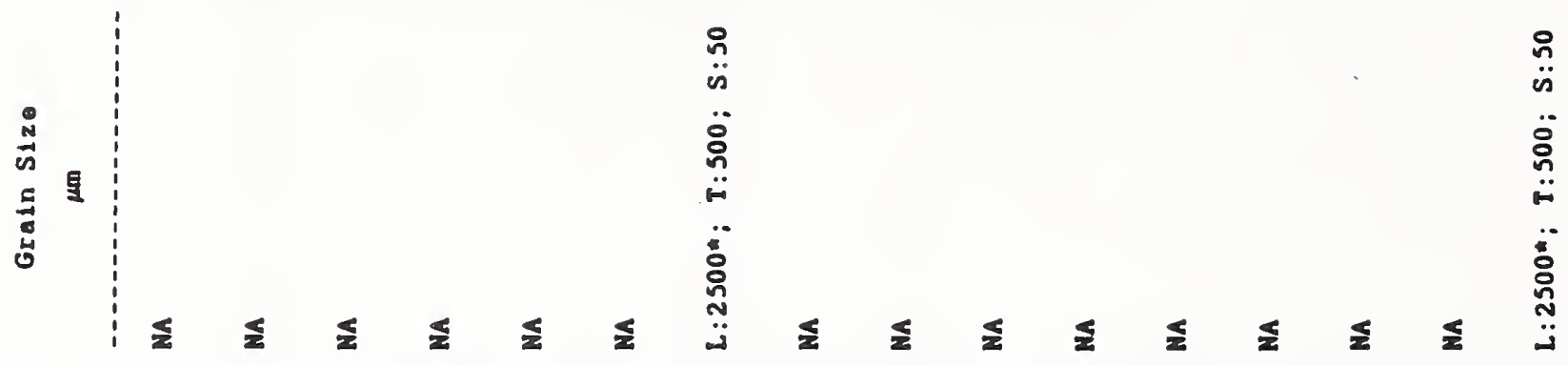

鄫焉

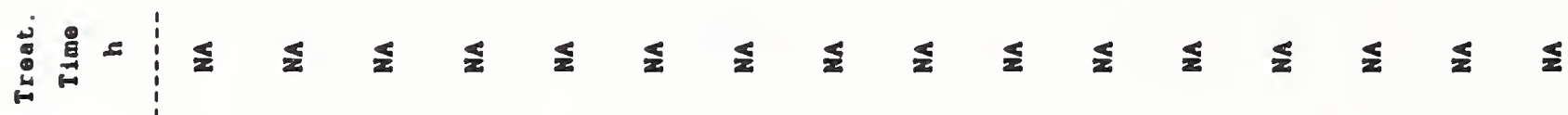

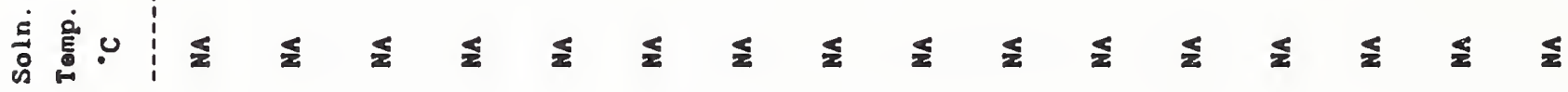
颉

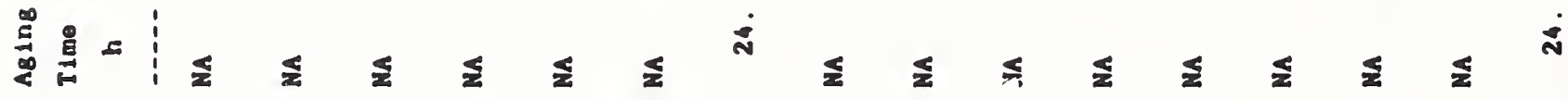
总亶。

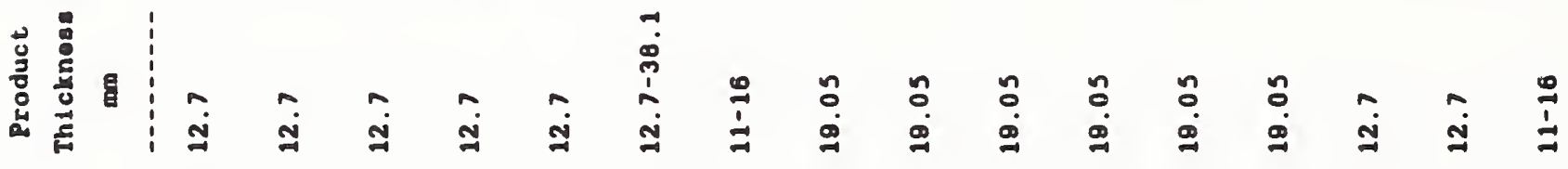

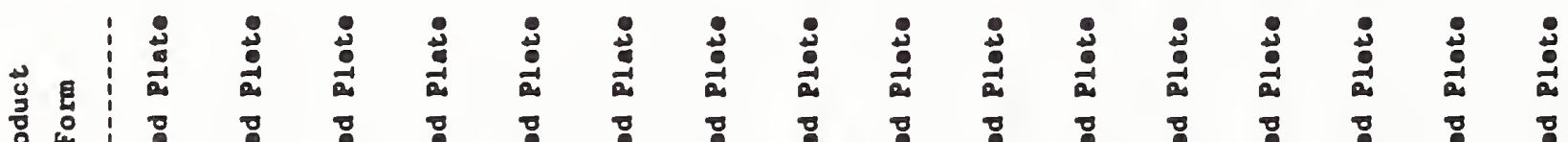

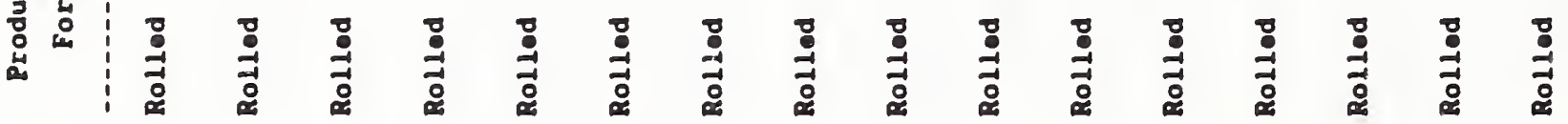

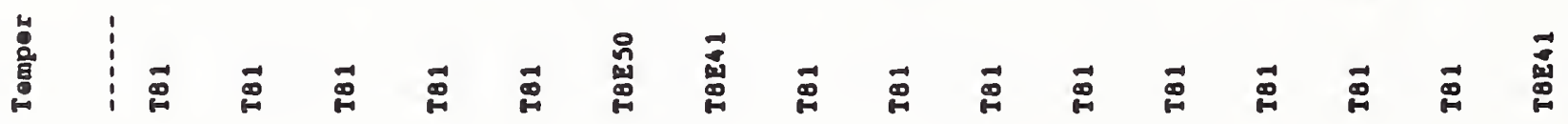

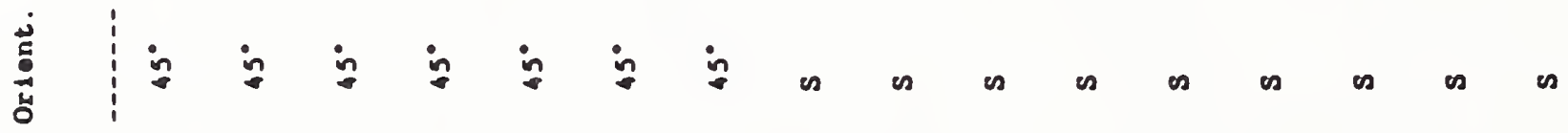

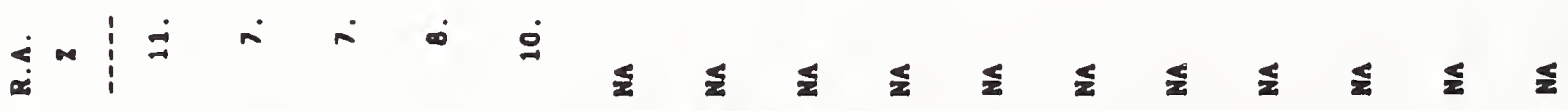

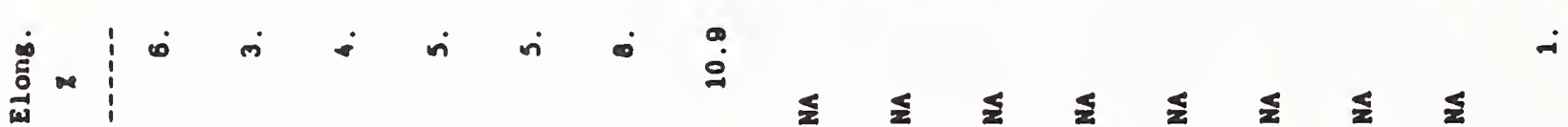

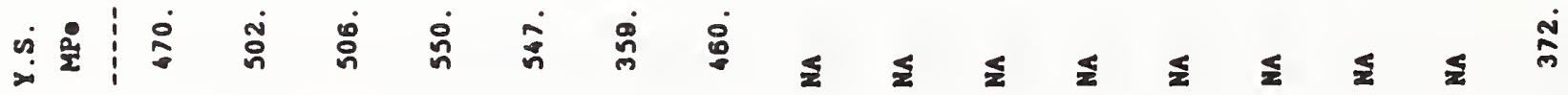

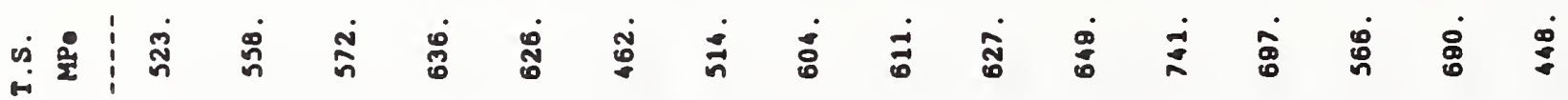

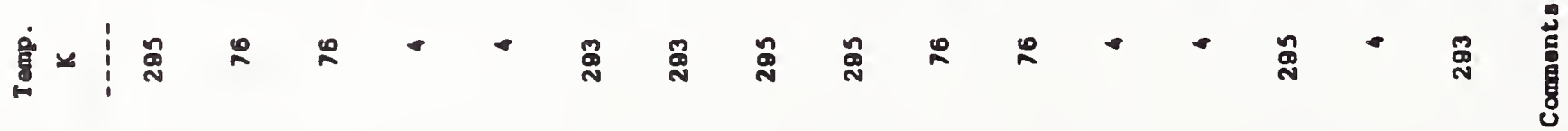

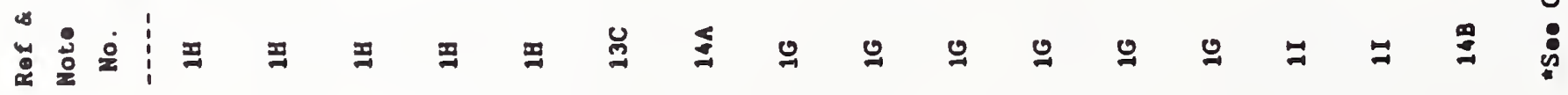


Comments from the Al-Li Alloy 2090 Data Table

Reference and

Note Number

13A--Values reported are "typical" properties.

13C--Values reported are "minimum" properties.

13E--Values reported are "minimum" properties.

14A--Value reported is the average of the range of grain sizes.

14B--Value reported is the average of the range of grain sizes.

$15 \mathrm{~A}$--Value reported is the average of the range of grain sizes. 


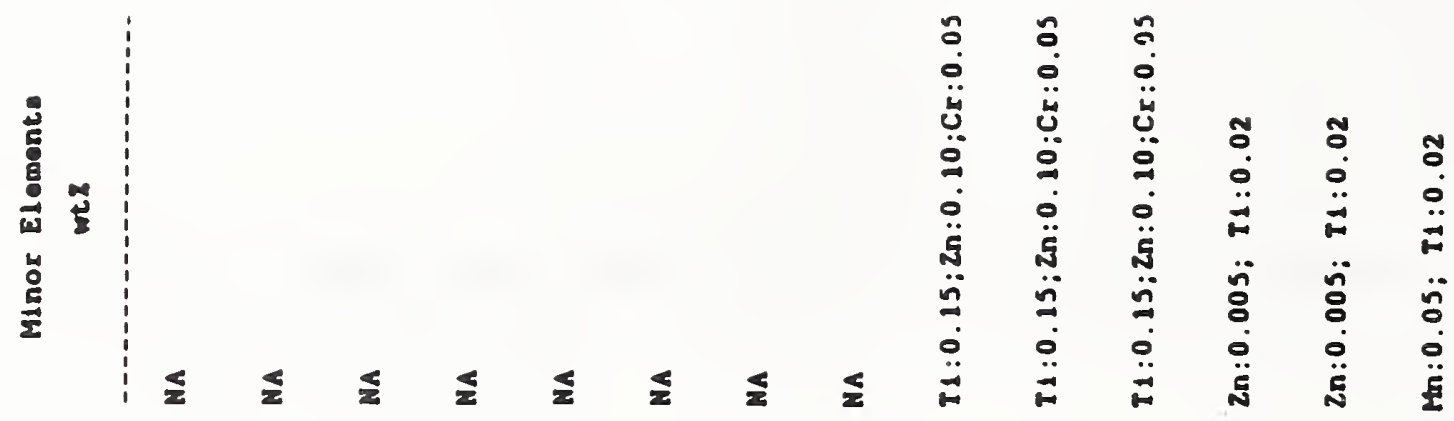

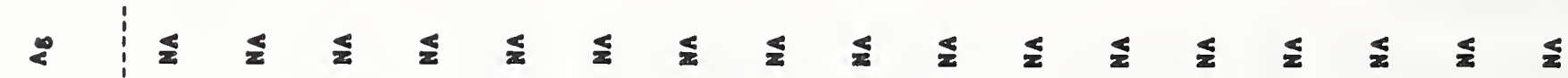

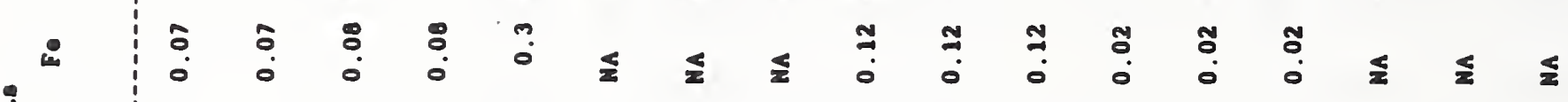

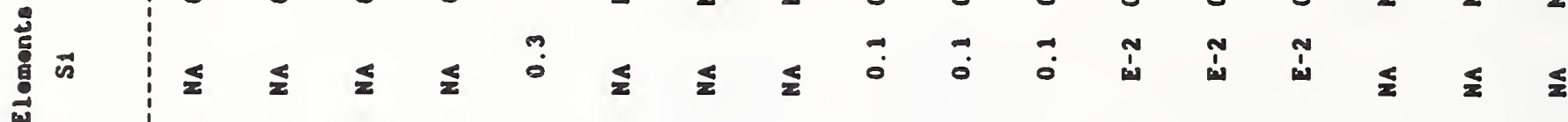
崖

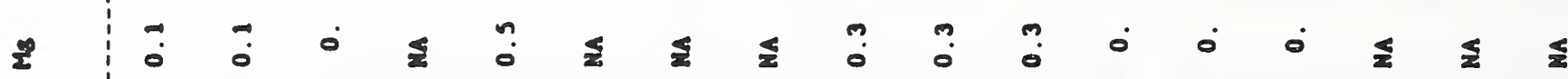

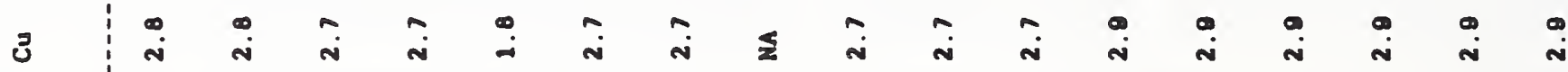

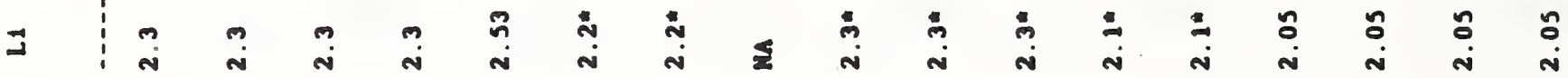

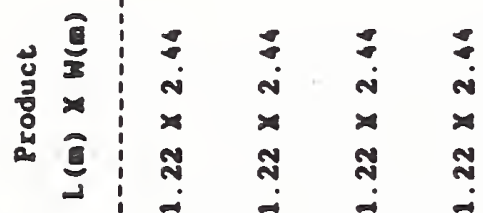

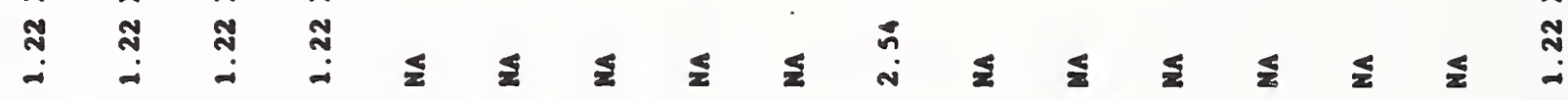

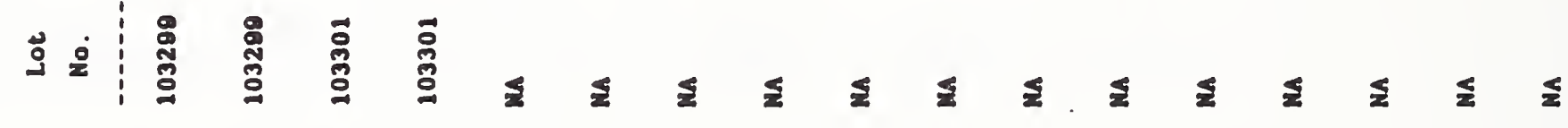

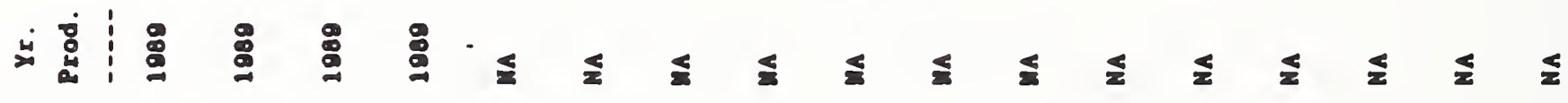

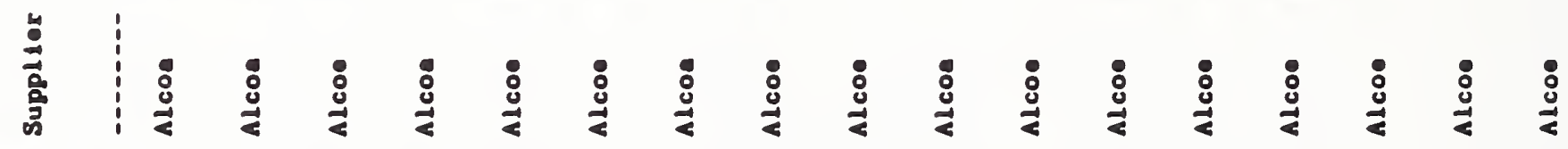
兽兽

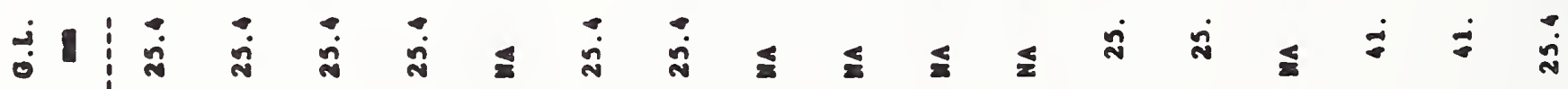

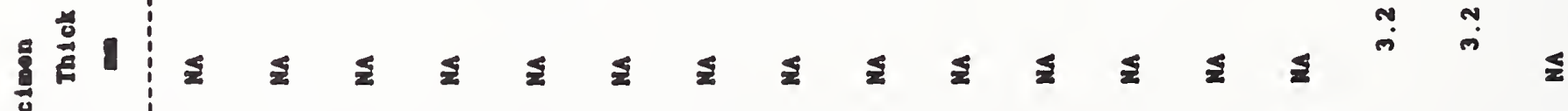

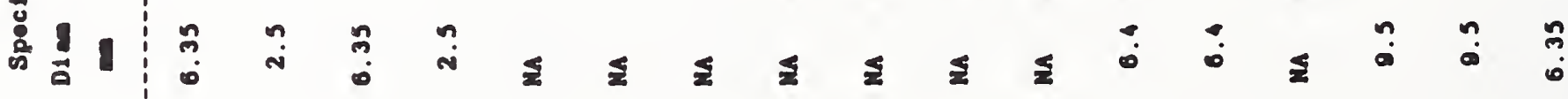

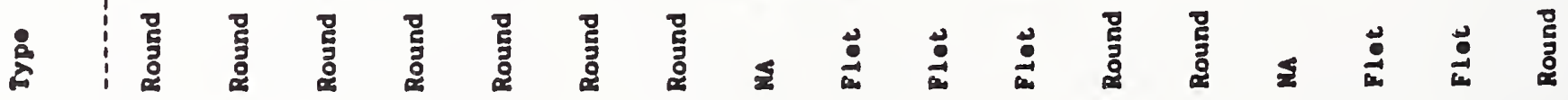

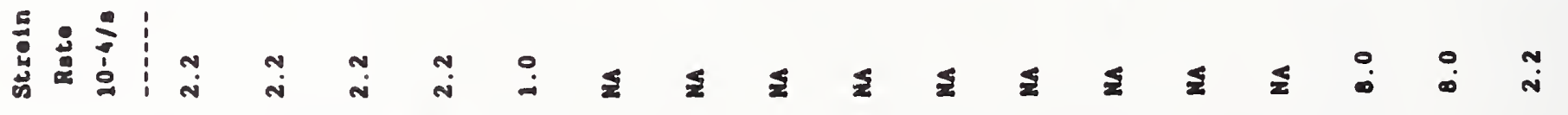

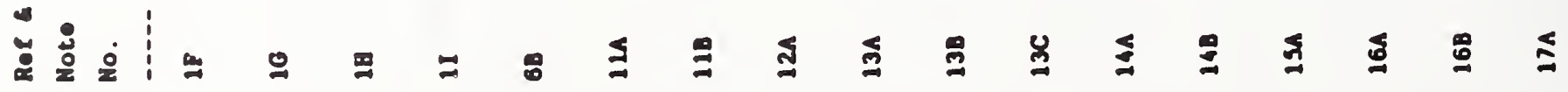




\section{Comments from the Al-Ii Alloy 2090 Test Parameter Table}

\section{Reference and}

Note Number:

11A--Reported composition is based on nominal values.

13A-C--Reported composition is the average of the minimum and maximum values.

14A--Reported composition is based on nominal values. 
ULTIMATE TENSILE STRENGTH, ksi

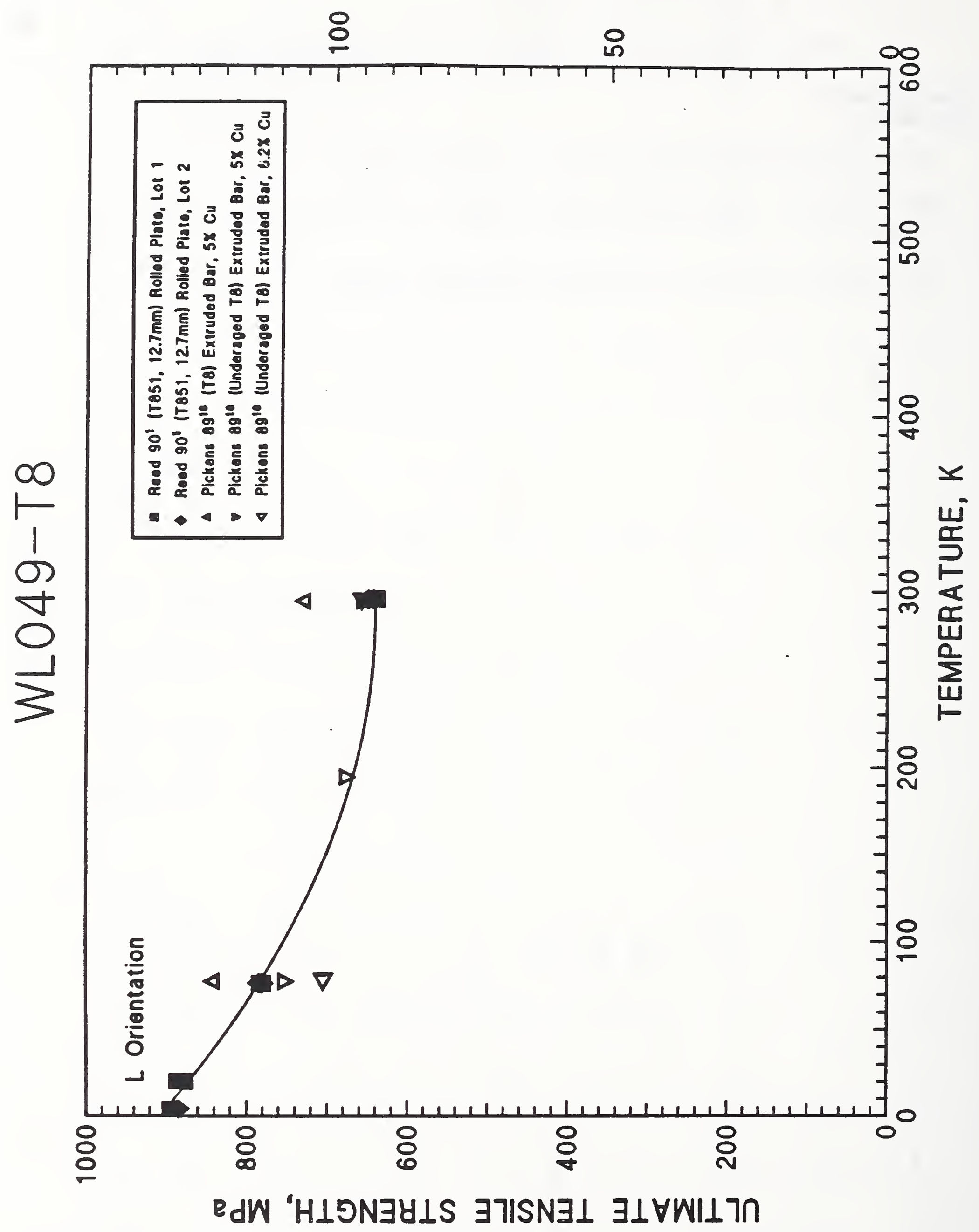


TENSILE YIELD STRENGTH, ksi

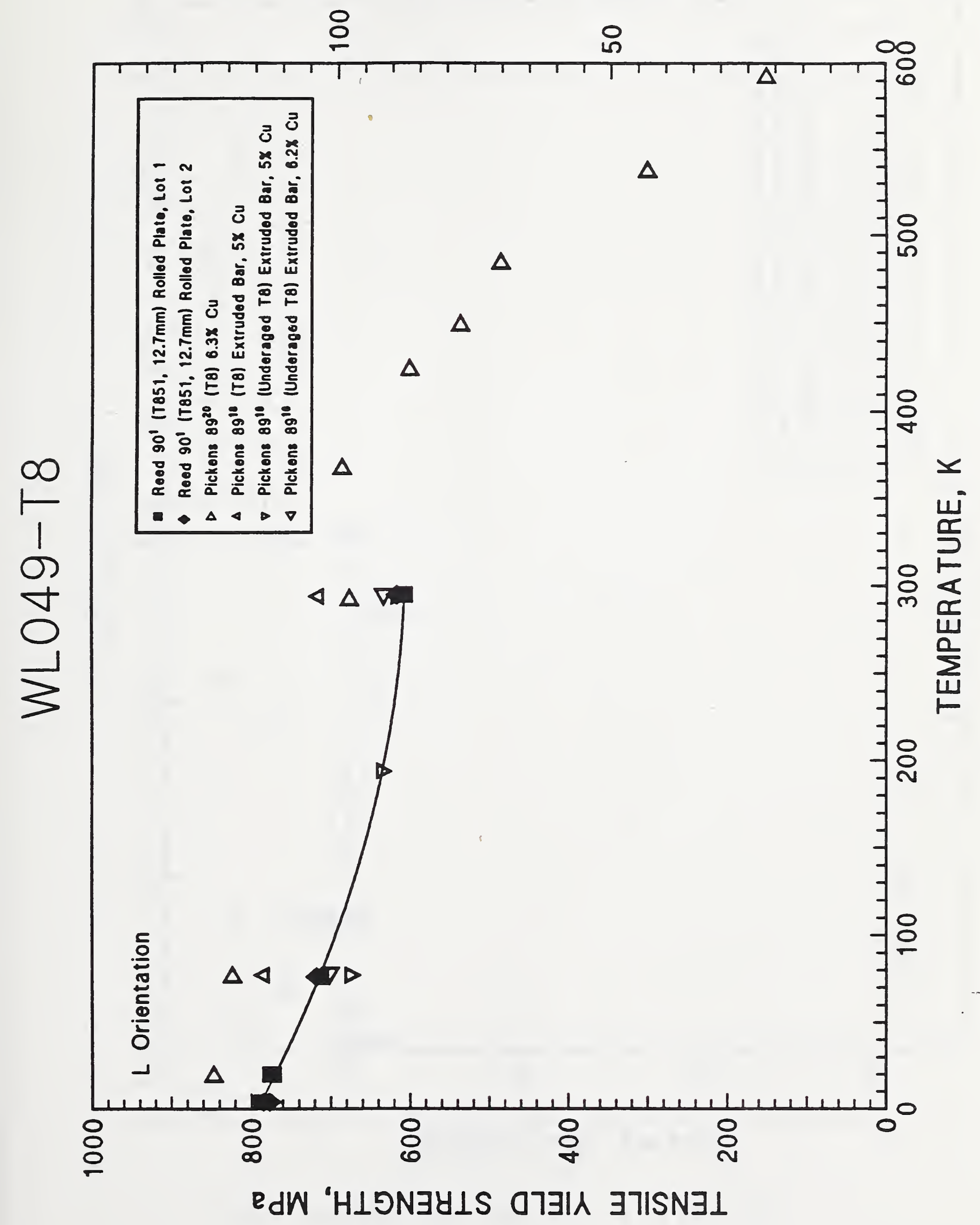




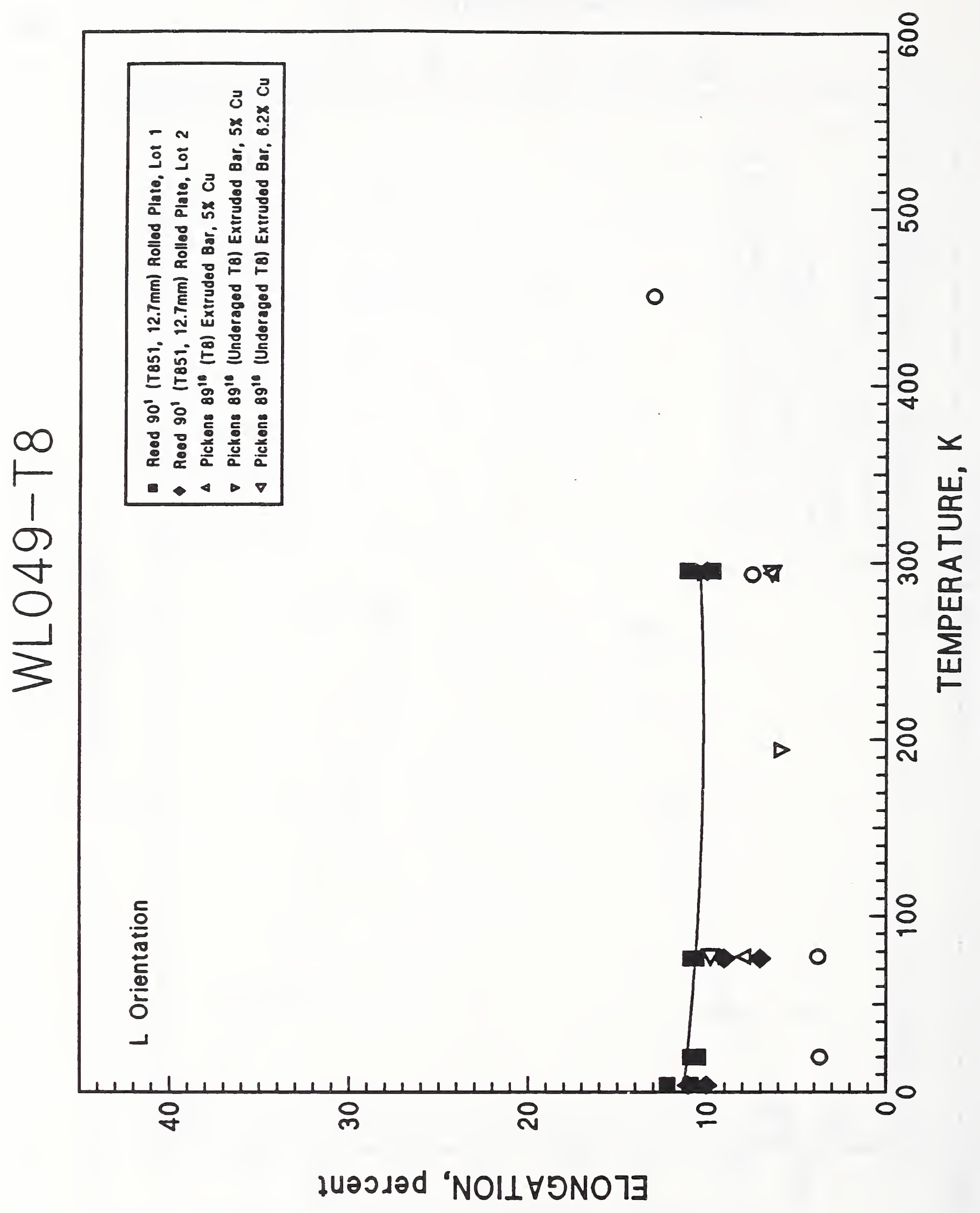


ULTIMATE TENSILE STRENGTH, ksi

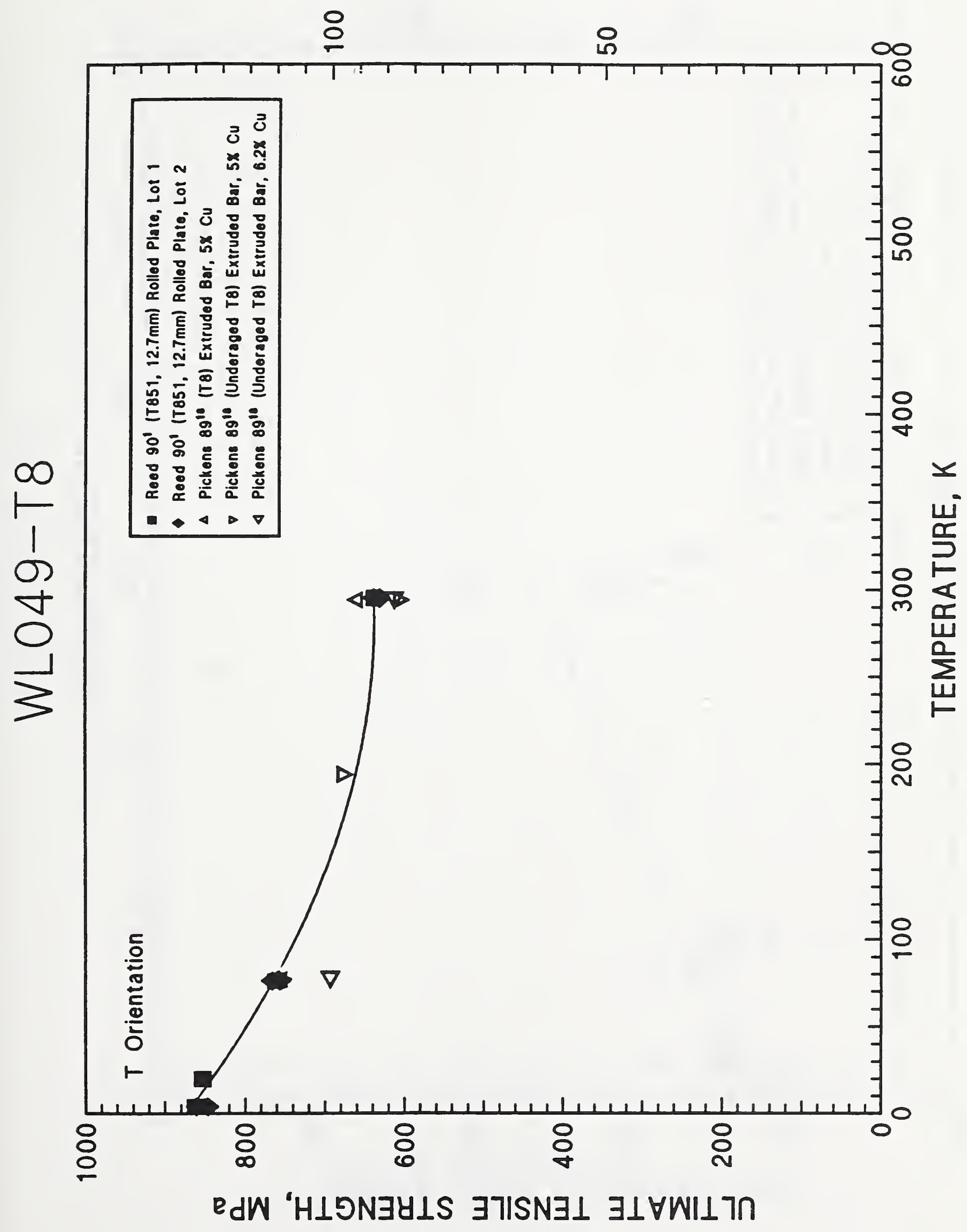


TENSILE YIELD STRENGTH, ksi

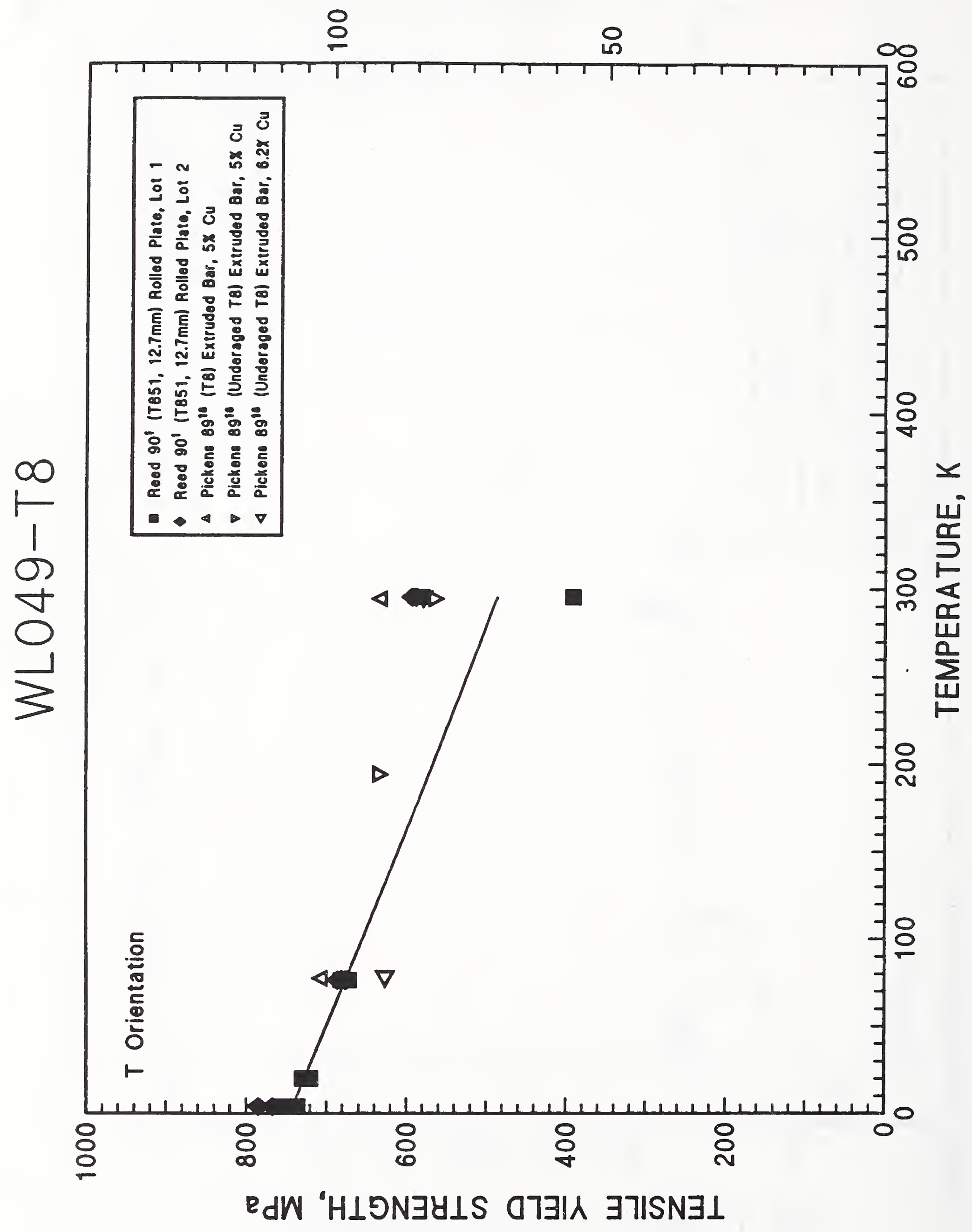




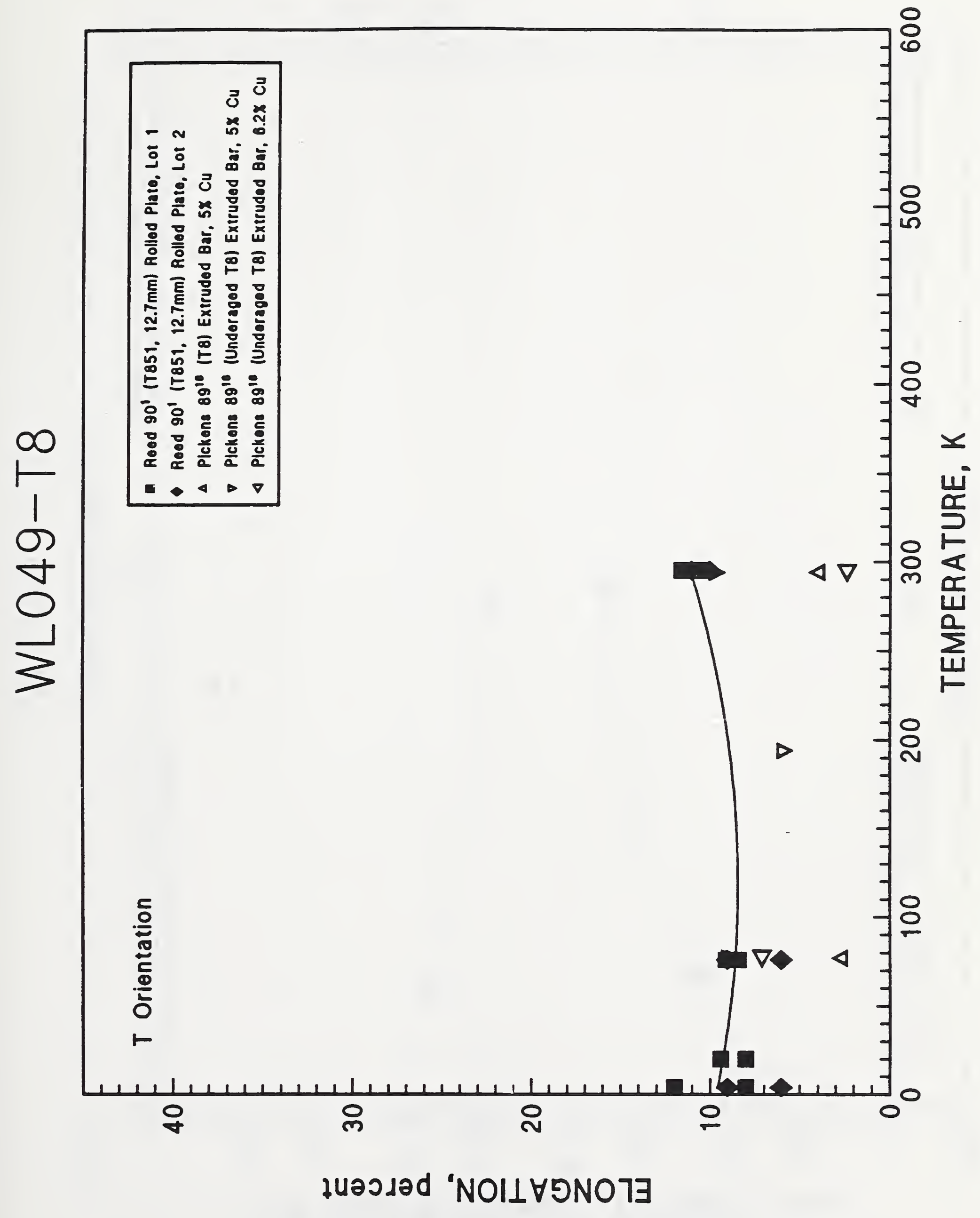


ULTIMATE TENSILE STRENGTH, ksi

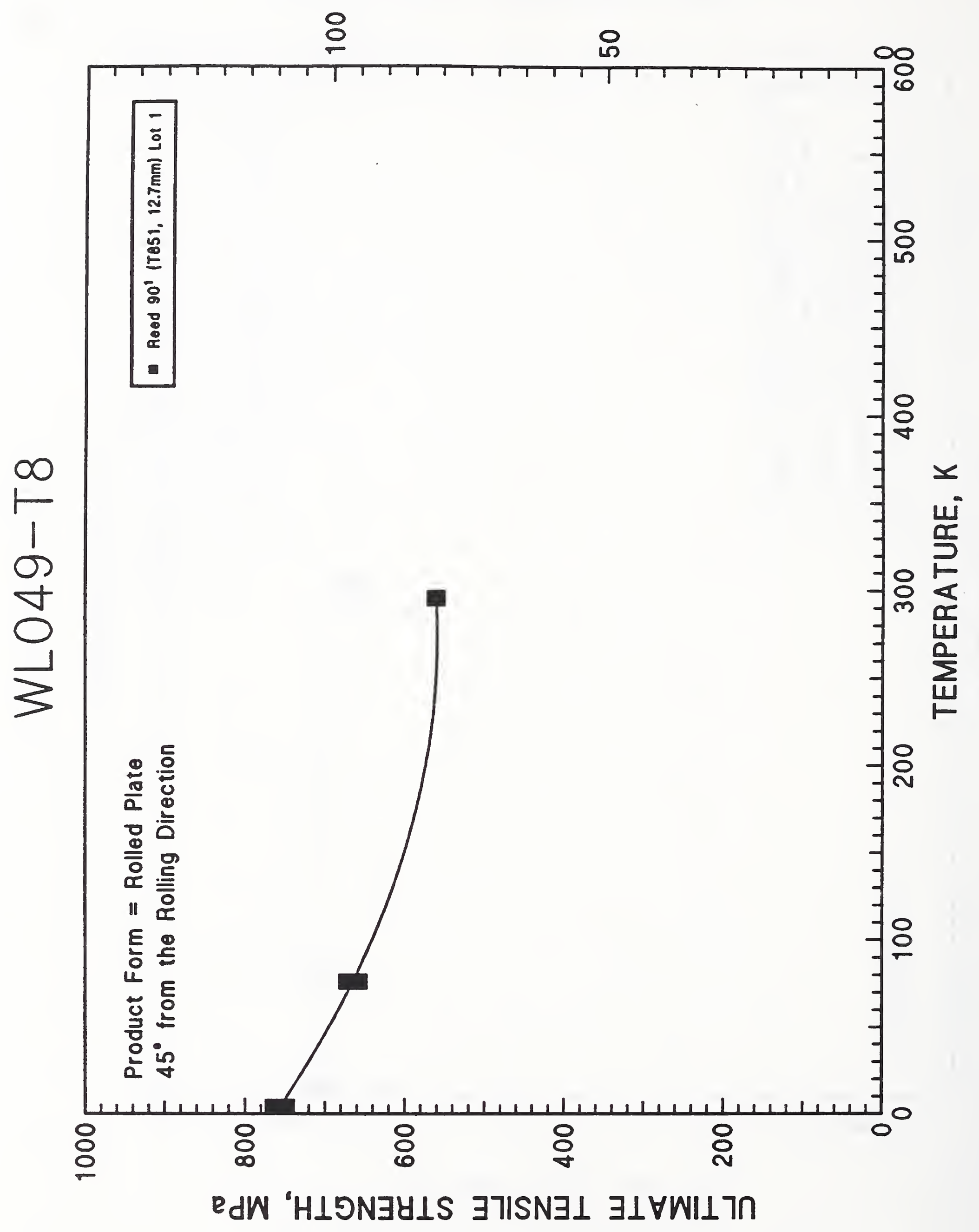


TENSILE YIELD STRENGTH, ksi

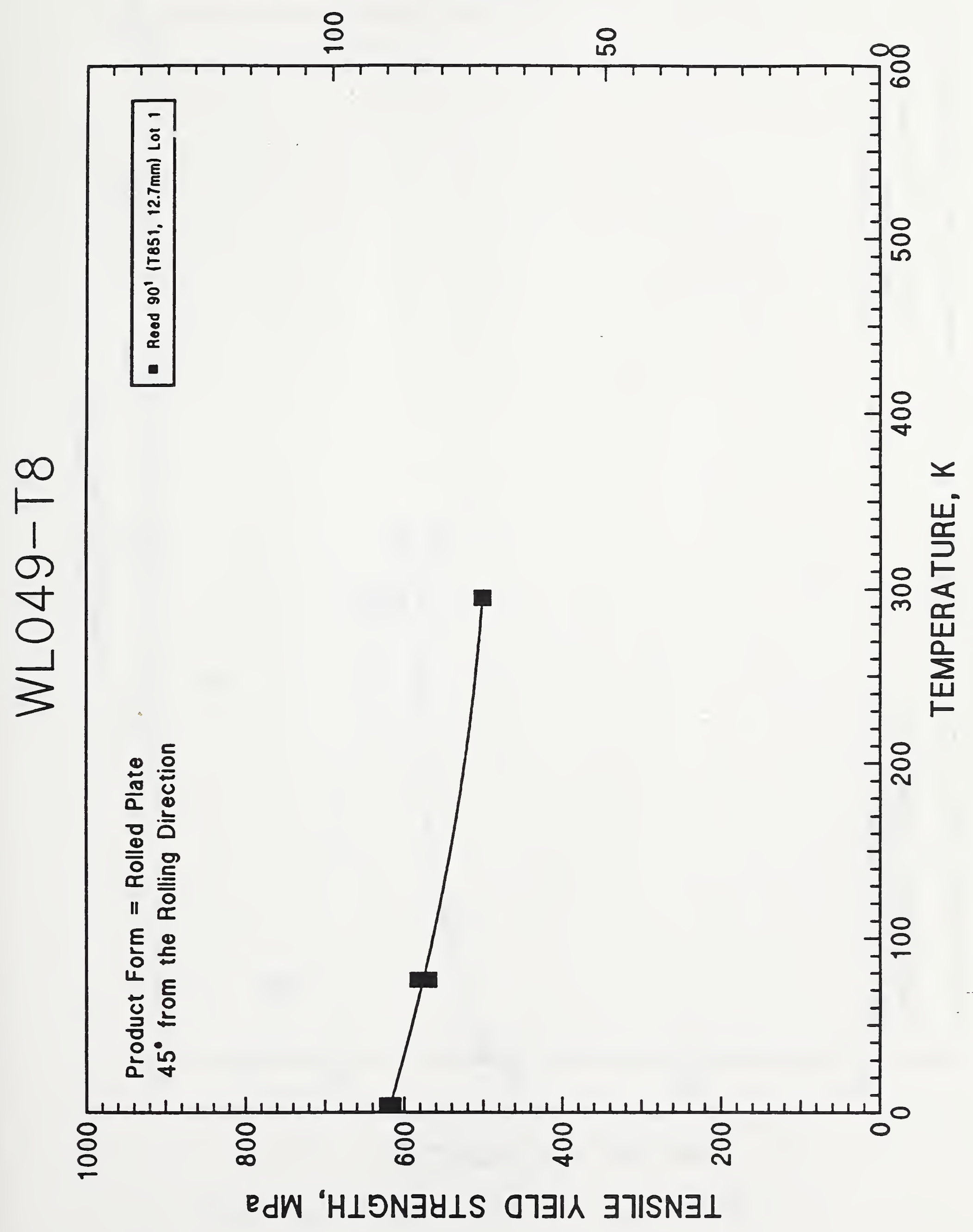




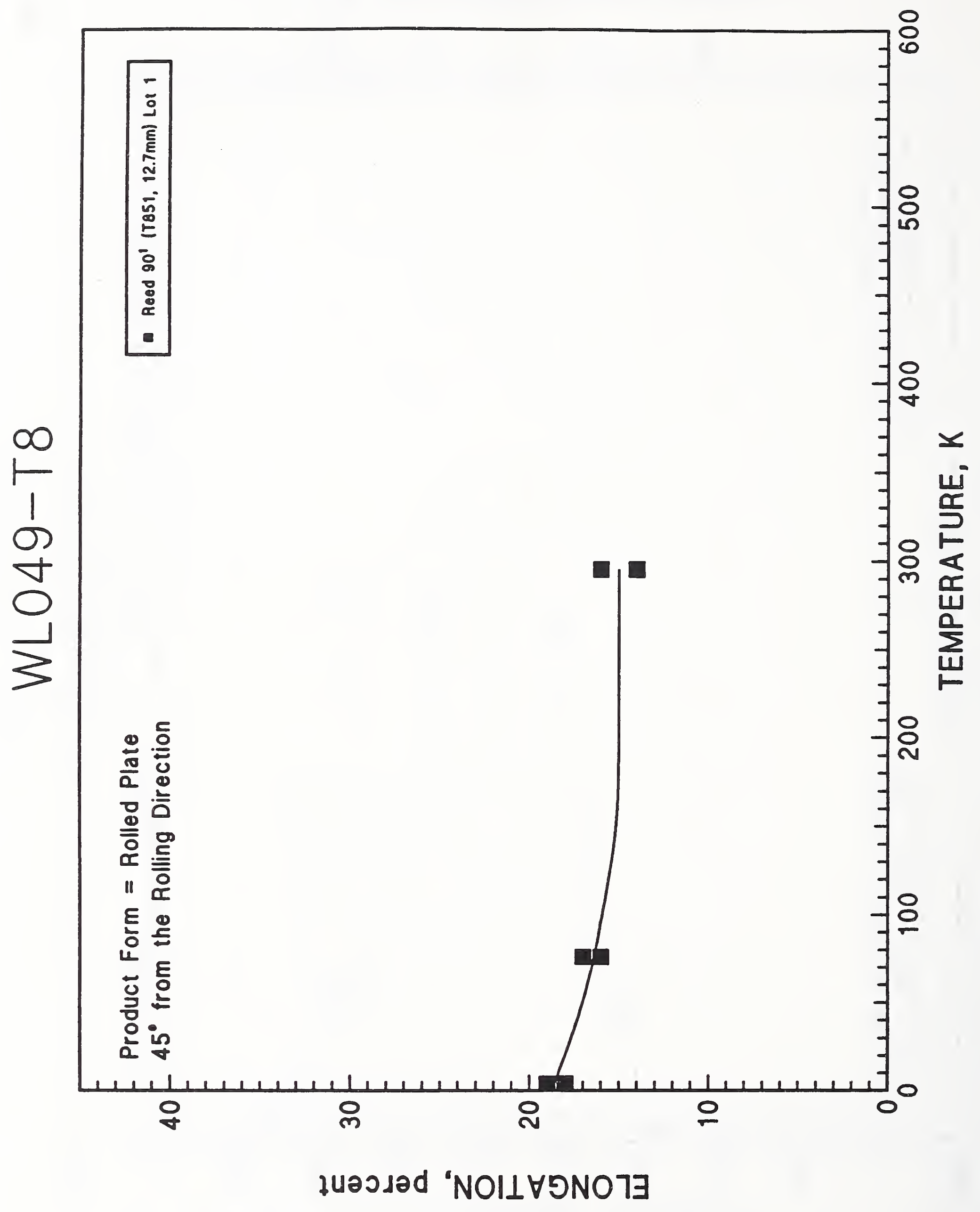


ULTIMATE TENSILE STRENGTH, ksi

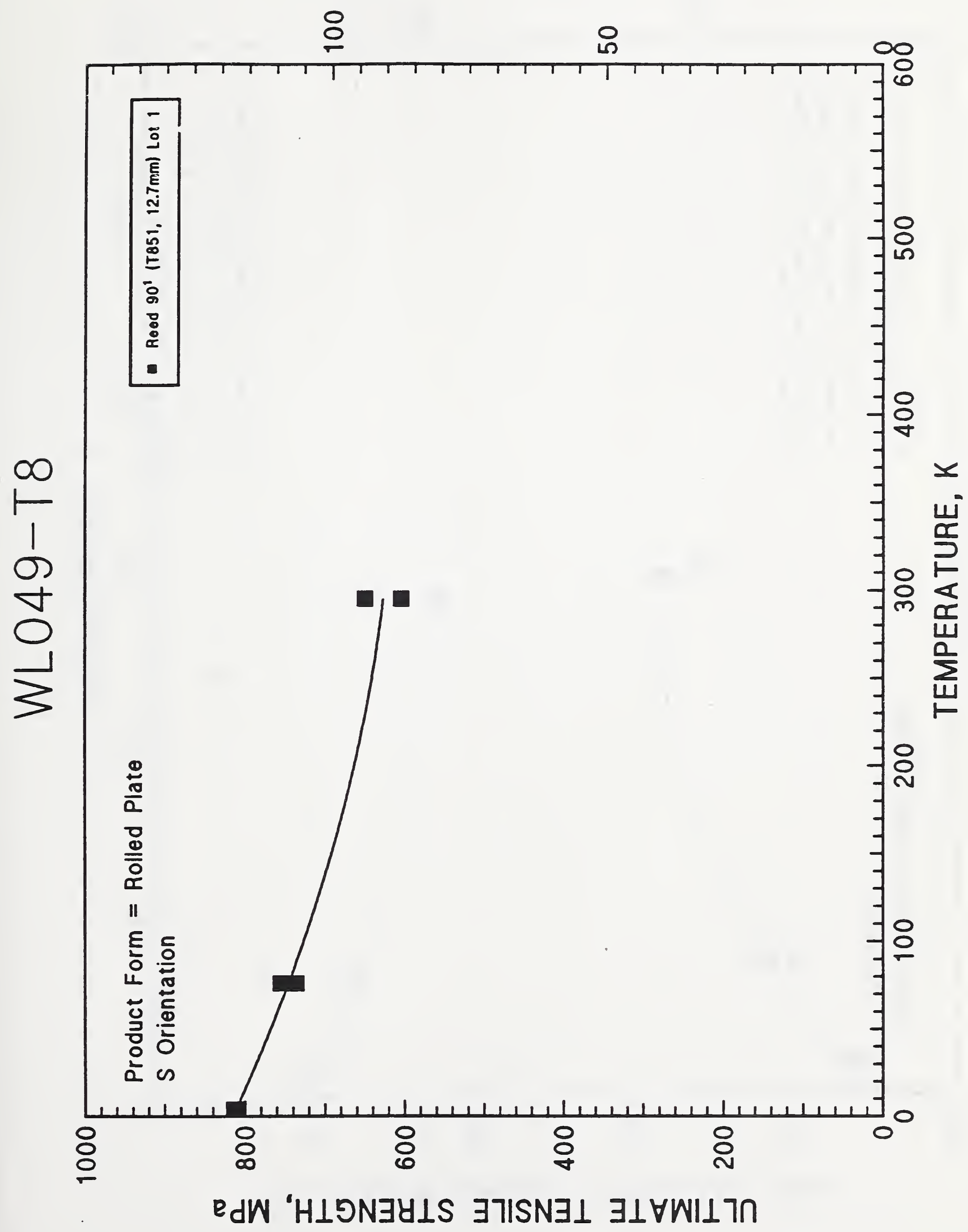


ULTIMATE TENSILE STRENGTH, ksi

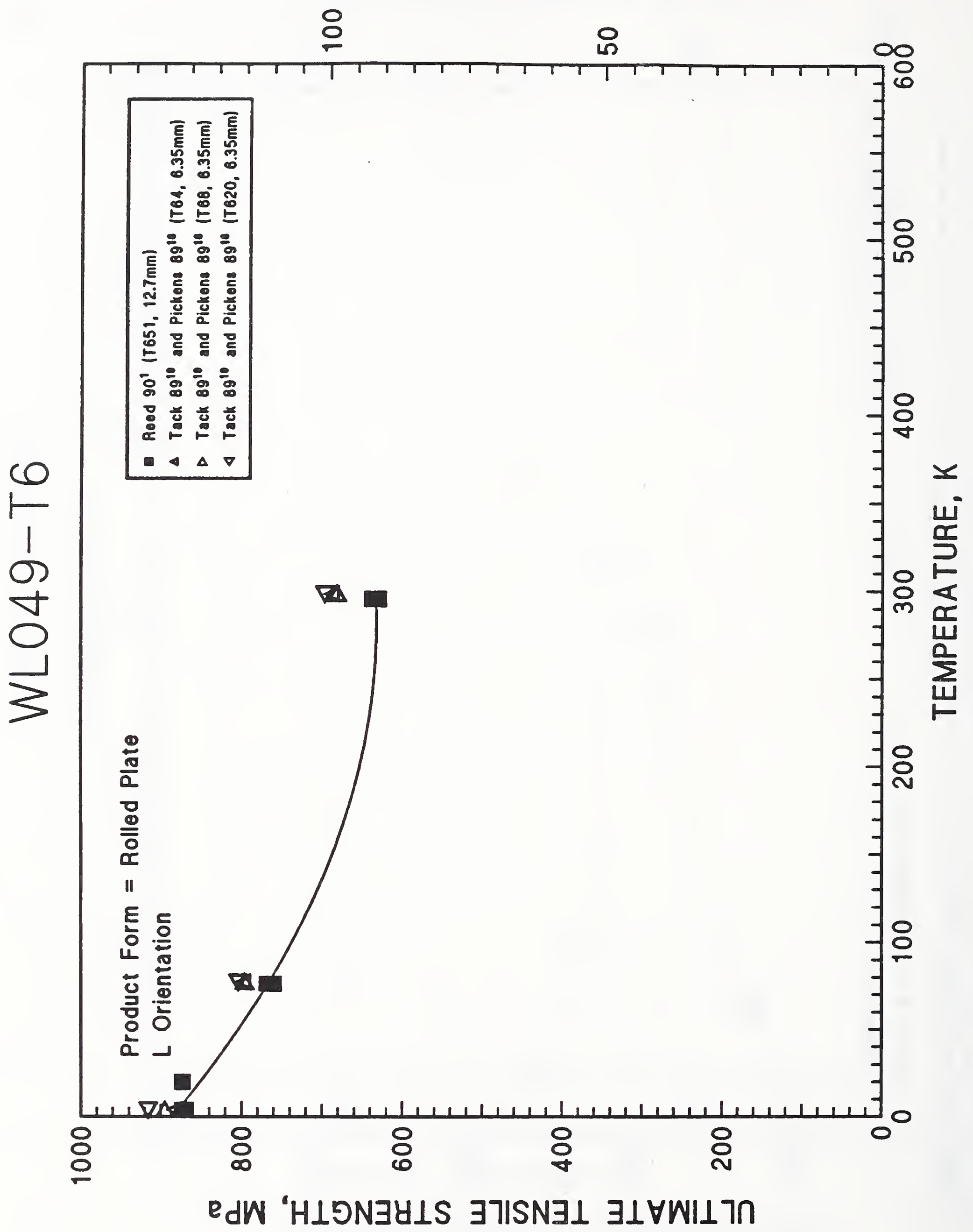


TENSILE YIELD STRENGTH, ksi

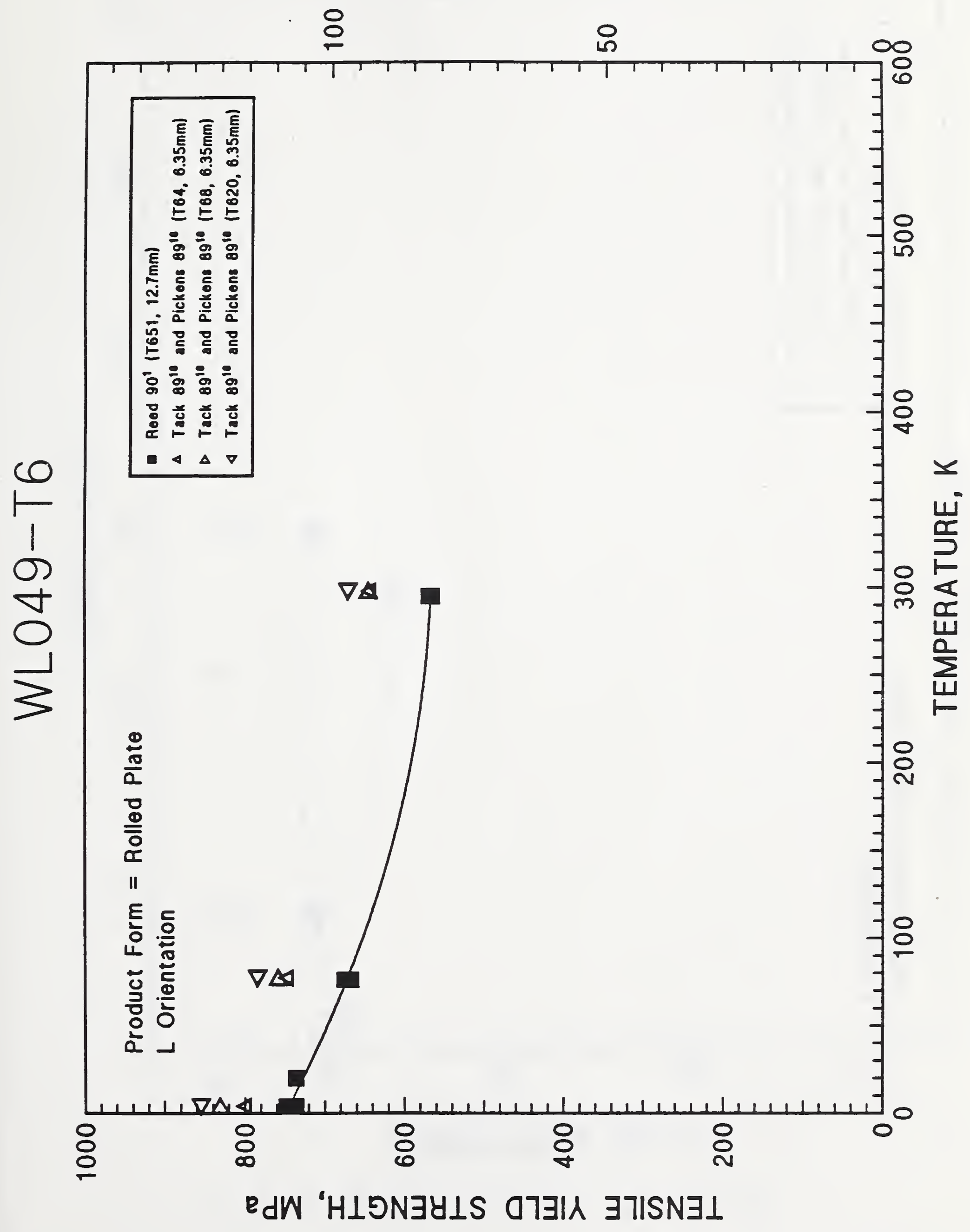




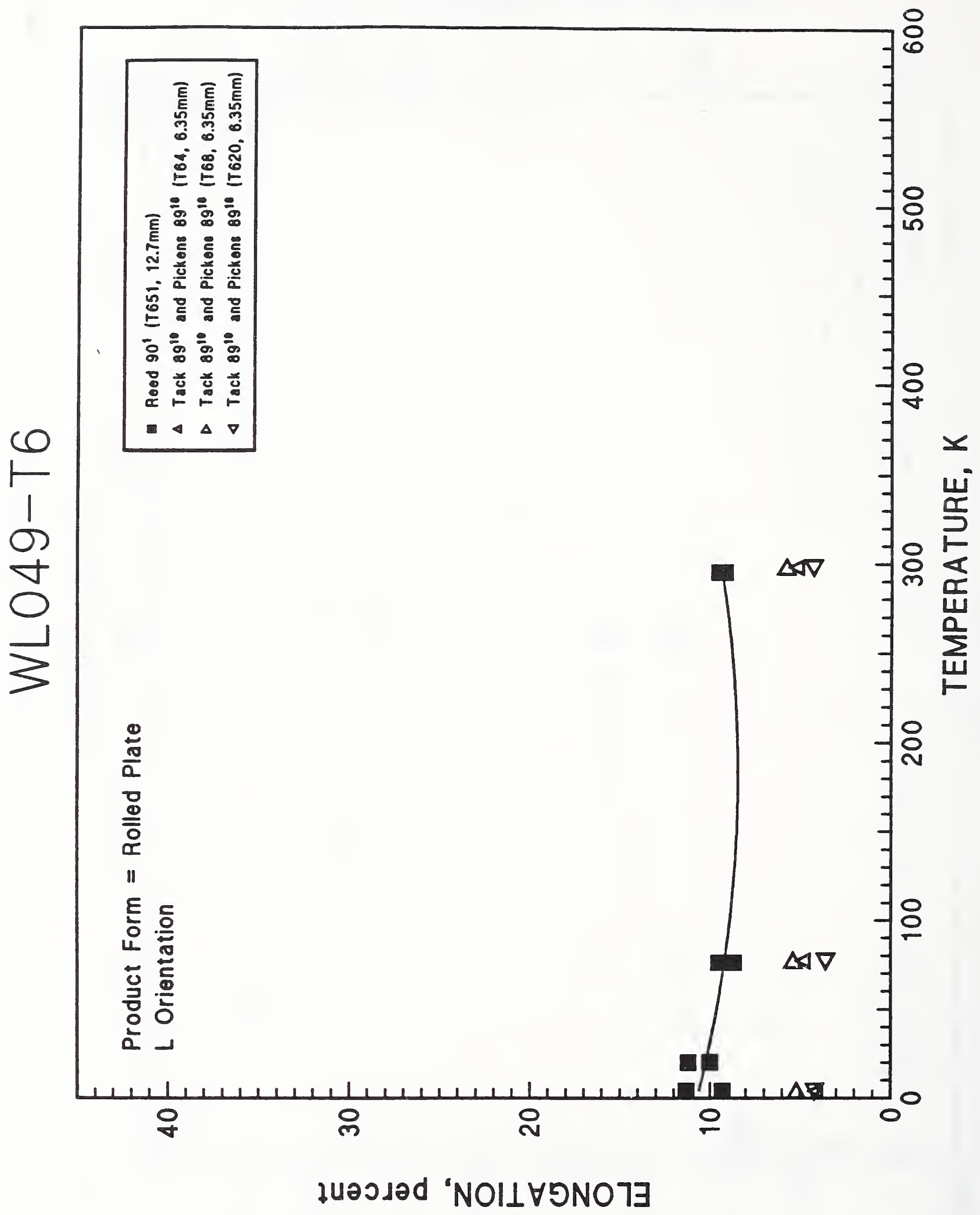


ULTIMATE TENSILE STRENGTH, ksi

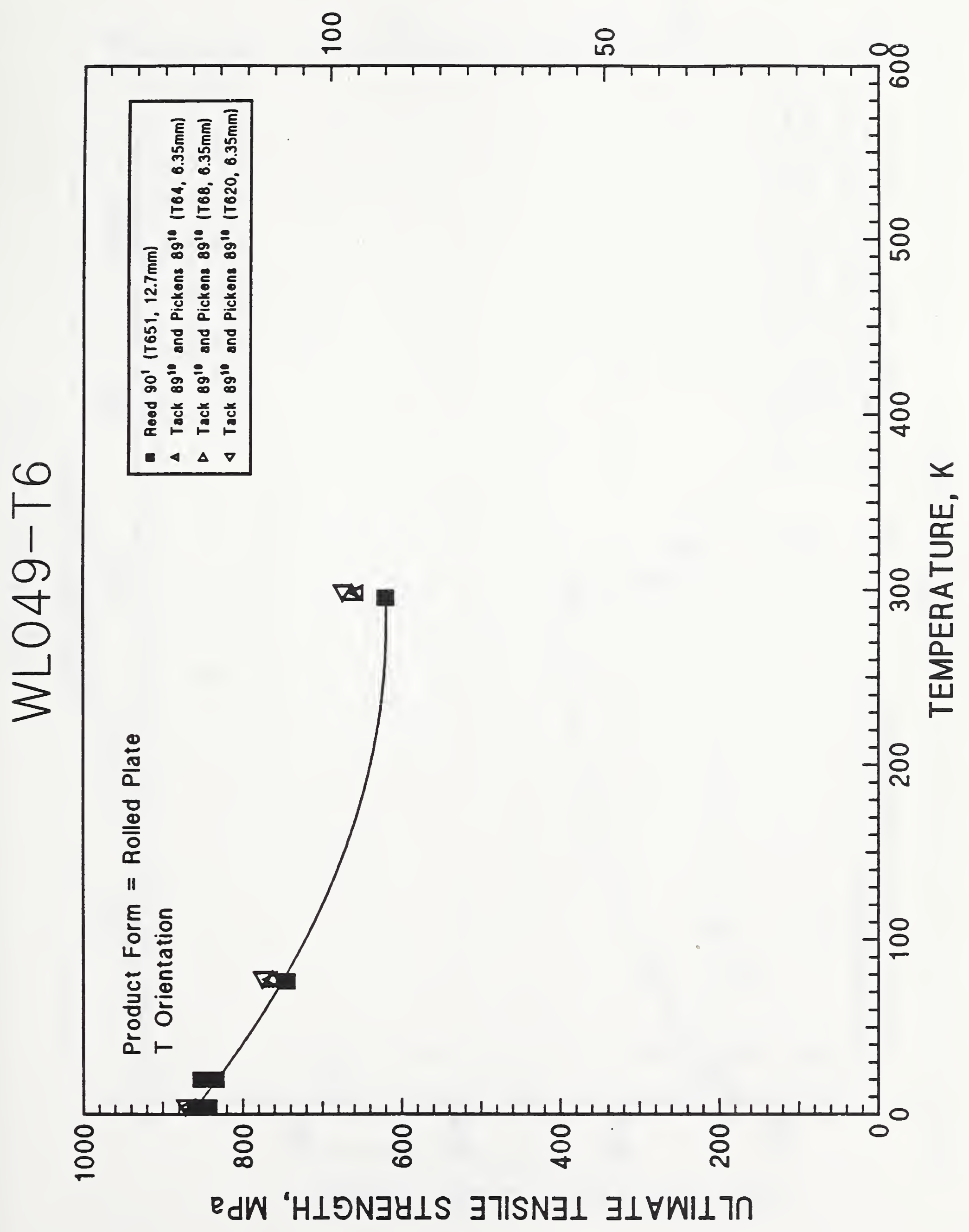


TENSILE YIELD. STRENGTH, ksi

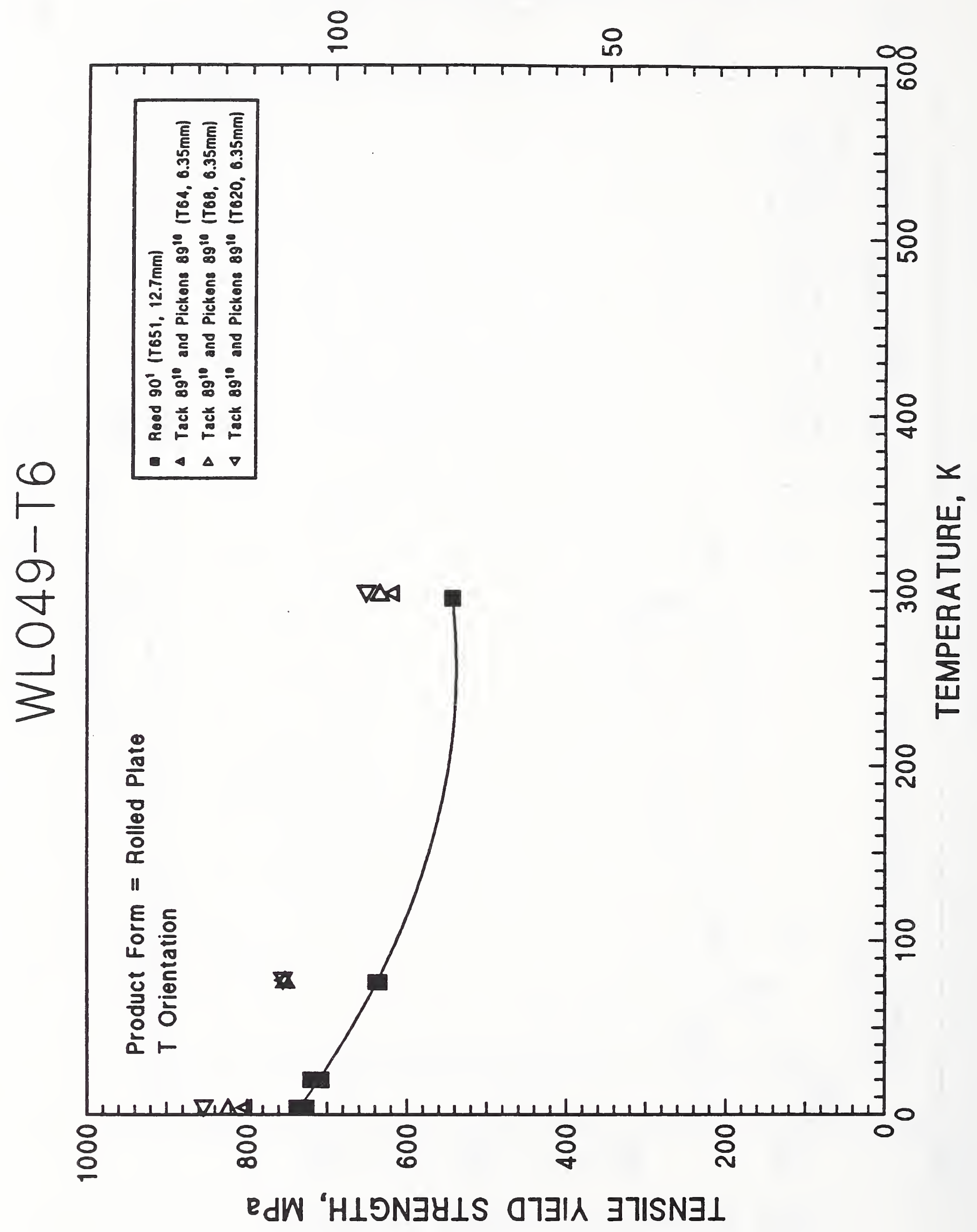




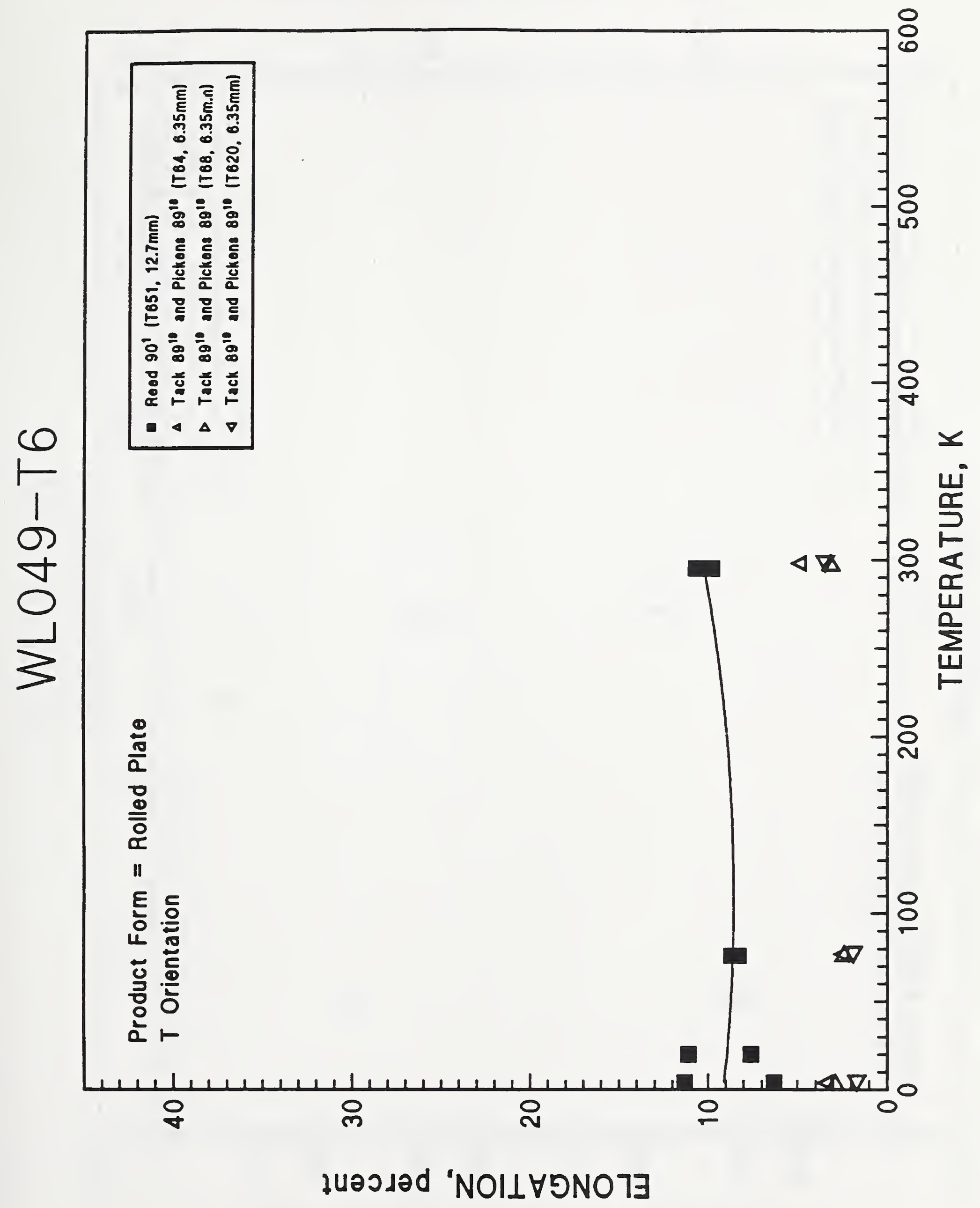


ULTIMATE TENSILE STRENGTH, ksi

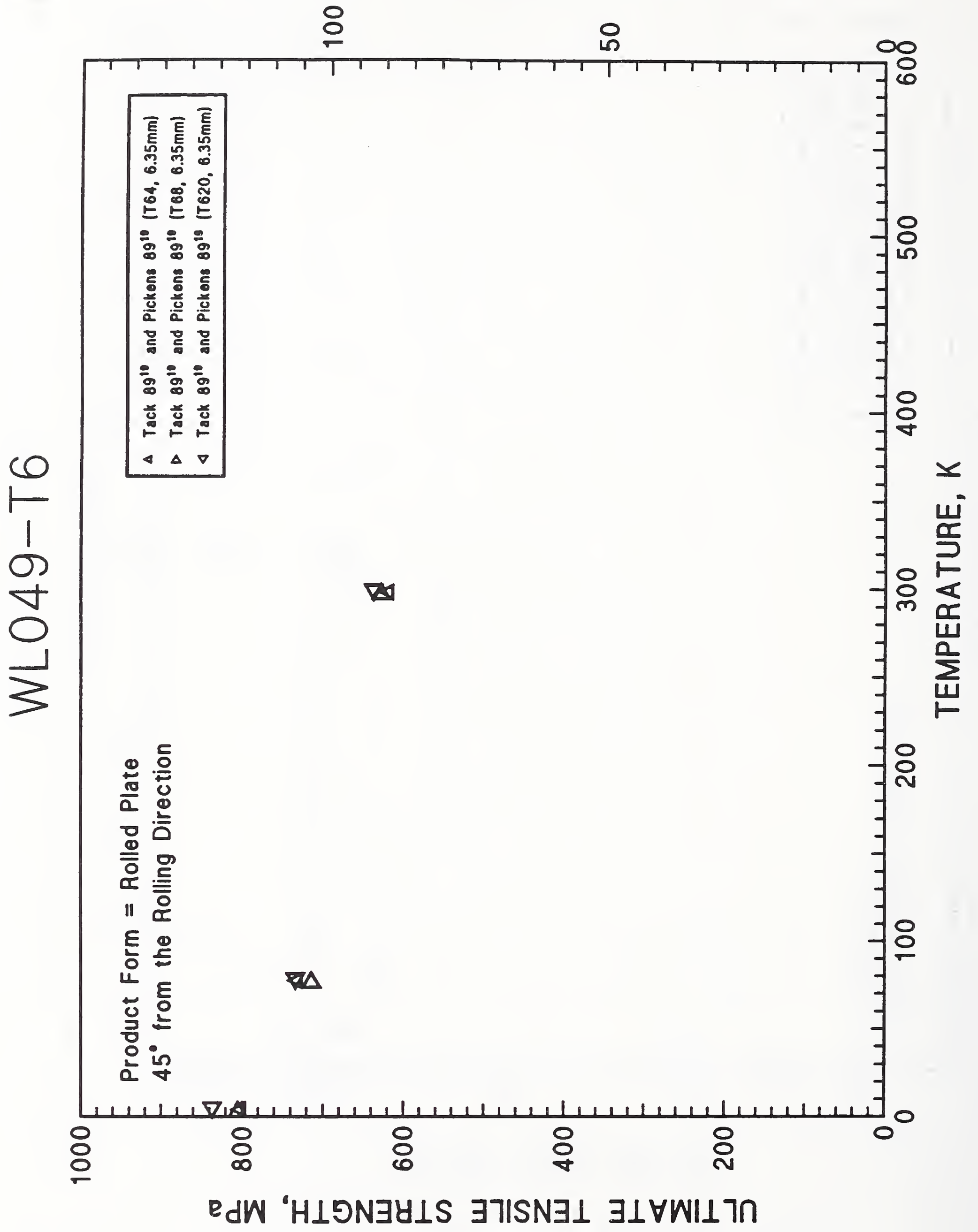


TENSILE YIELD STRENGTH, $\mathrm{ksi}$

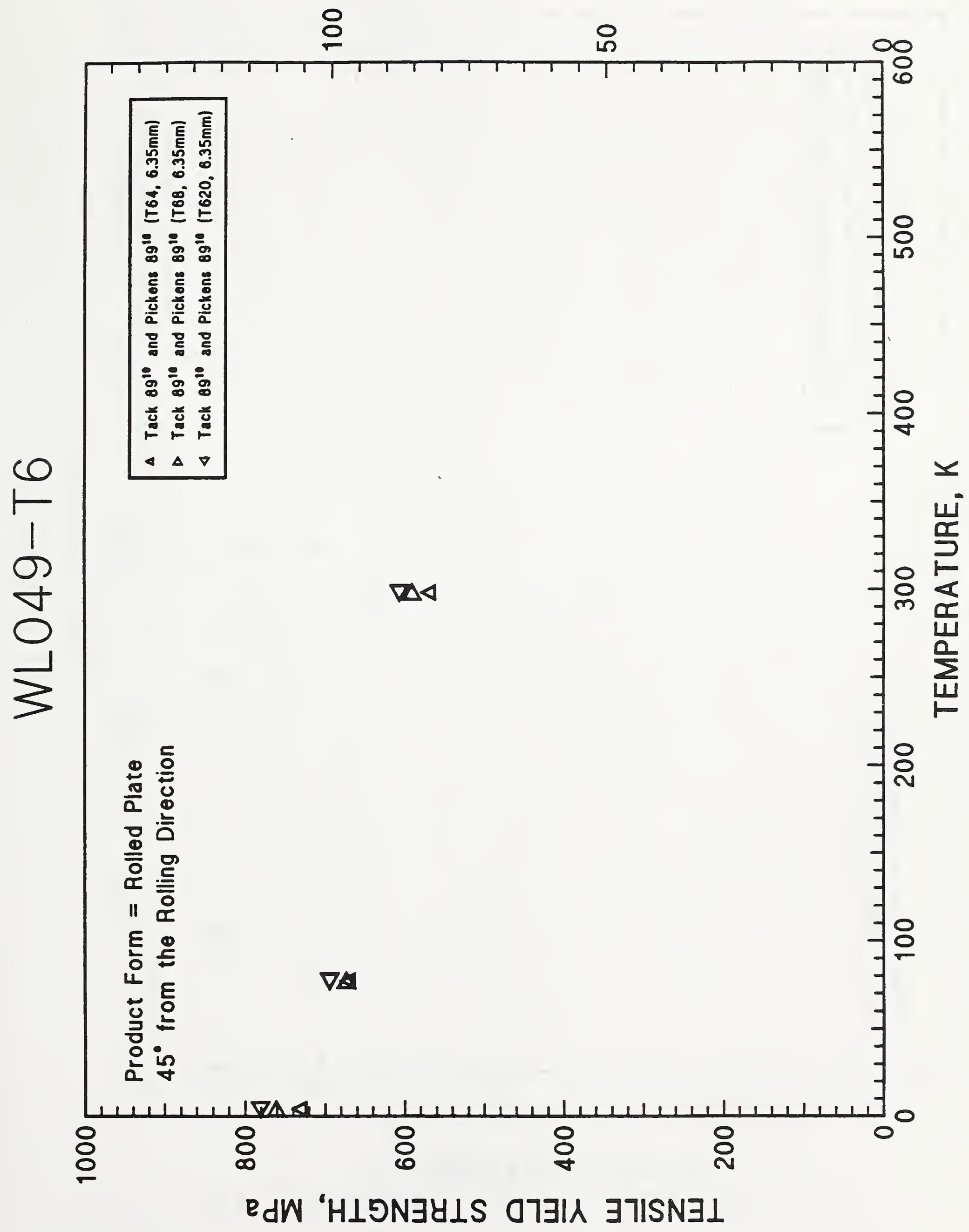




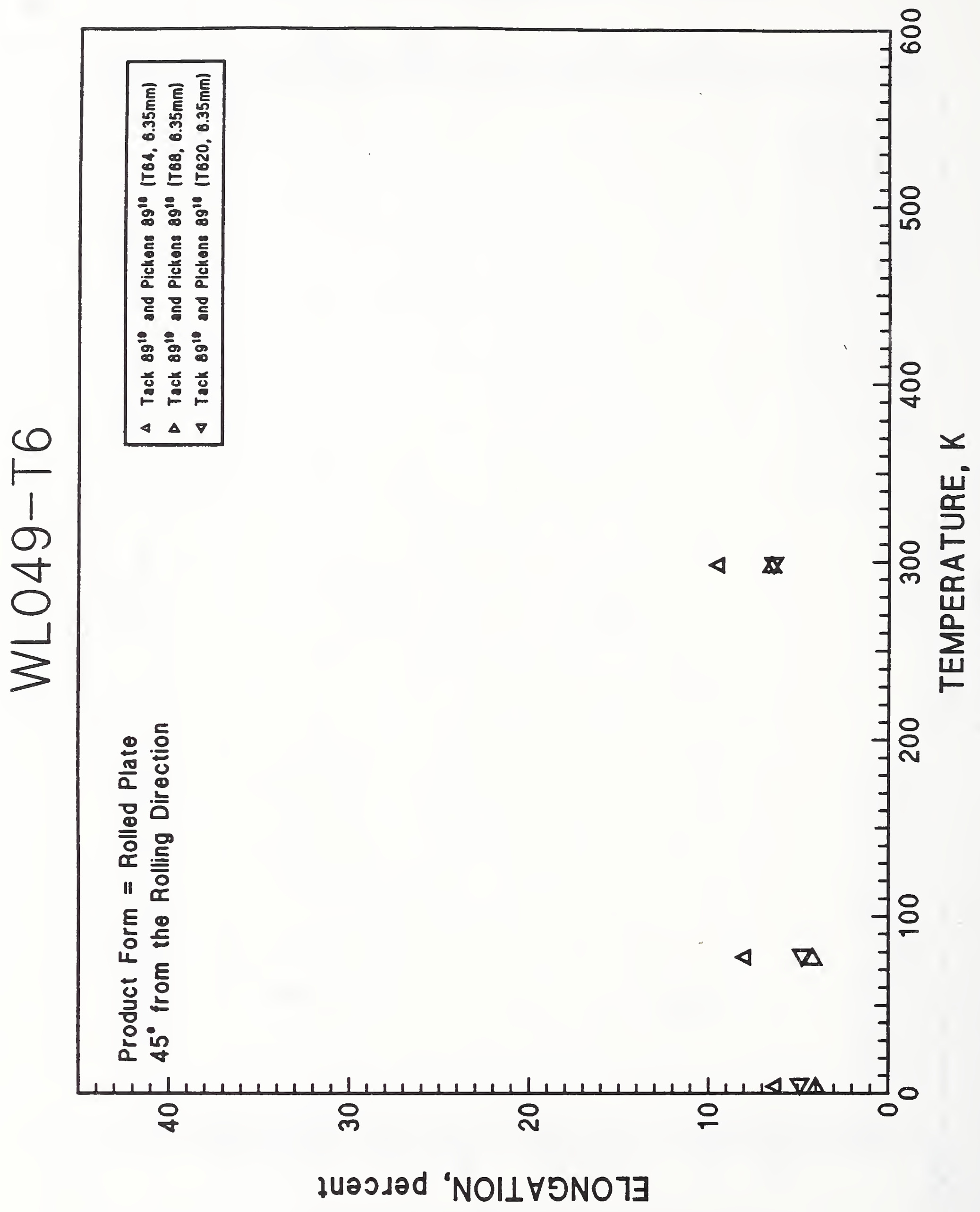


ULTIMATE TENSILE STRENGTH, ksi

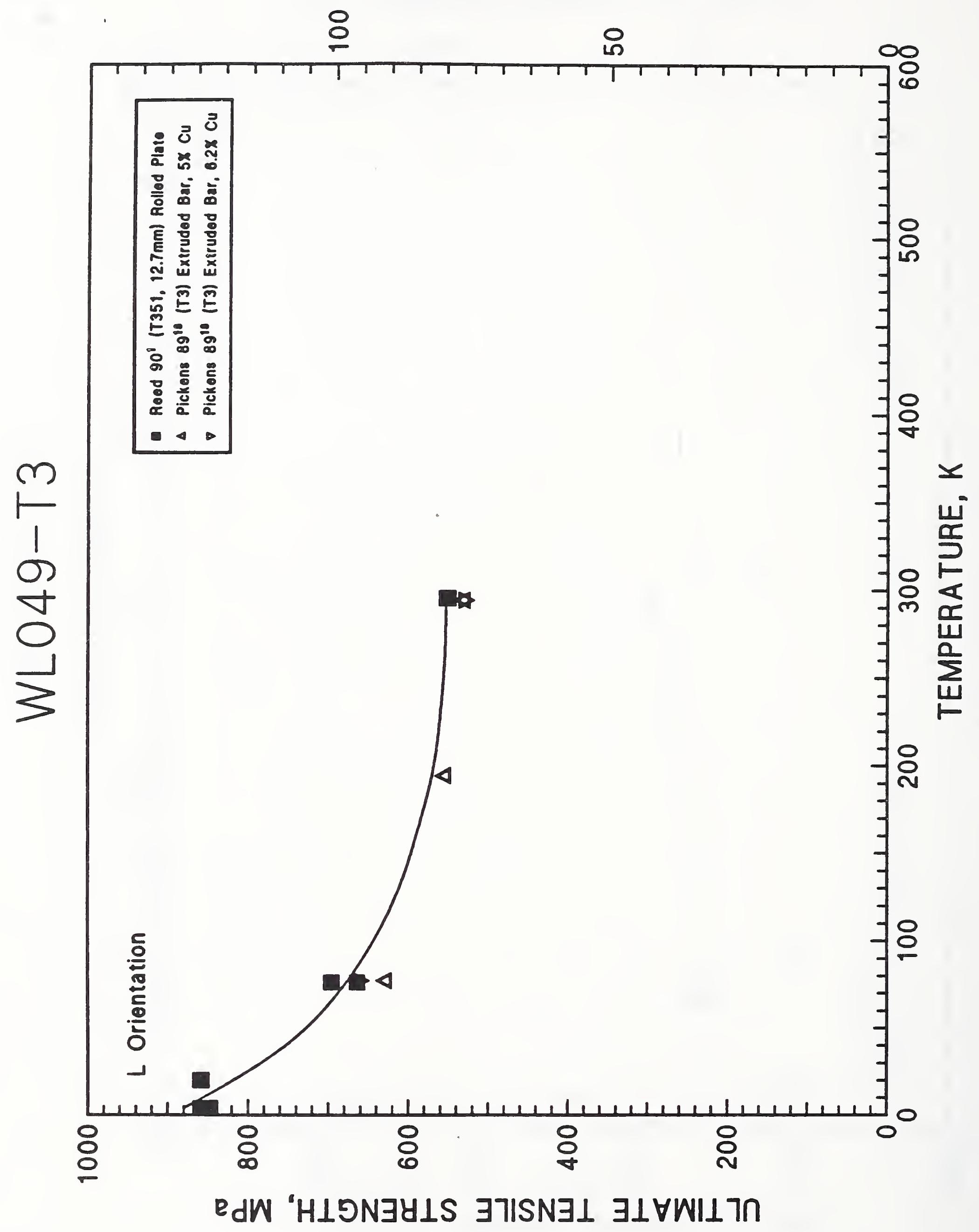


TENSILE YIELD STRENGTH, ksi

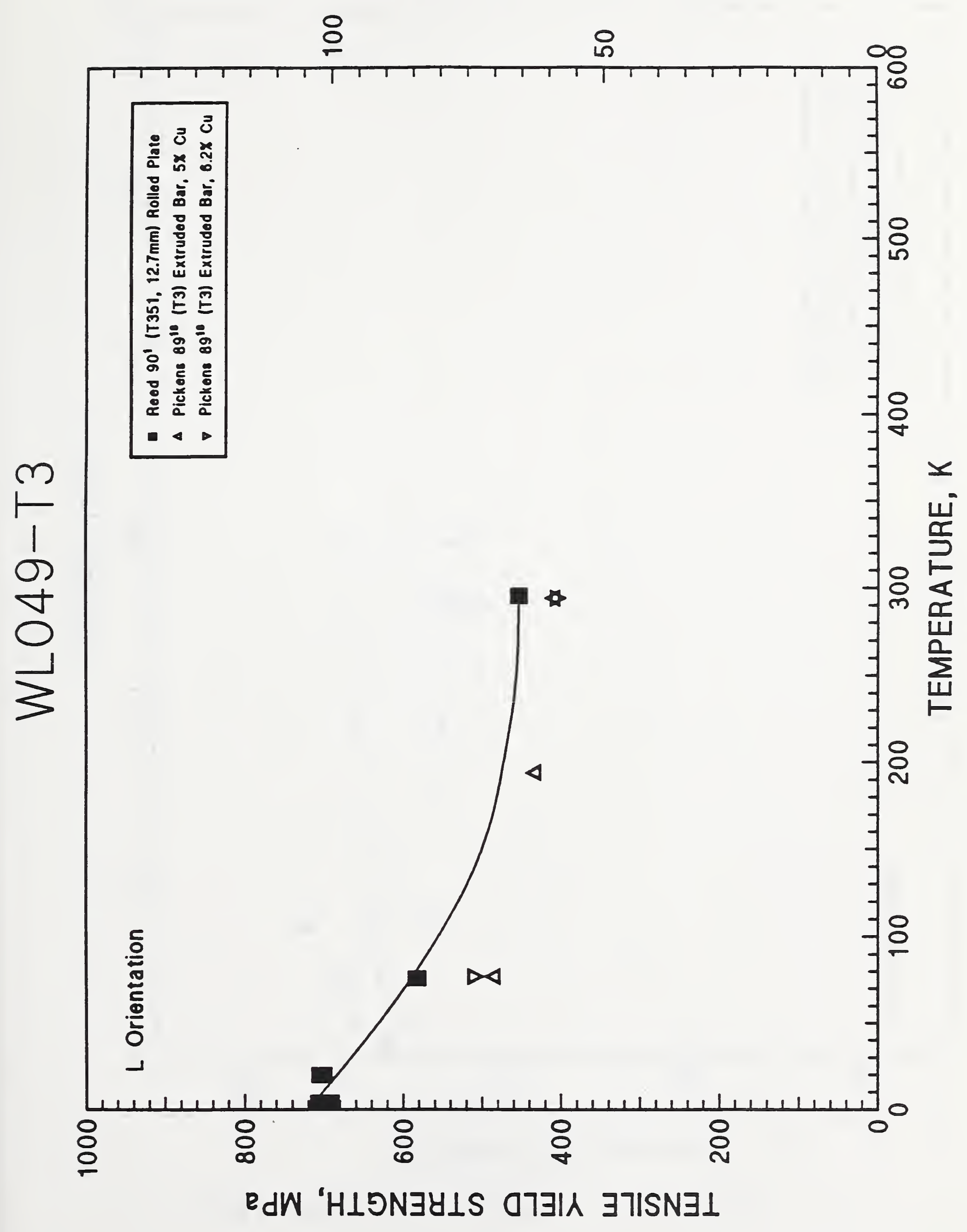




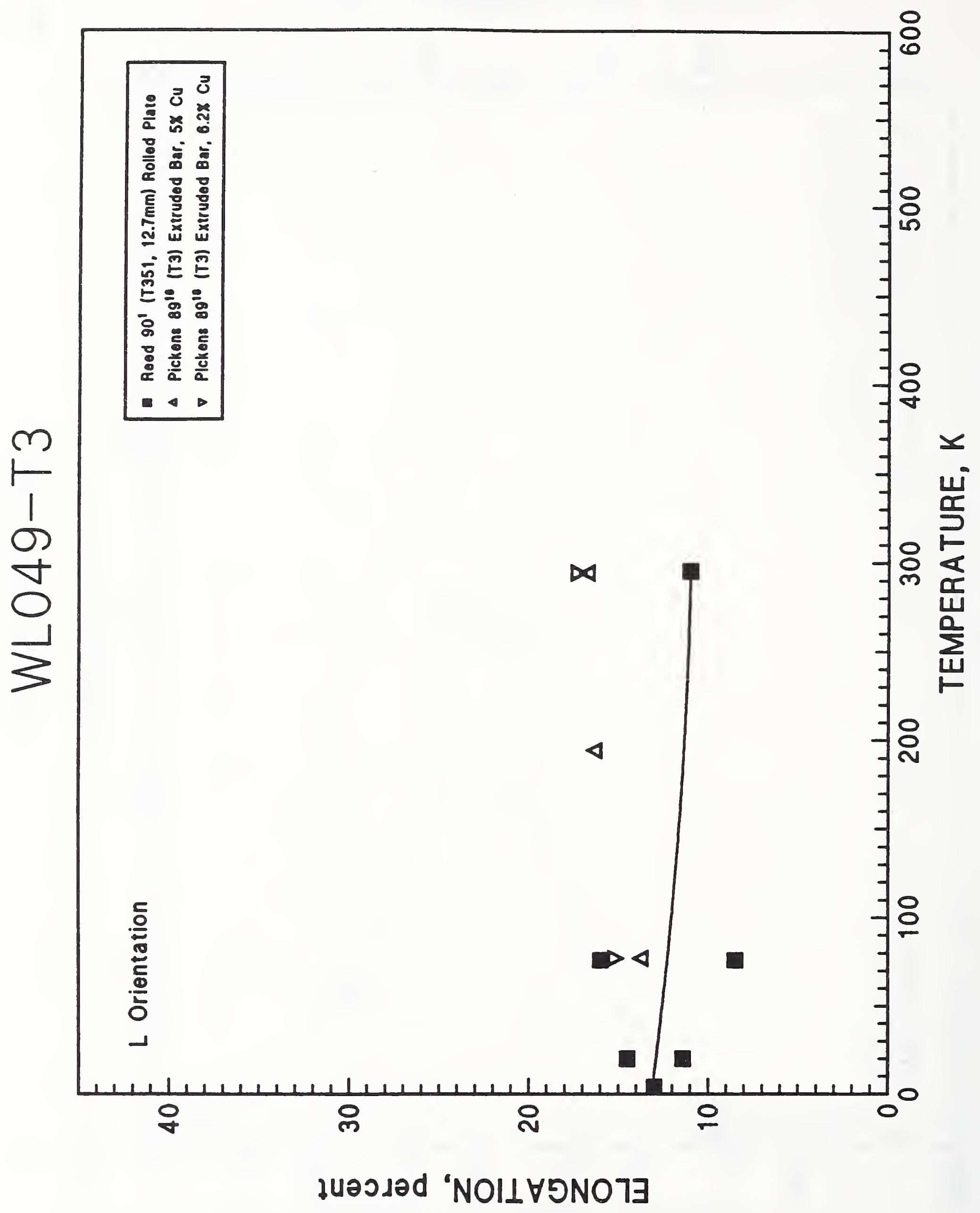


ULTIMATE TENSILE STRENGTH, ksi

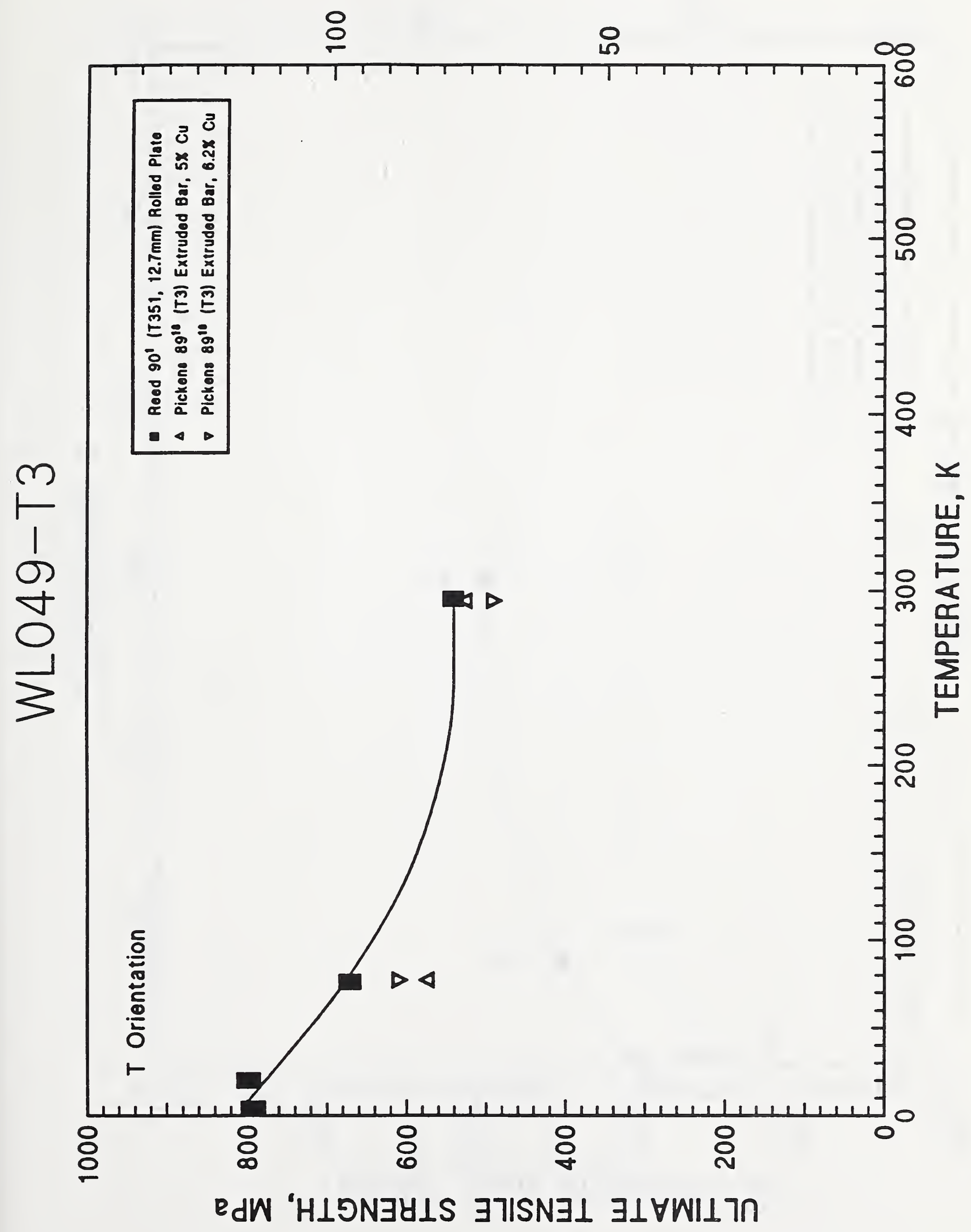


TENSILE YIELD STRENGTH, ksi

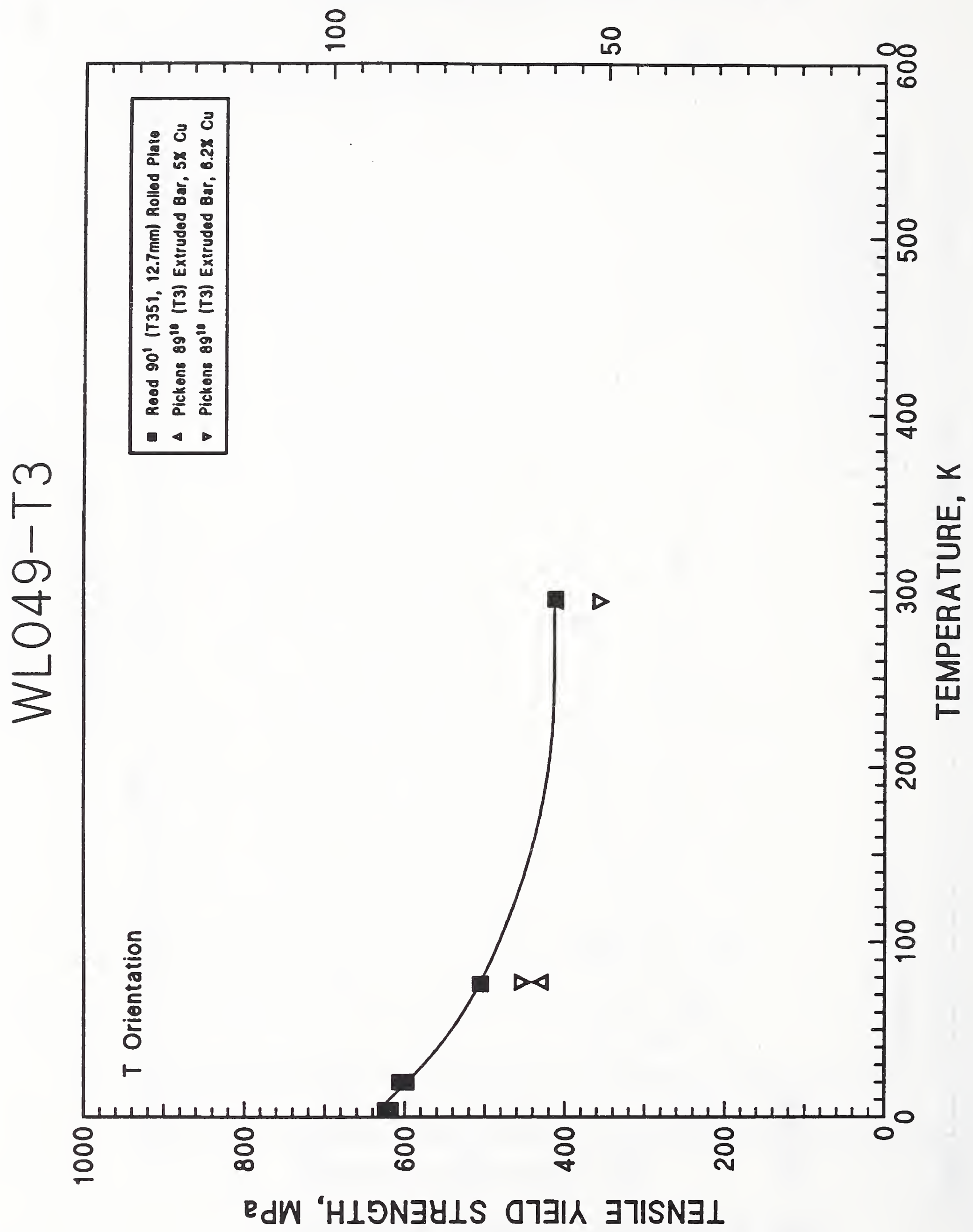




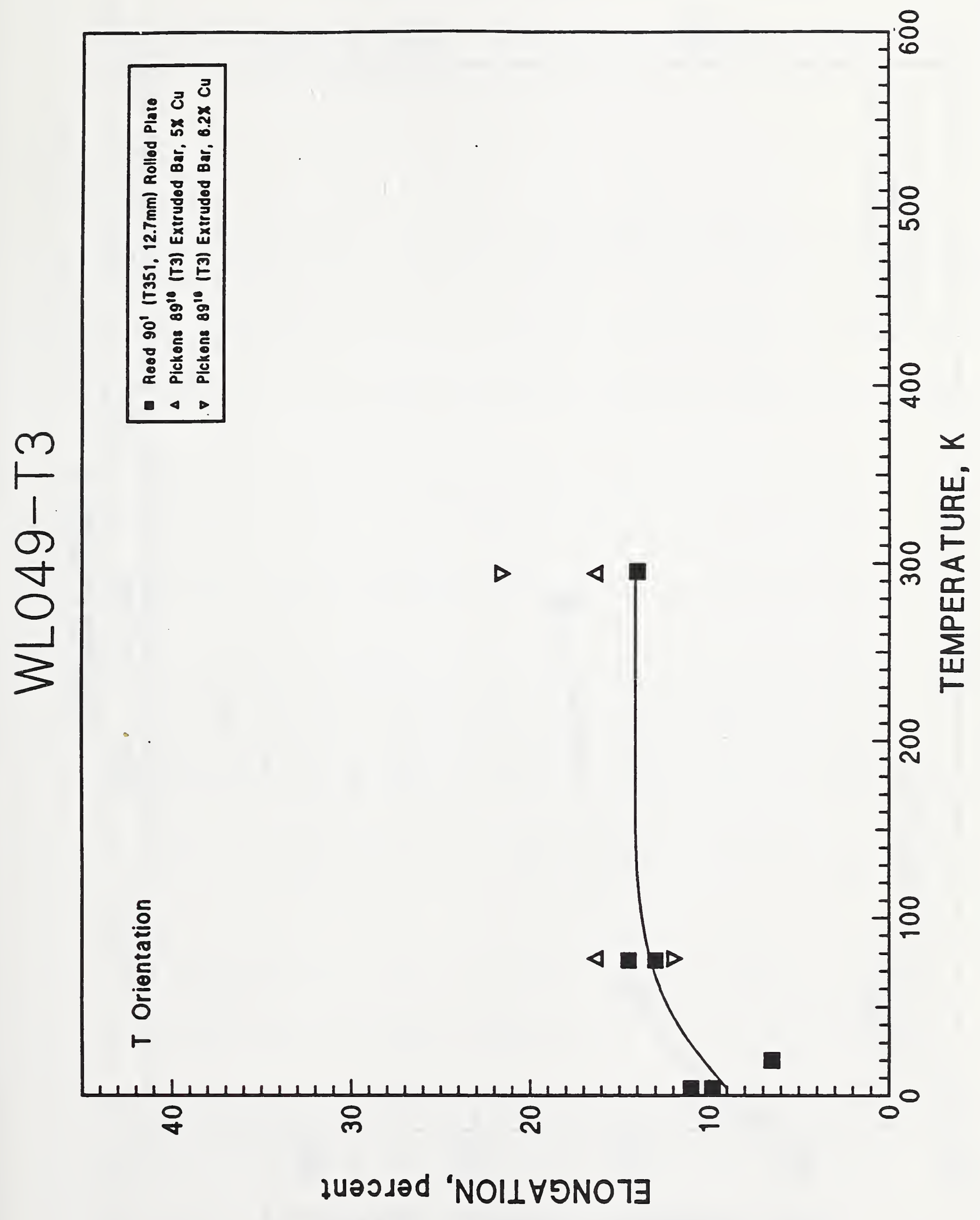


ULTIMATE TENSILE STRENGTH, ksi

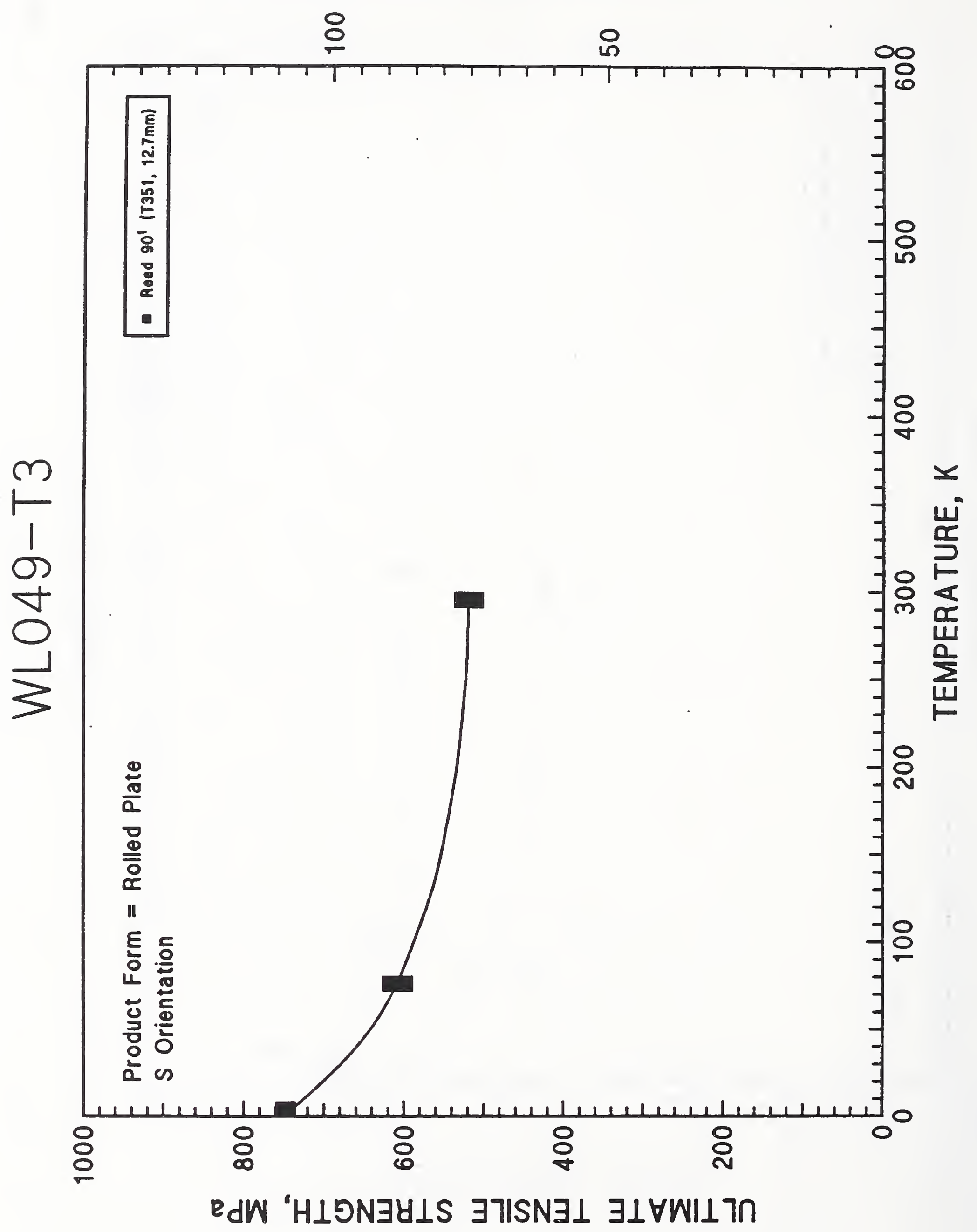




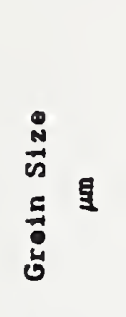

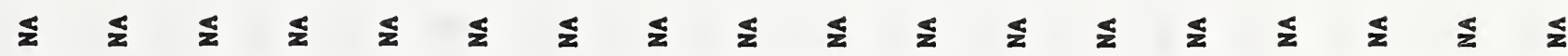
递㝘

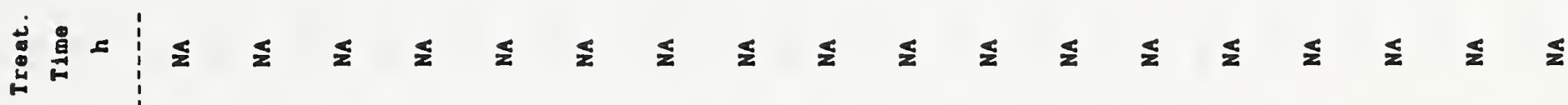

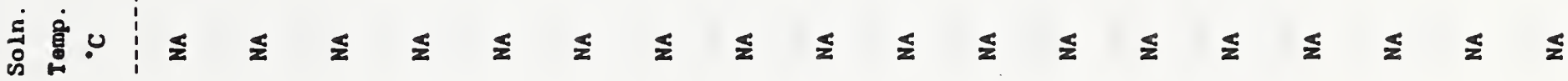

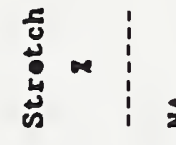

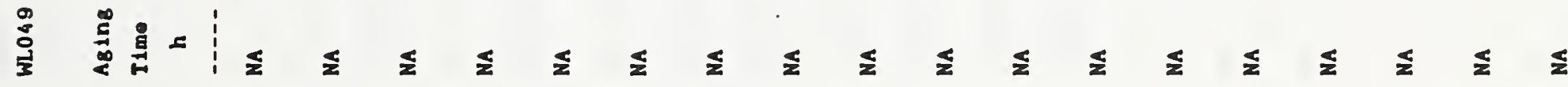

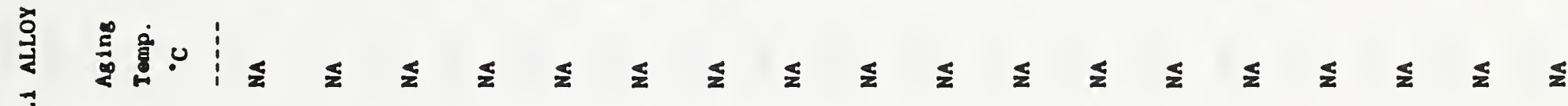
$\stackrel{\overrightarrow{1}}{a}$

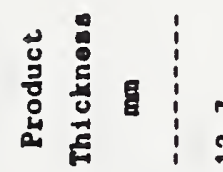

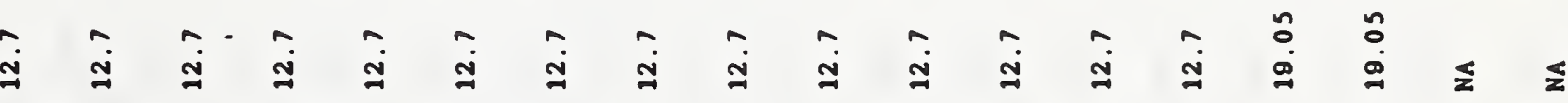

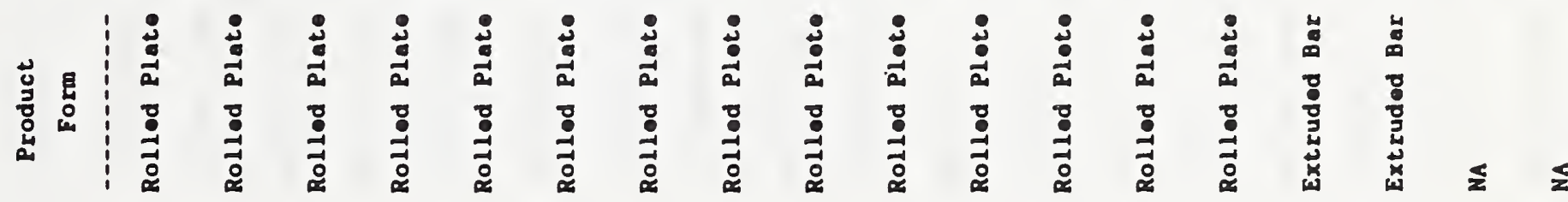
兽 蔮 ¿্்

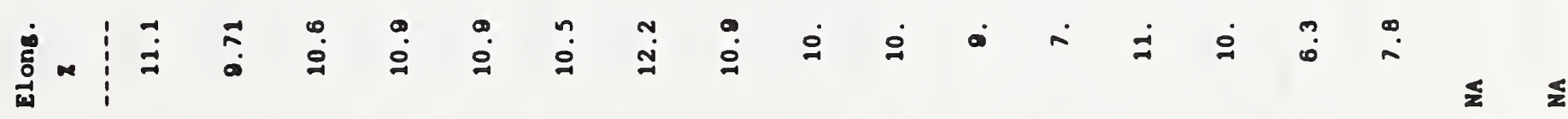
ن் ن

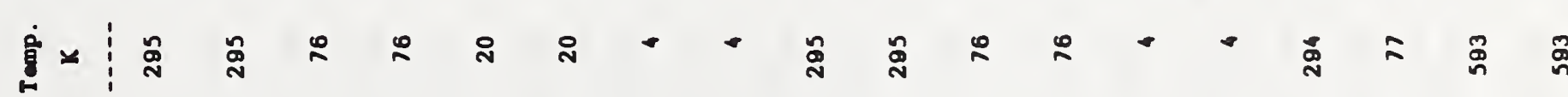
: 


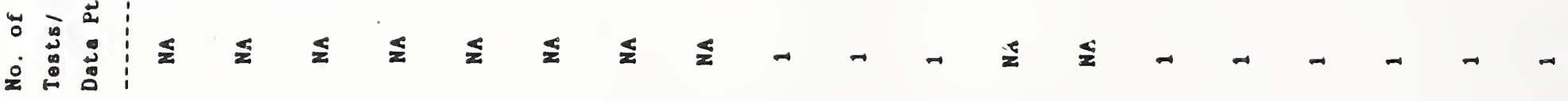

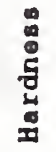

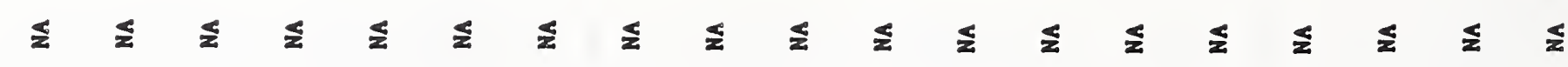

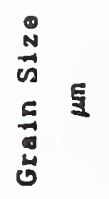

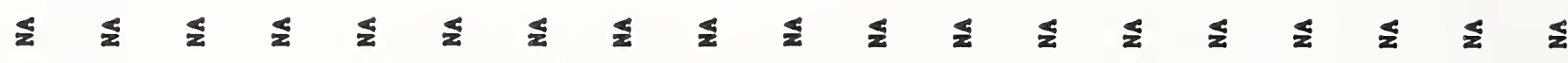
焉

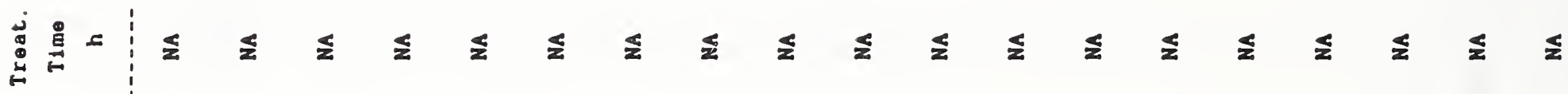

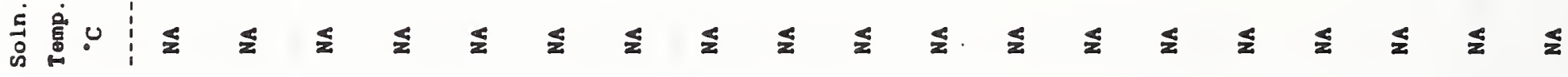

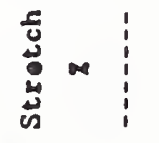

造是: 道兽。:

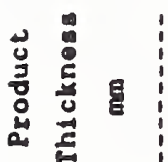

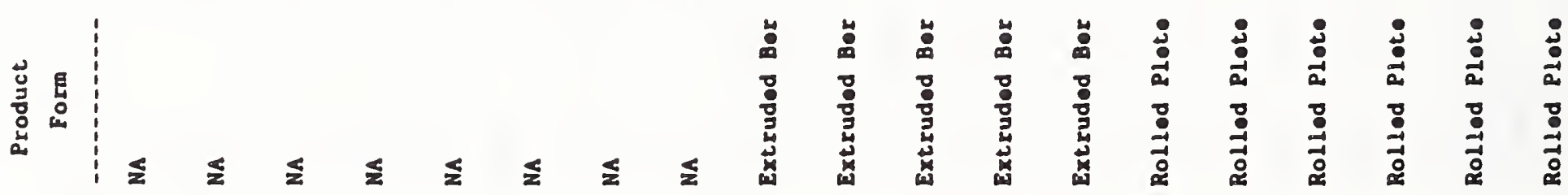

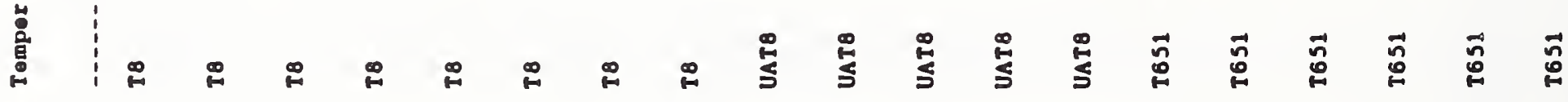
范

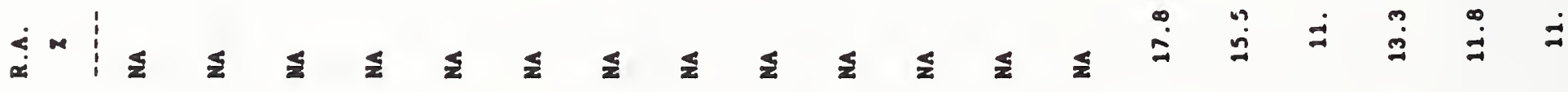

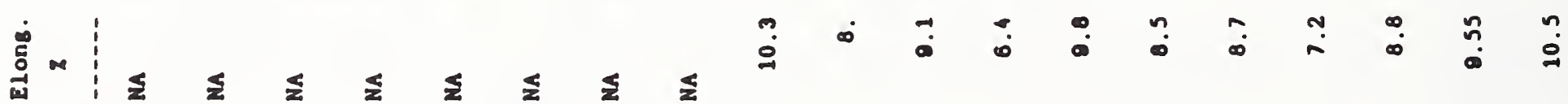

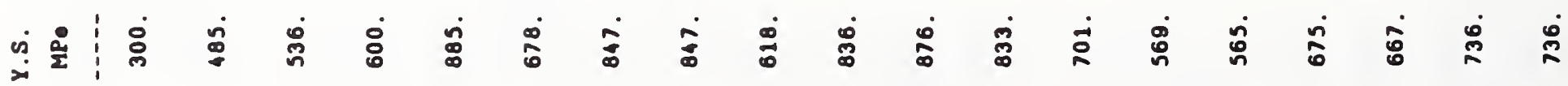

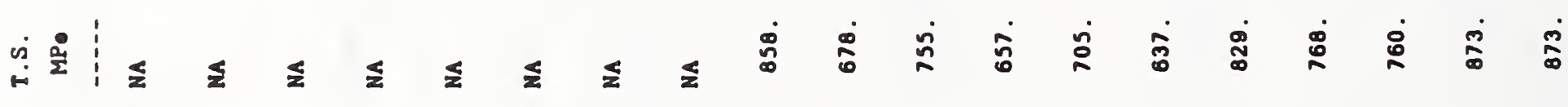
尊 ๘ 


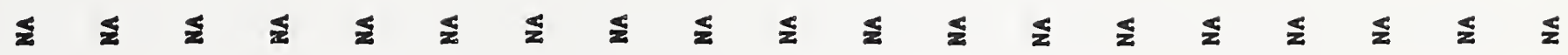

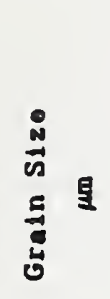

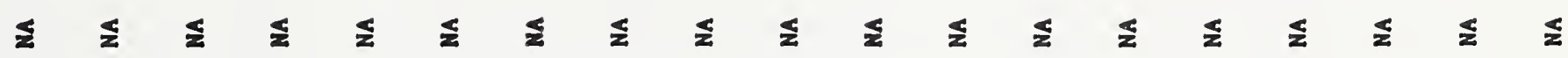

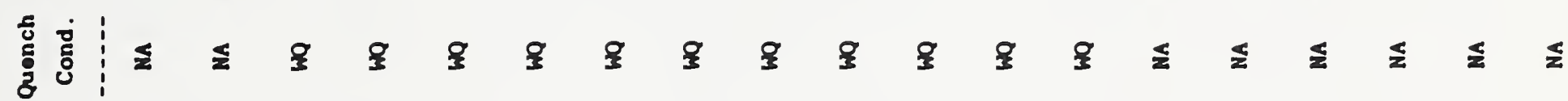
造是

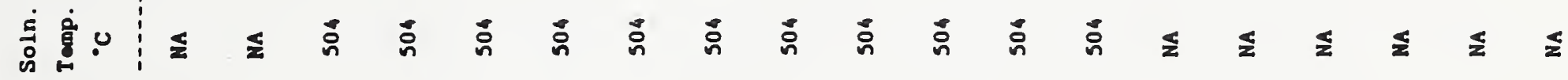

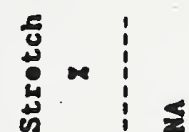
递首 过尊 苍:

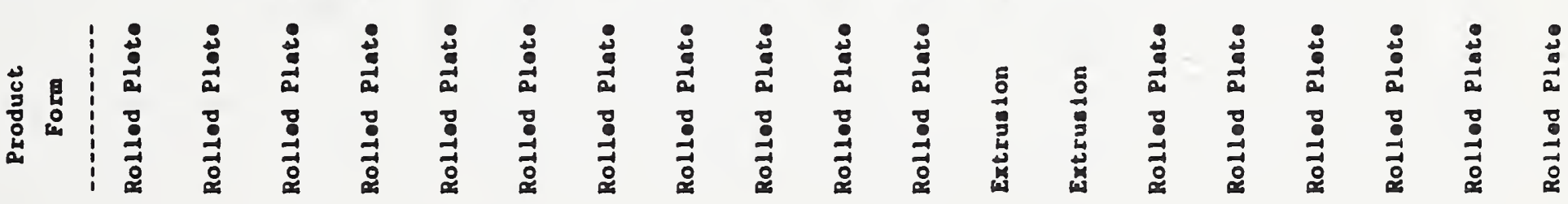
兽 :

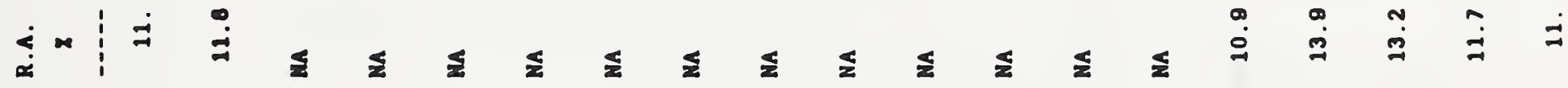

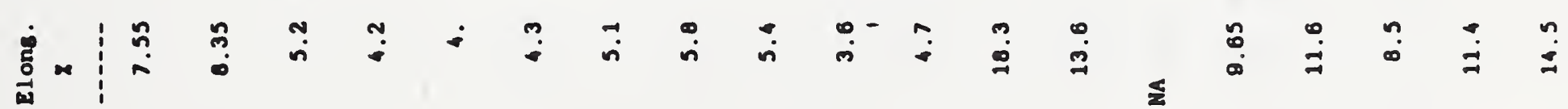

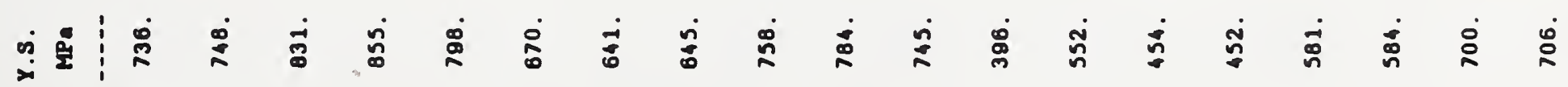
官

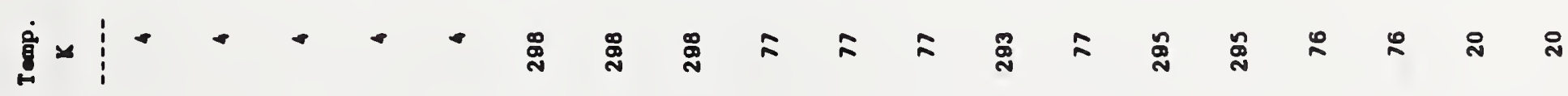
过旁 
要离

曾

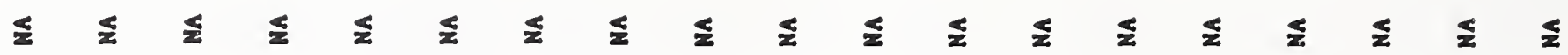

究

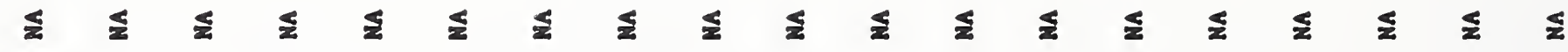

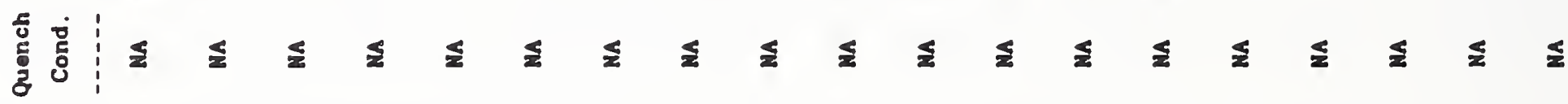

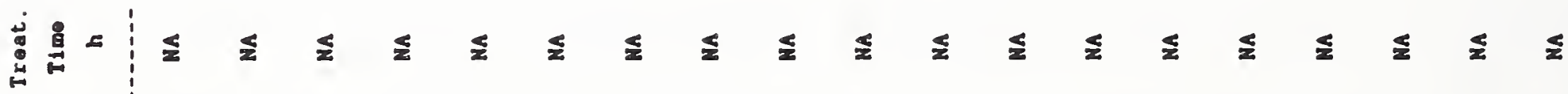

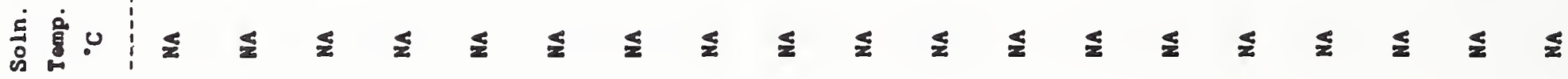
苔落

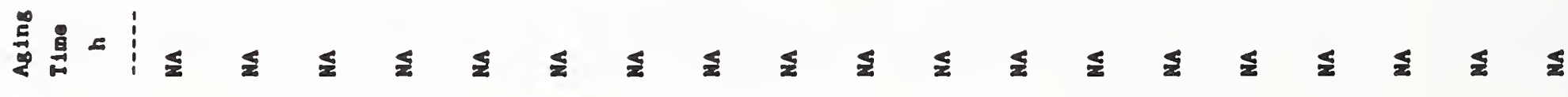

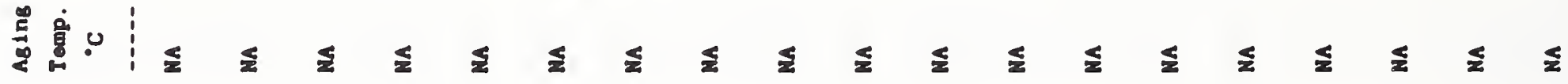

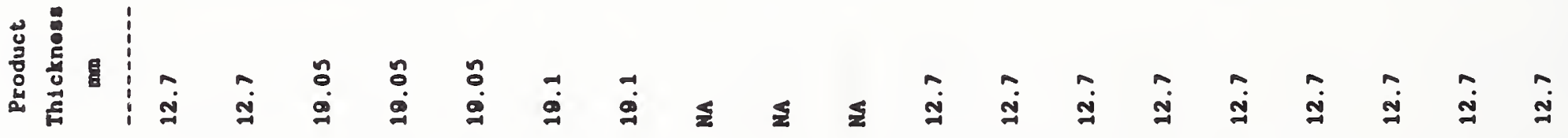

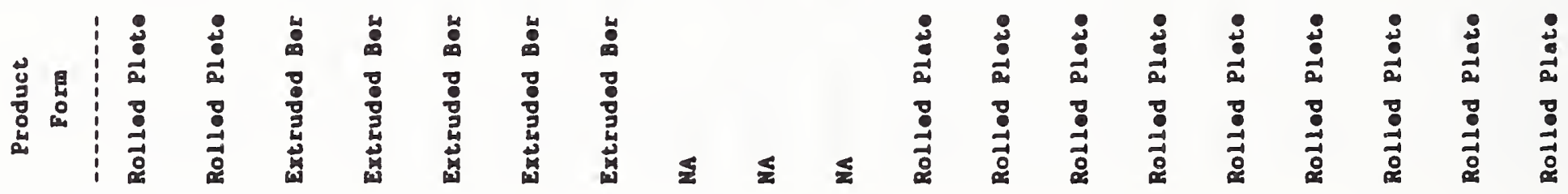

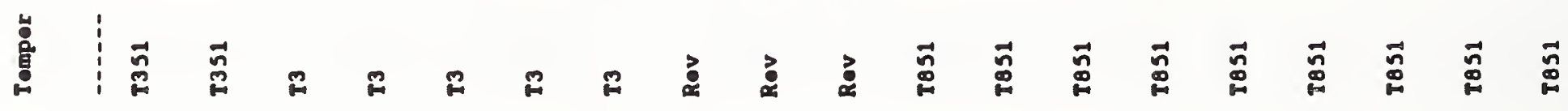

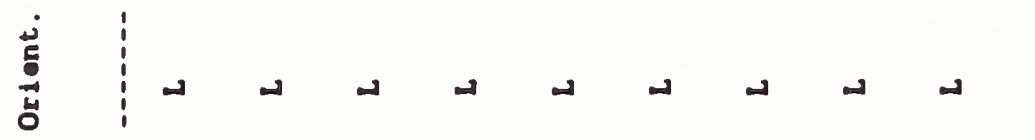

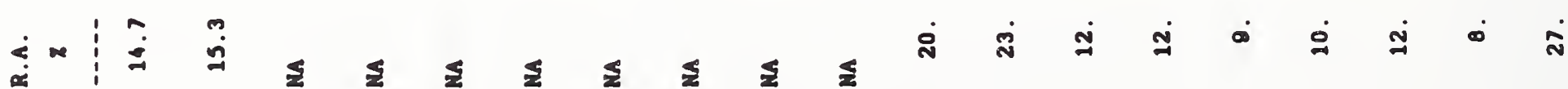

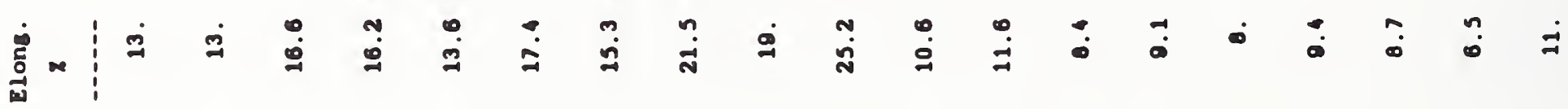
نூ

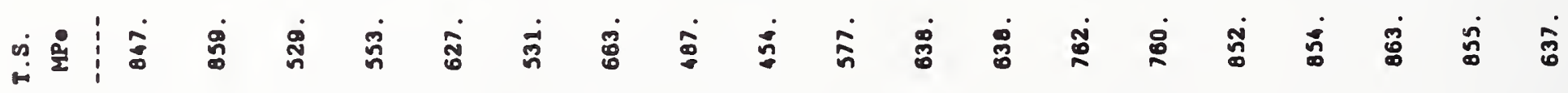

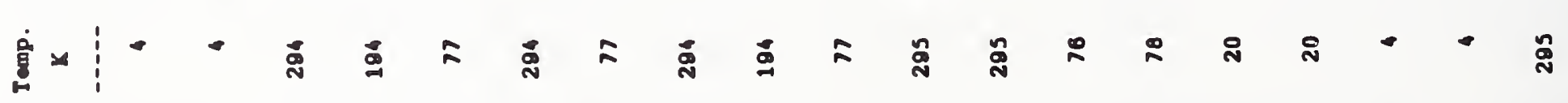

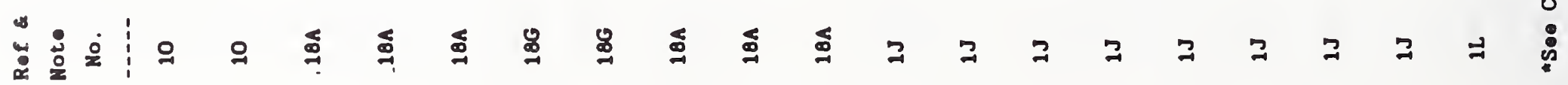




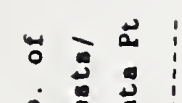

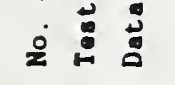

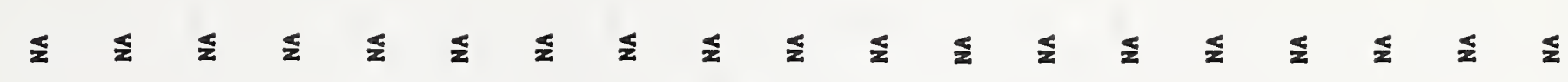

苟

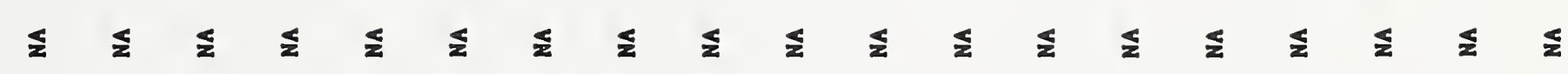

兽咅

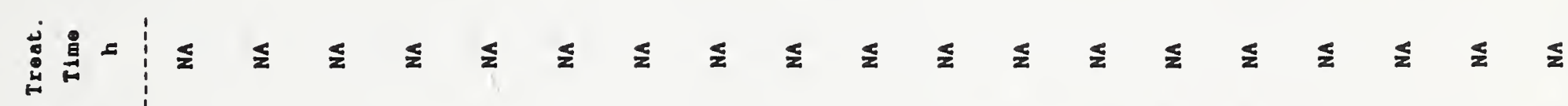

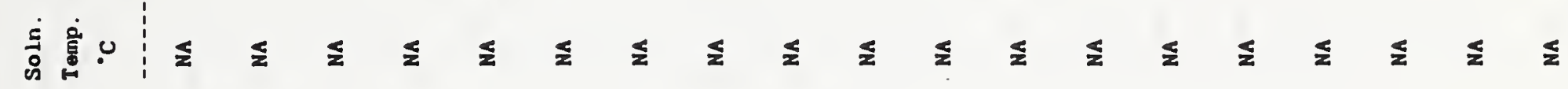
:

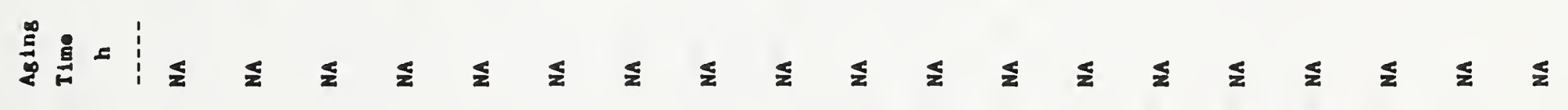

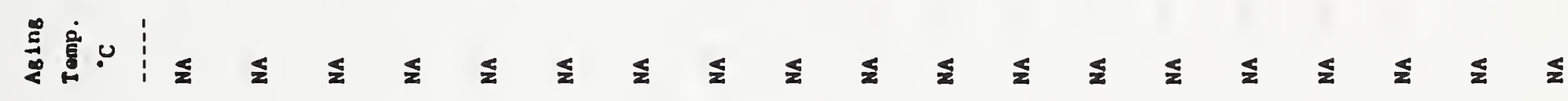
害

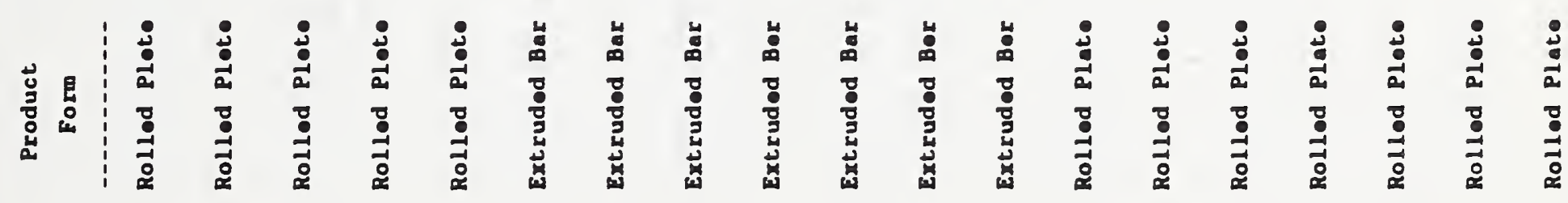
兽

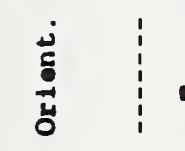

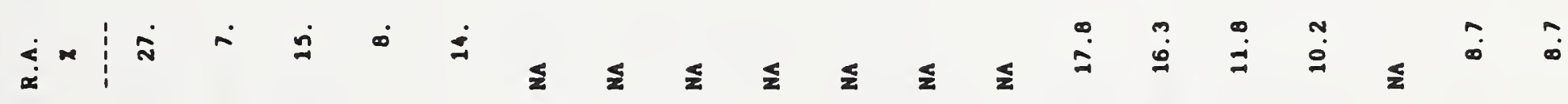

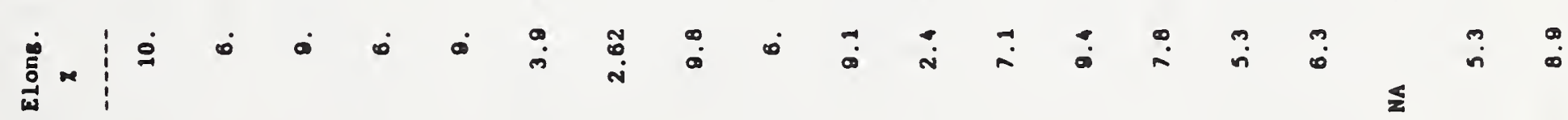
ن

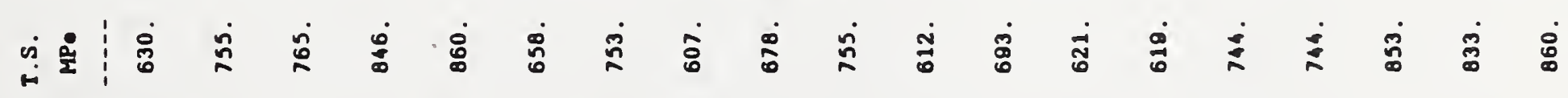

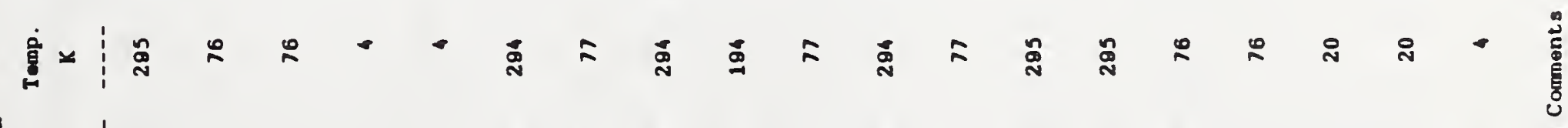
范㝘宗 


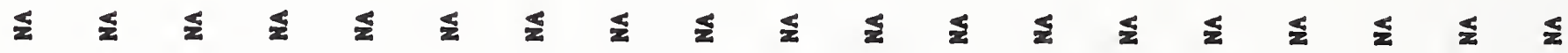

岳咅

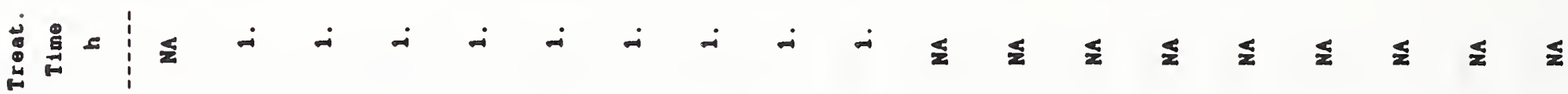
宫密

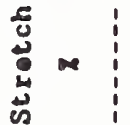

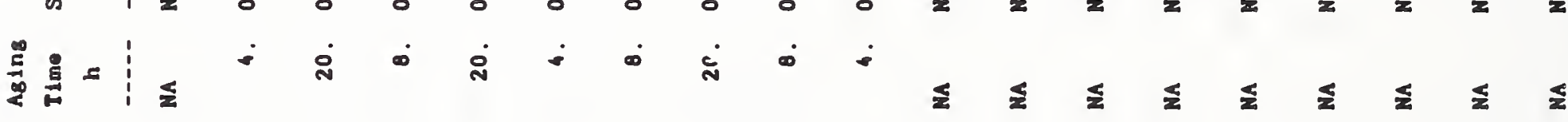

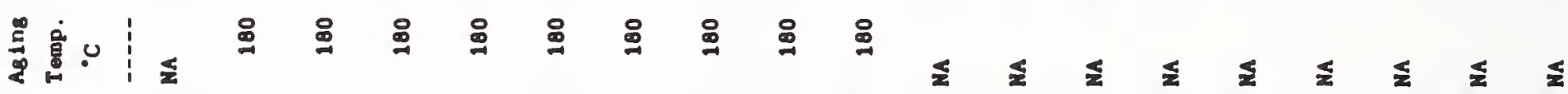

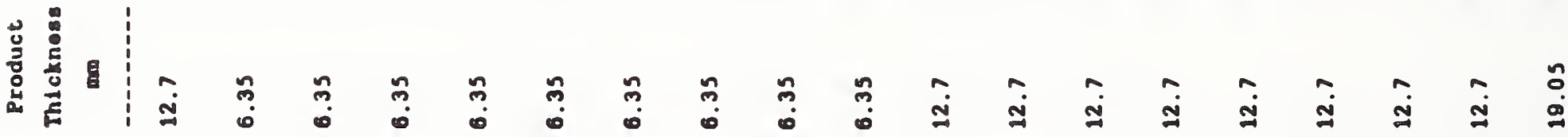

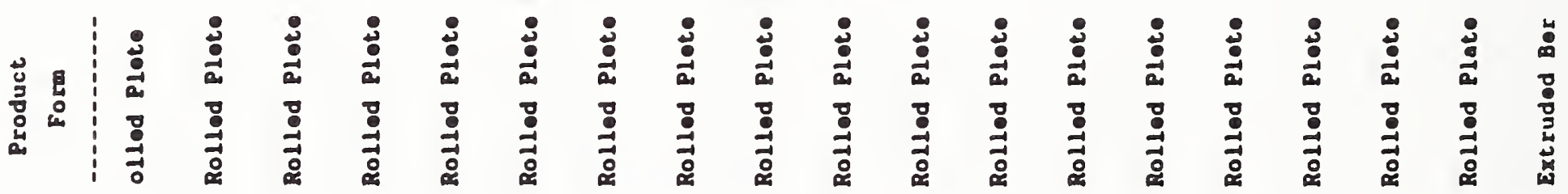
兽 苛

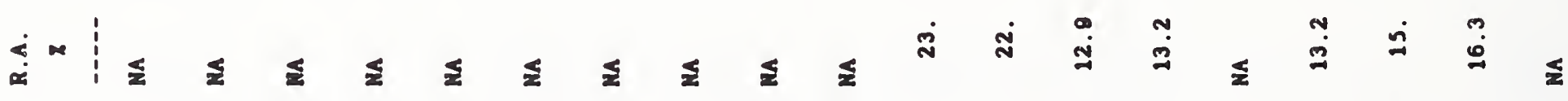
晜 ن ஸ்

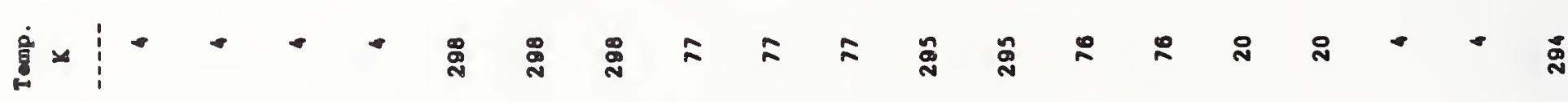

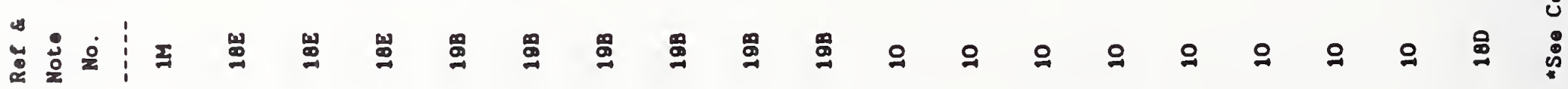




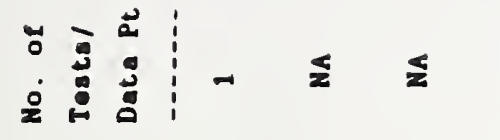

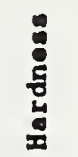

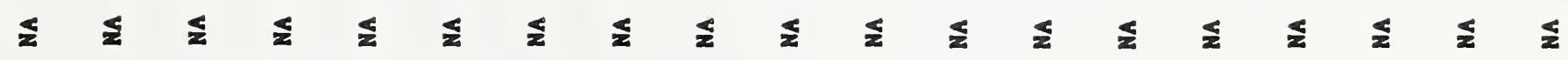

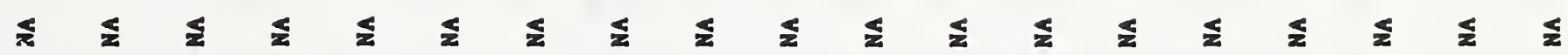

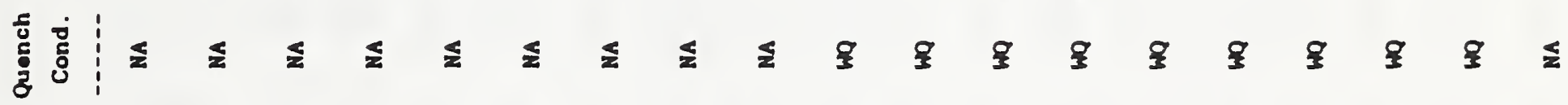

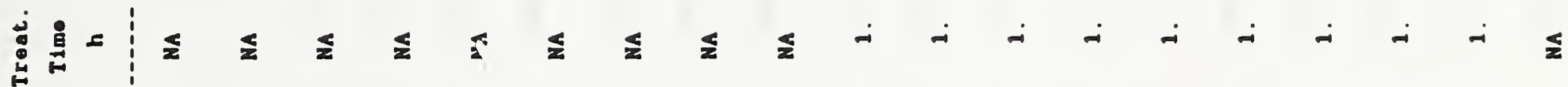

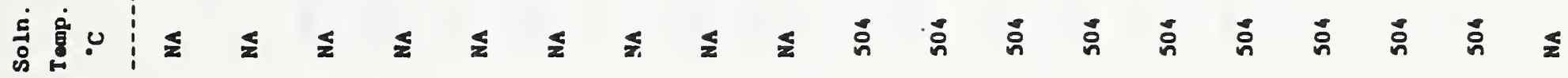
尊

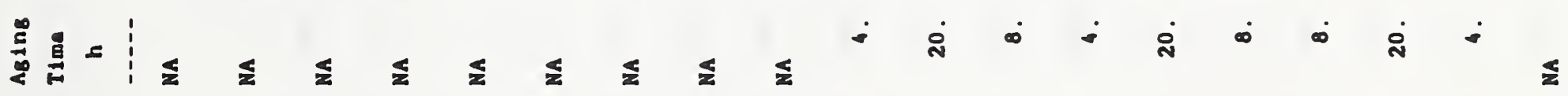
逜富

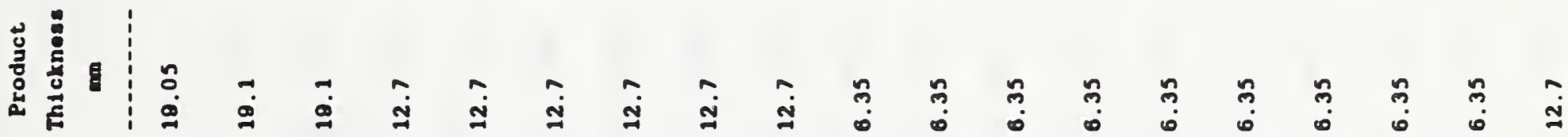

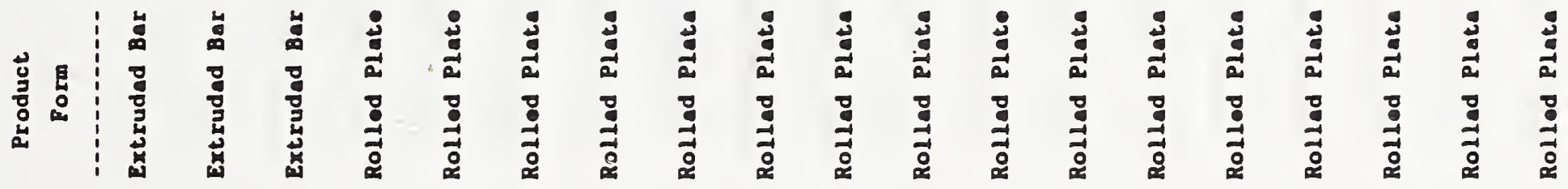
兽 है

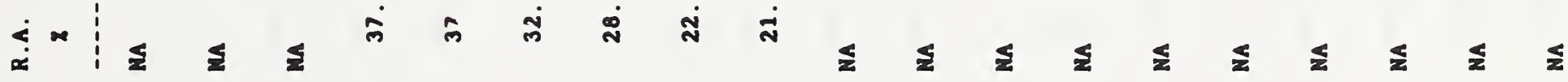
家

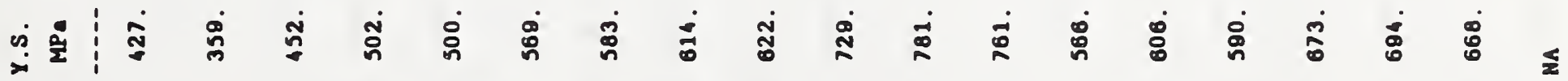
ن

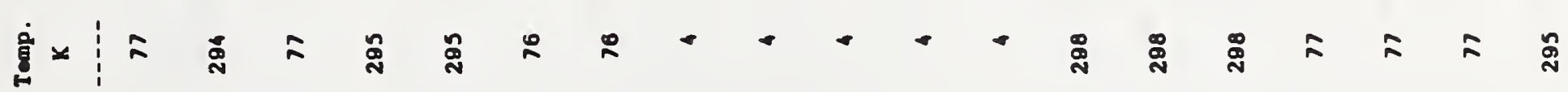
ڤ 


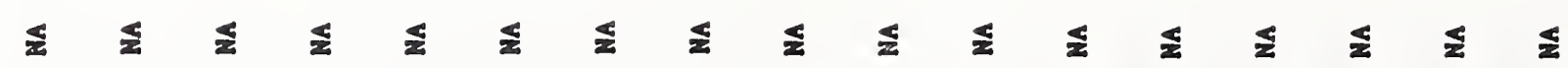

离

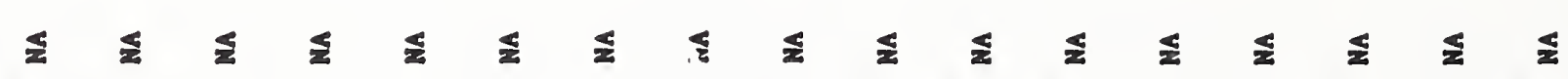
践

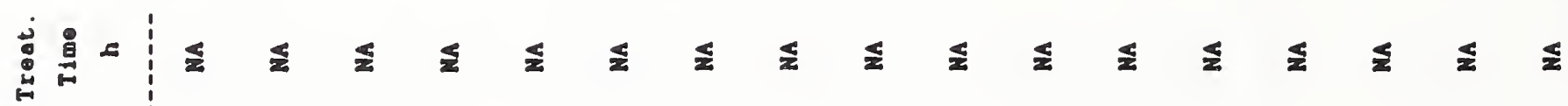

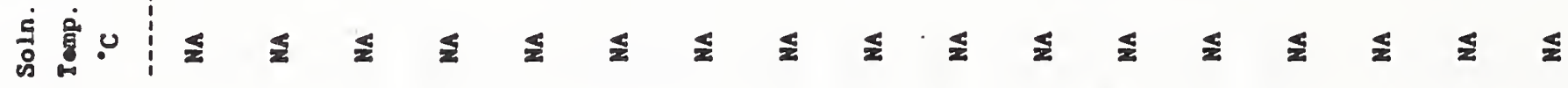

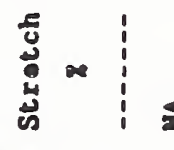
进曷: 递兽:

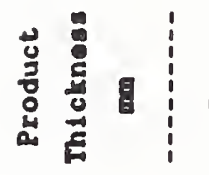

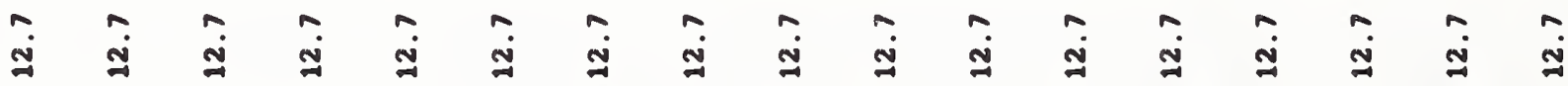

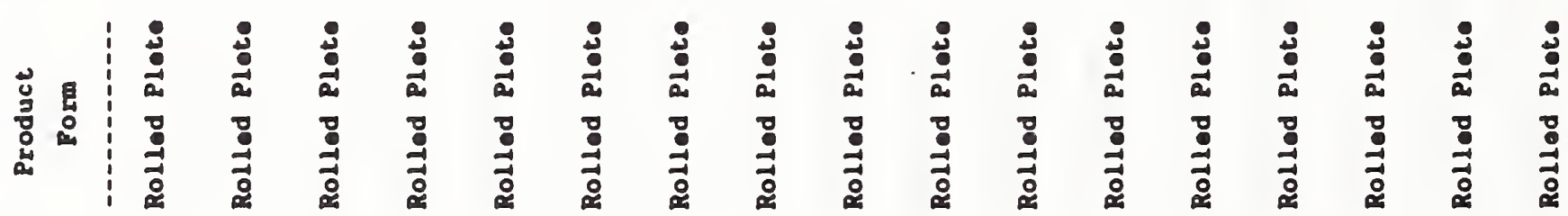

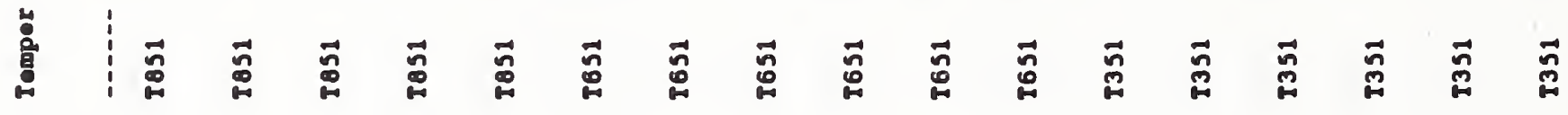
䒴 ¿ 总山 过 ஸे

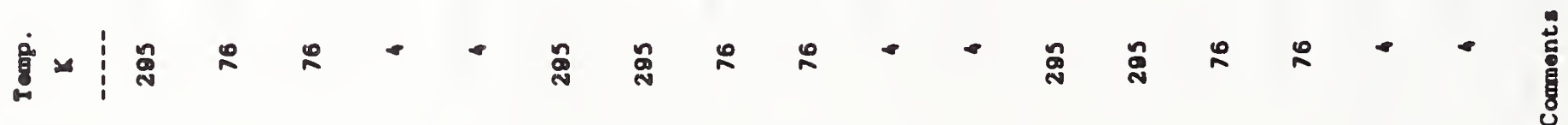
过察定 


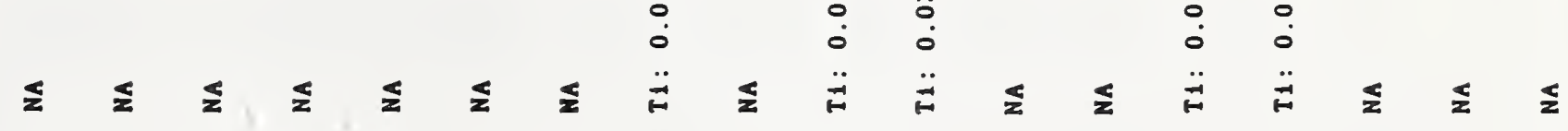

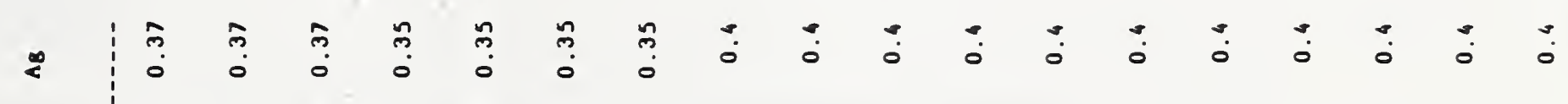

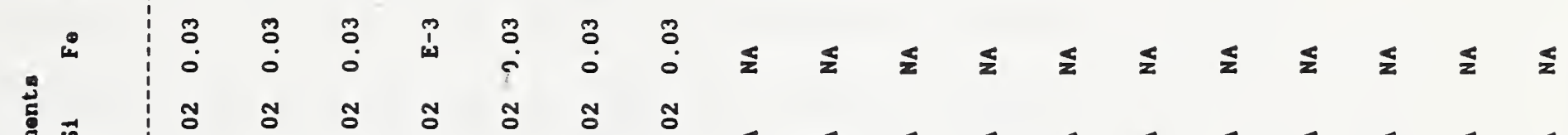

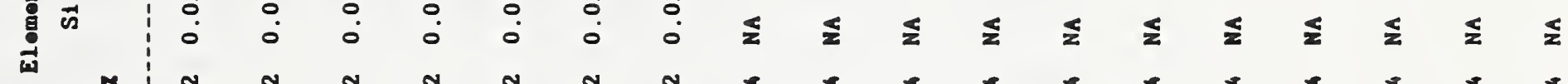

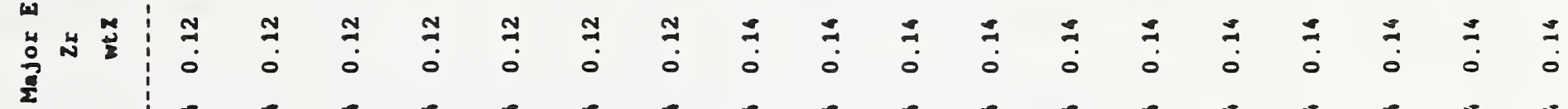

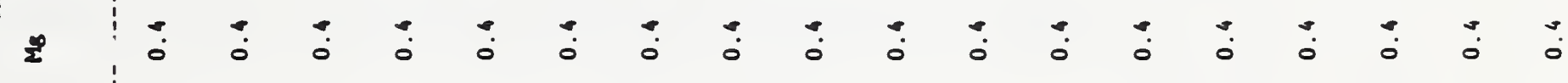

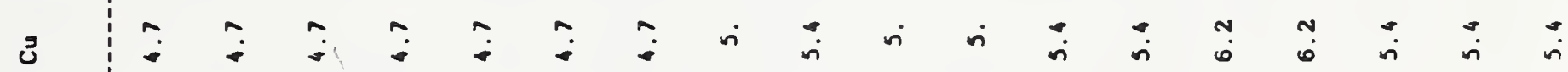

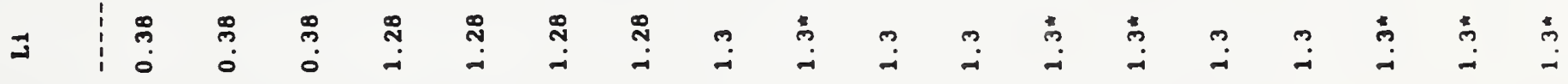

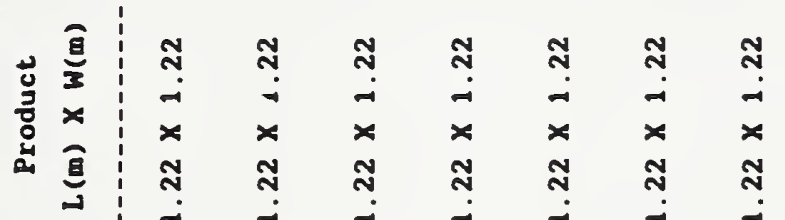

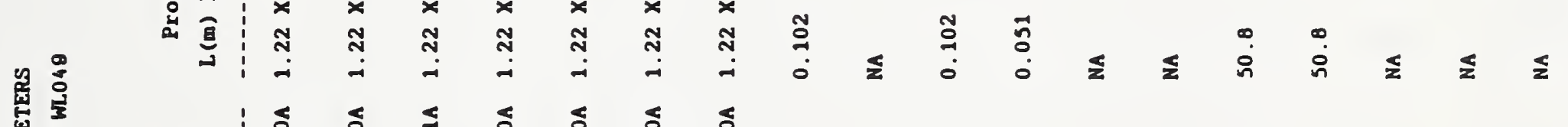

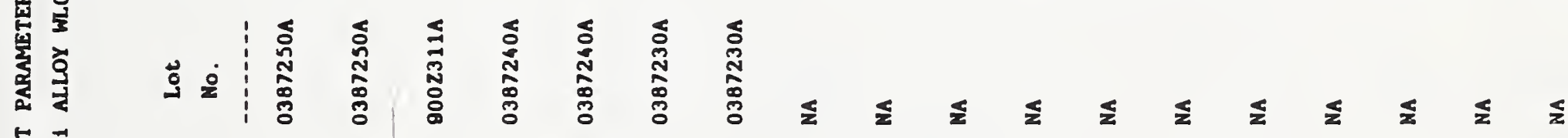

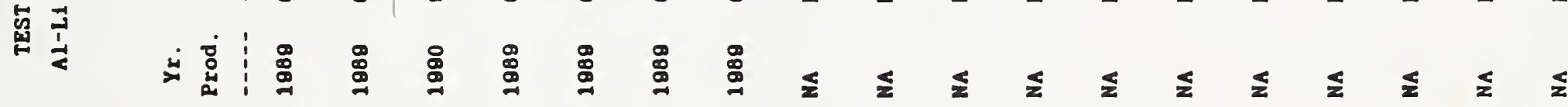

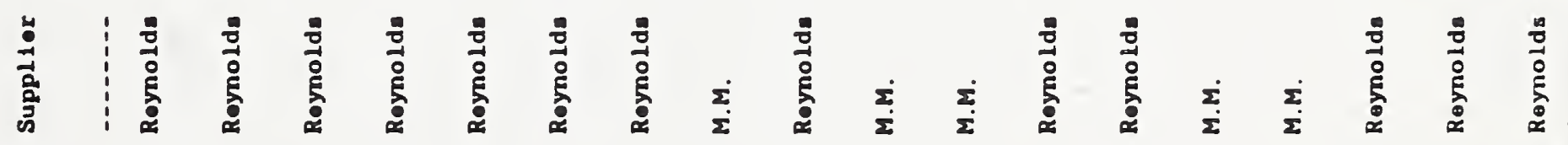

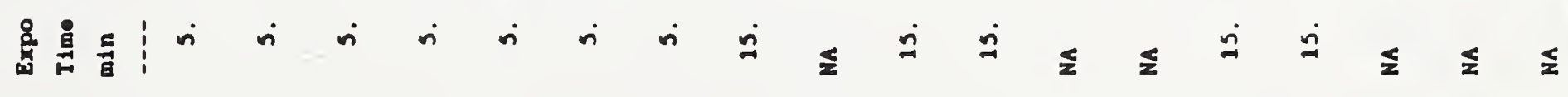

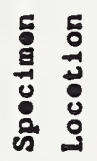

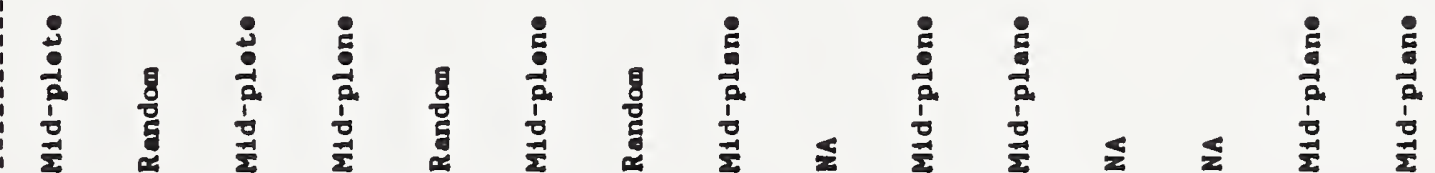

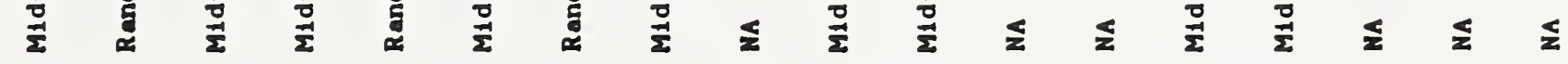

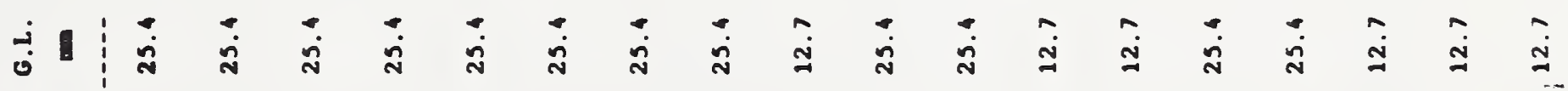

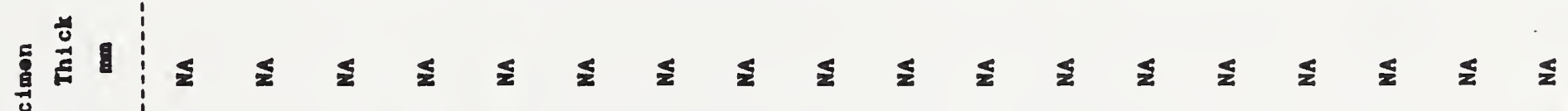

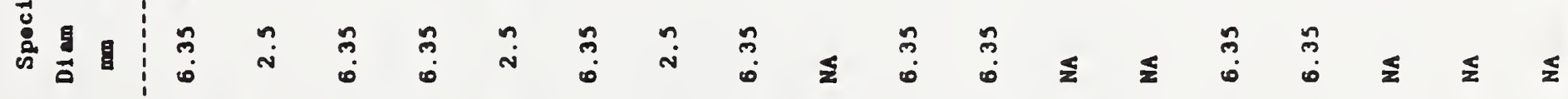

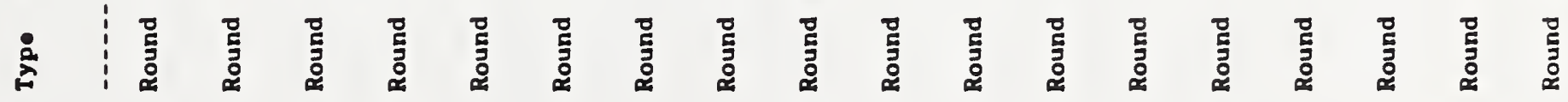

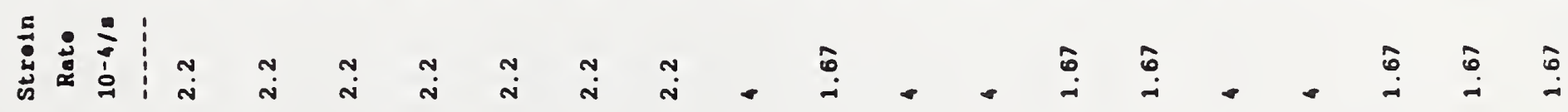

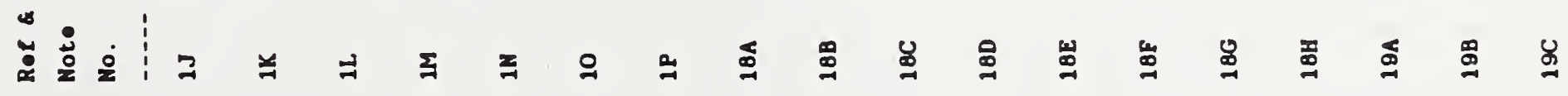




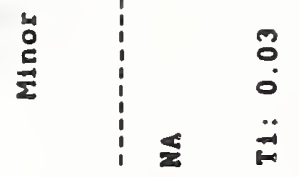

\begin{tabular}{l|ll} 
& 0 & 0
\end{tabular}

i $1 \leq$

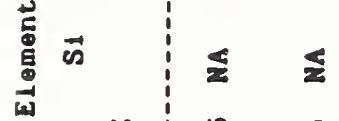

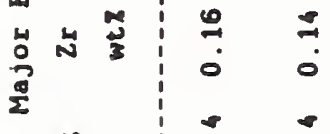

2

$3 \quad \stackrel{0}{\circ}$

$\exists \stackrel{9}{-}$

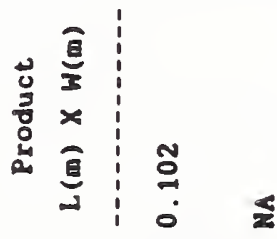

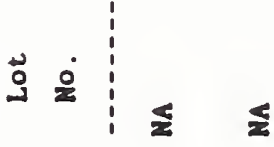

这宫

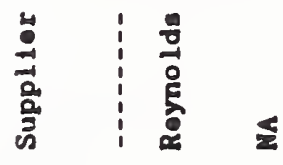

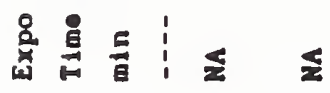

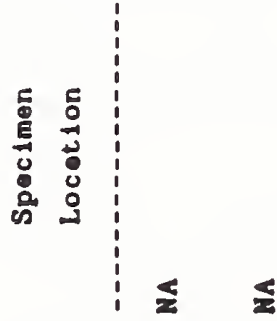

过目

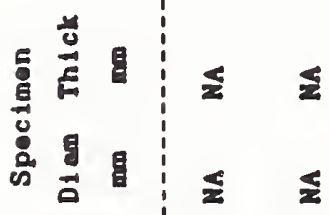

$\begin{array}{l:l}\dot{2} & \leq\end{array}$

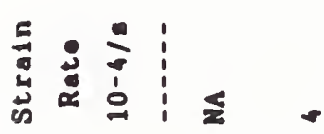

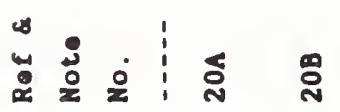


Comments from the Al-Li Alloy WL049 Test Parameter Table

\section{Reference and}

Note Number

18B--Reported composition is based on nominal values.

18E--Reported composition is based on nominal values.

18F--Reported composition is based on nominal values.

19A-C--Reported composition is based on nominal values. 
ULTIMATE TENSILE STRENGTH, ksi

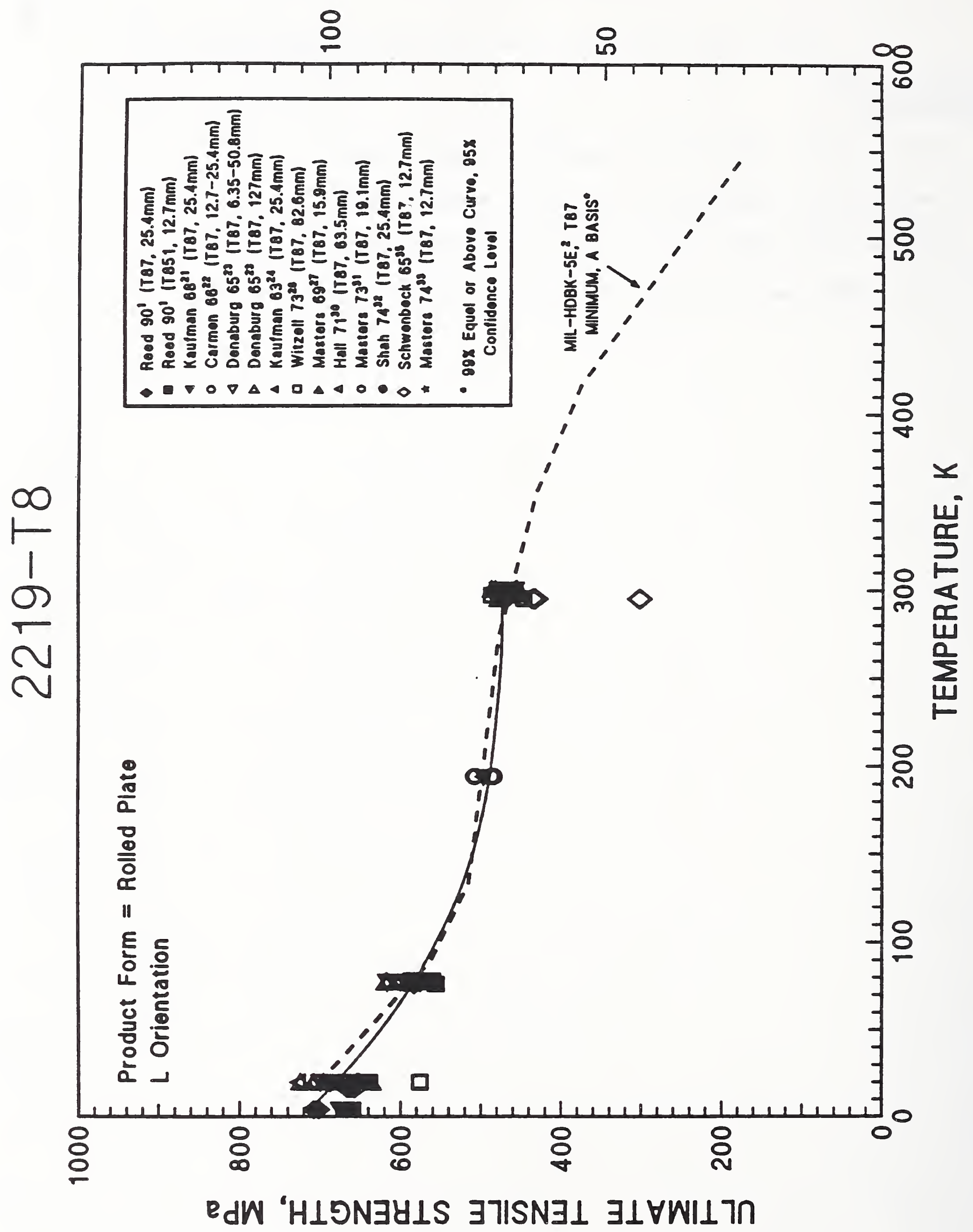


TENSILE YIELD STRENGTH, ksi

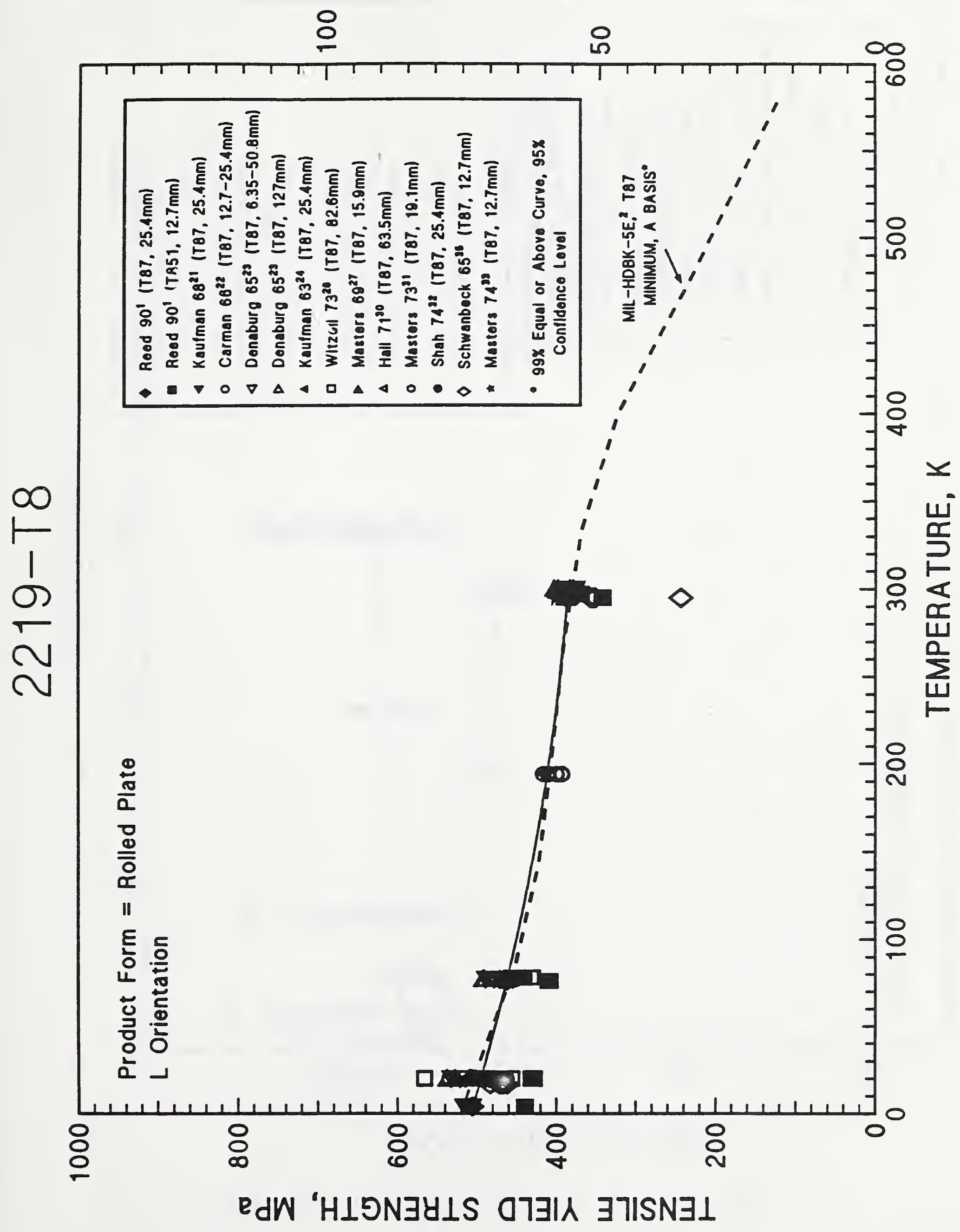




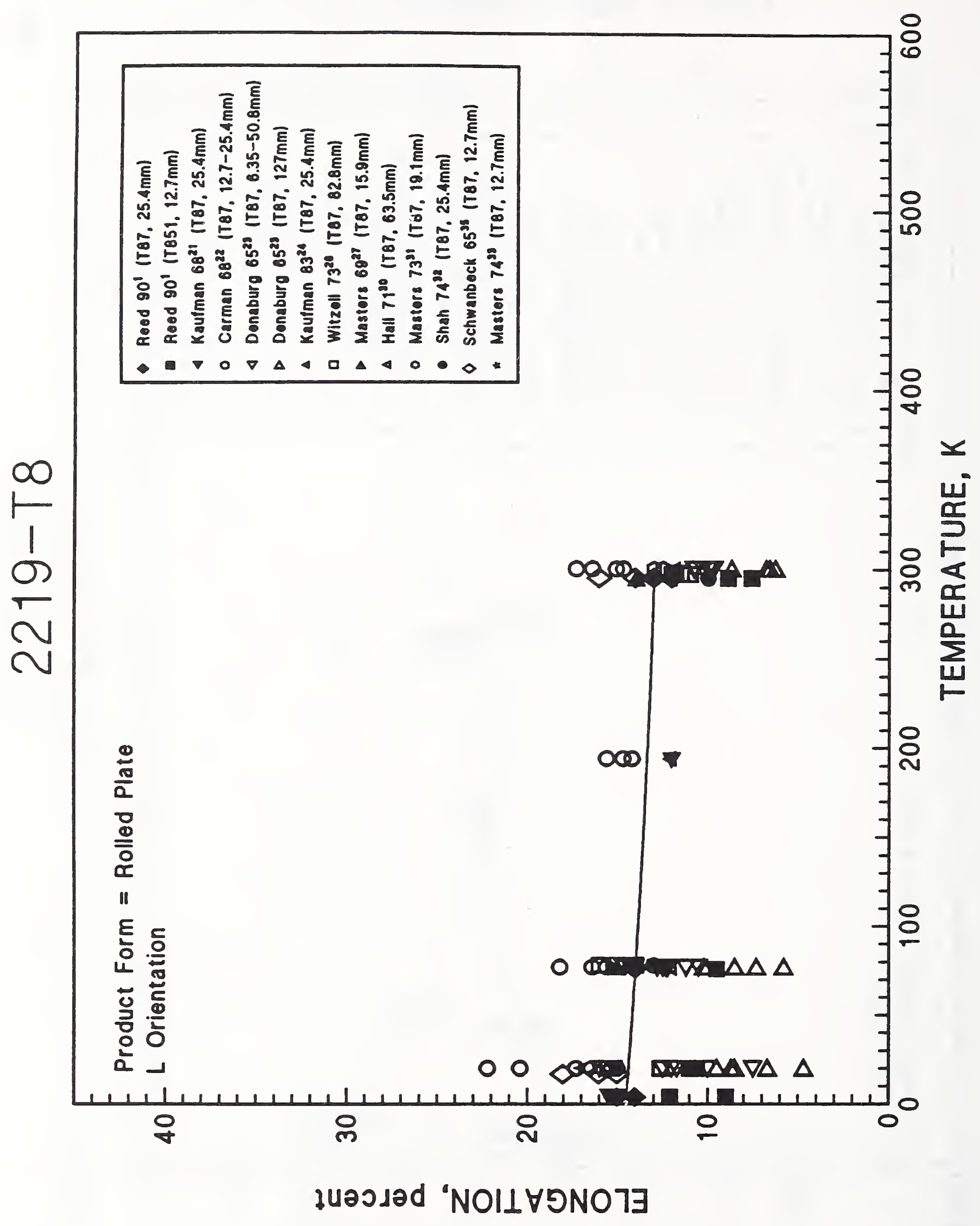


ULTIMATE TENSILE STRENGTH, ksi

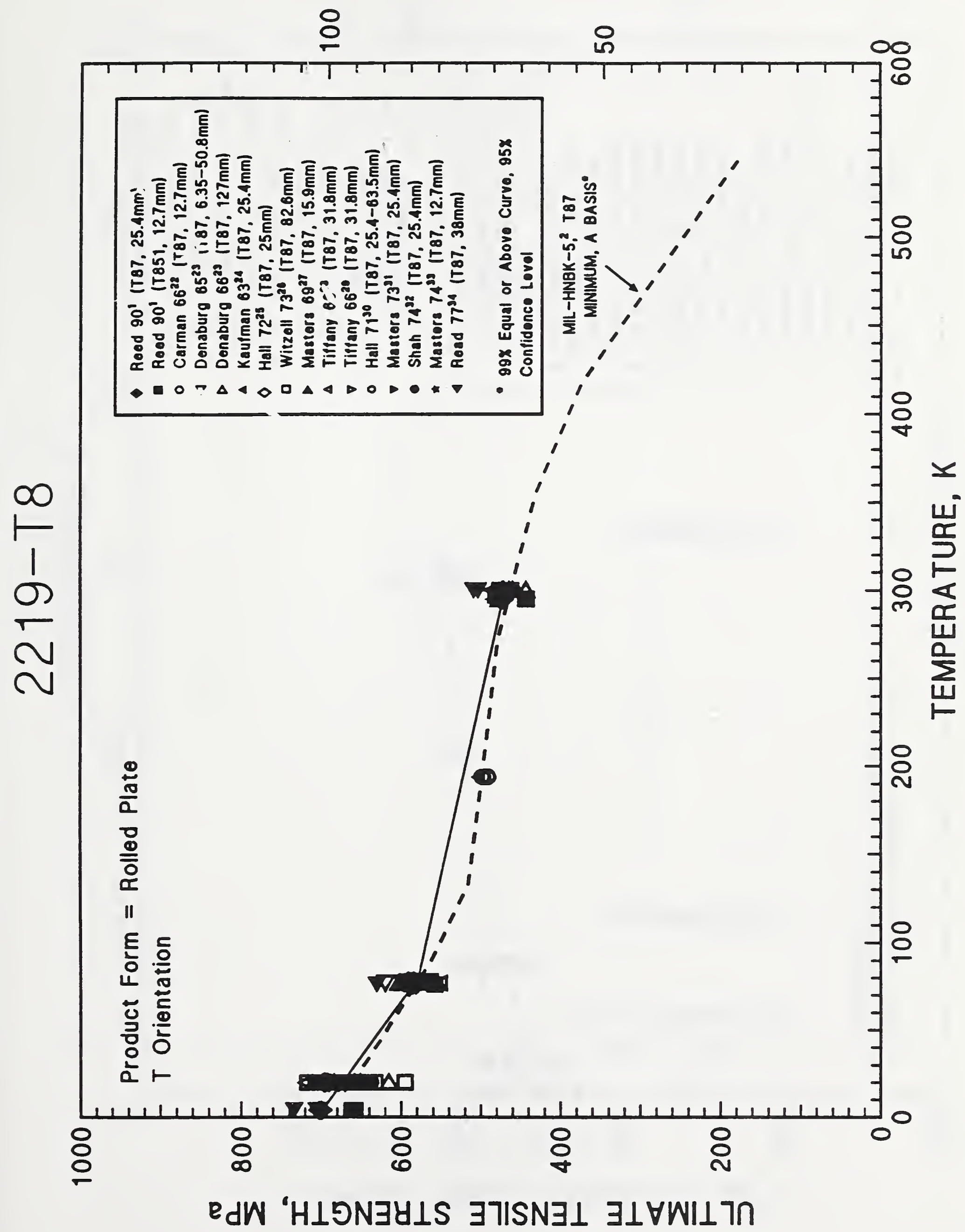


TENSILE YIELD STRENGTH, ksi

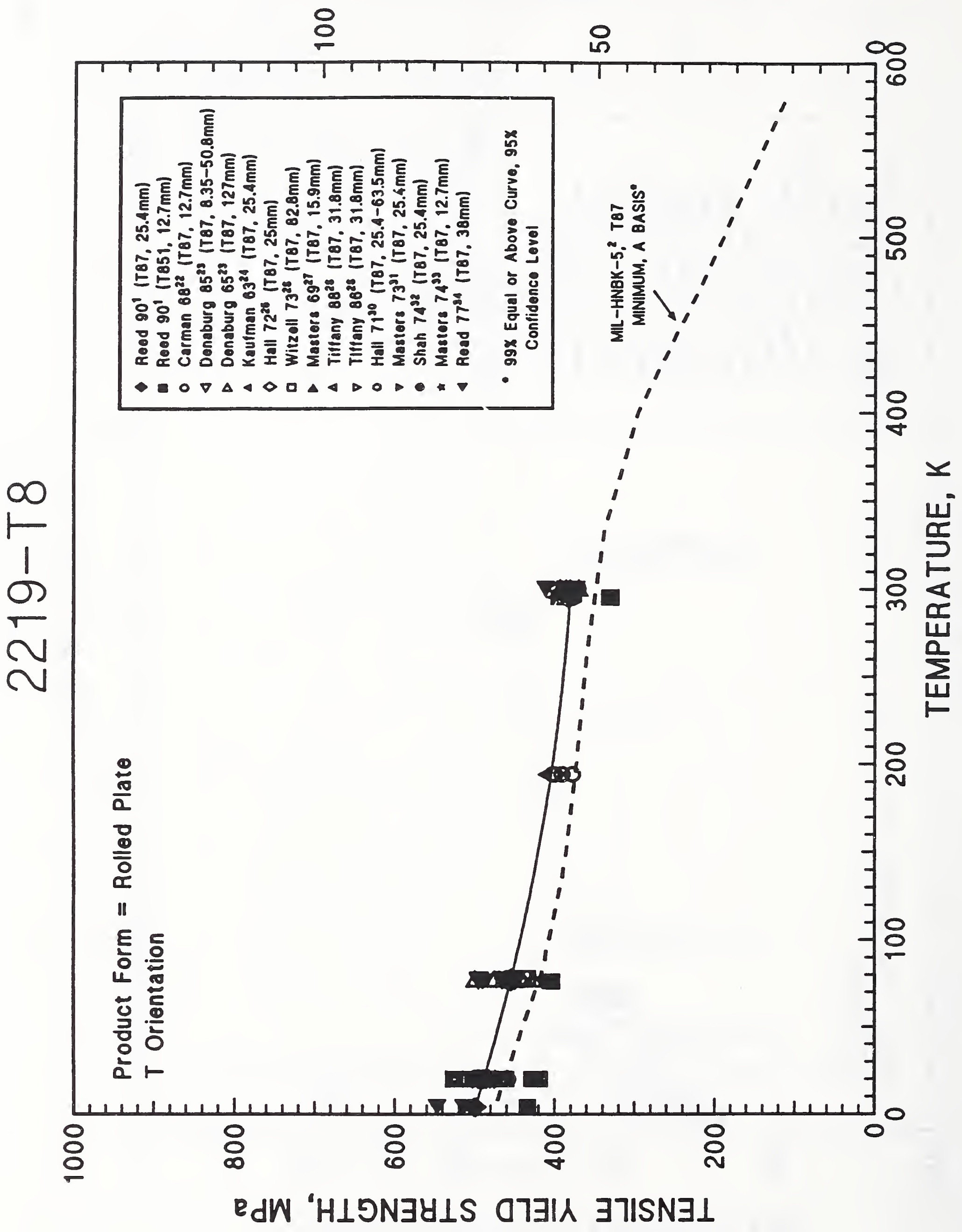




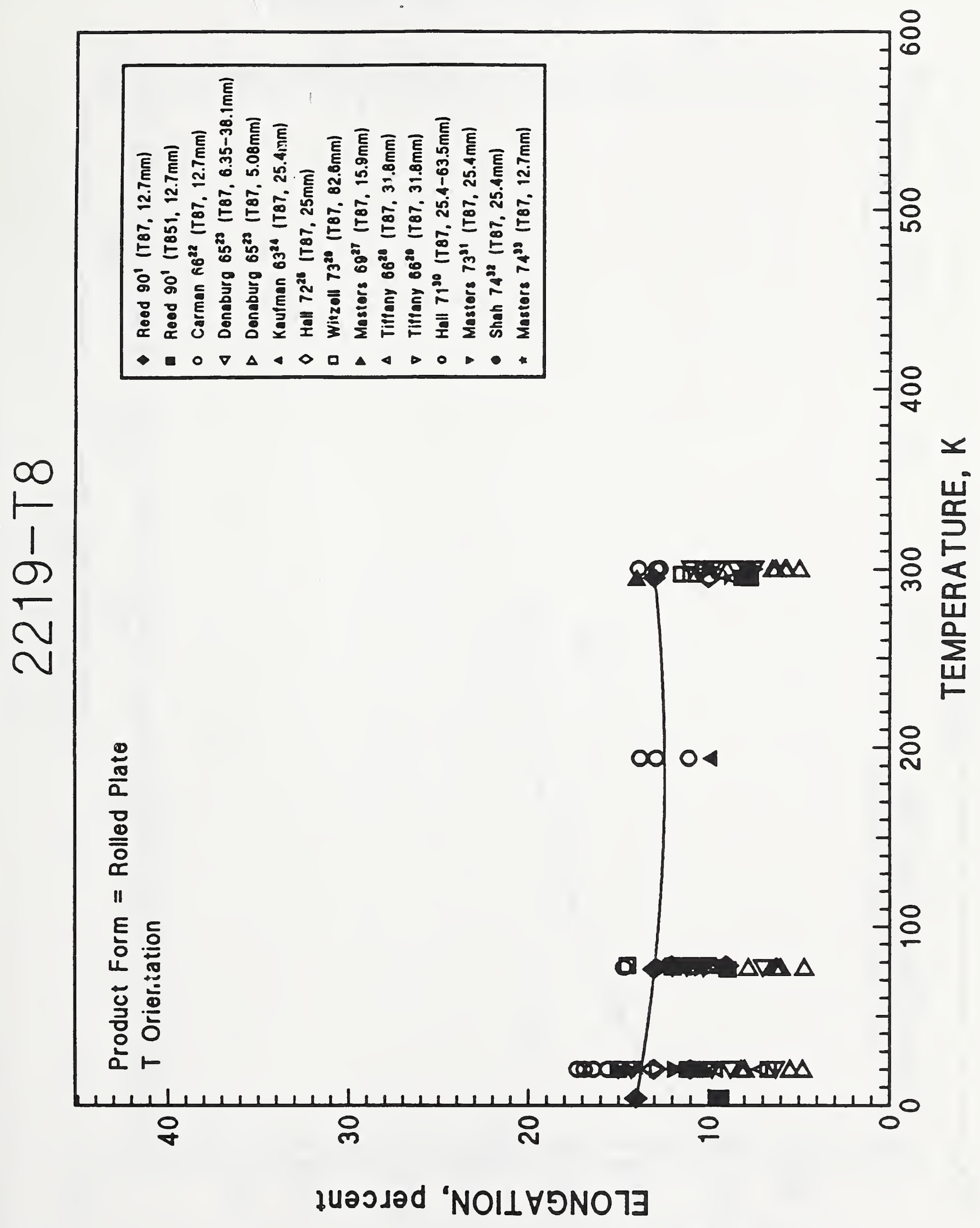


ULTIMATE TENSILE STRENGTH, ksi

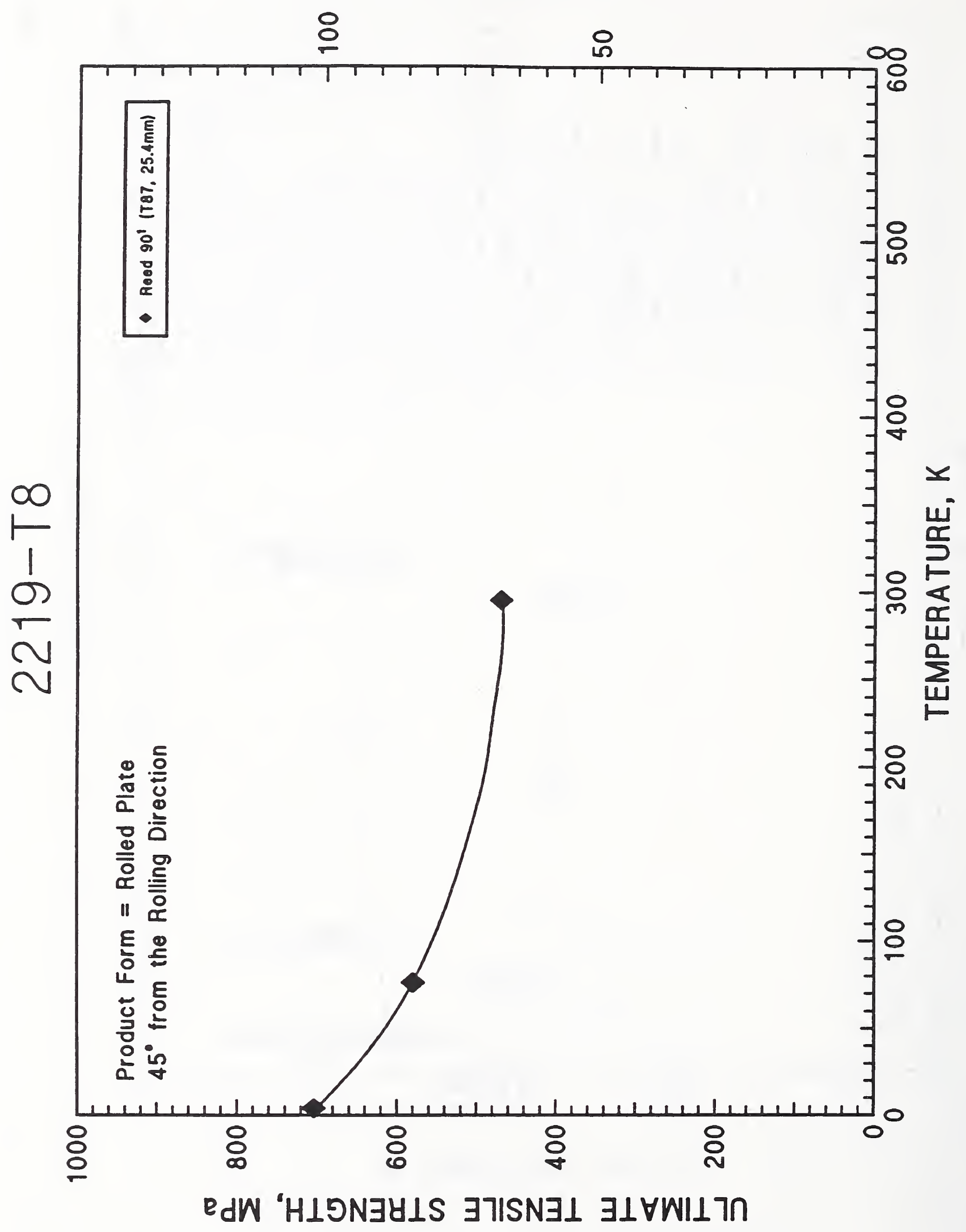


TENSILE YIELD STRENGTH, $k s i$

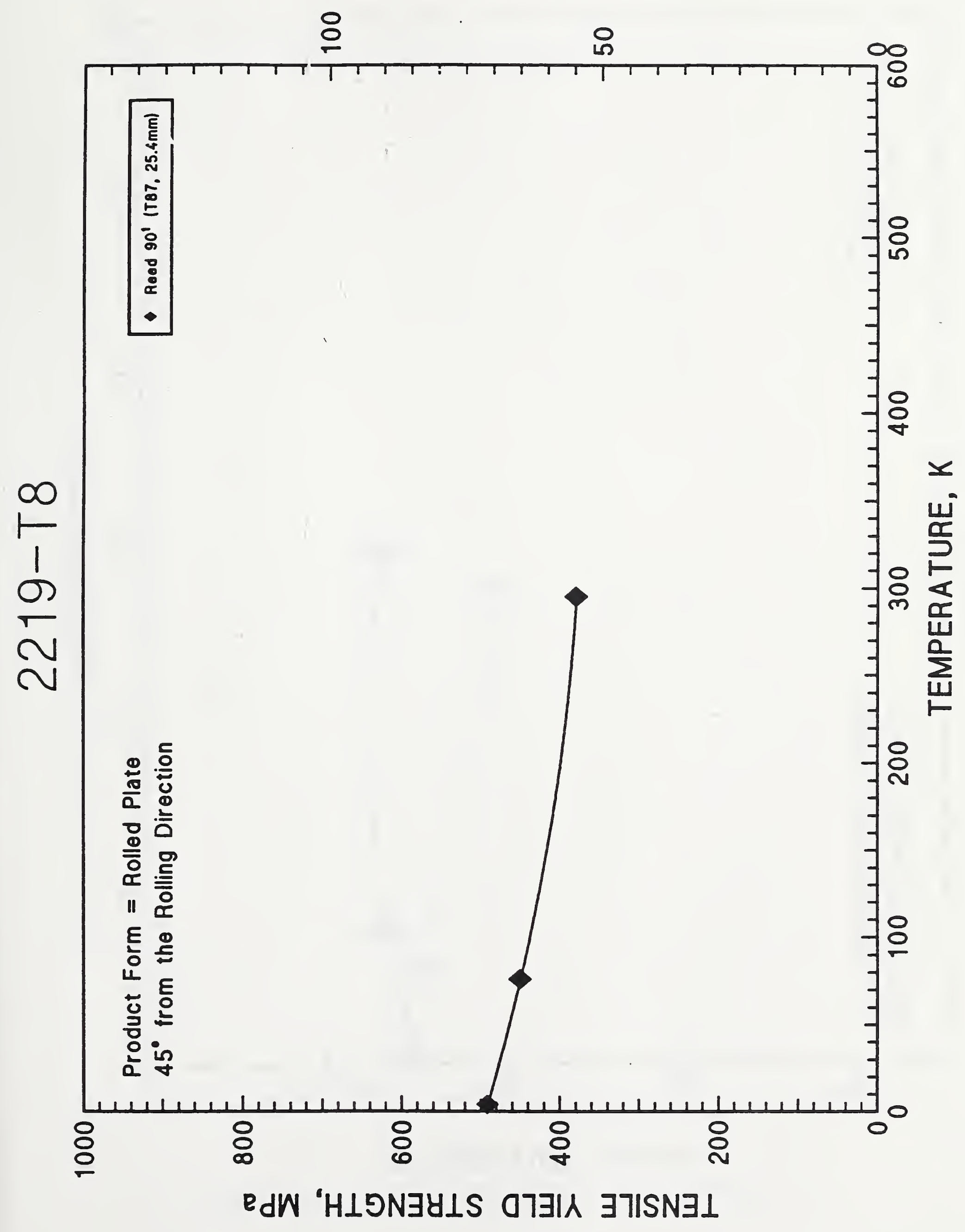




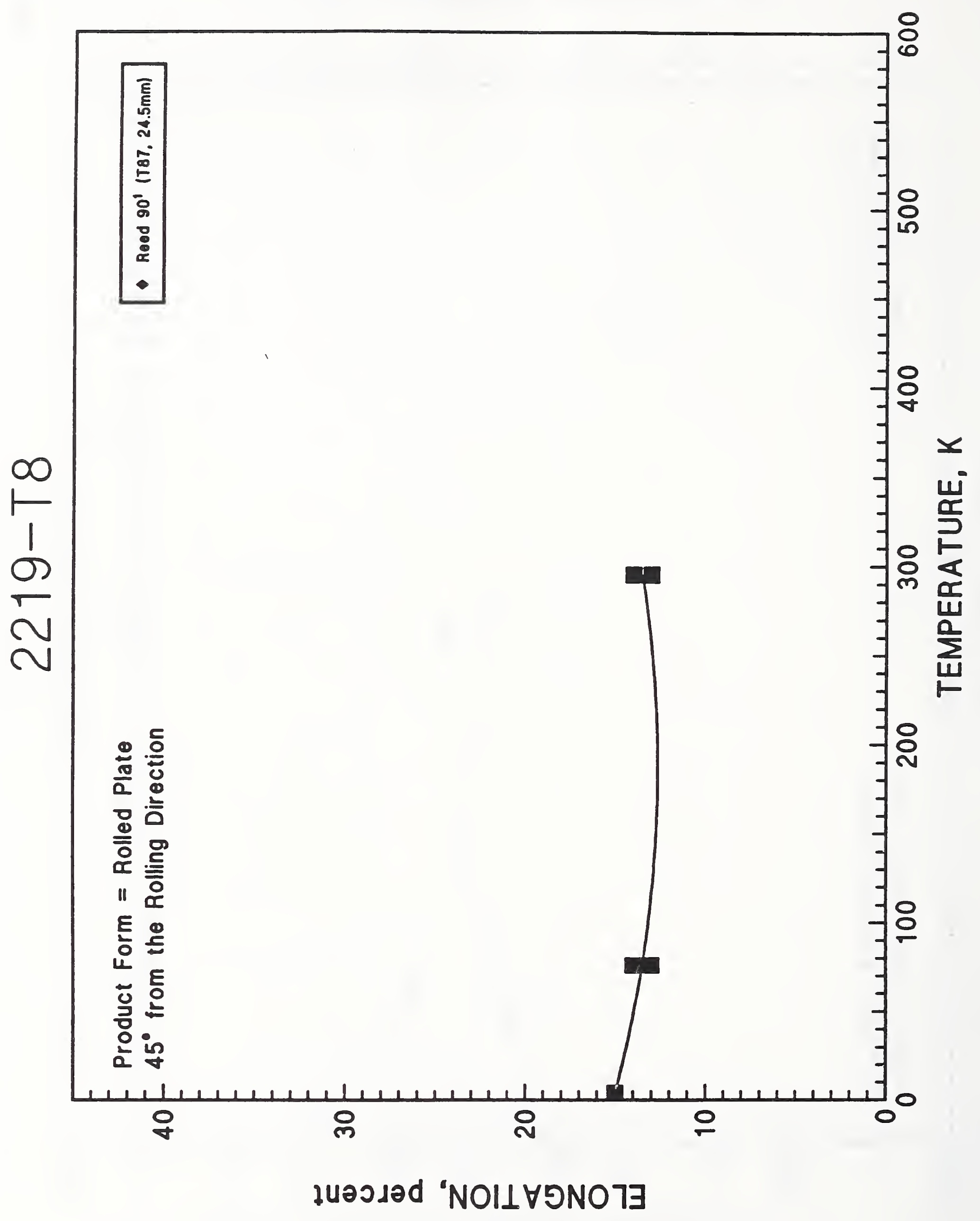


ULTIMATE TENSILE STRENGTH, ksi

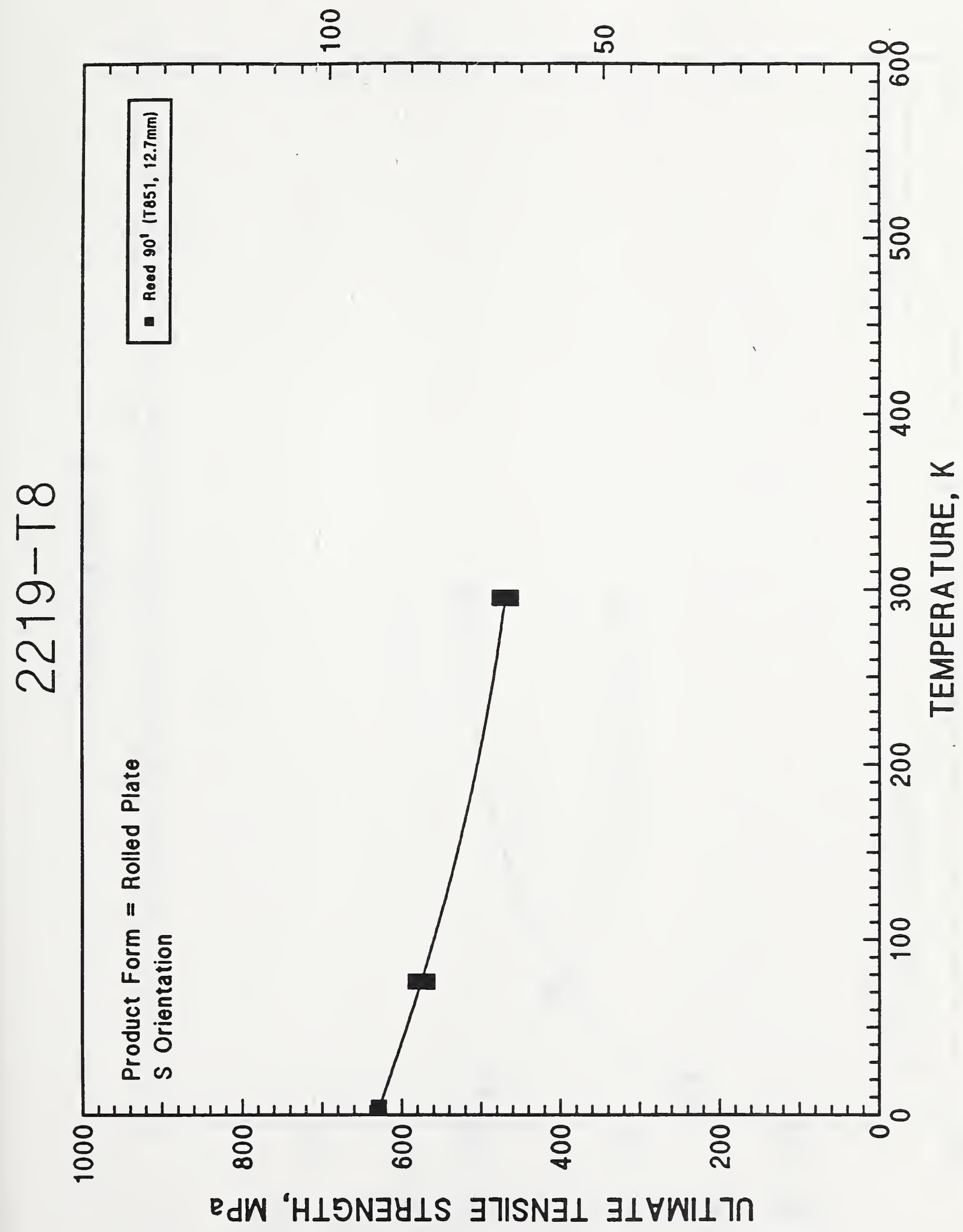




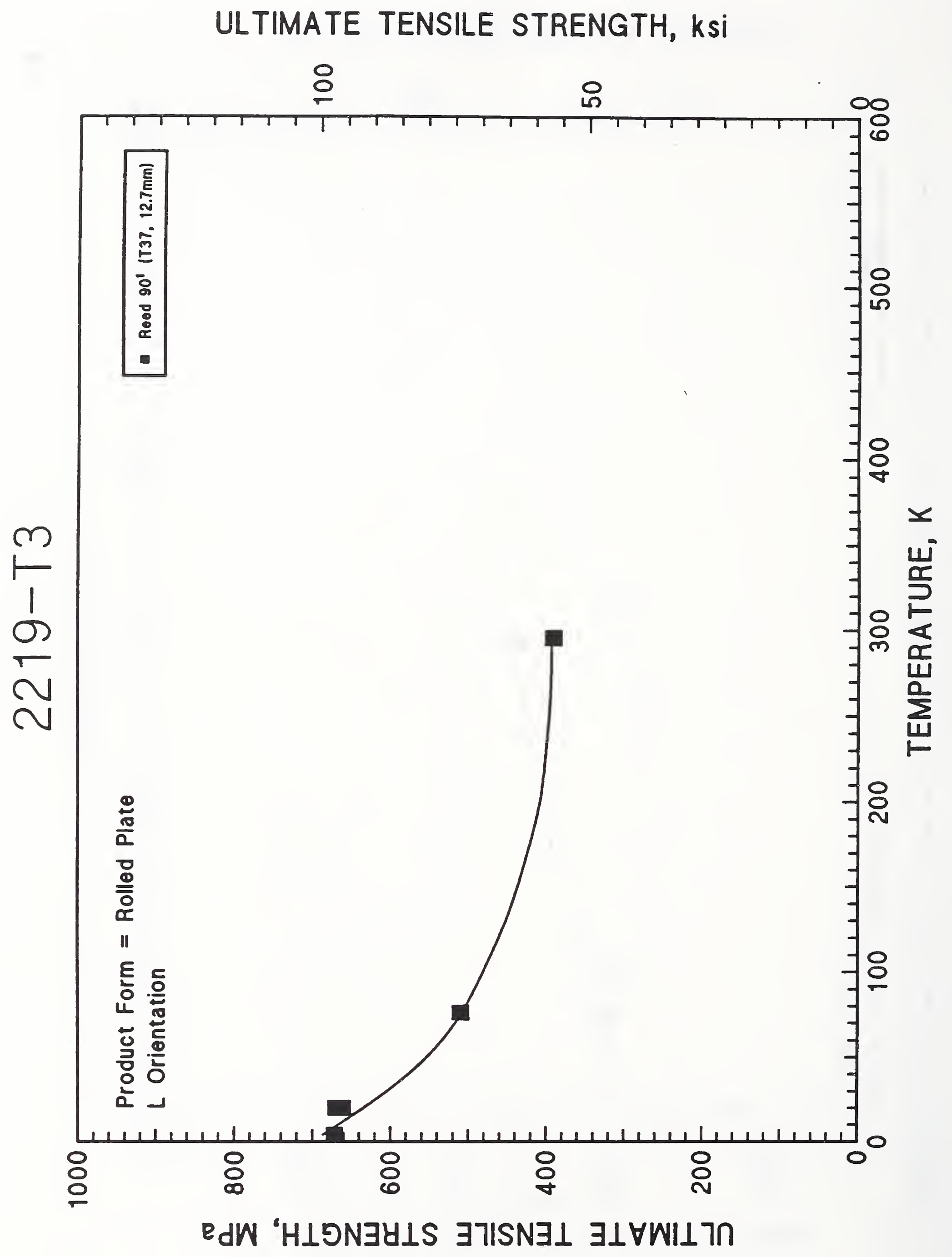


TENSILE YIELD STRENGTH, ksi

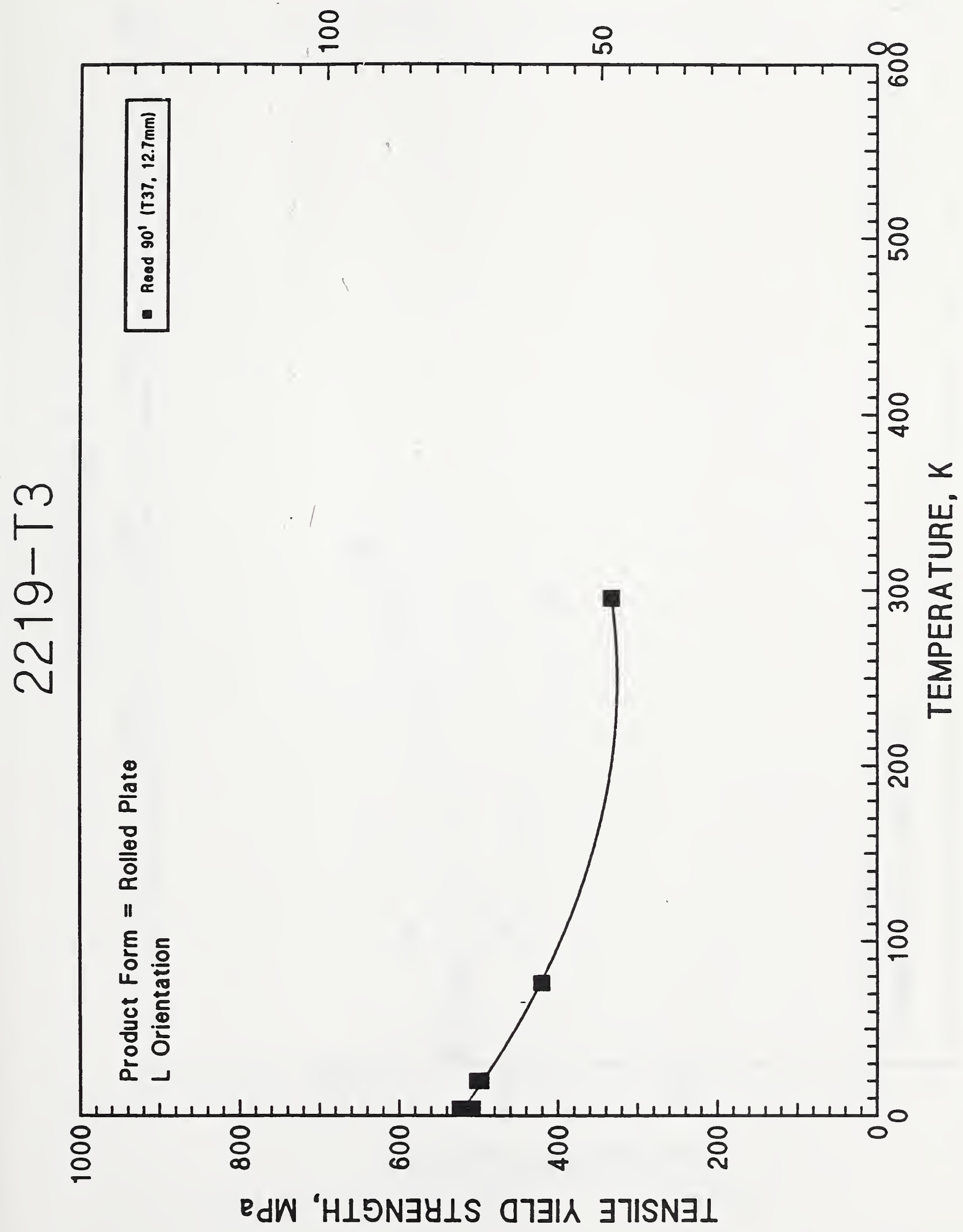




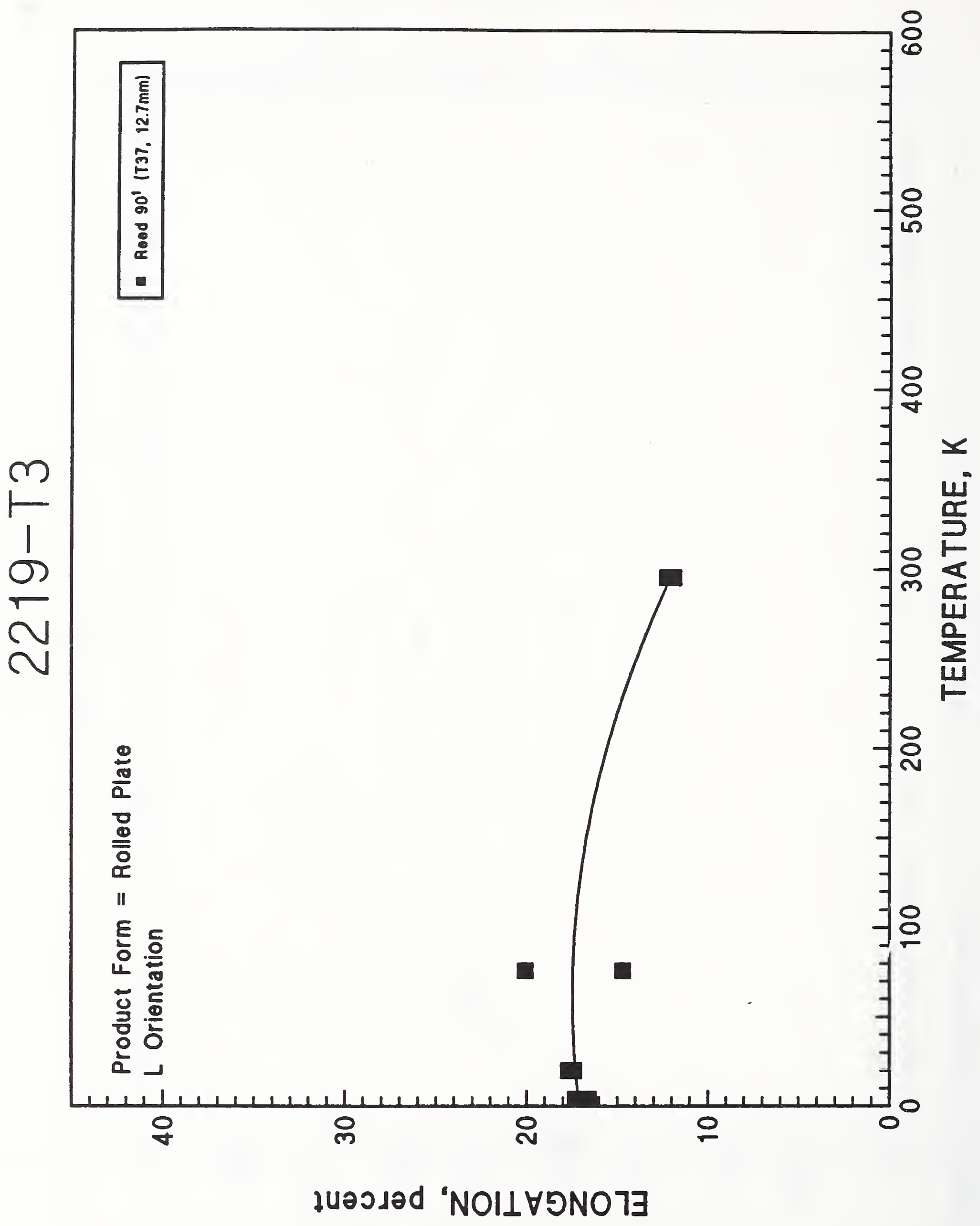


ULTIMATE TENSILE STRENGTH, ksi

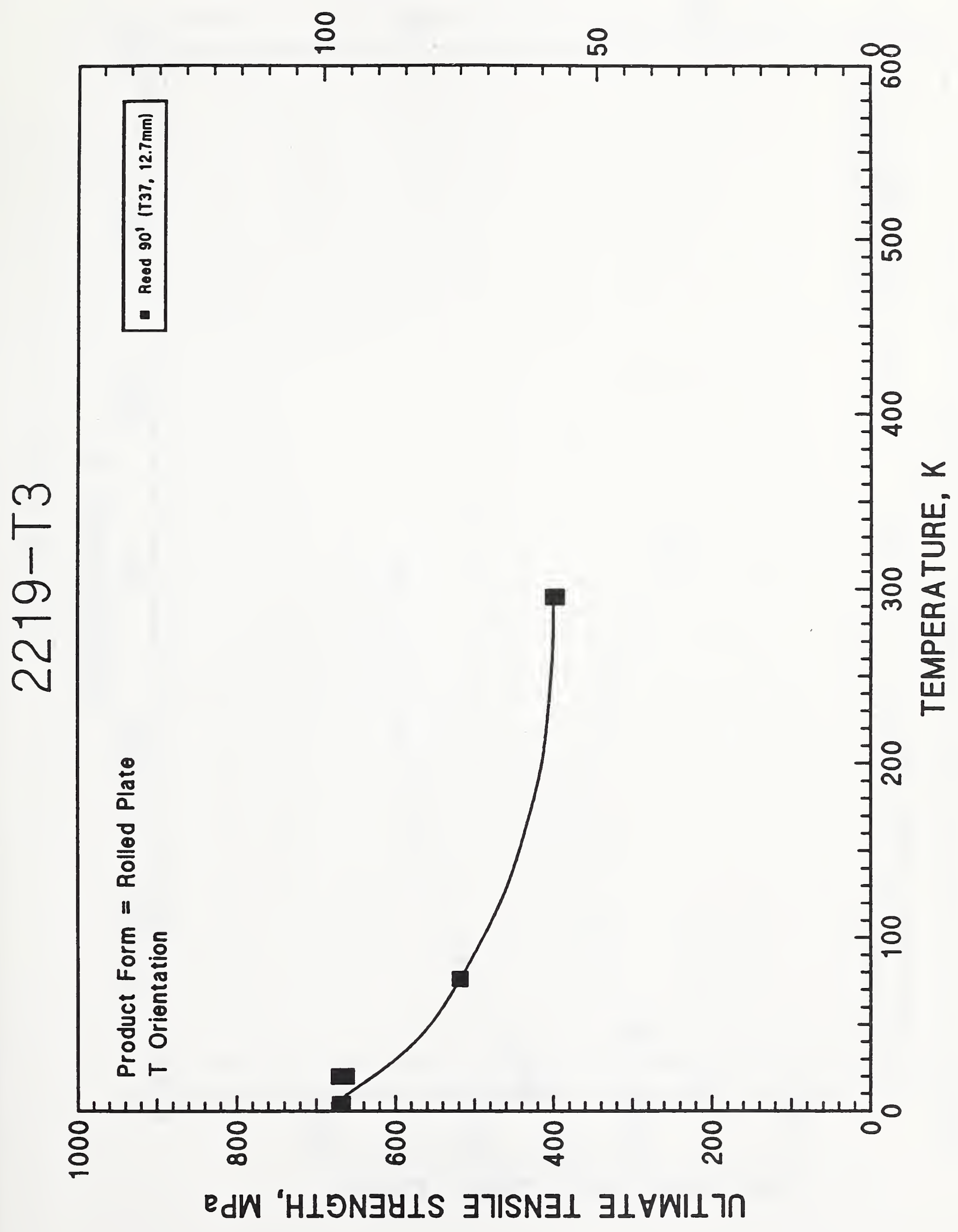


TENSILE YIELD STRENGTH, ksi

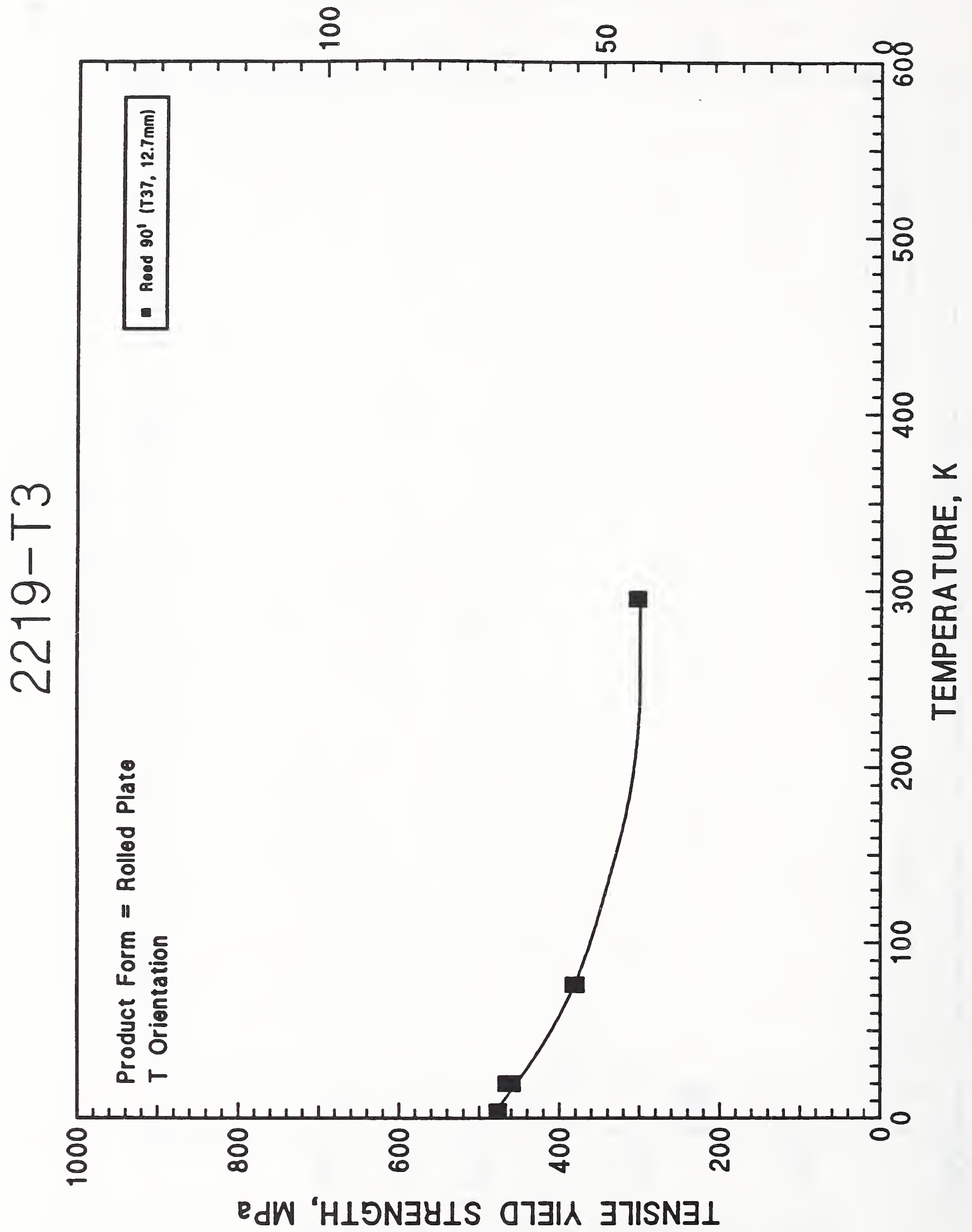




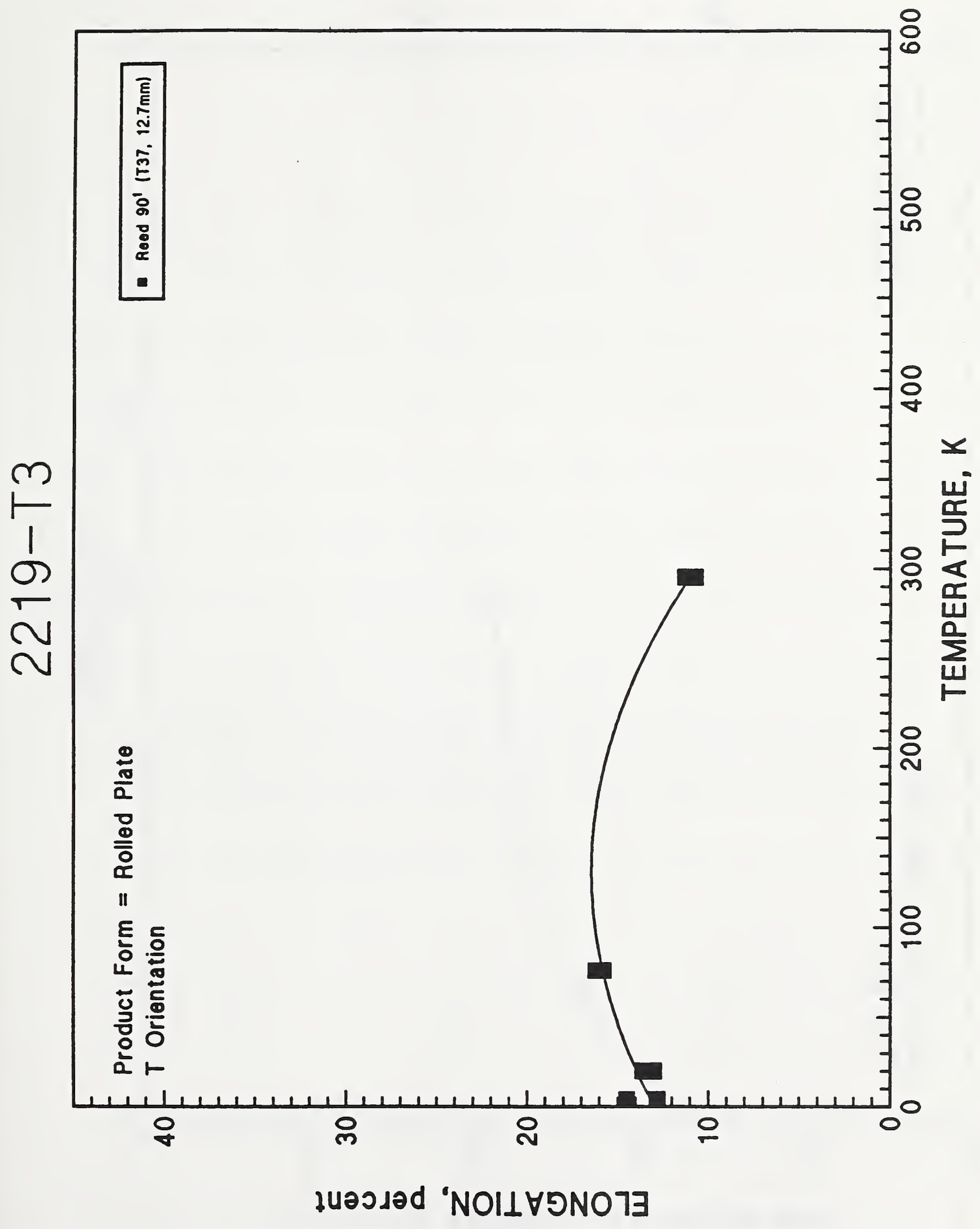


ULTIMATE TENSILE STRENGTH, ksi

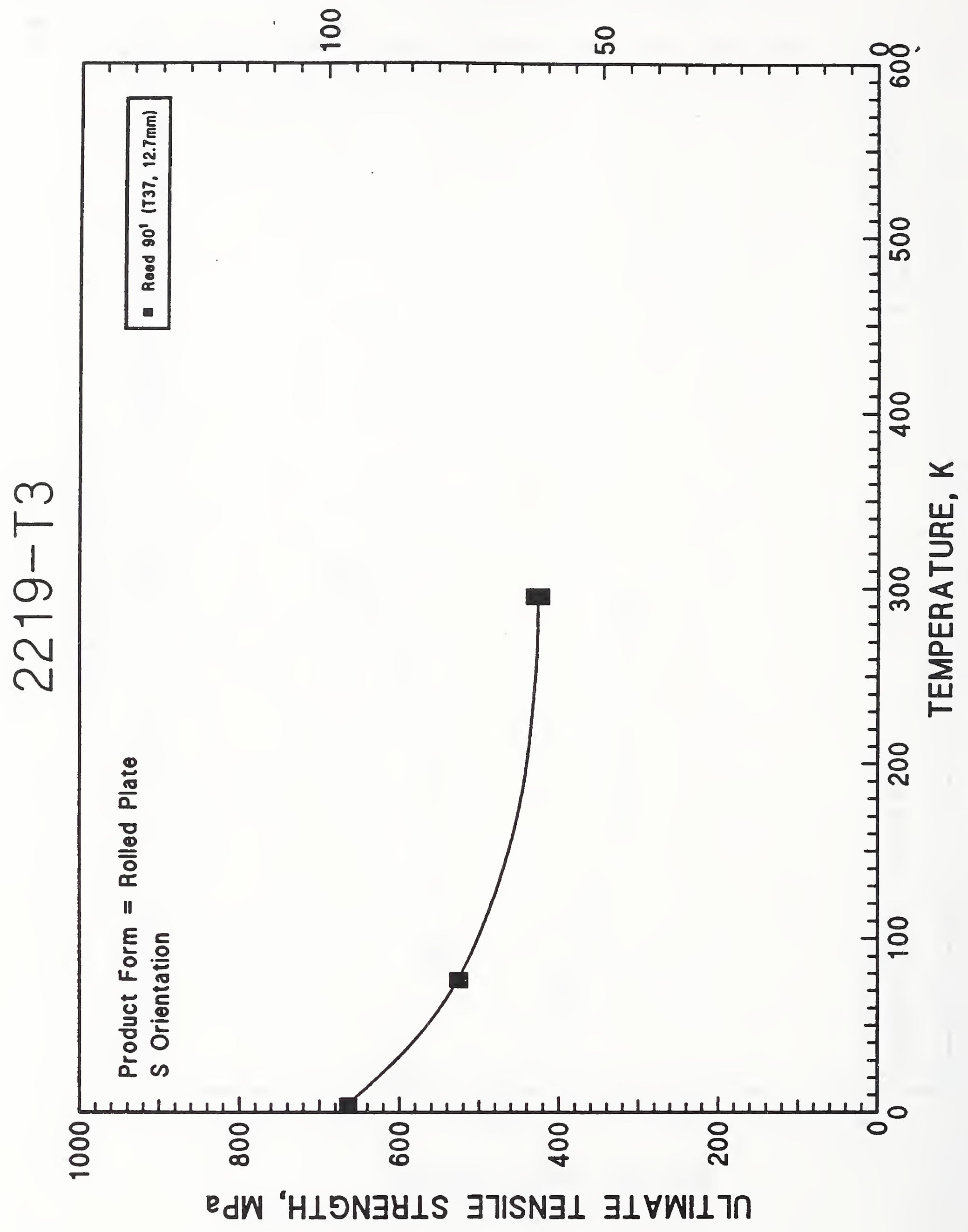




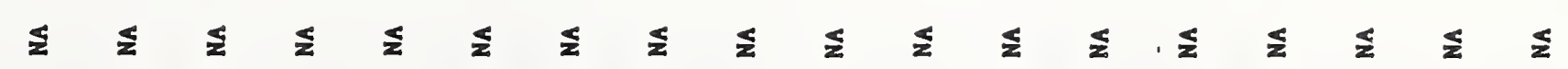

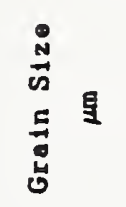

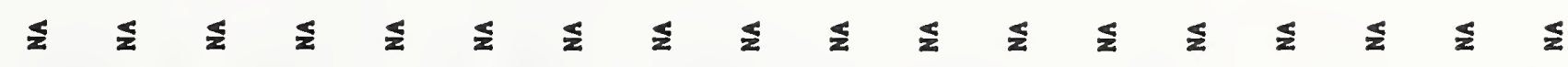
戛尊

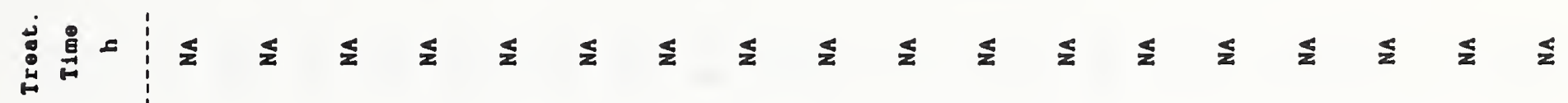

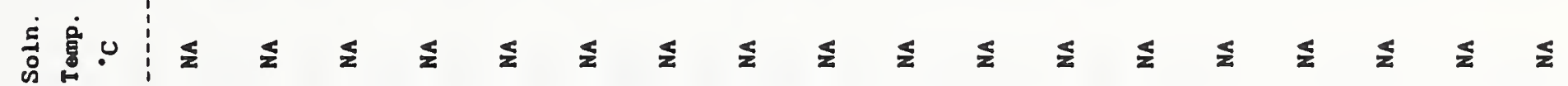

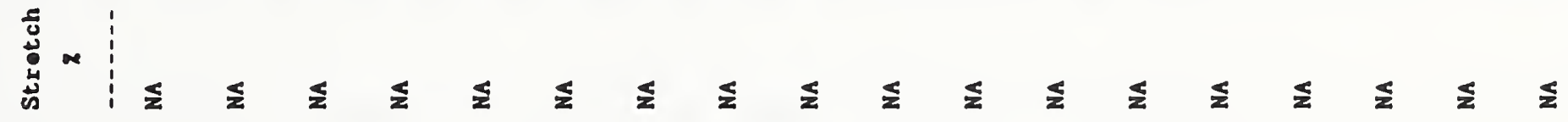
忢

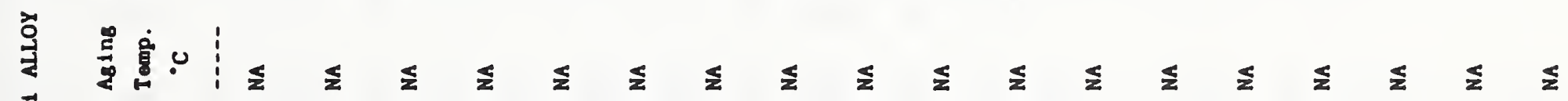
$\overrightarrow{3}$

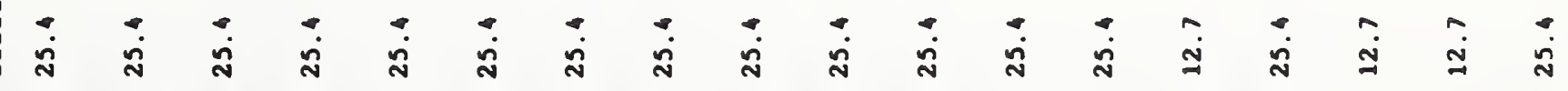

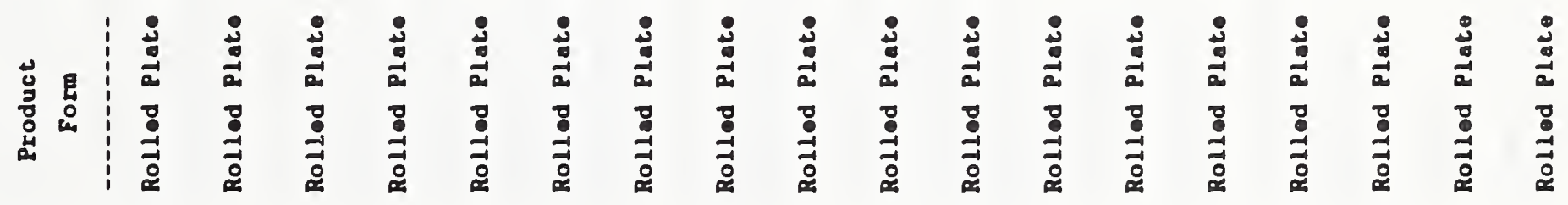
兽

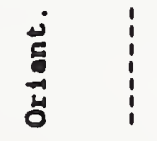

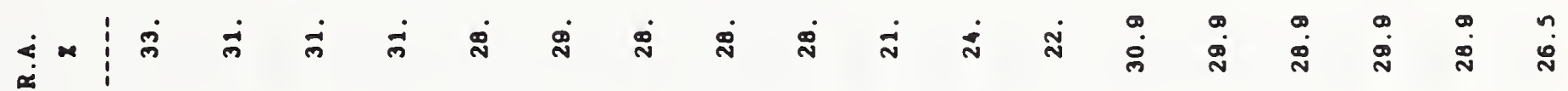

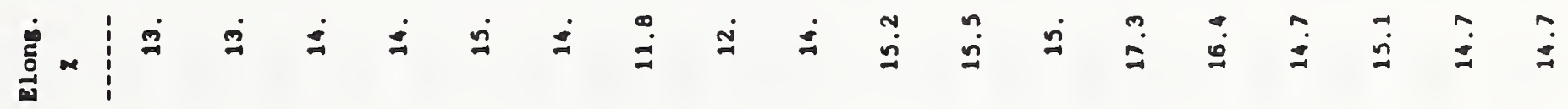
வ்

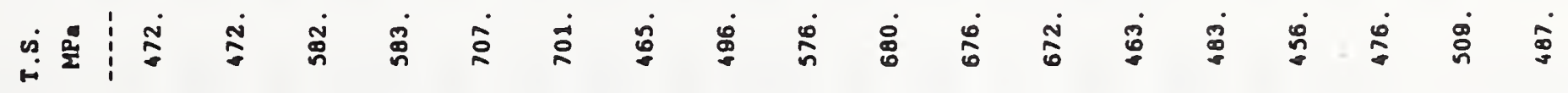

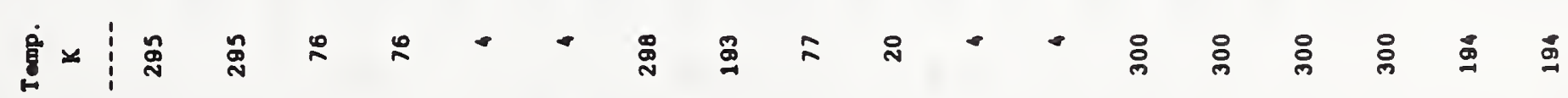

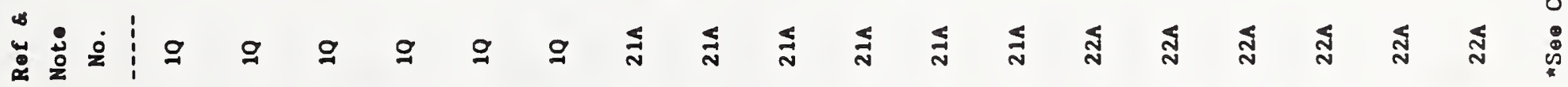




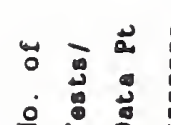

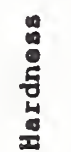

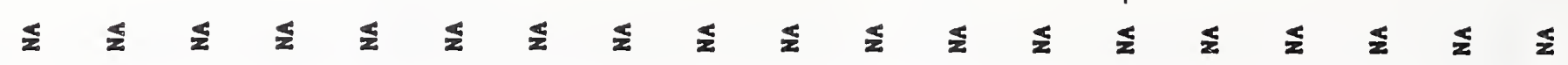

总

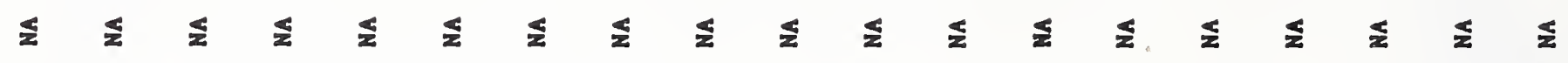
总总 总夏上

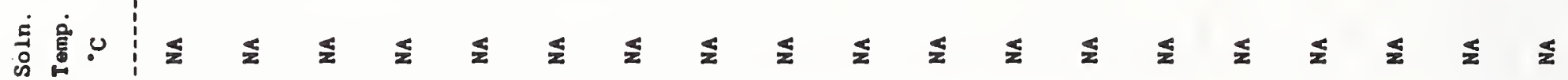
焉 兽兽: 递亶:

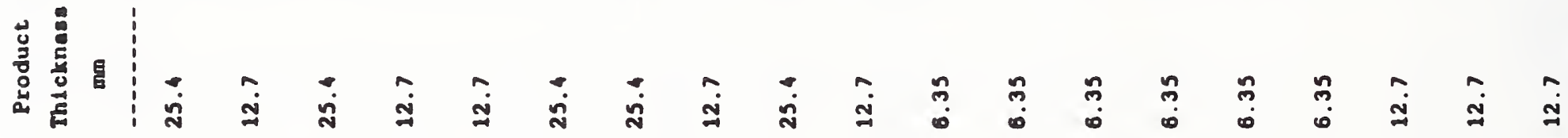

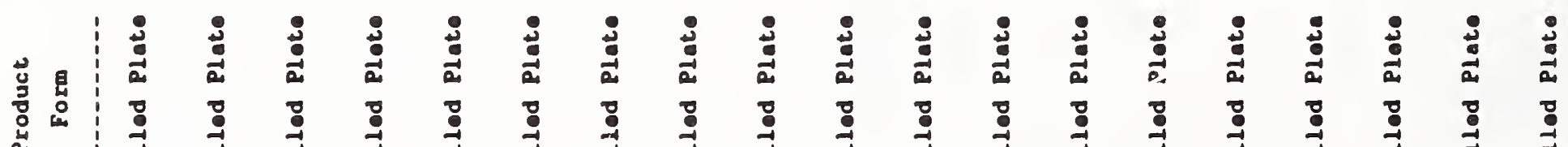

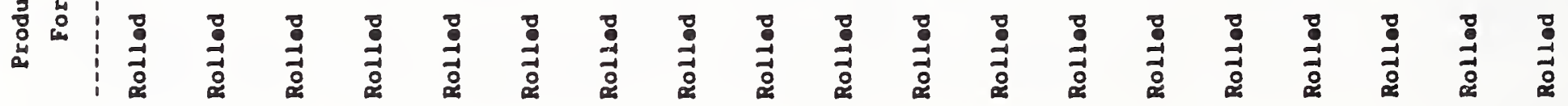
兽 $\dot{\underline{g}}$

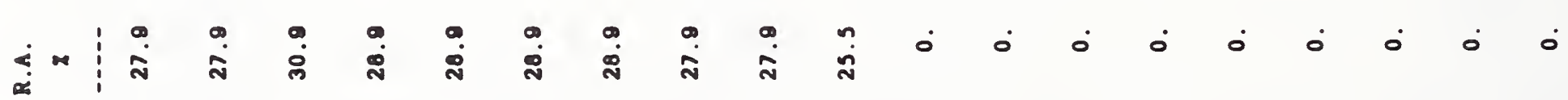

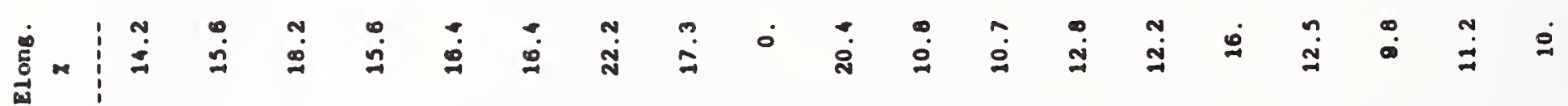
نூ نั

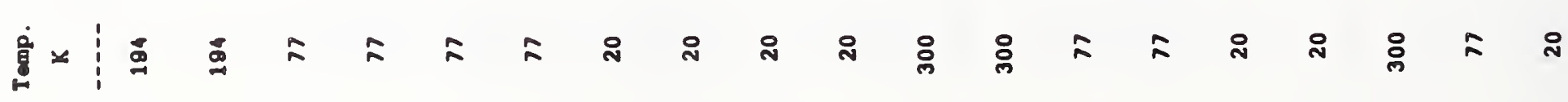

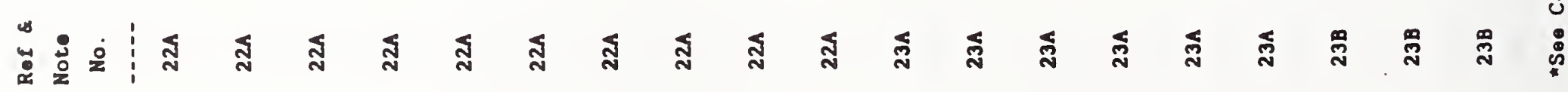




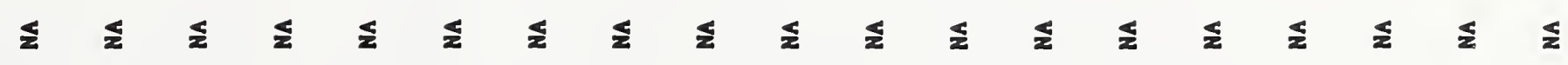
递㝘 遭晃= 官密. 密苛 退首上

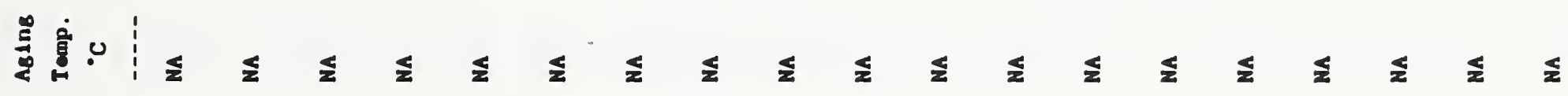

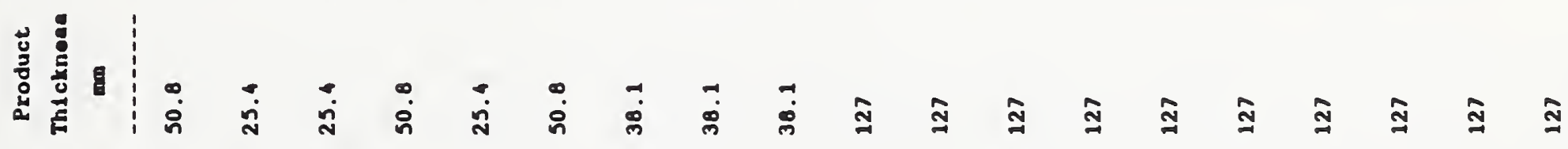

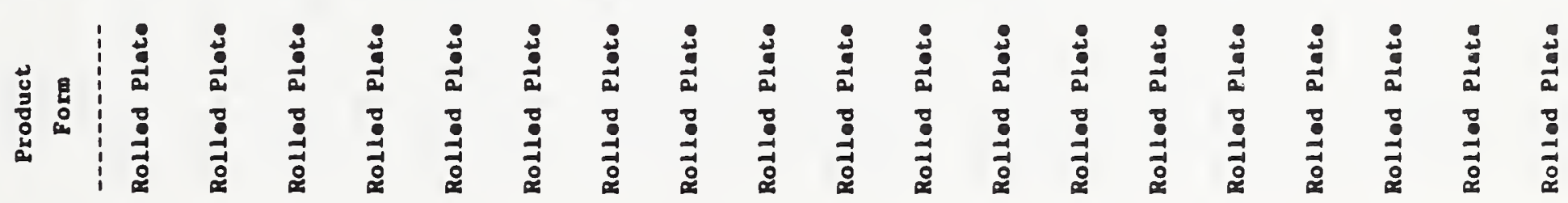
兽 苔

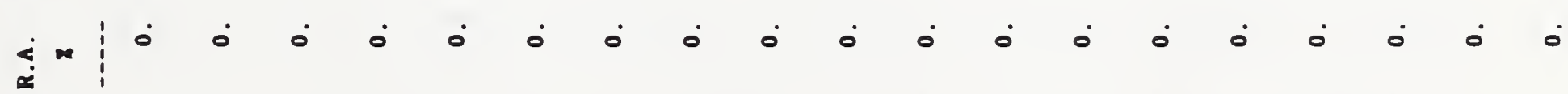
产 近造 ن 酱

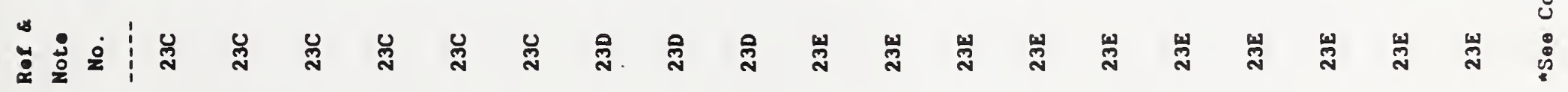




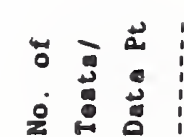

흄

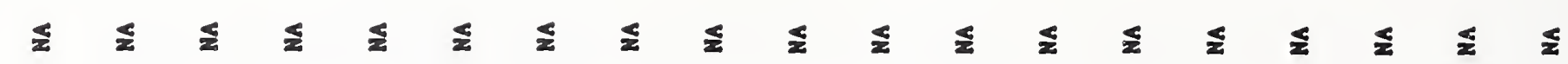

遂

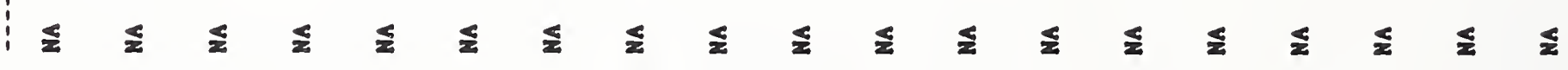

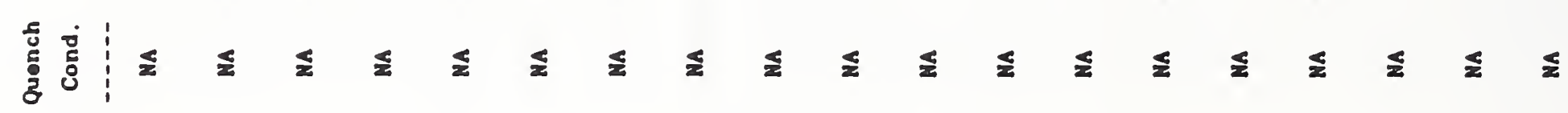

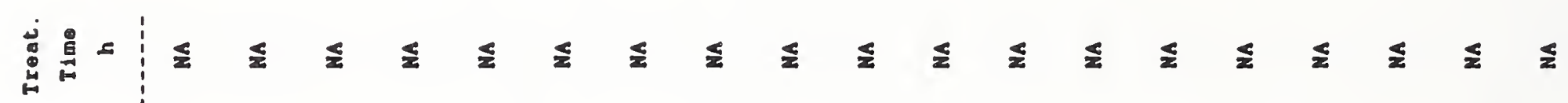

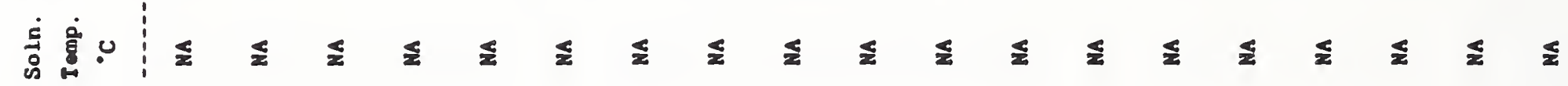

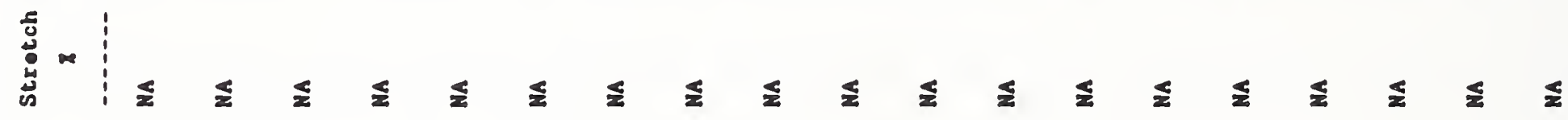
道兽:

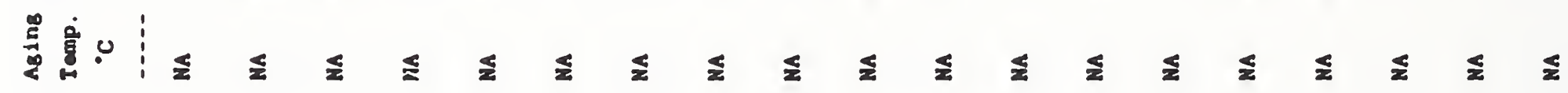

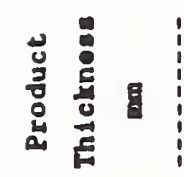

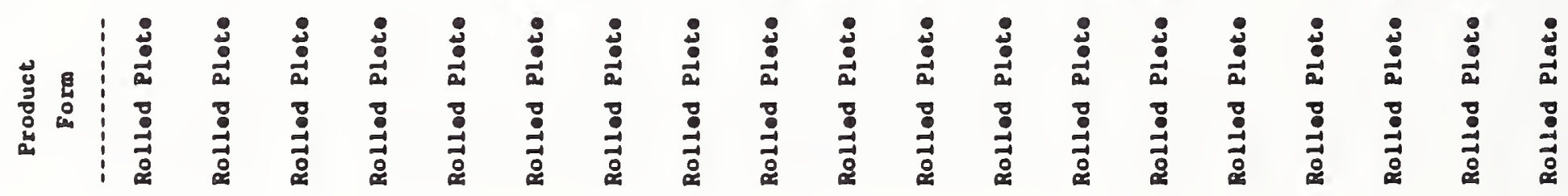
兽

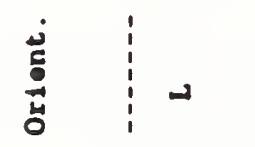

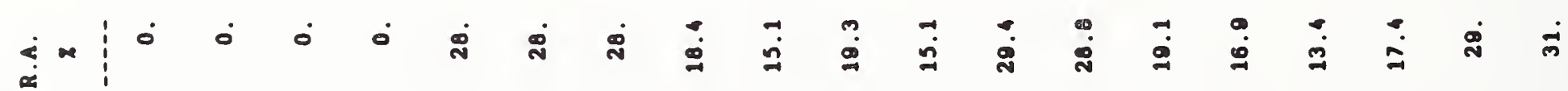

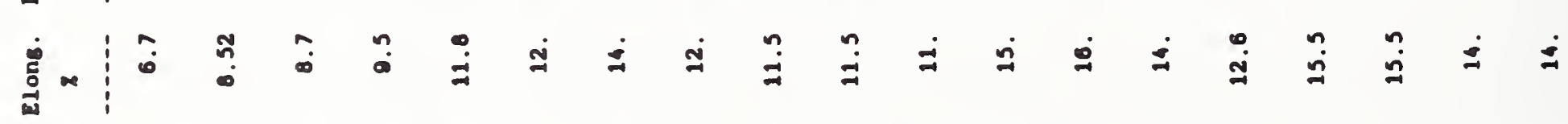
近

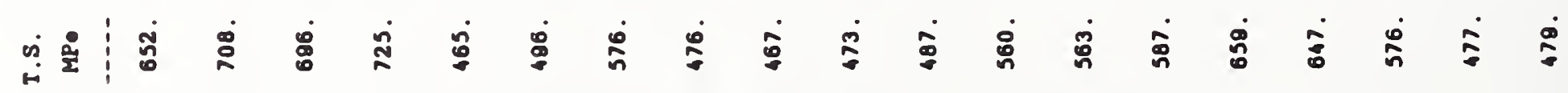
畺ะ

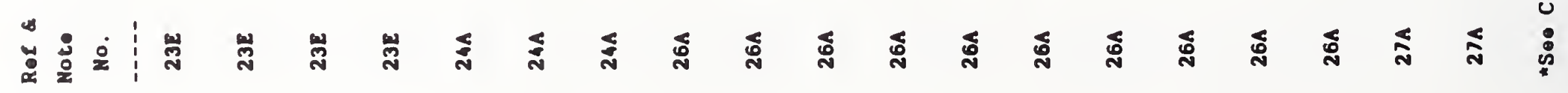




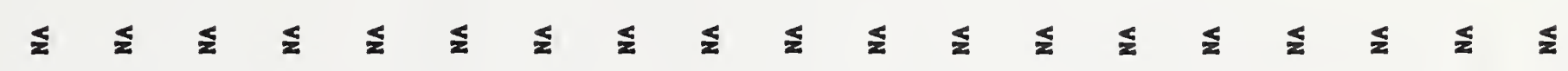

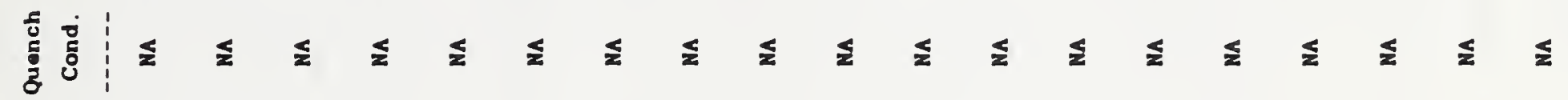

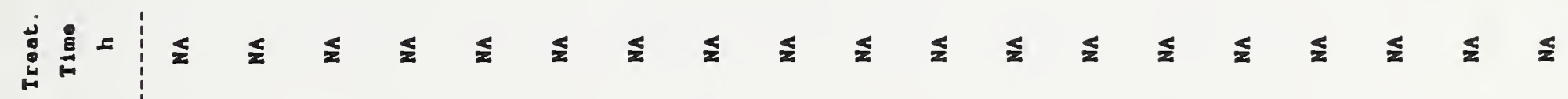

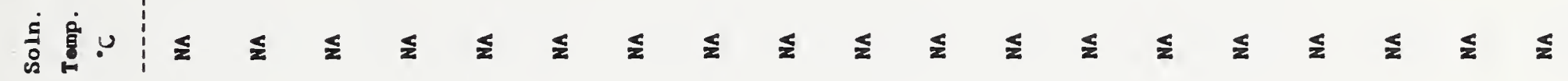

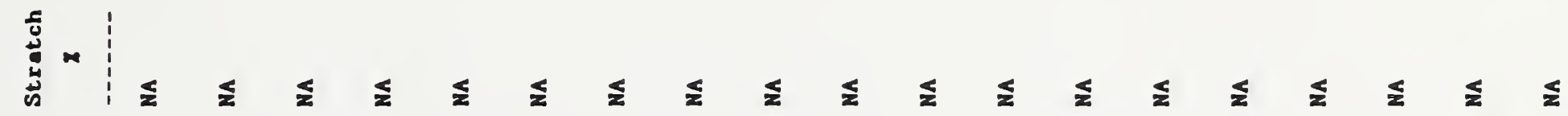
迸量

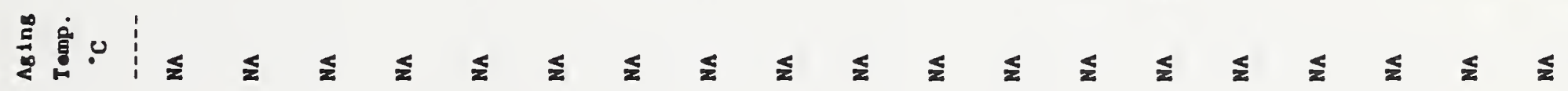
离

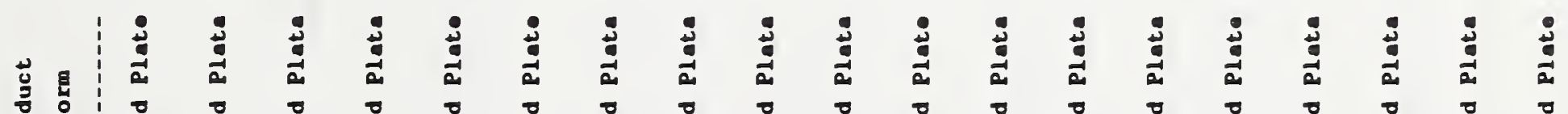

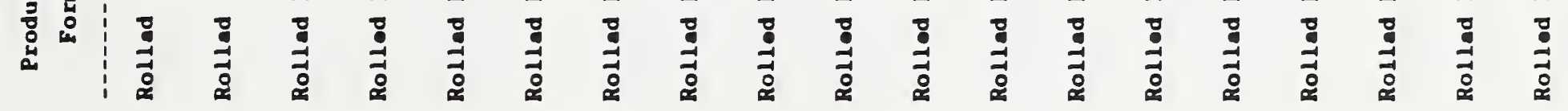
兽 泀 வ

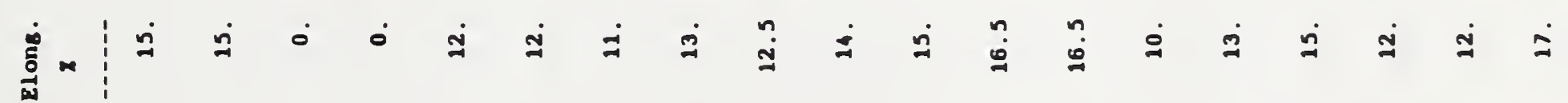
ن்

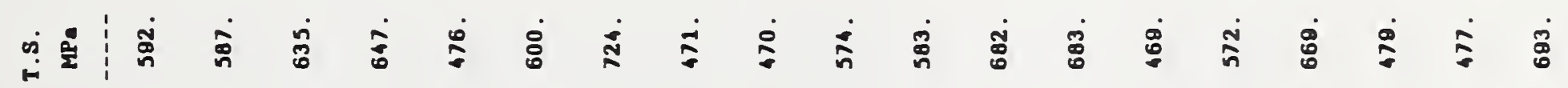
苗ะ $\approx$ ก

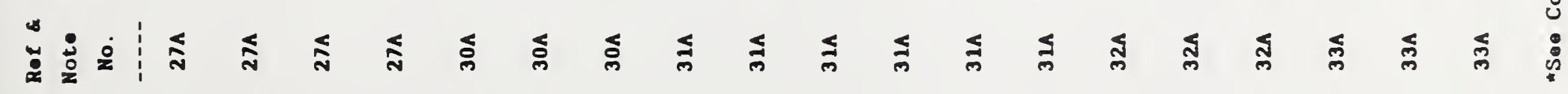




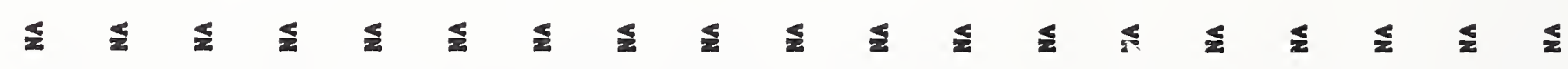
है:

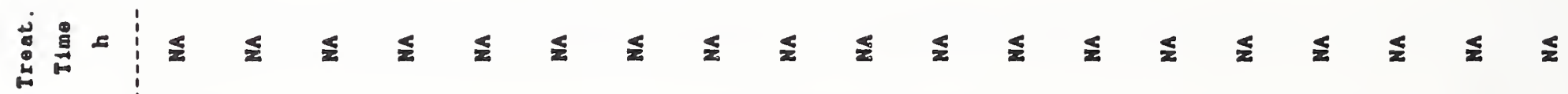
实鄫 : :

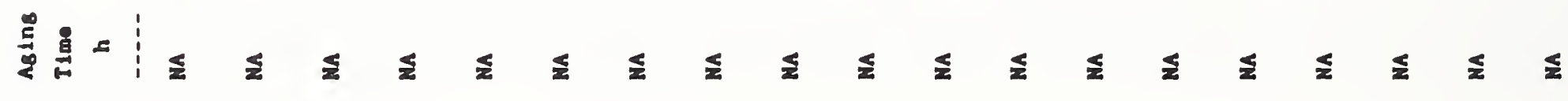

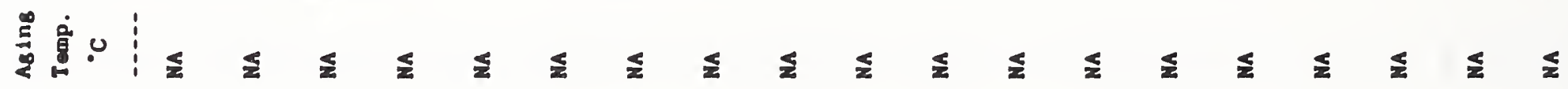
总总

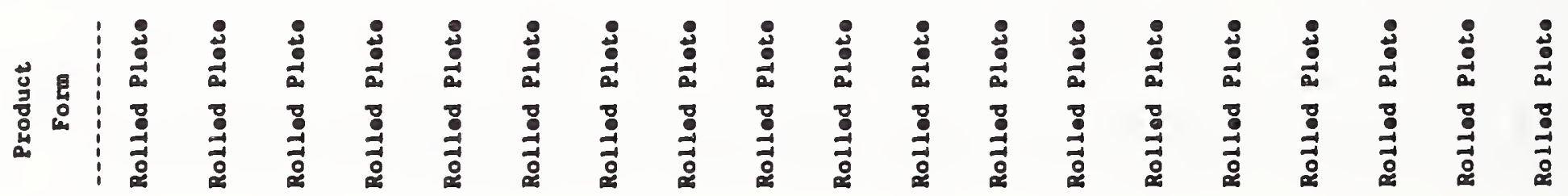
兽

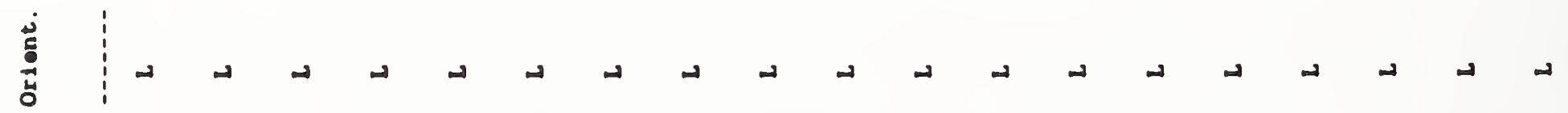

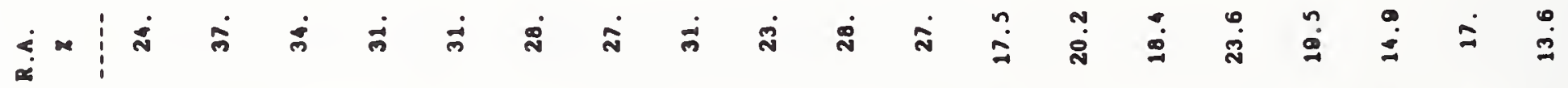

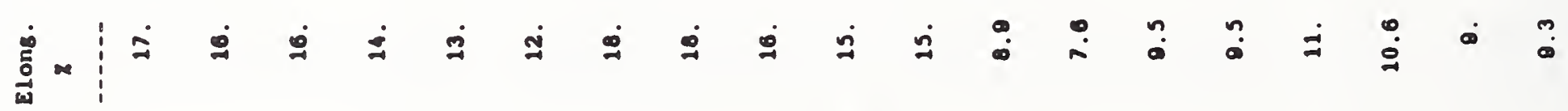
ن भं

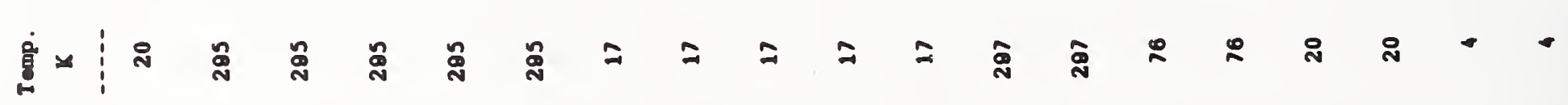

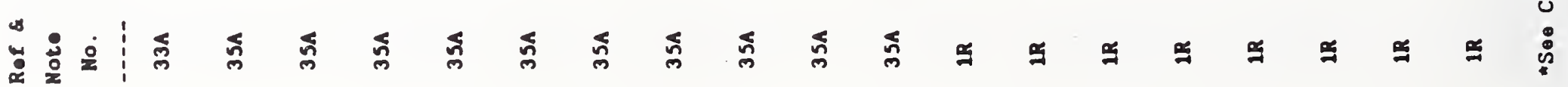




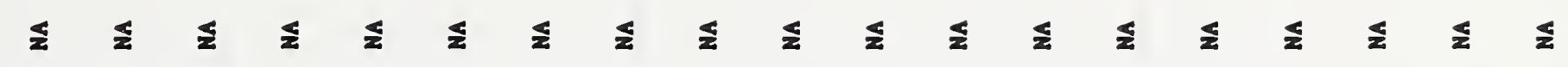
है

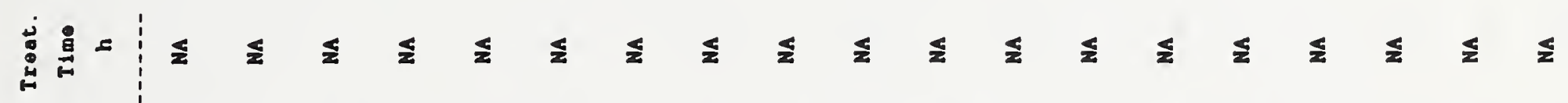

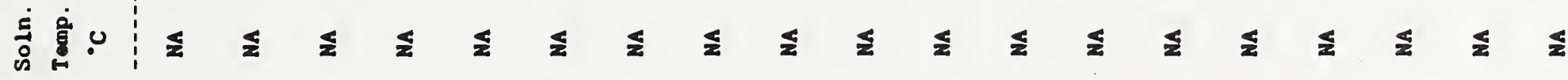
密

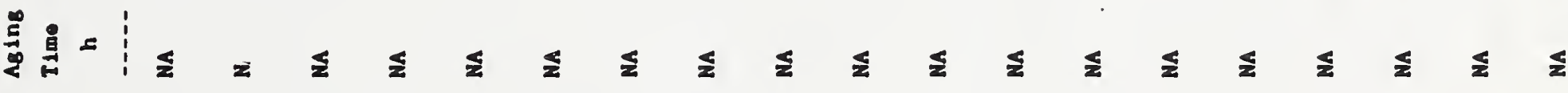

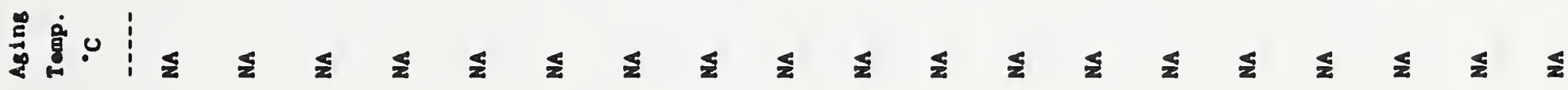

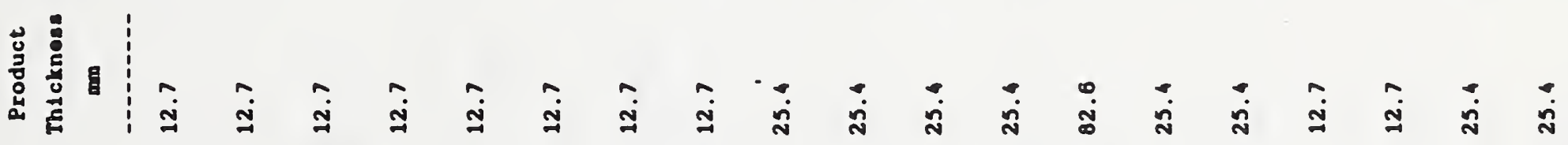

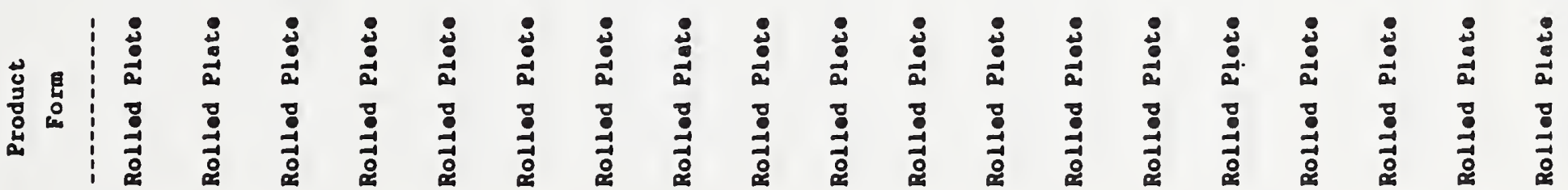
兽

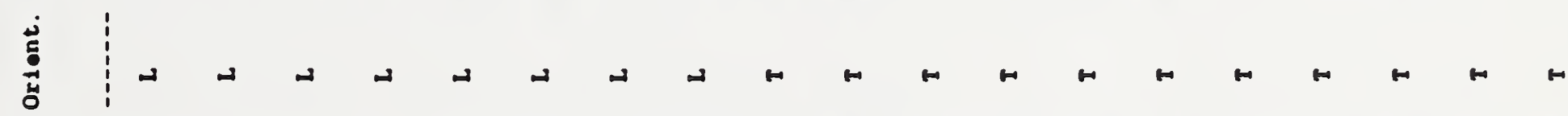

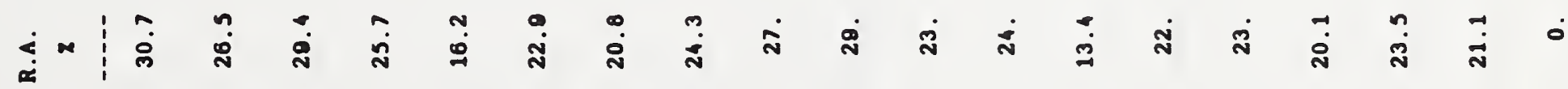

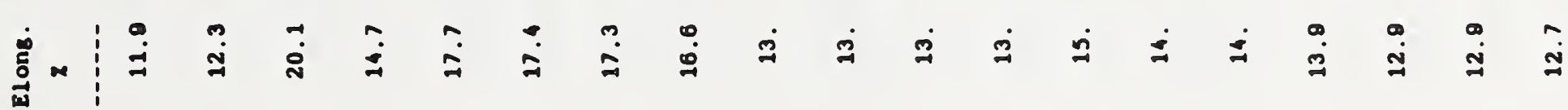
ن 我完 葛 过㻤 


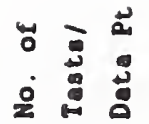

:

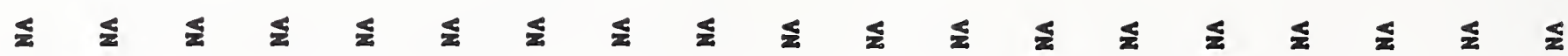

章是

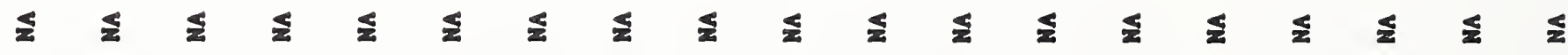

焉焉

递息 实客 密苟

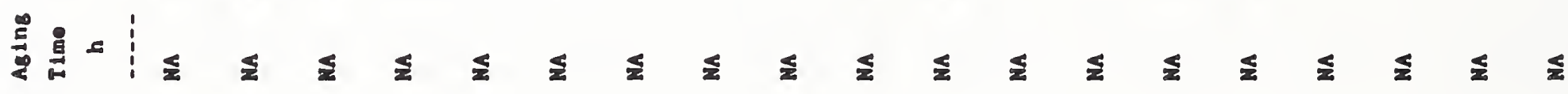
总富 总

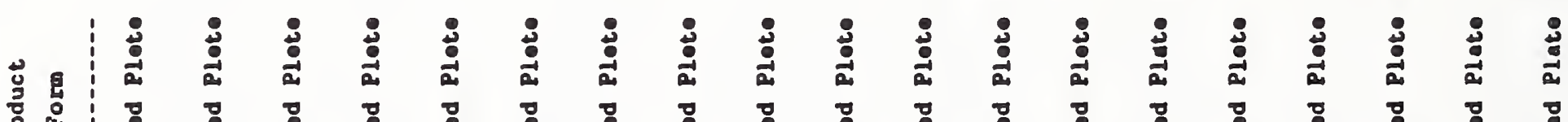

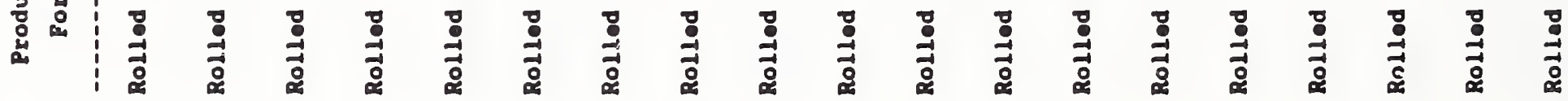
兽 莺

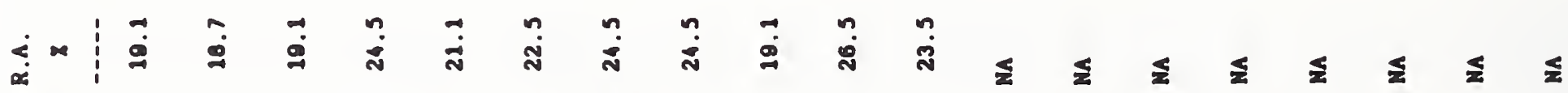

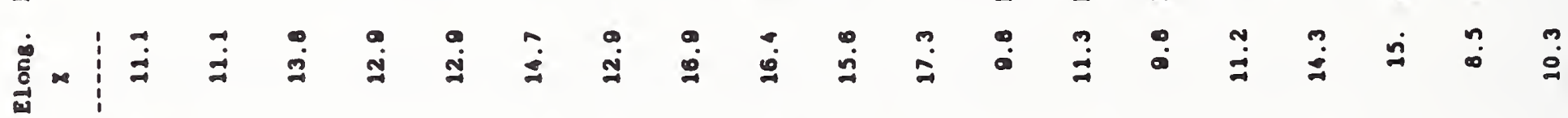
ن i

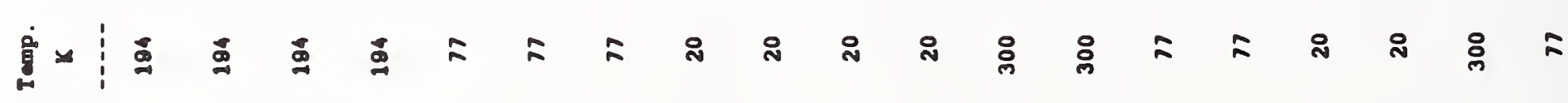
๖ั 
$\stackrel{0}{\circ} \div$

$\dot{0}: \dot{\Xi}$

:

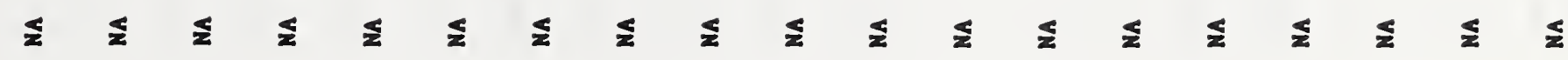

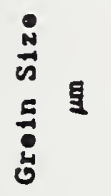

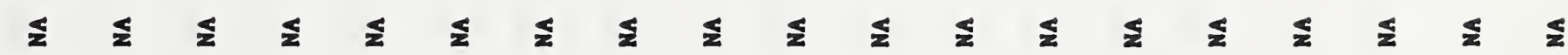

过 递兽

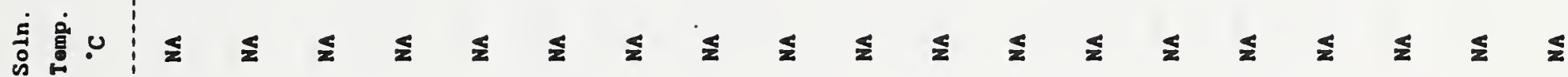

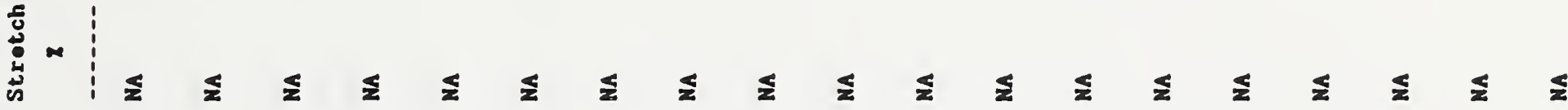

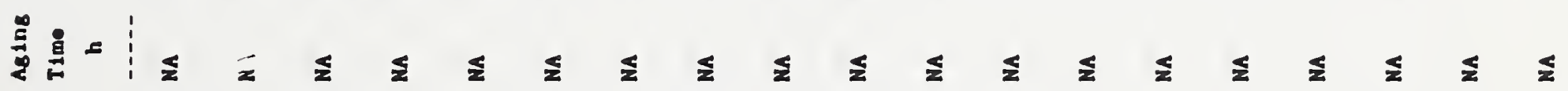

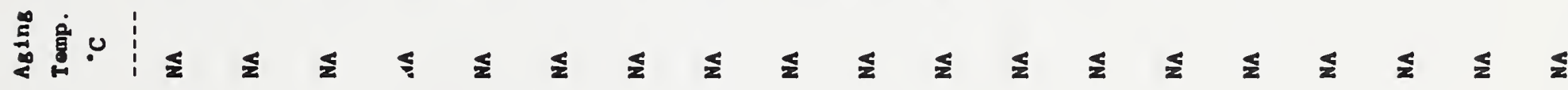

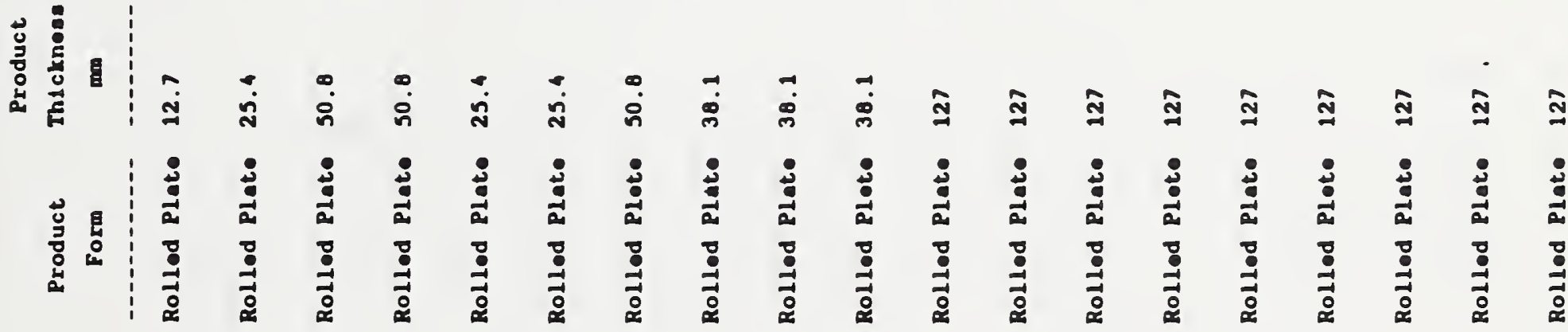

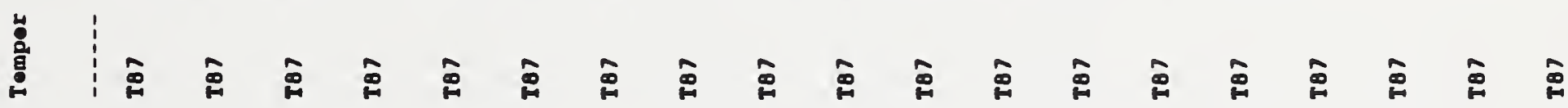

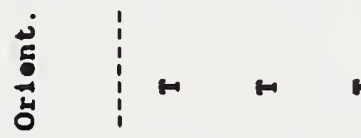

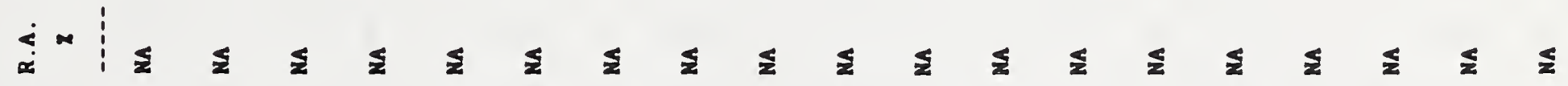

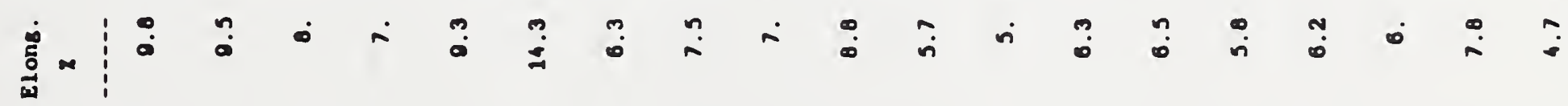
我 ن 菑ะ

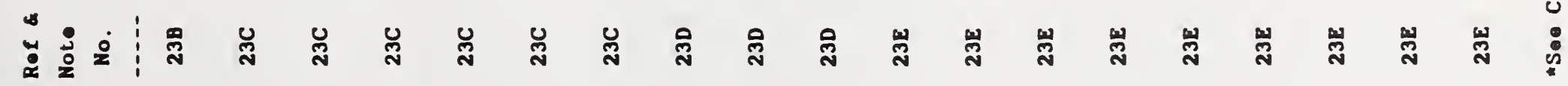




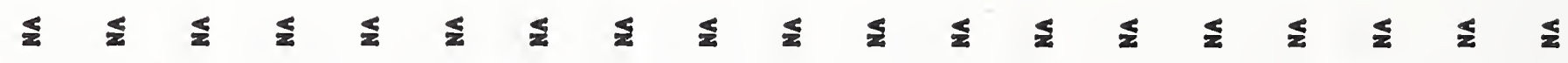

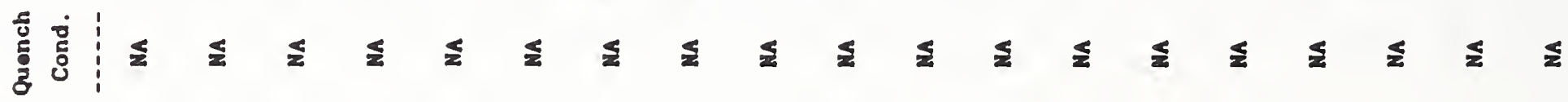

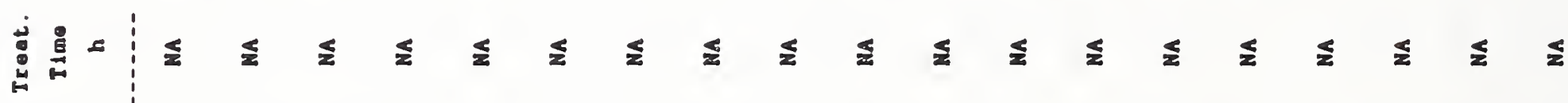

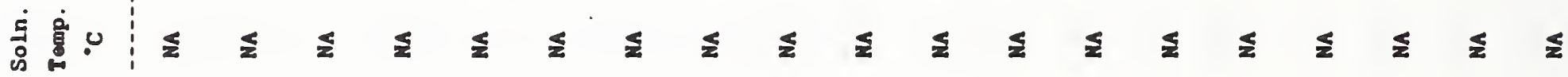
咅:

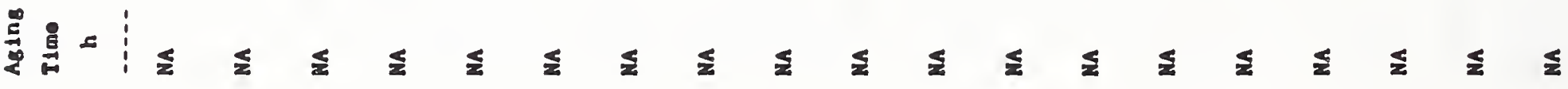

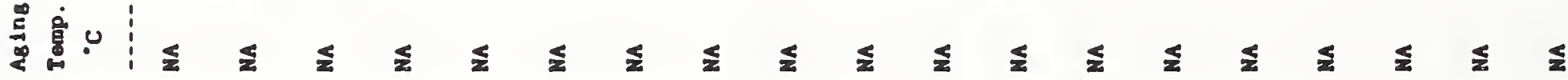
害薏

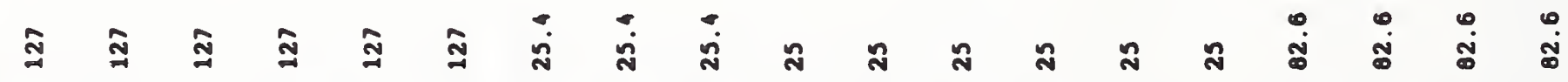

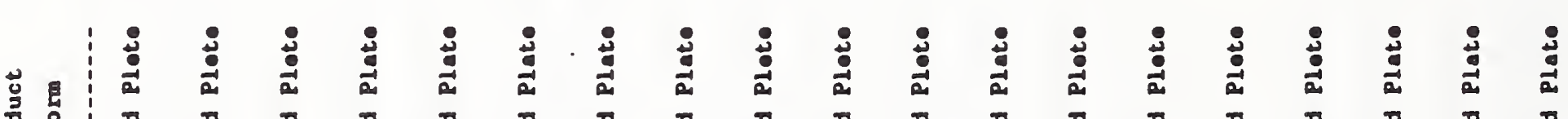

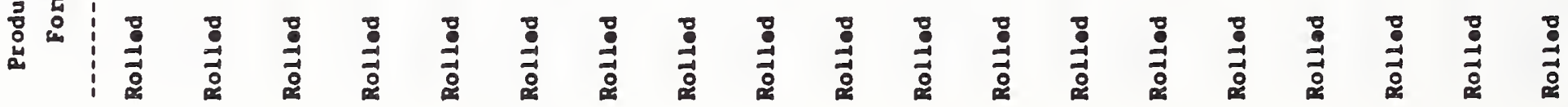
暮 蒡

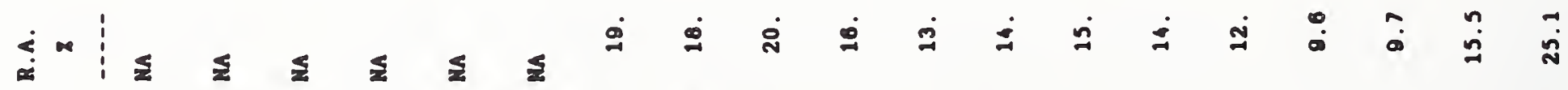

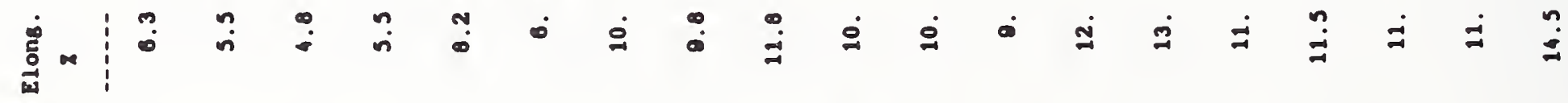

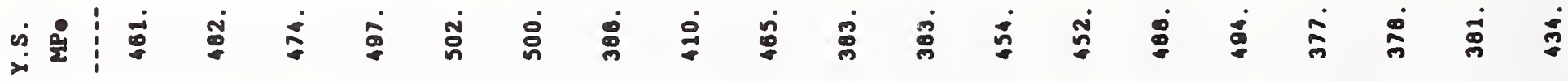

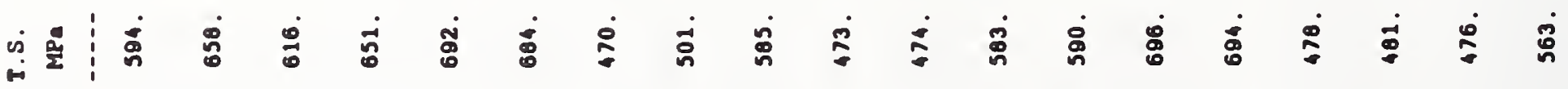

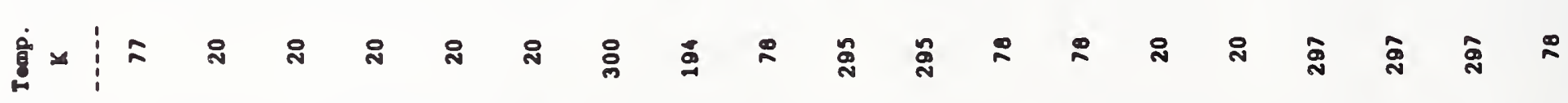

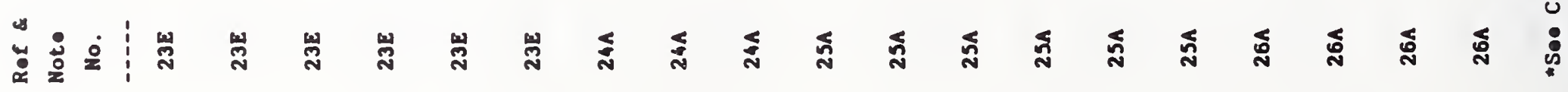




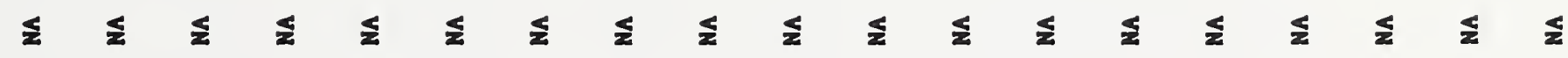

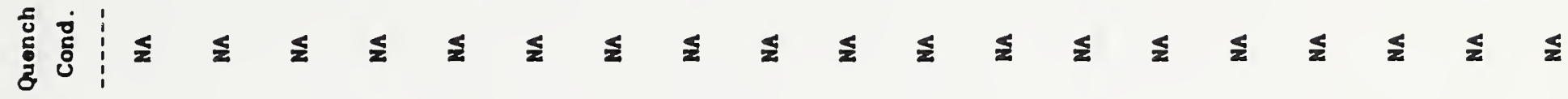

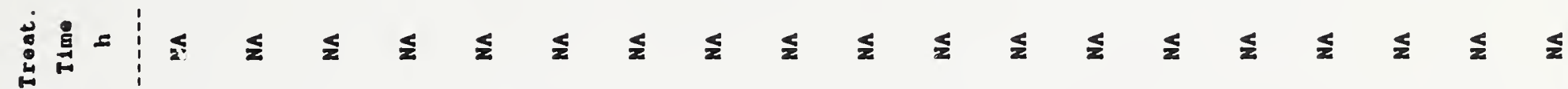

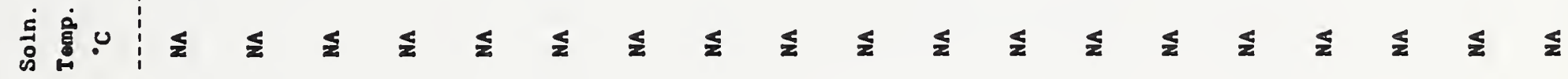

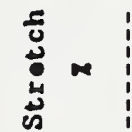

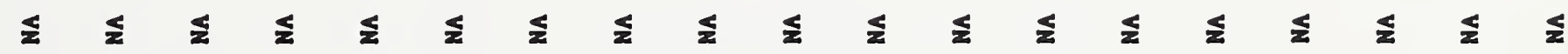
递首 尊富:

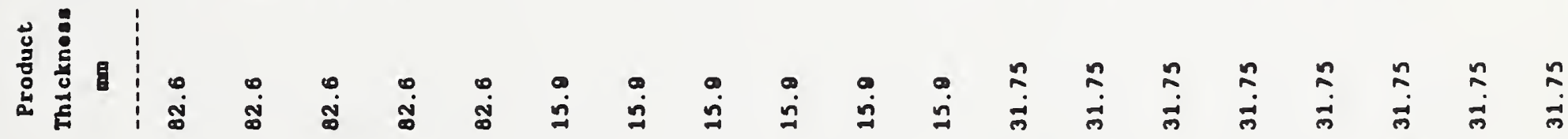

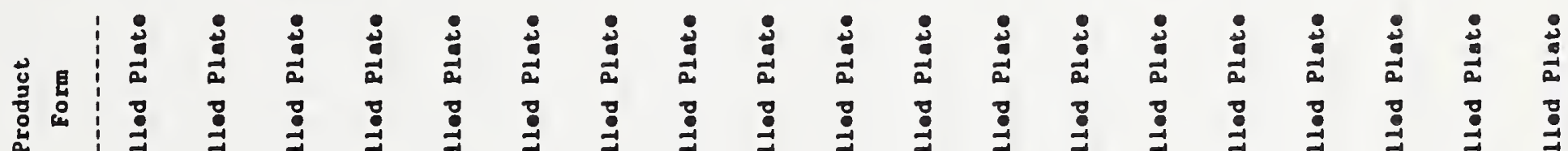
苛 兽 $\frac{5}{5}$

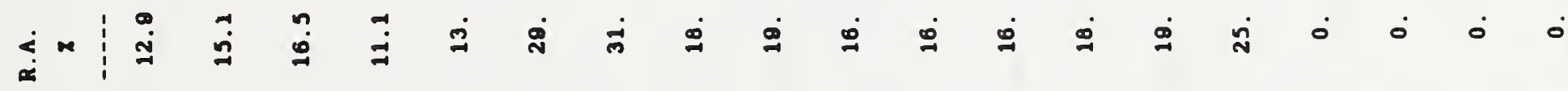

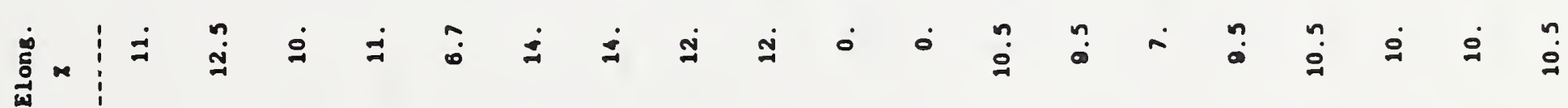
ن

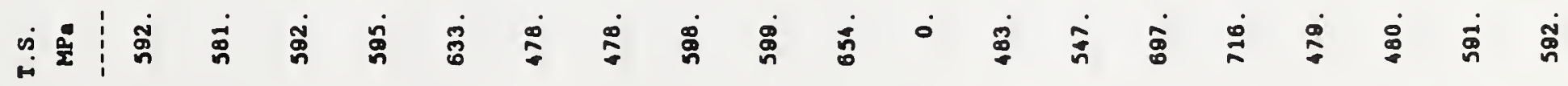
完ะ

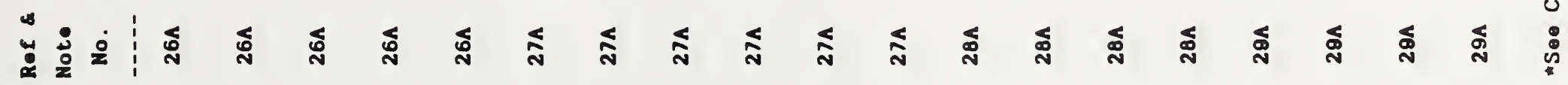




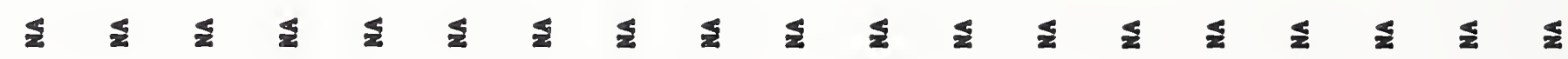
尊 离曾

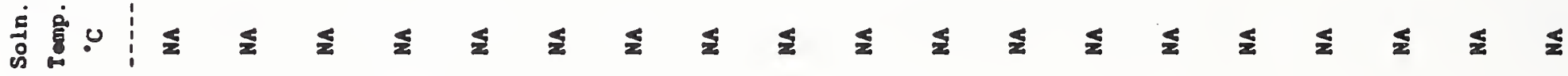

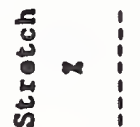

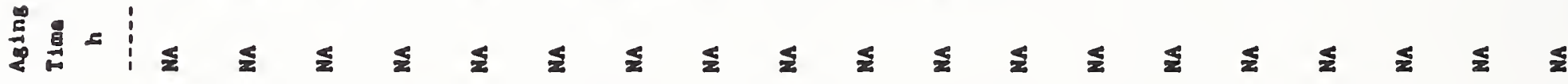

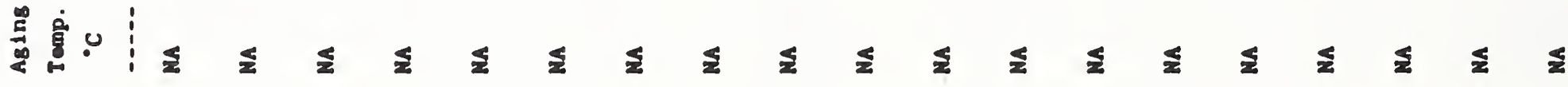

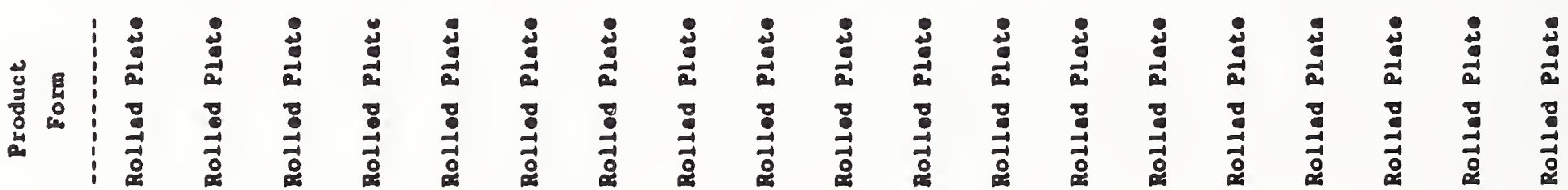
惫 戛

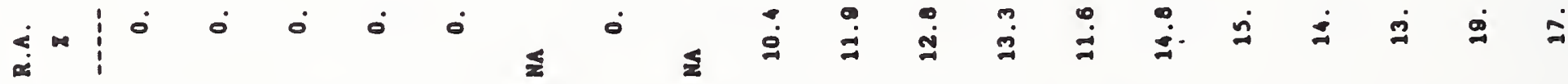

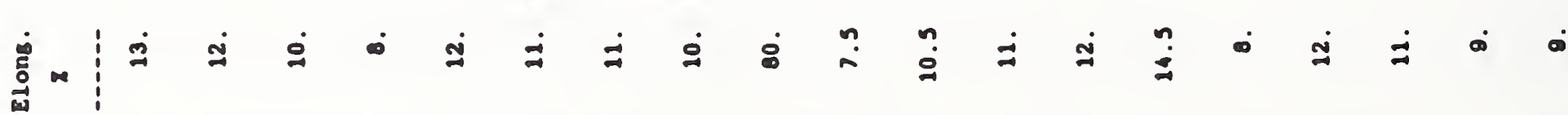

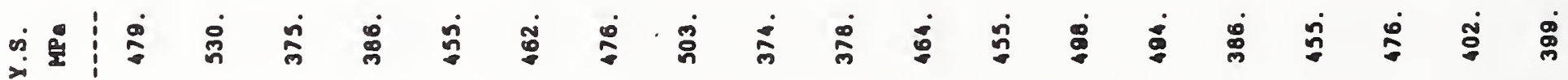
ம் 完 过 


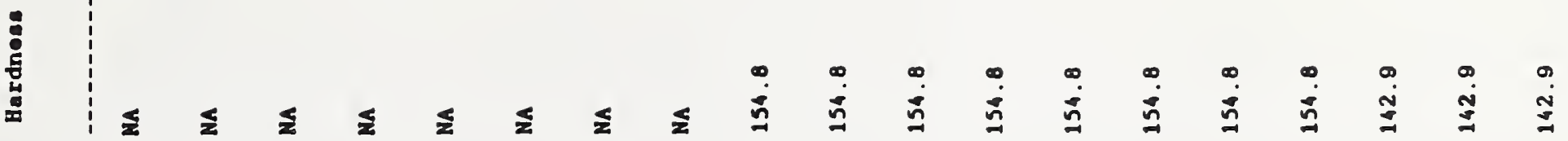

空

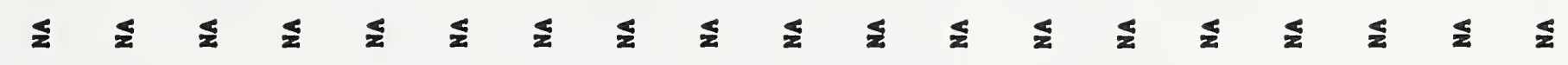
吾焉 递宣 㲐客

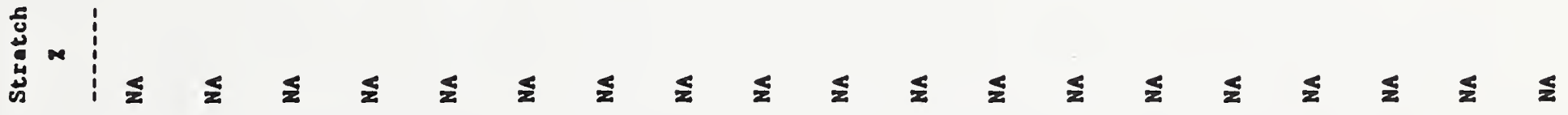

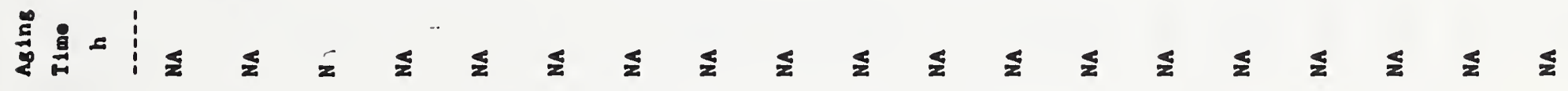

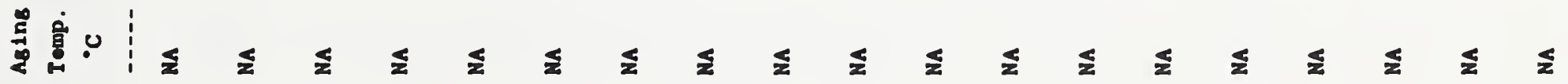
总总

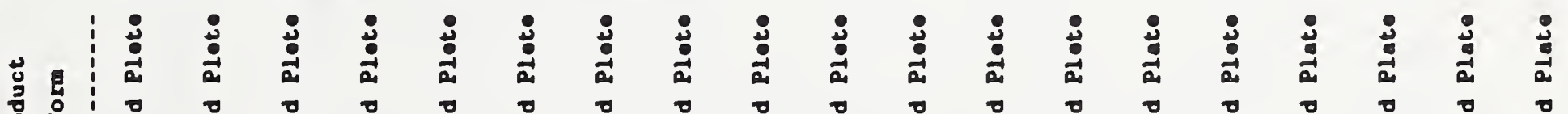

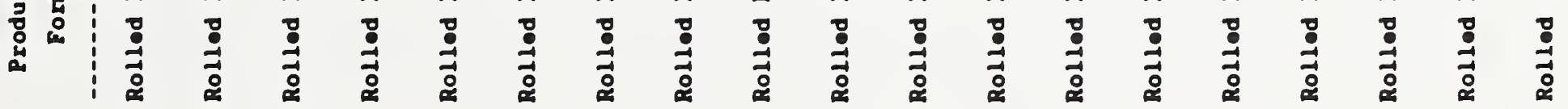

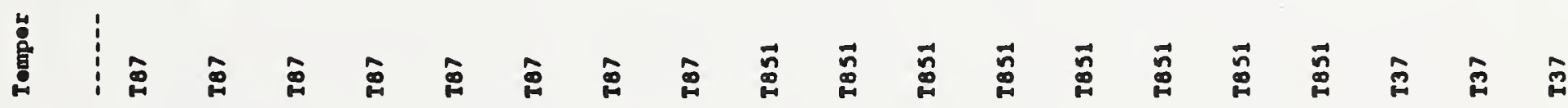

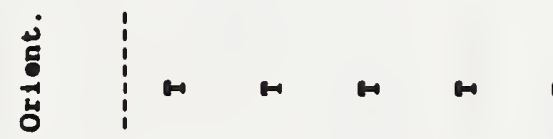

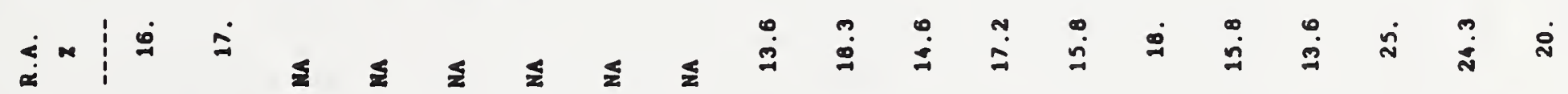
苛 ஸ்

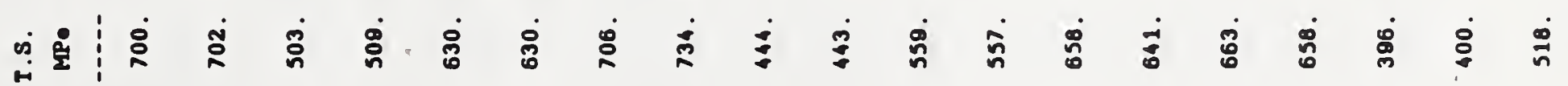
莤ะ

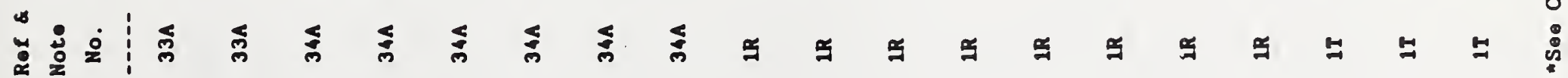




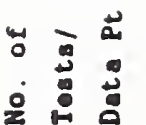

窟

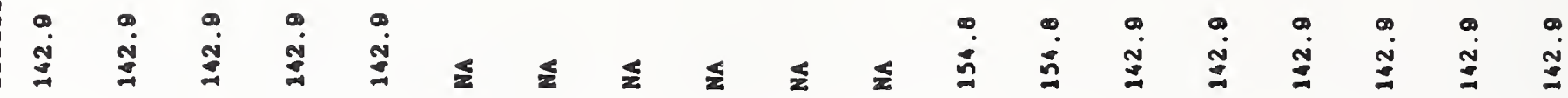

的里

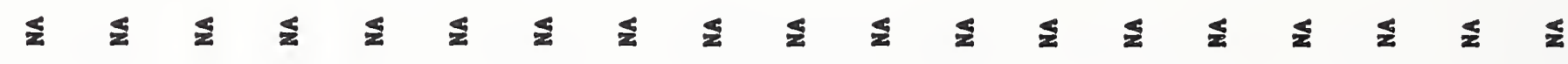

豆

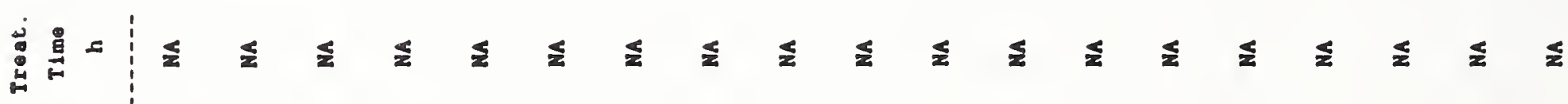

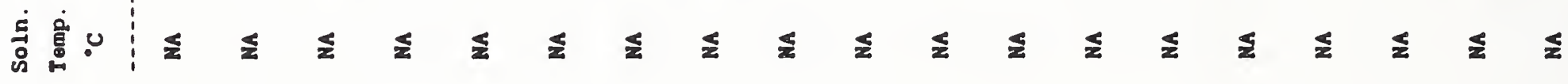

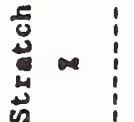

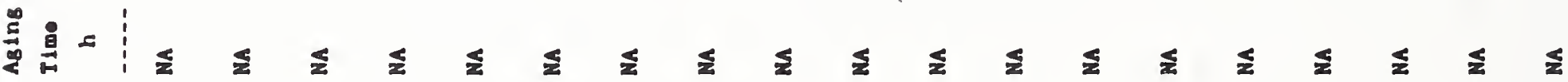

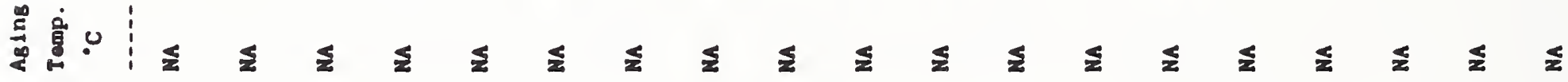
要营

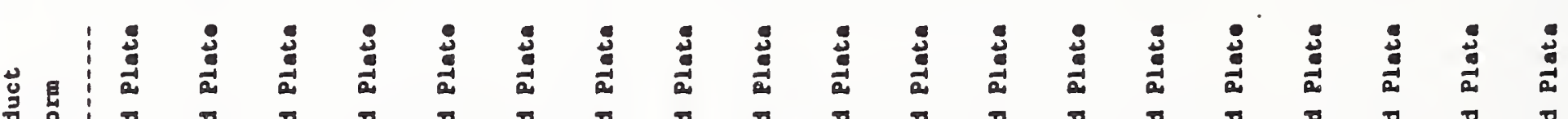
总 兽 蓆 வ

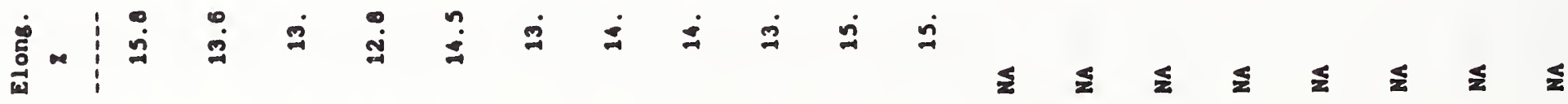
i ஸ 尊 落: 


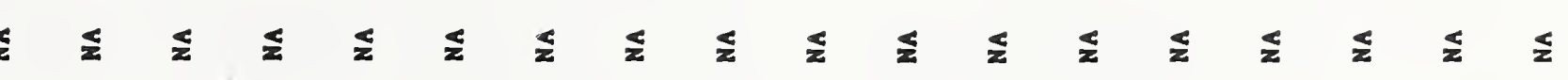

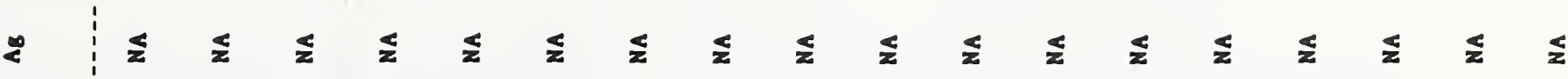

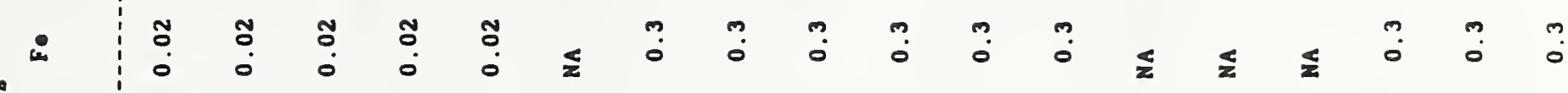

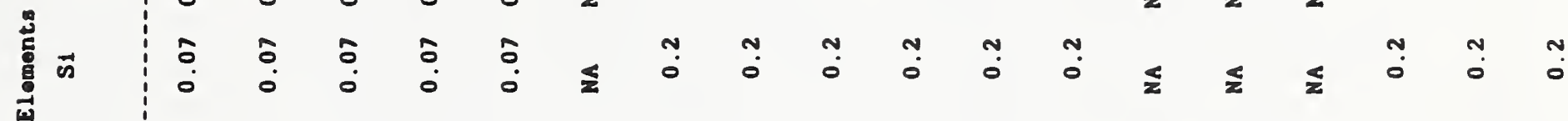

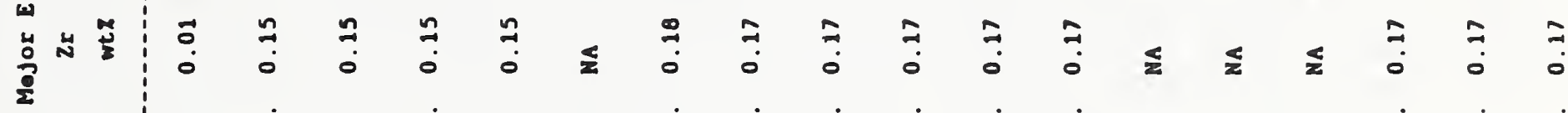

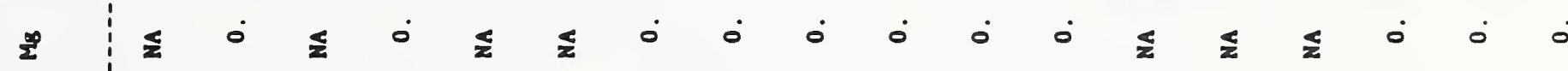

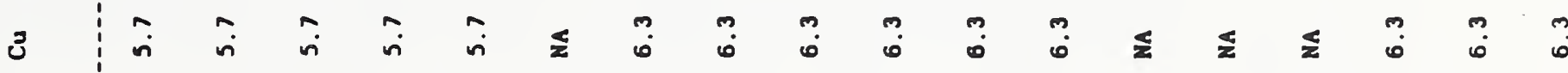
J

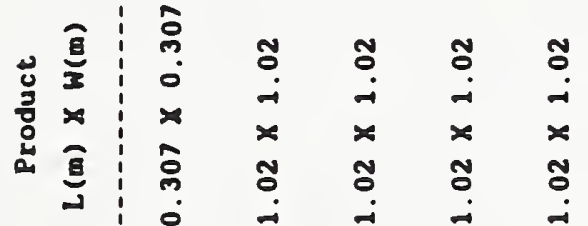

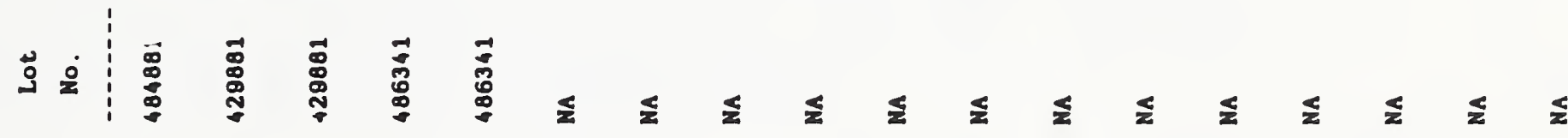
它㻤 葶葶

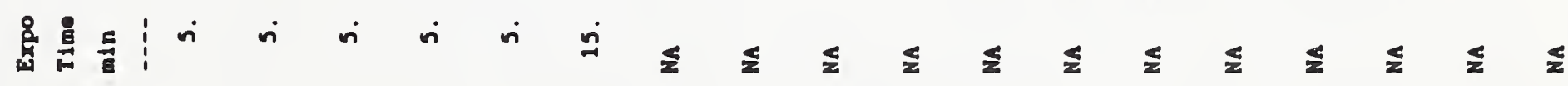

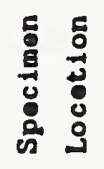

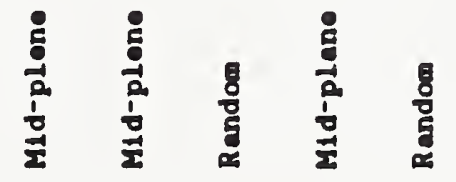

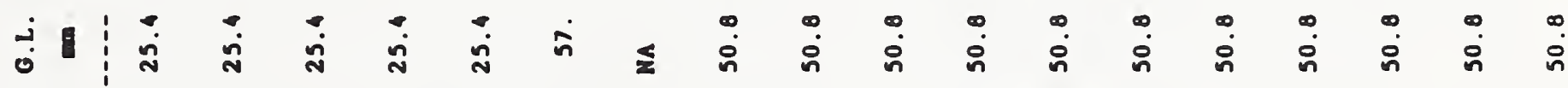

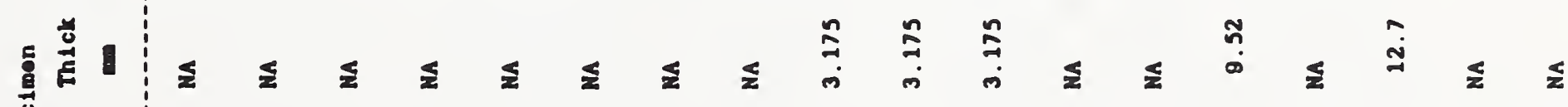

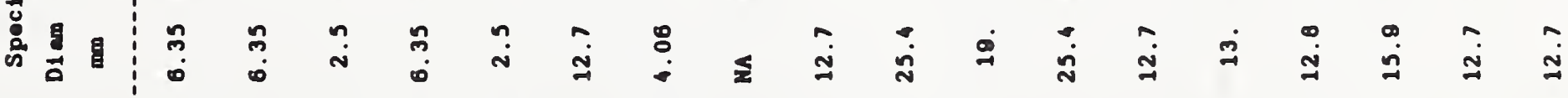

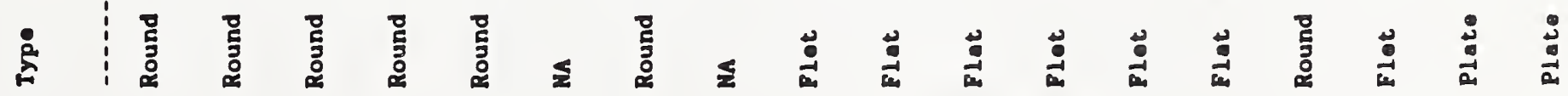

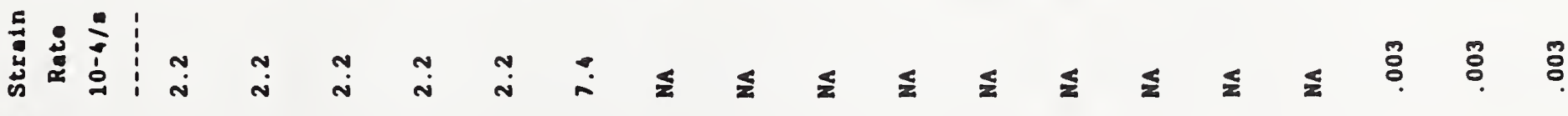

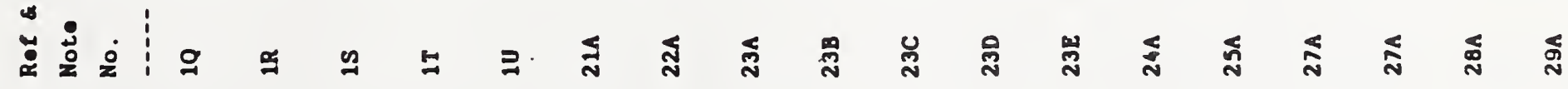




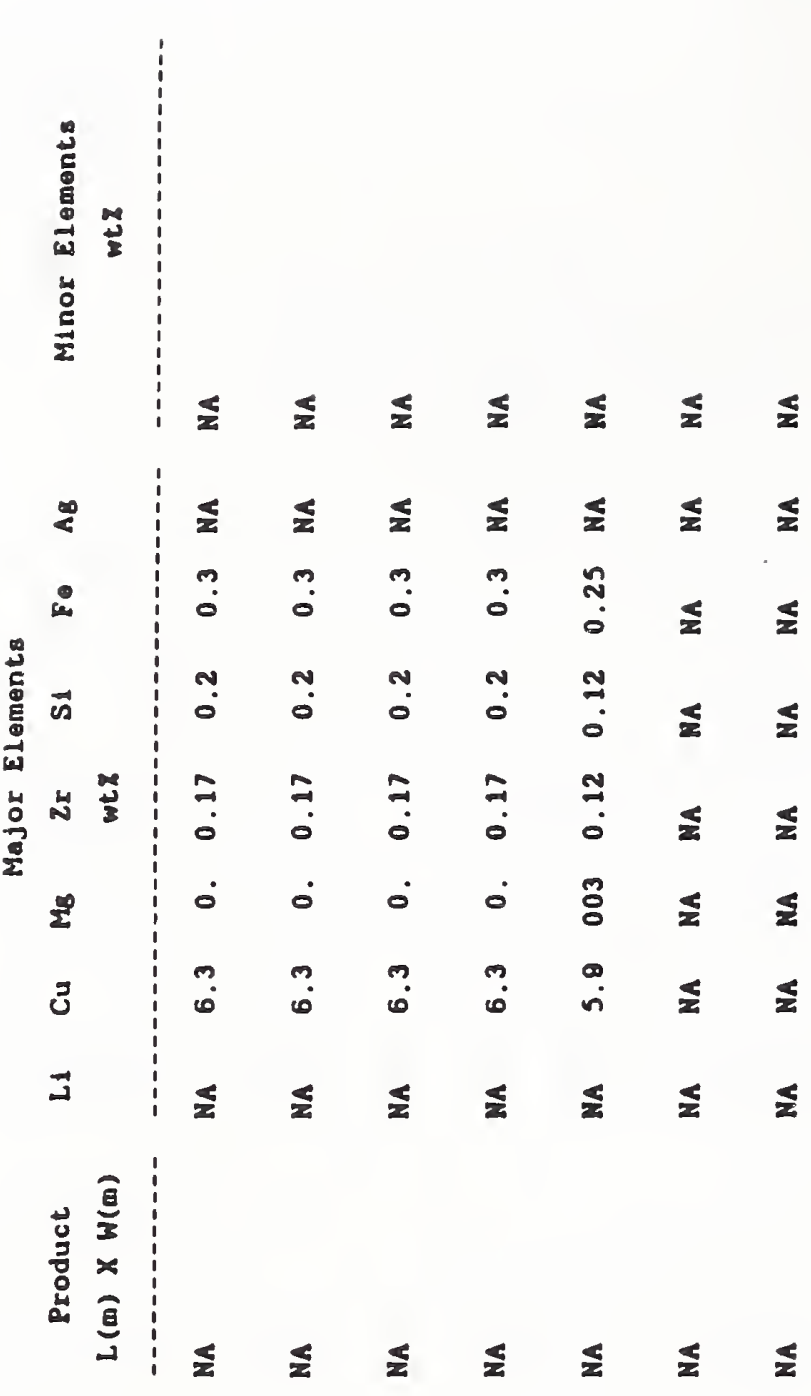

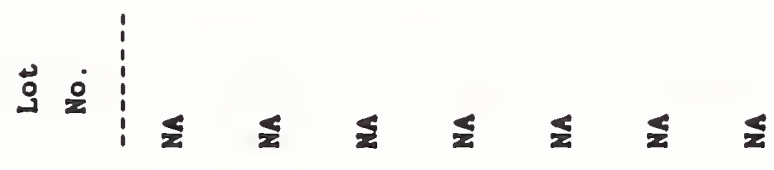

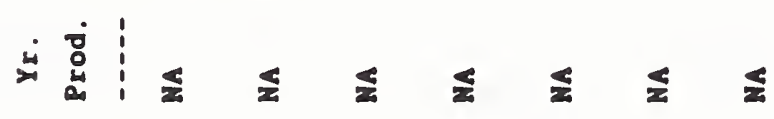

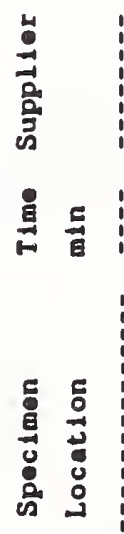

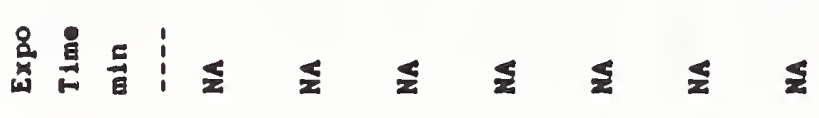

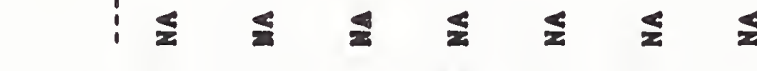

نं

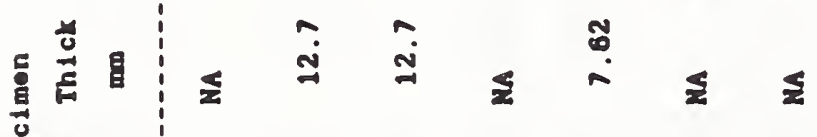

产胃冒

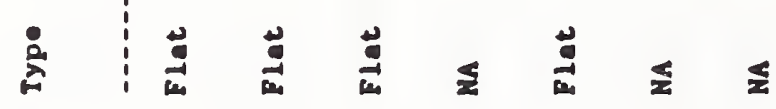

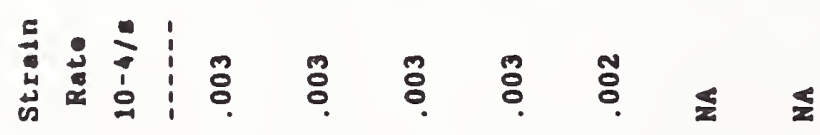

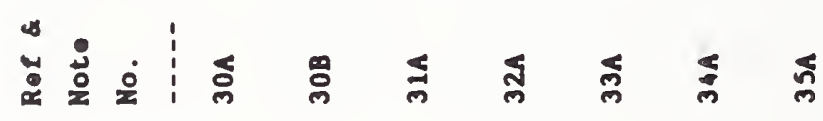




\section{FRACTURE TOUGHNESS}

\subsection{Introduction to Graphs}

Fracture toughness data at room temperature are presented (with few exceptions) only when measurements at cryogenic temperatures are part of the data set. Thus, only $K_{I c}$ data on CT (compact tension) specimens are presented in this review. These data are currently available because measurements are relatively easy to carry out in conventional cryostats compared with wide-panel center-crack or part-through crack tests. Most of the measurements on current production vintages and tempers were carried out during the last year at NIST. These measurements are discussed more fully, including fracture mode and microstructural considerations, in another NIST report ${ }^{1}$ on comparative cryogenic mechanical properties. A figure showing the possible specimen orientations with respect to the rolling direction preceeds the figures.

All graphical data are presented and referenced in tables following the graphs. The properties presented in the data tables are the fracture toughness and yield strength, along with temper, product information, thermomechanical processing, grain size, hardness, number of tests per data point, and the reference and note number. The reference and note number is a guide to the accompanying test conditions table, which gives information on the specimen type and dimensions, precrack conditions, existance of side grooves or muitiple specimens, invalidating criterion, chemistry, and proceedures, including the test standard used.

NIST is currently engaged in a program to expand the cryogenic fracture toughness database by testing wider CT specimens [152-mm (6.0-in)] and $102-\mathrm{mm}$ (4.0-in) panels with part-through cracks. The type of fracture toughness data presented in this new program is determined by design needs of the ALS program, where these alloys are under consideration for use in cryogenic tankage. Generally, a leak is equivalent to failure, so plane-strain conditions in CT specimens and part-through cracks in wide panel testing are more relevant than center-crack tests. Wide panel testing at temperatures of 20 and $4 \mathrm{~K}$ is quite limited. 
Specific comments from the data table follow:

Reference and

Note Number

Alloy 8090:

8A--Values reported are "minimum" properties.

Alloy 2090:

36B--Value reported is a proposed minimum value.

12A--Value reported are "minimum" properties.

Alloy WL049:

$6 \mathrm{~J}-\mathrm{K}-$-Values reported are the average of the range of grain sizes.

17A-E--Under the supplier column M.M. = Martin Marietta.

Specific comments from the test conditions table follow:

Reference and

Note Number

Alloy 8090:

8A--Reported composition is the average of the range provided for in the Lockheed requirements.

Alloy 2090:

10A--Reported composition is based on nominal values. values

12A--Reported composition is the average of the minimum and maximum

17A--Reported composition is based on nominal values.

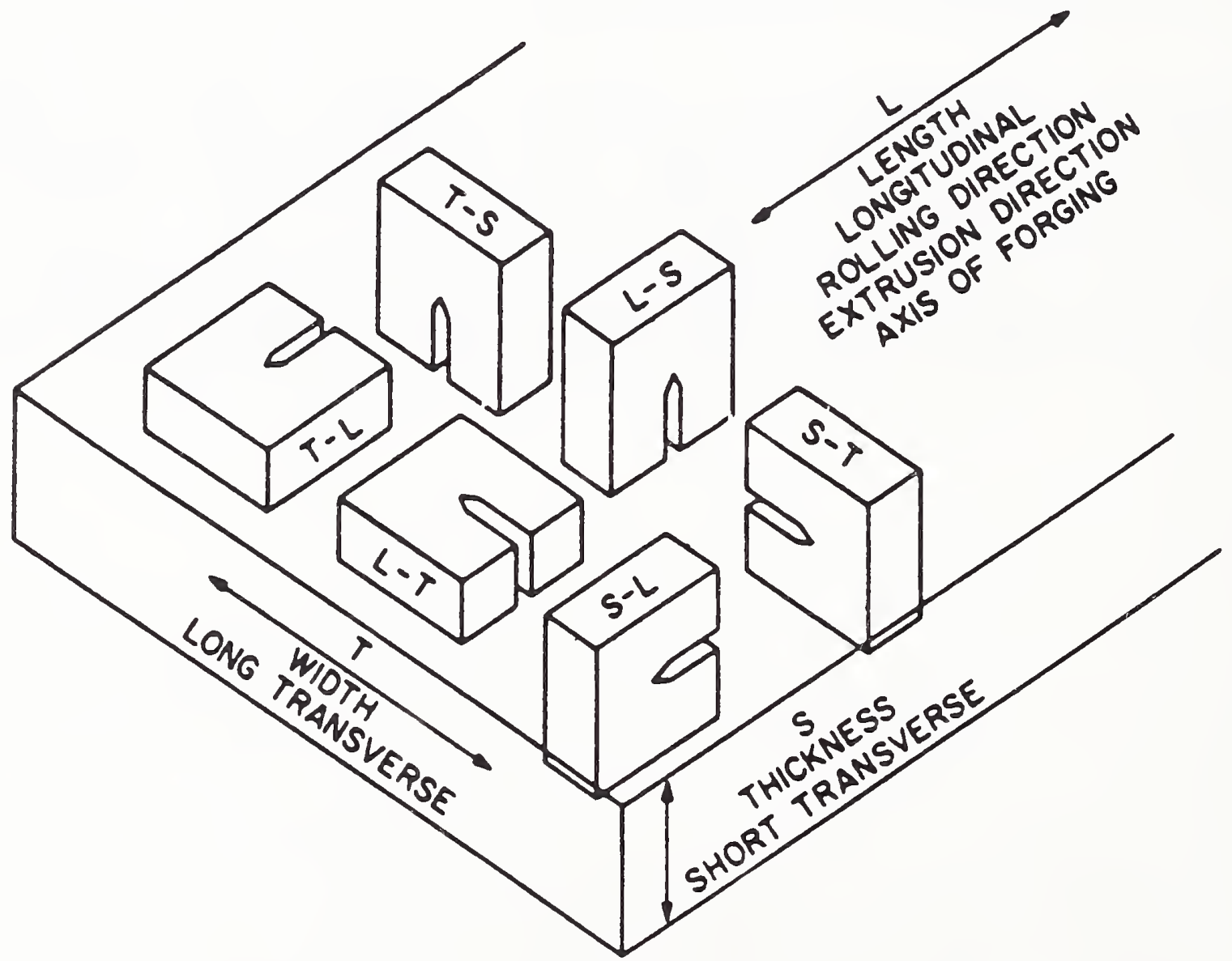


FRACTURE TOUGHNESS, $\mathrm{ksi}^{-1 \mathrm{n}^{1 / 2}}$

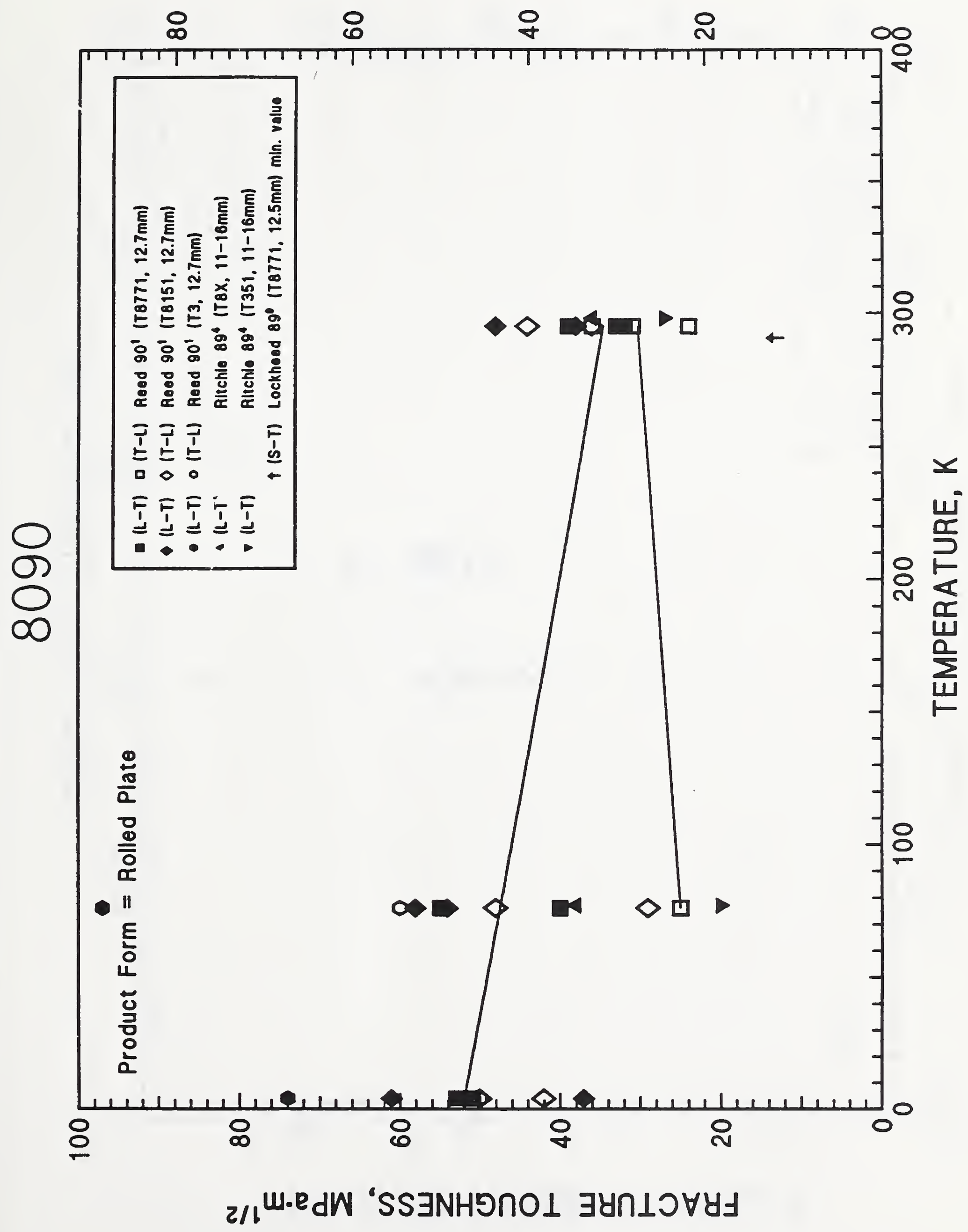


FRACTURE TOUGHNESS, $\mathrm{ksi} \cdot \mathrm{in}^{1 / 2}$

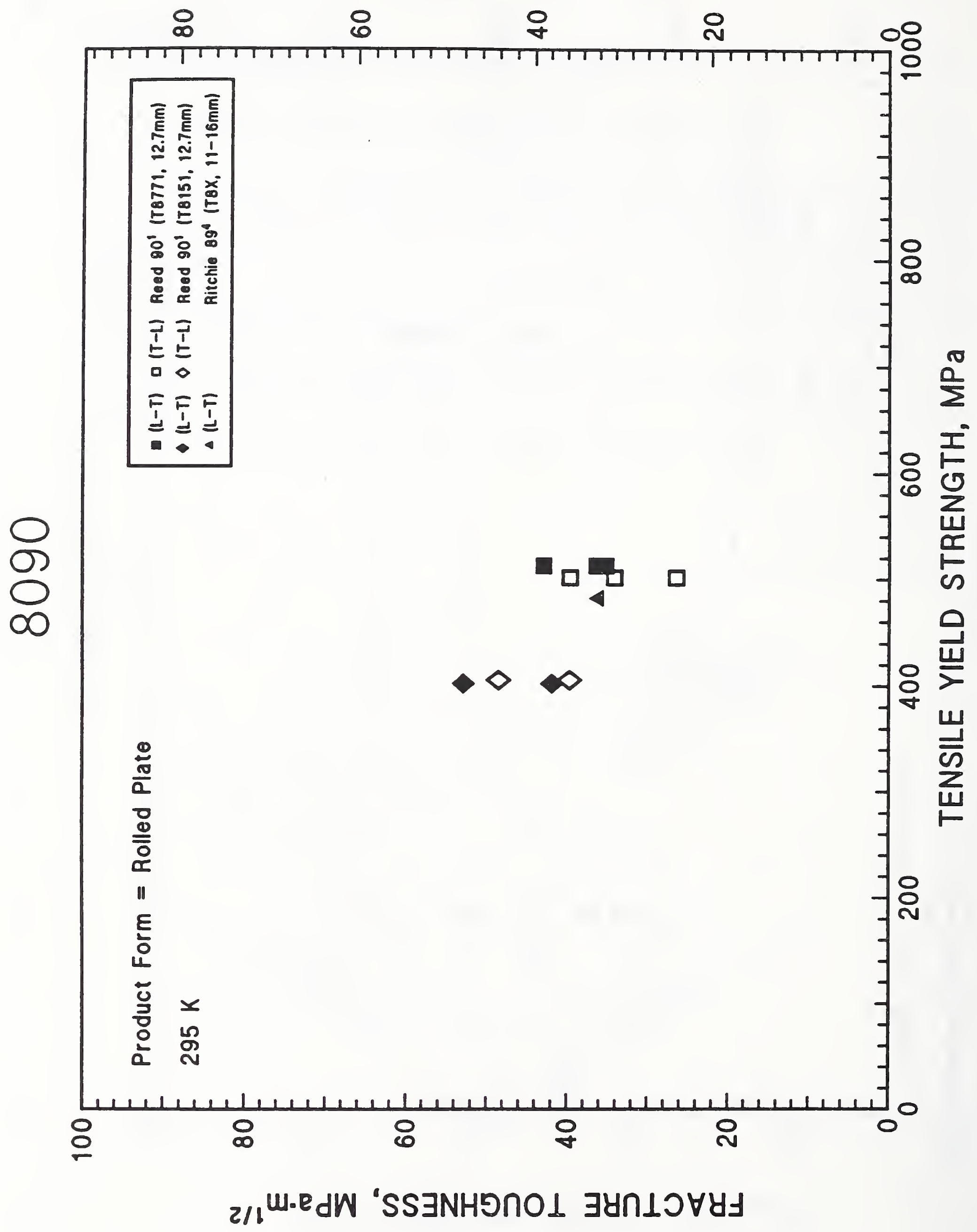


FRACTURE TOUGHNESS, $\mathrm{ksi} \cdot \mathrm{in}^{1 / 2}$

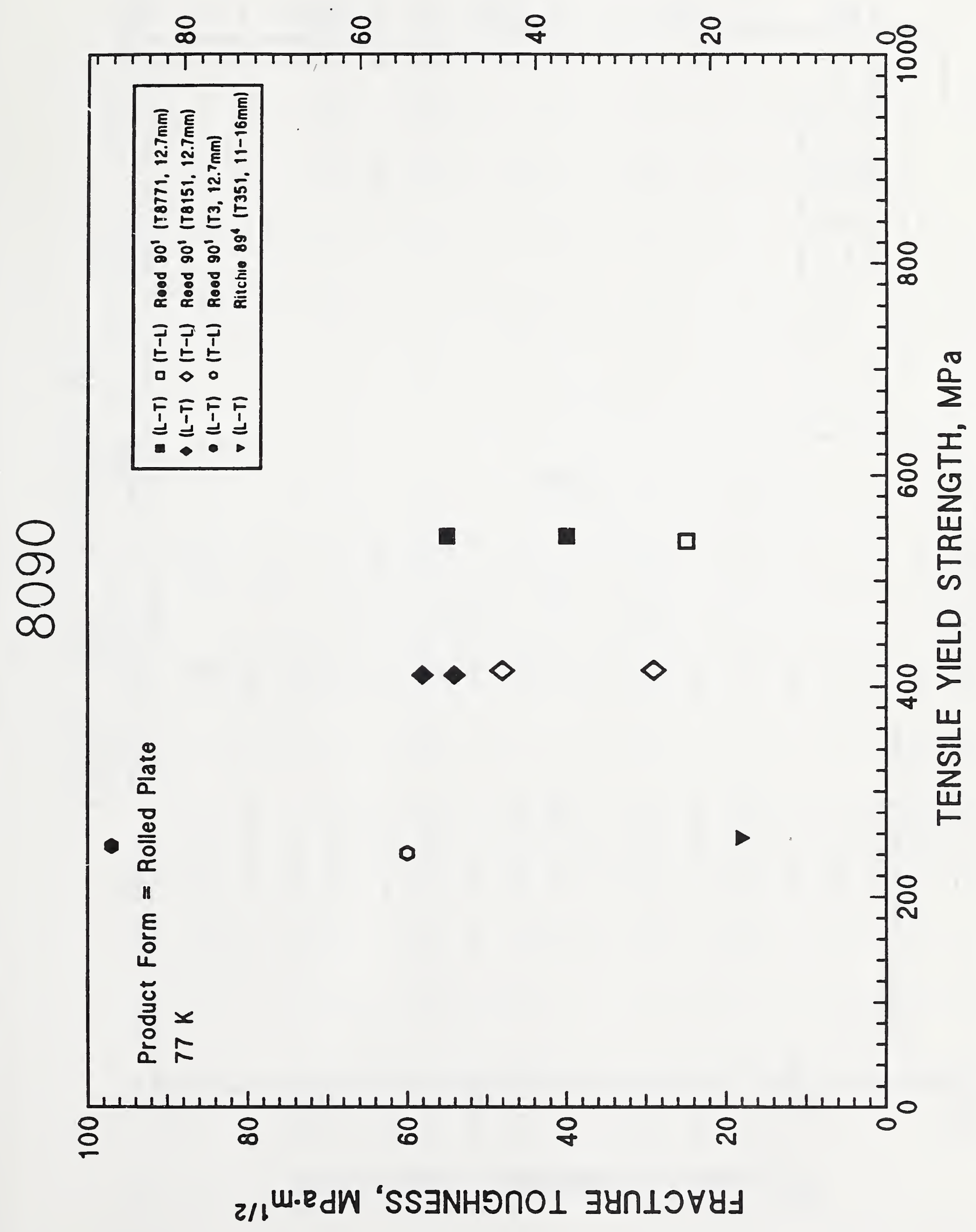


FRACTURE TOUGHNESS, $\mathrm{ksi}^{\mathrm{i}} \mathrm{in}^{1 / 2}$

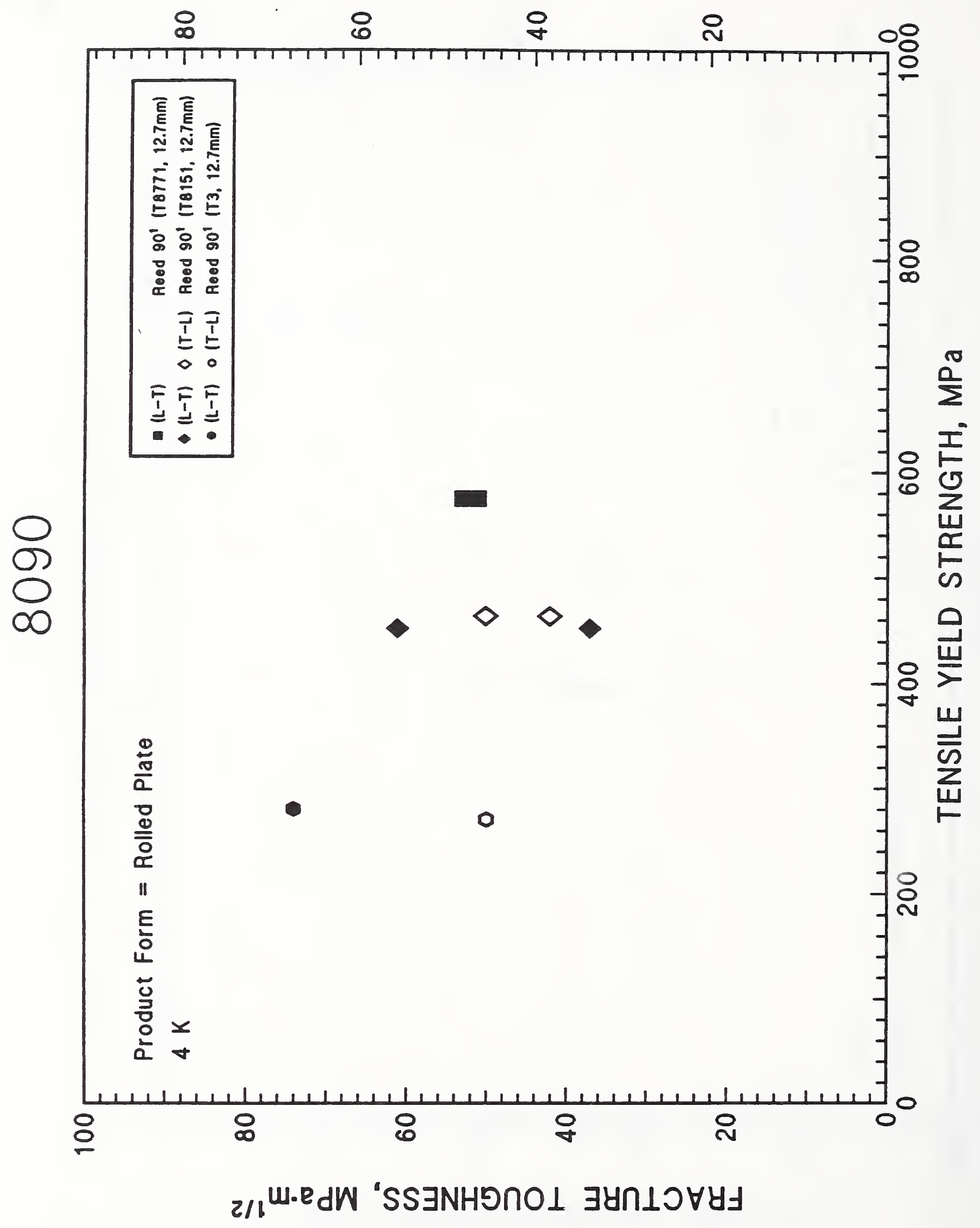




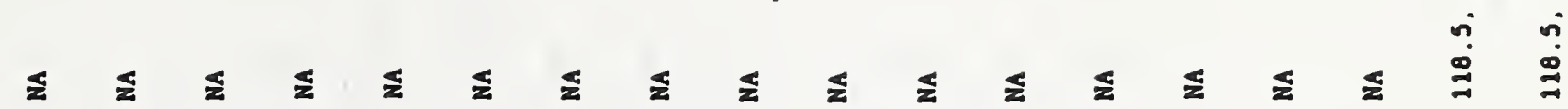
造占

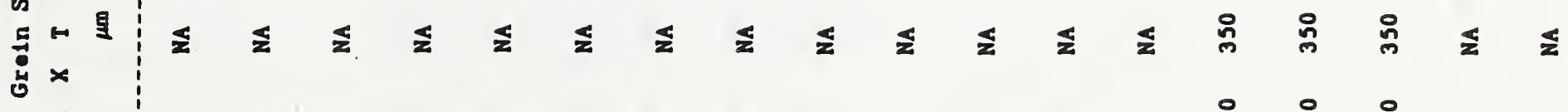

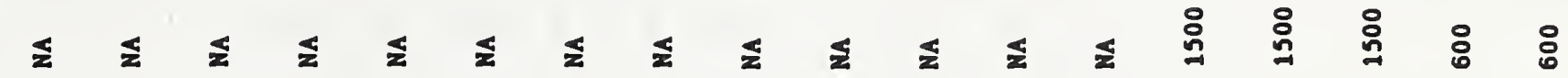

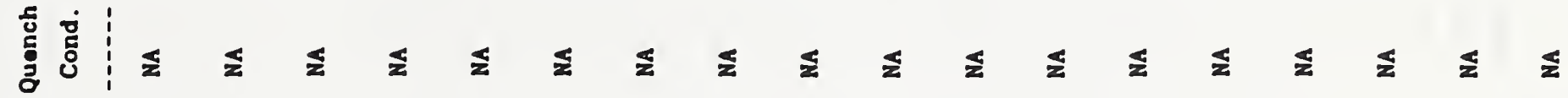
遮息

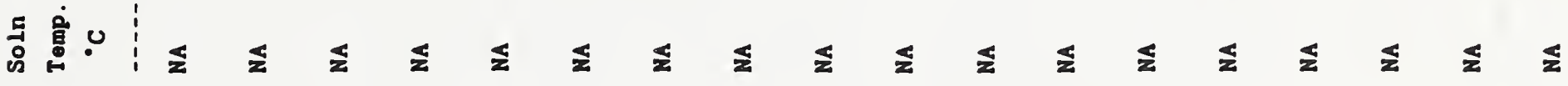

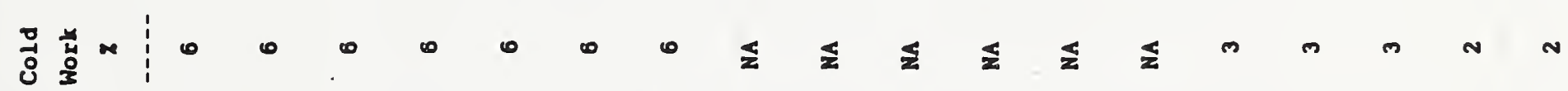

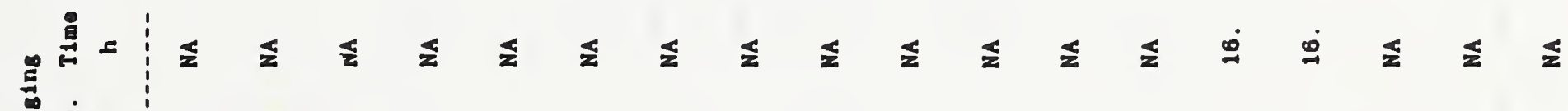

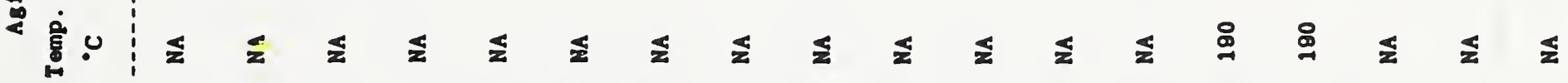

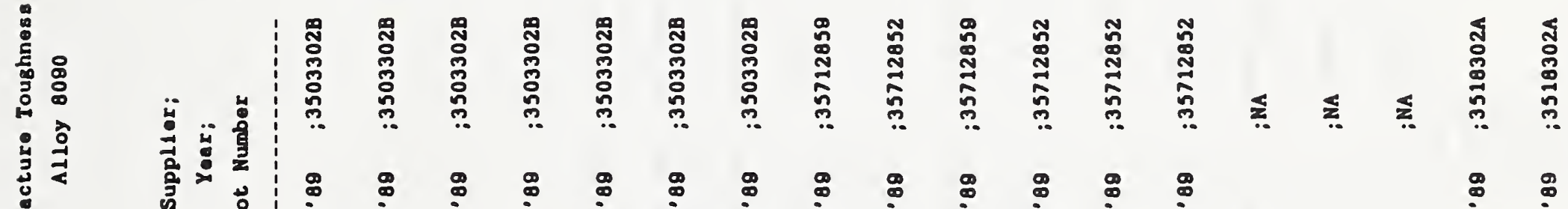

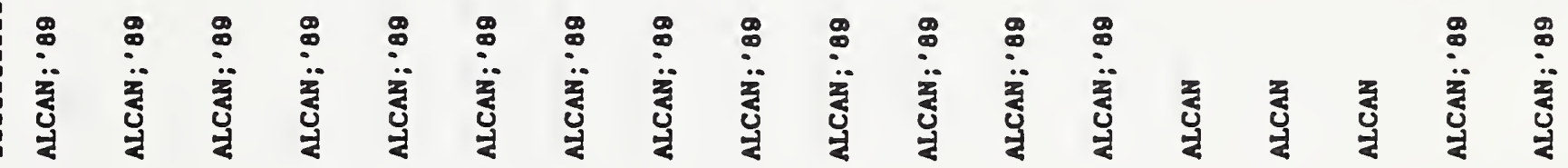

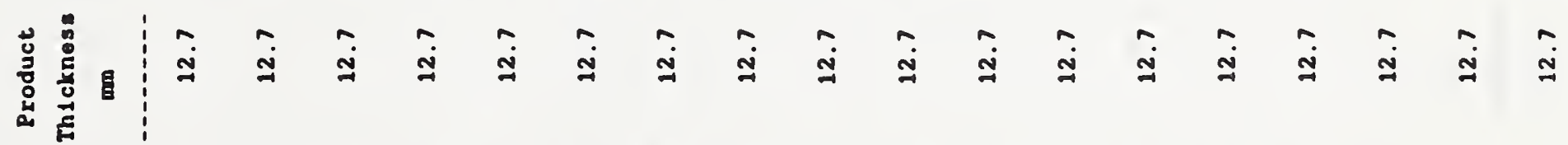

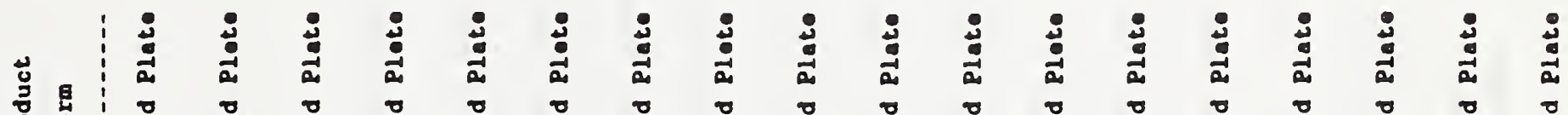

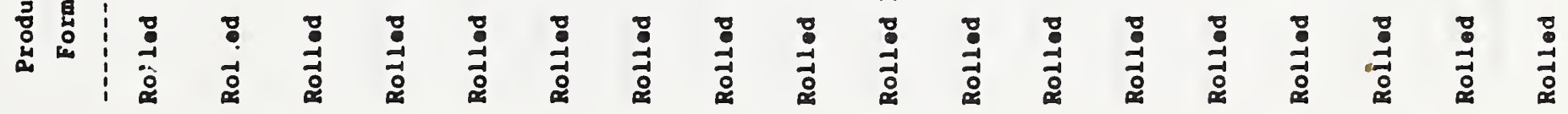
兽

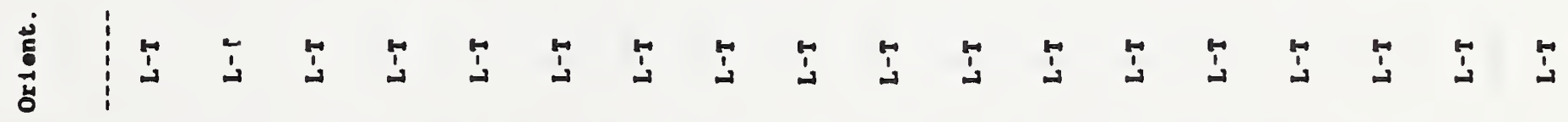

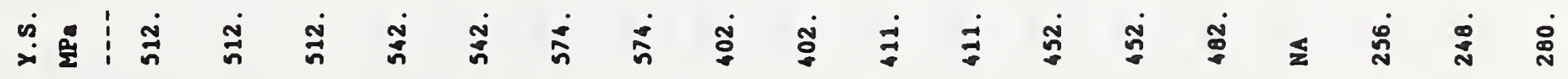
×

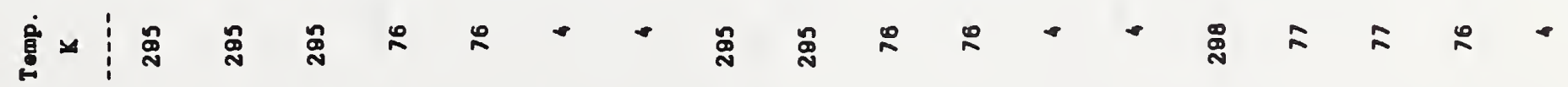
过 


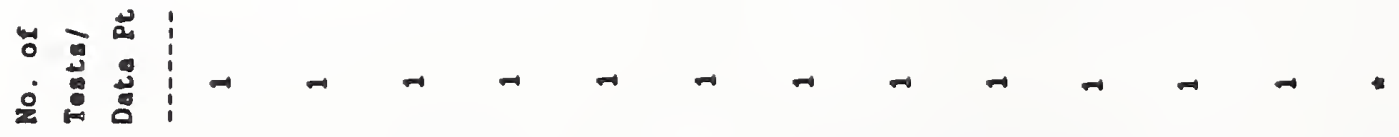

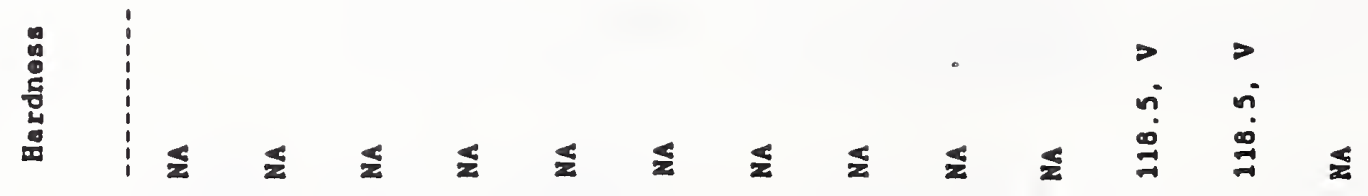

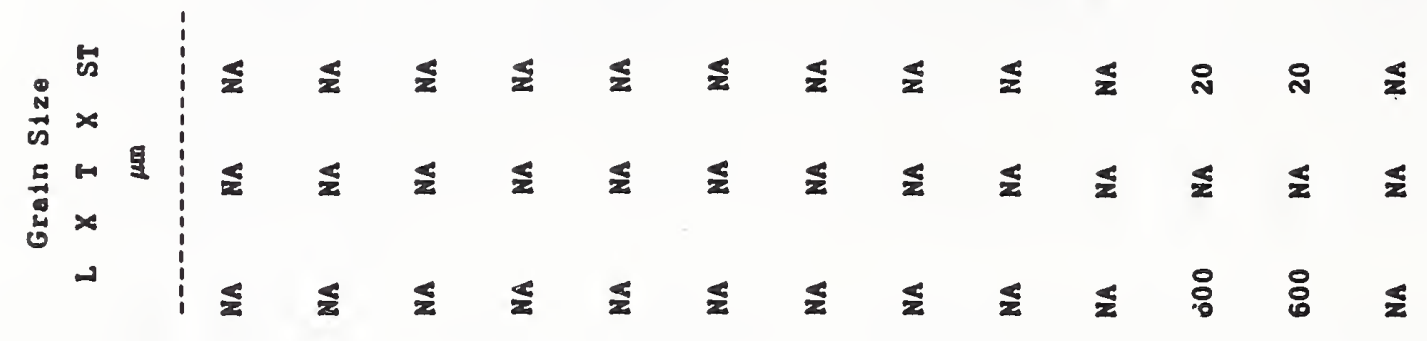

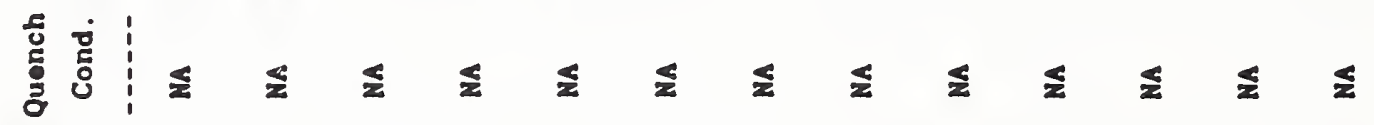
离离上:

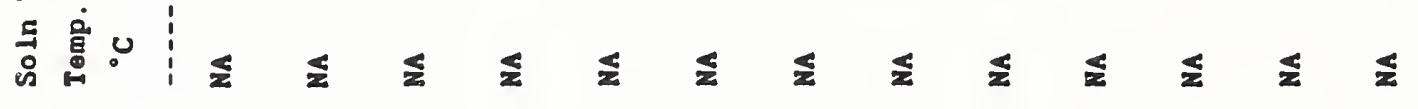

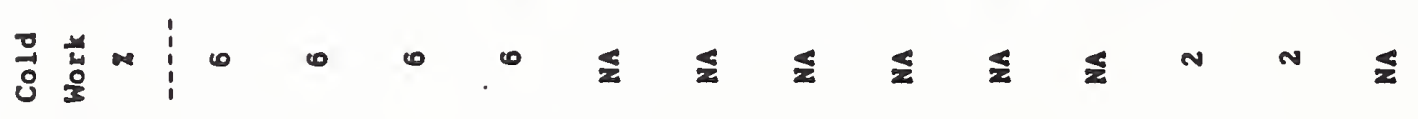

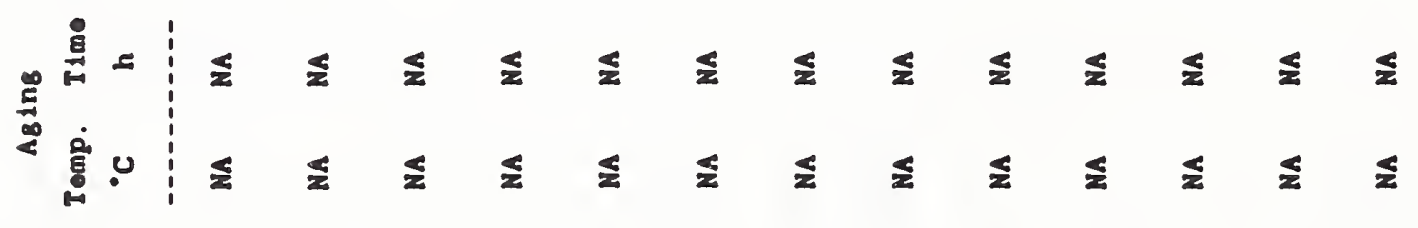

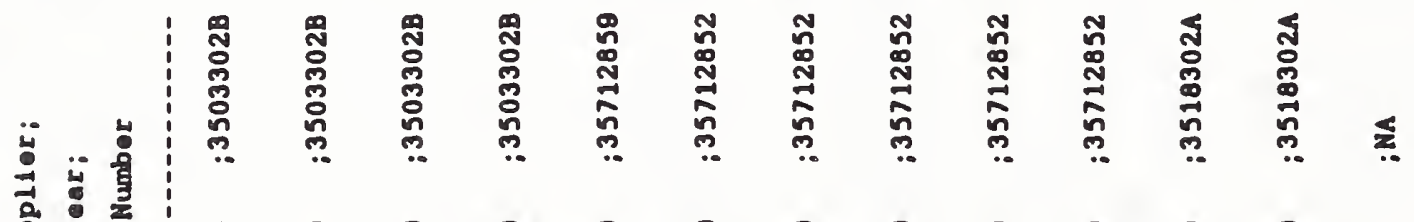

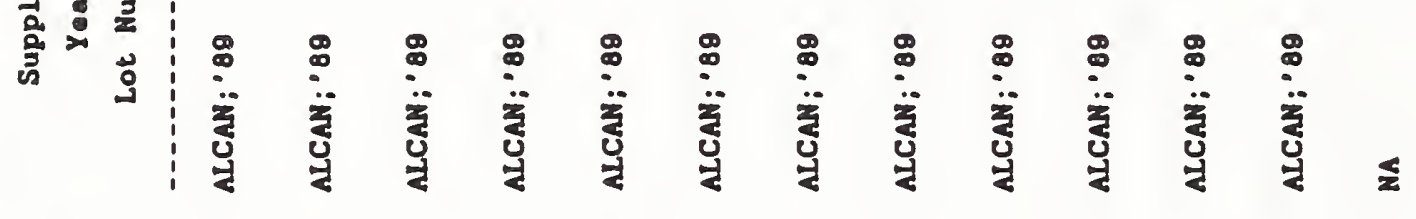

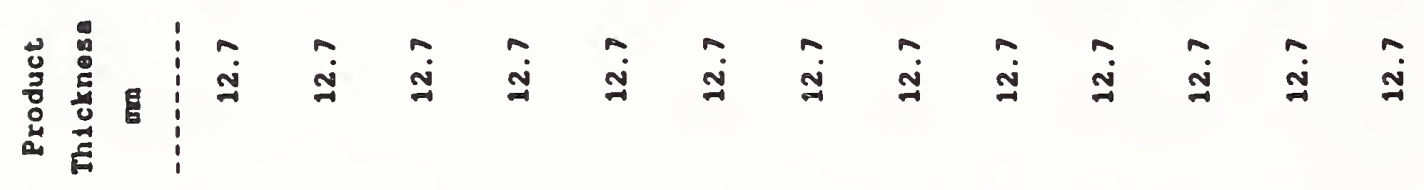

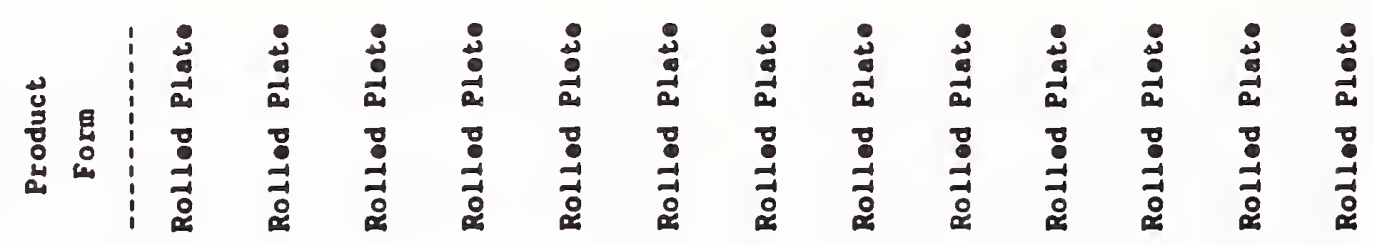

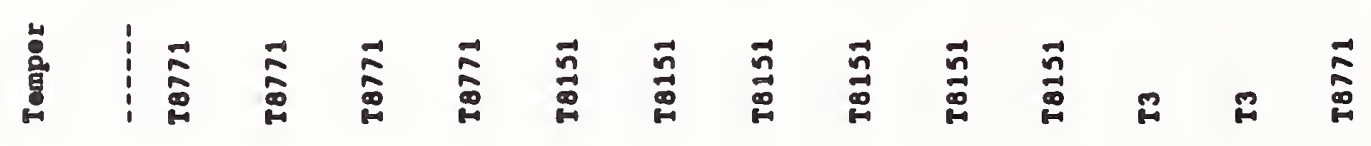

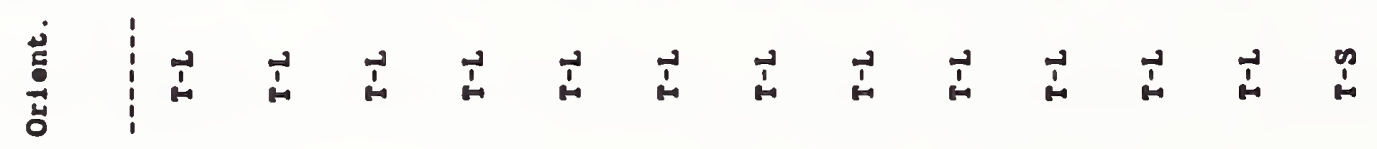

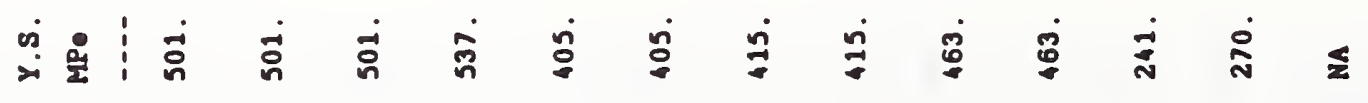

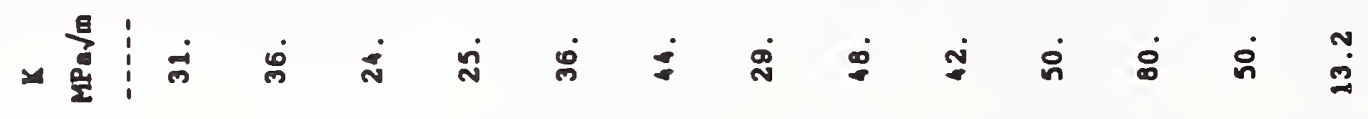

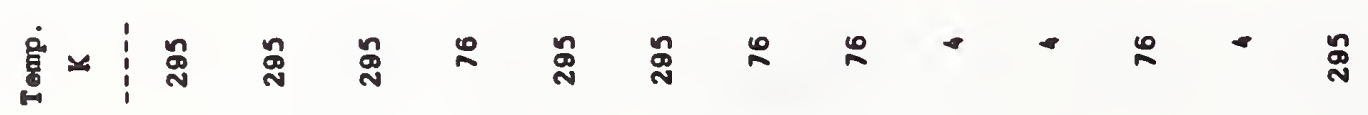

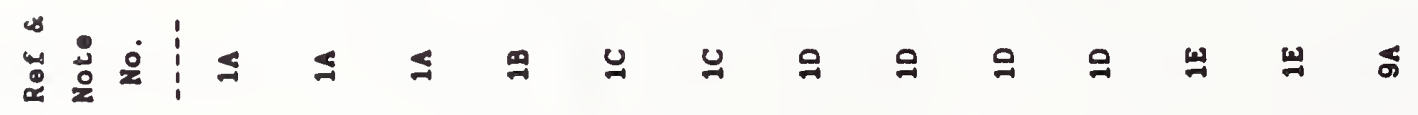


Comments from the Al-Li Alloy 8090 Data Table

\section{Reference and}

Note Number

9A--Values reported are "minimum" properties. 


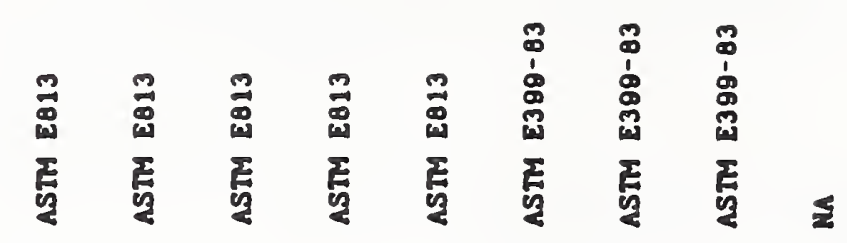

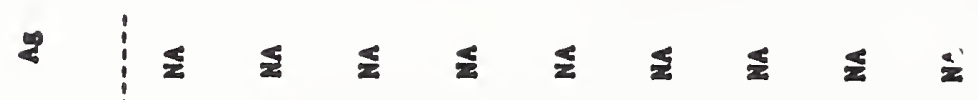

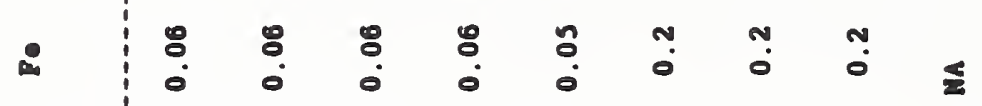

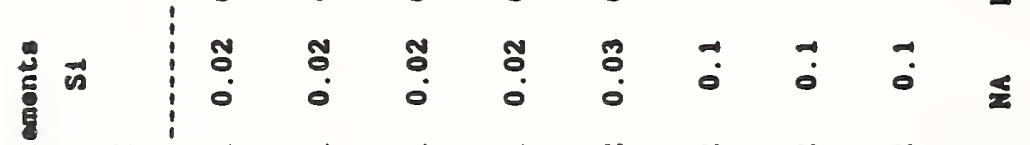

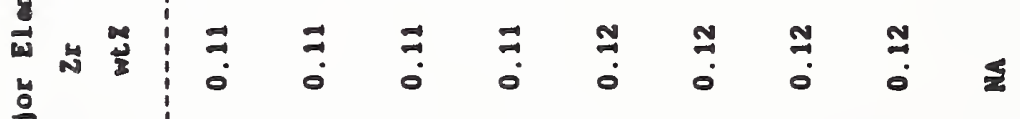

严定

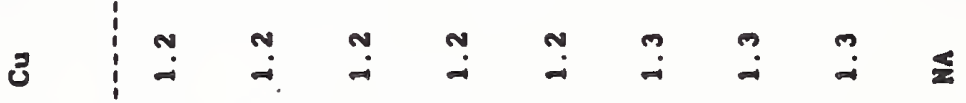

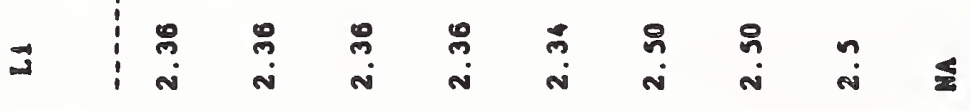

$\frac{\ln }{\operatorname{lin}^{2}}$

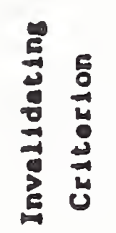

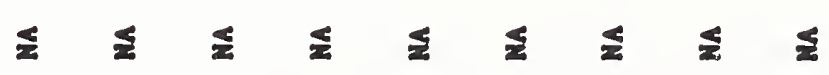

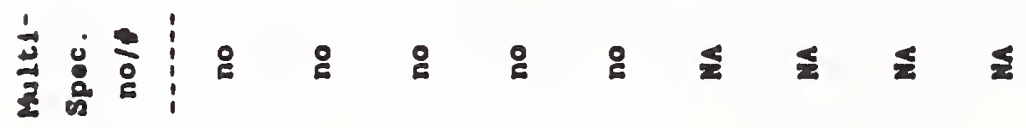
施竞:

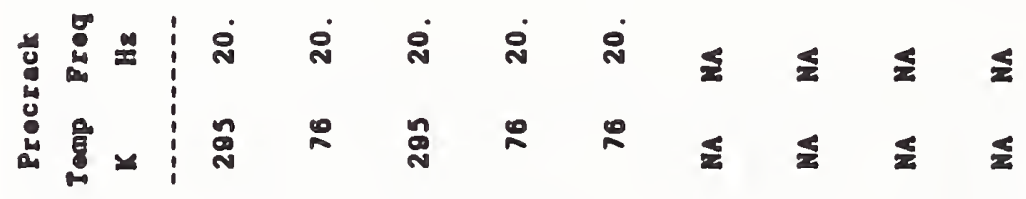

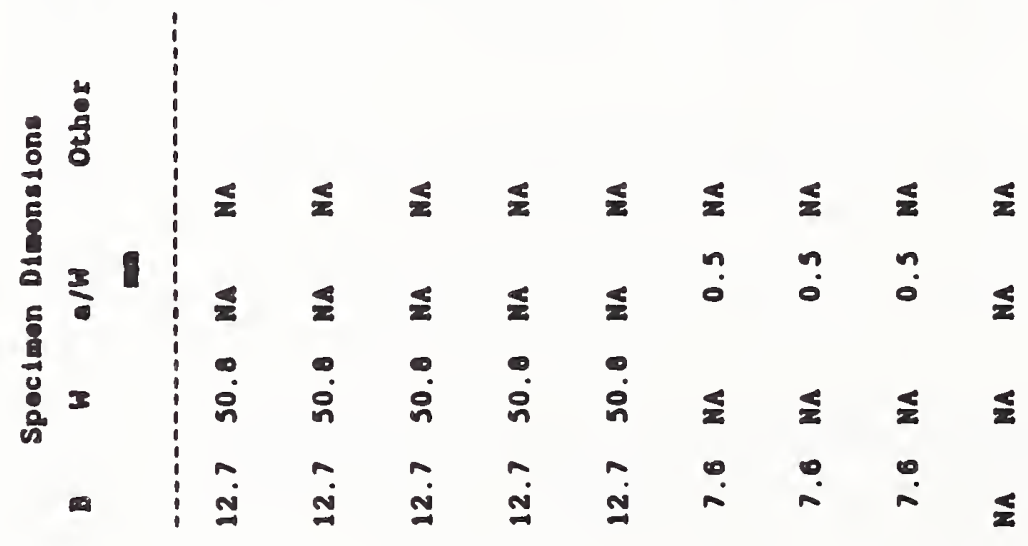
量:

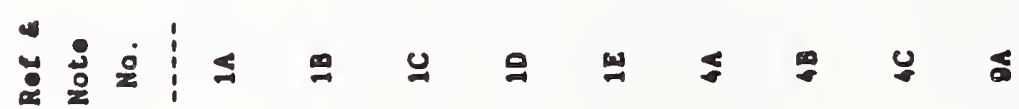




\section{Comments from the Al-Li Alloy 8090 Test Conditions Table}

\section{Reference and}

Note Number

9A--Reported composition is the average of the range provided for in the Lockheed requirements. 
FRACTURE TOUGHNESS, $\mathrm{ksi}^{\mathrm{i}} \mathrm{in}^{1 / 2}$

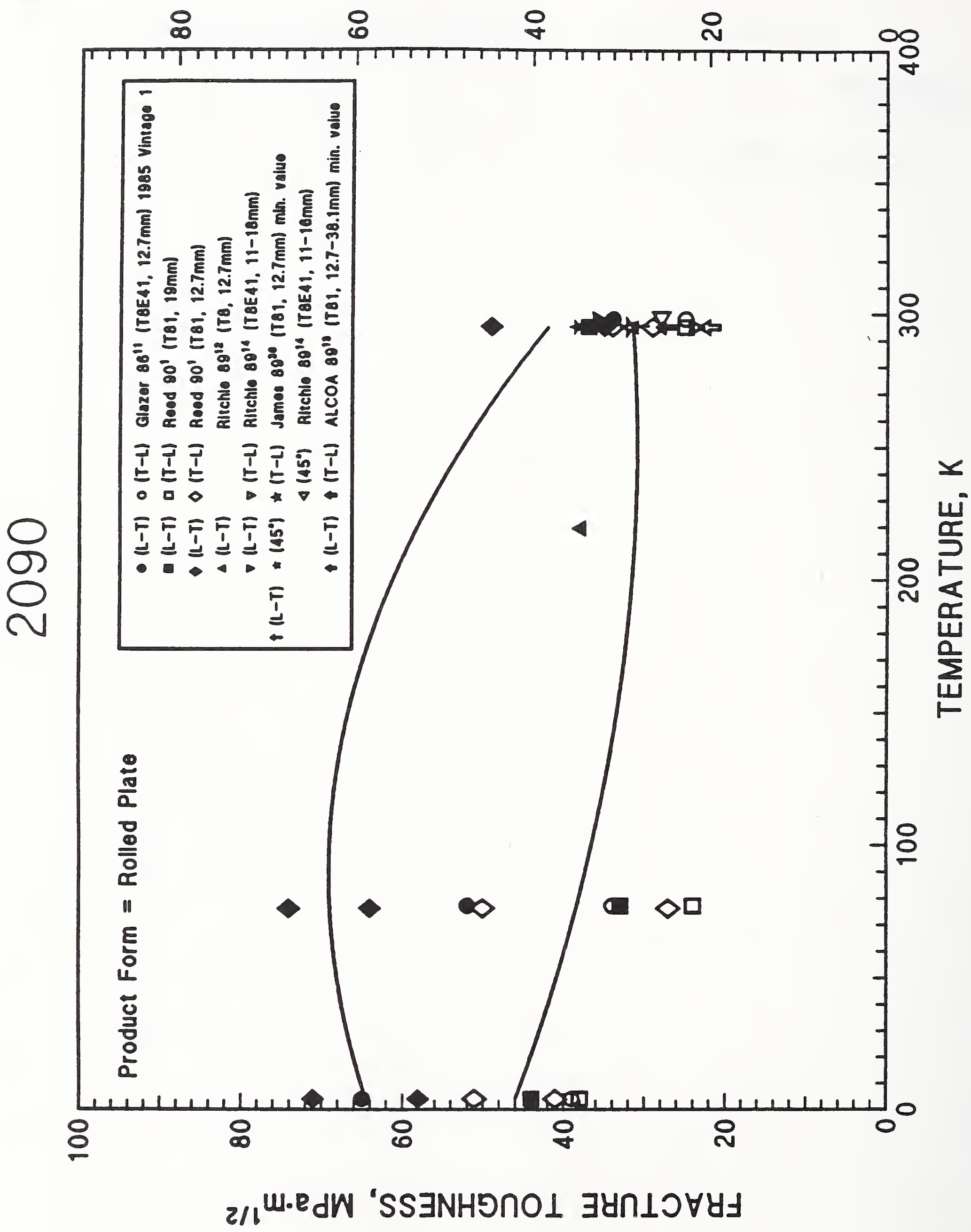


FRACTURE TOUGHNESS, $\mathrm{ksi} \cdot \mathrm{in}^{1 / 2}$

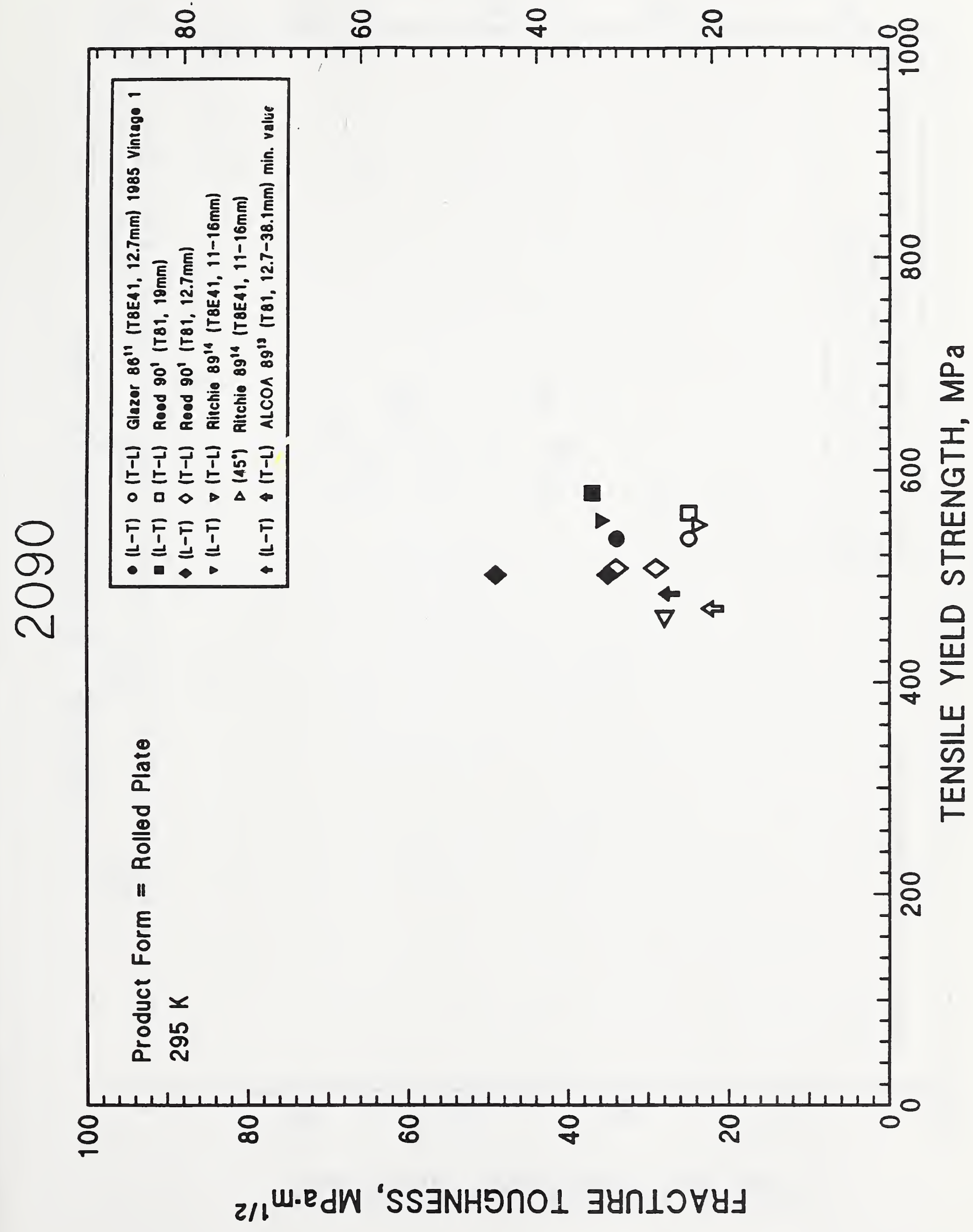


FRACTURE TOUGHNESS, $\mathrm{ksi}^{\mathrm{i}} \mathrm{n}^{1 / 2}$

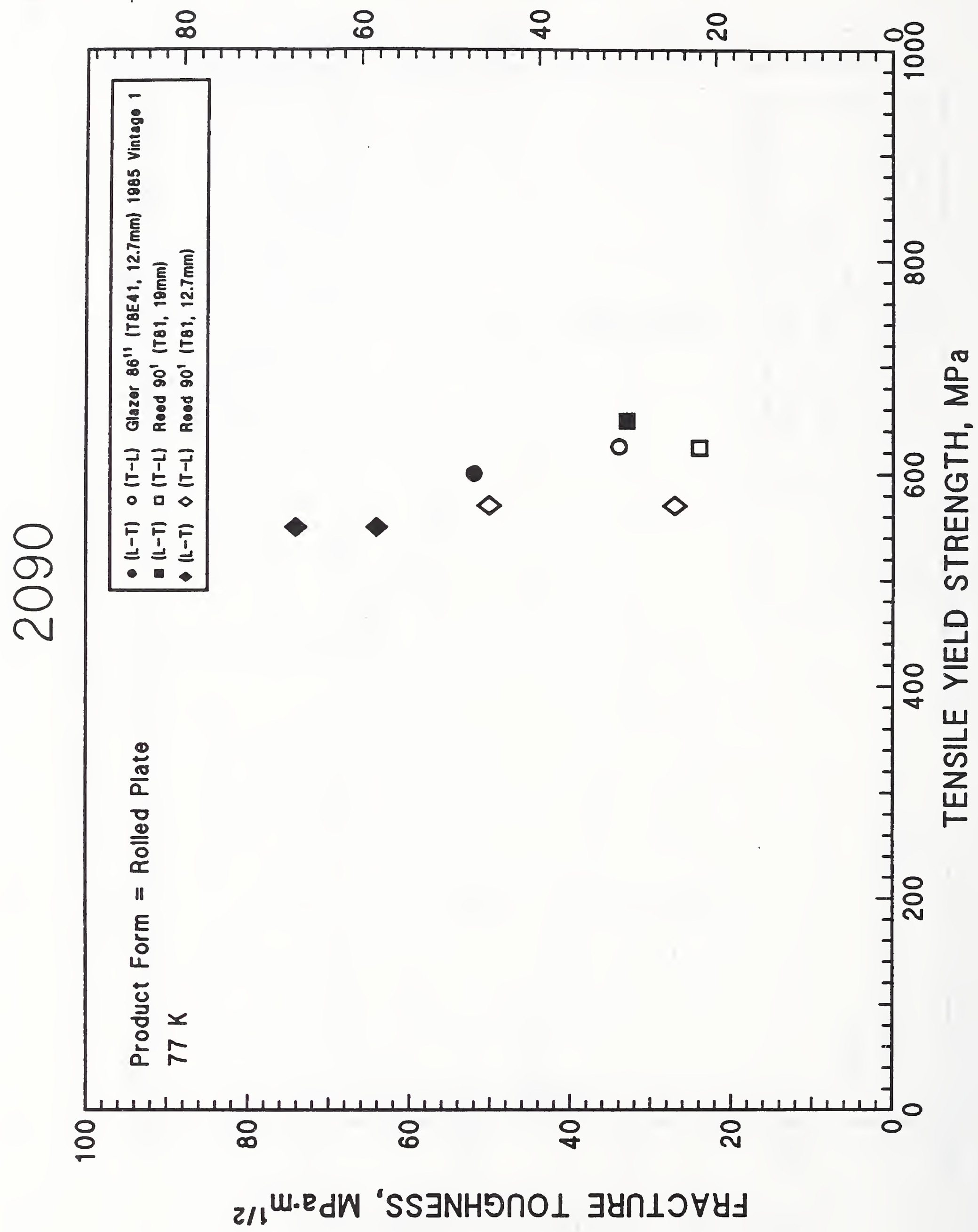


FRACTURE TOUGHNESS, $\mathrm{ksi}^{\mathrm{i}} \mathrm{in}^{1 / 2}$

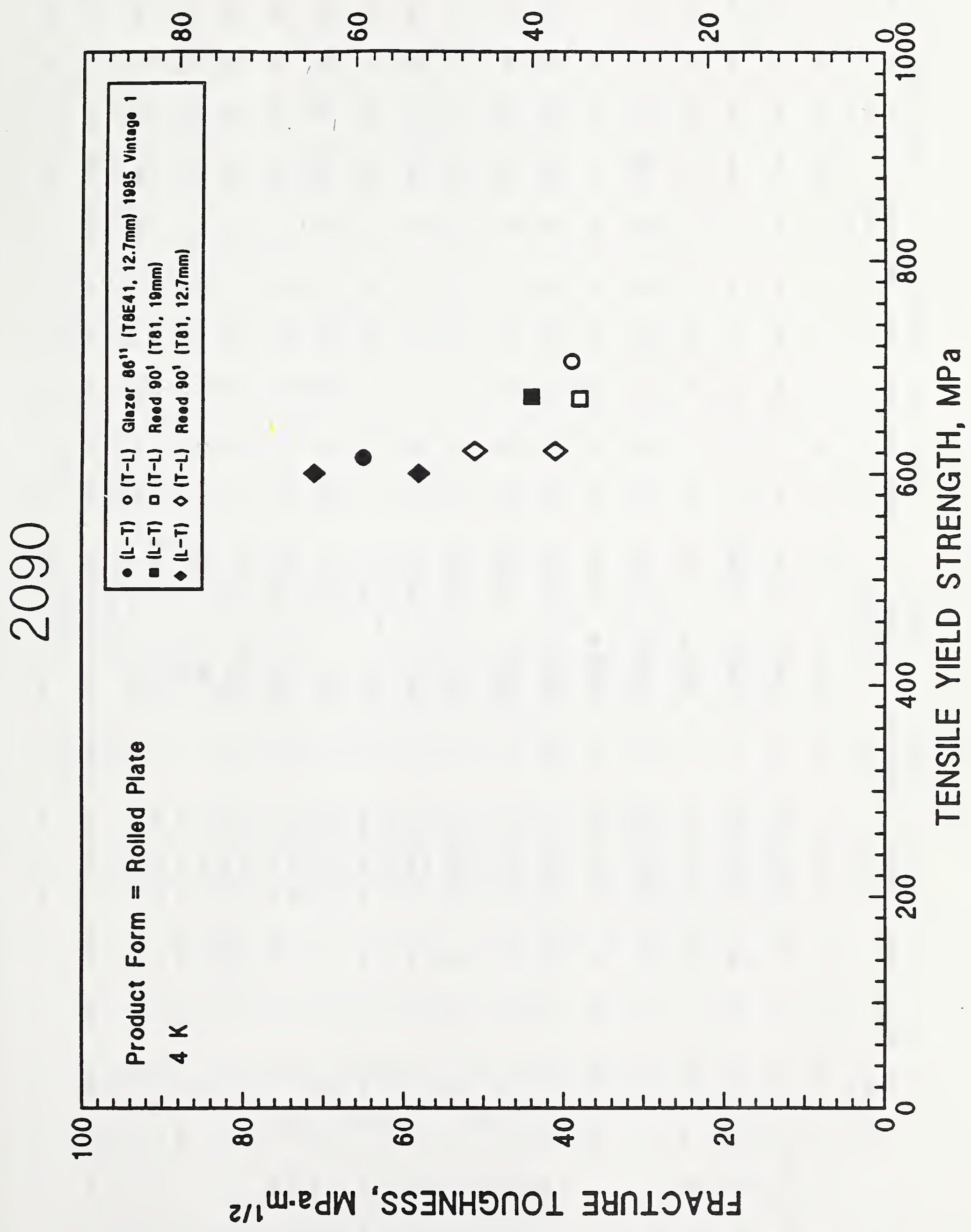




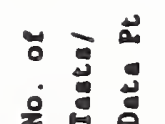

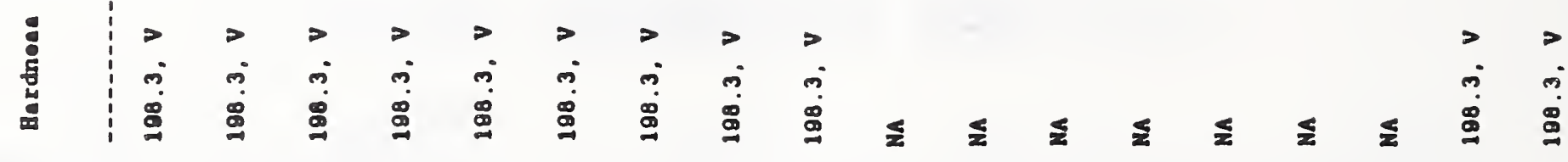
:

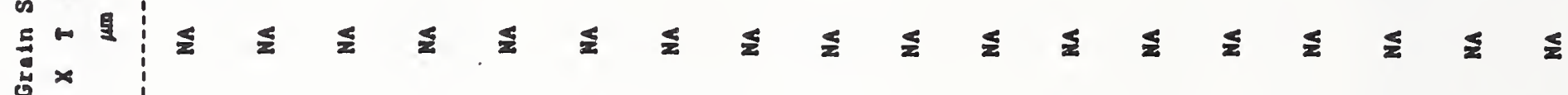

•

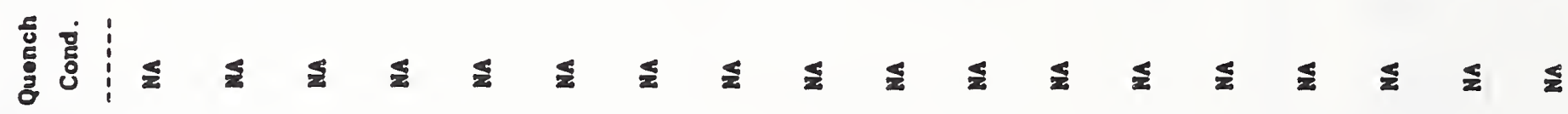
:

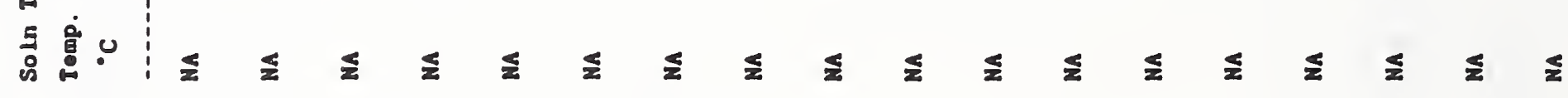

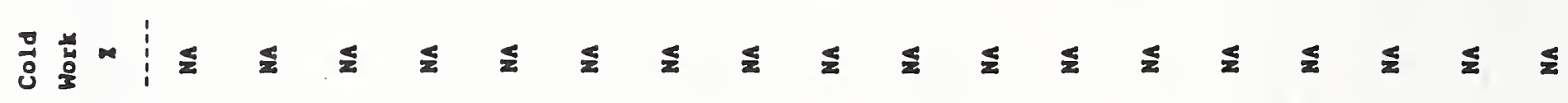

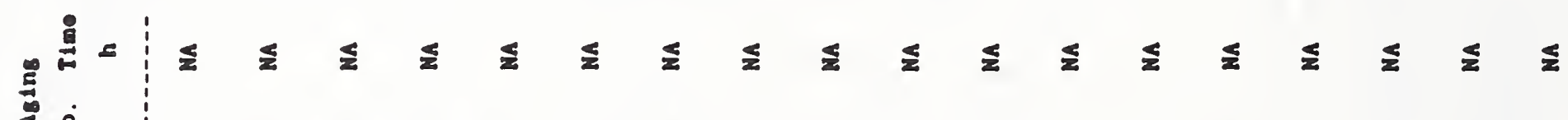

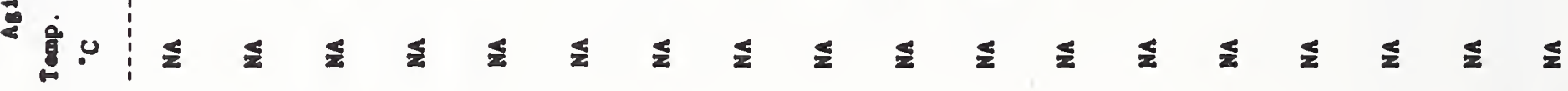

\section{:}

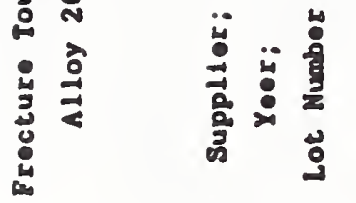

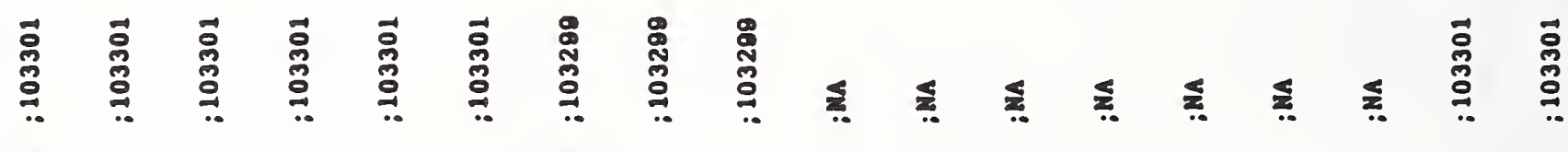

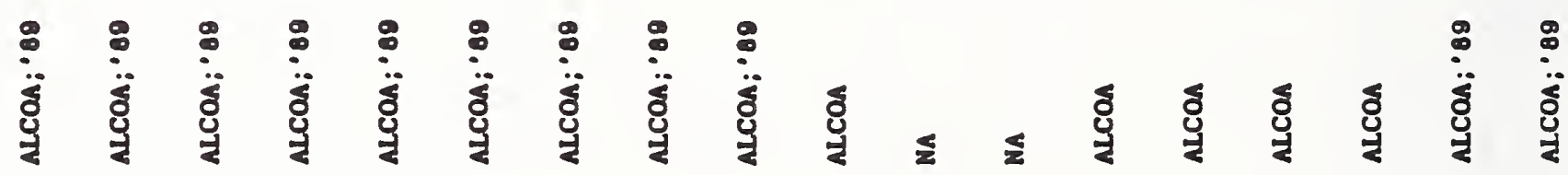

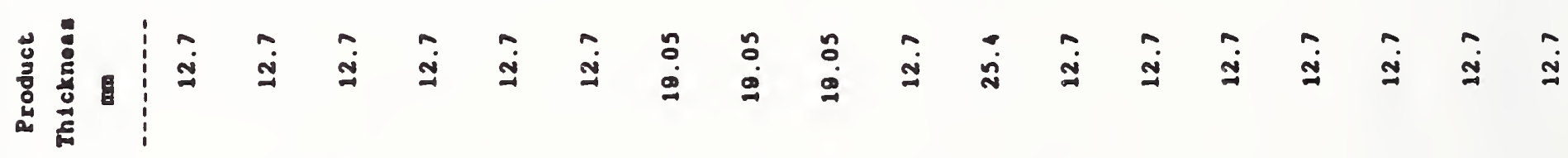

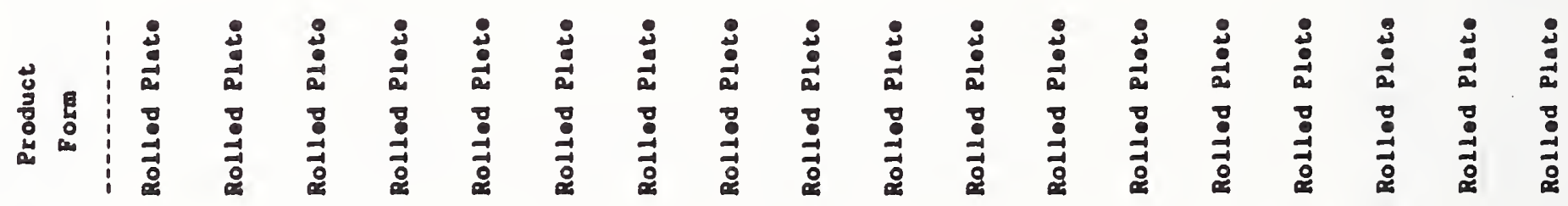

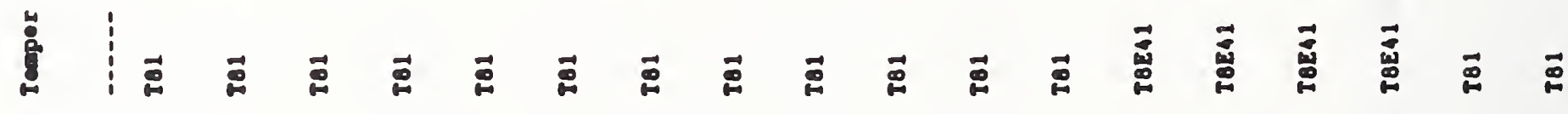

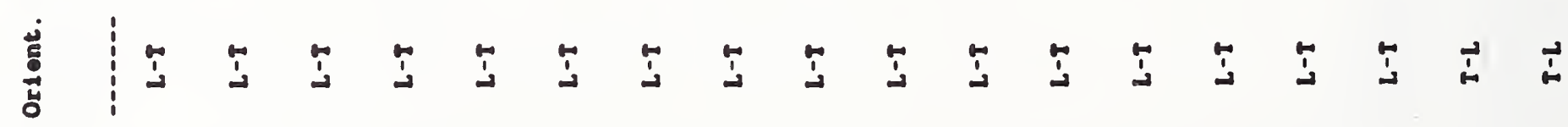

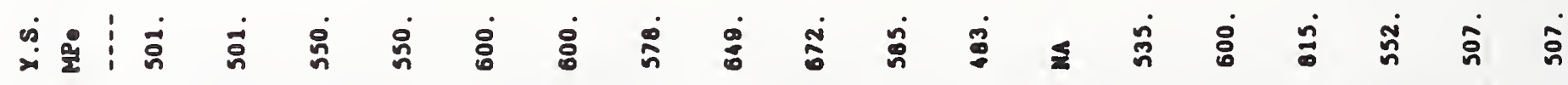

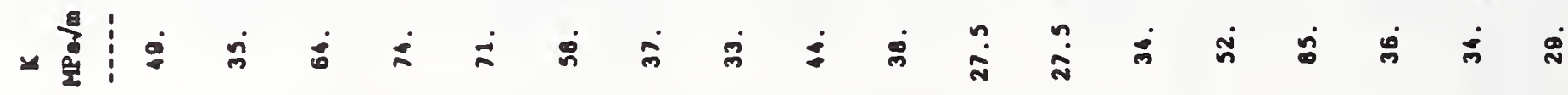
1)

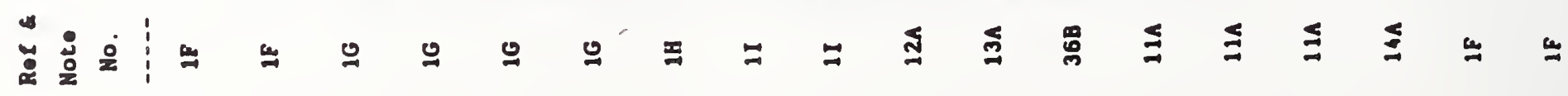




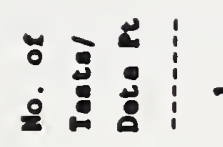

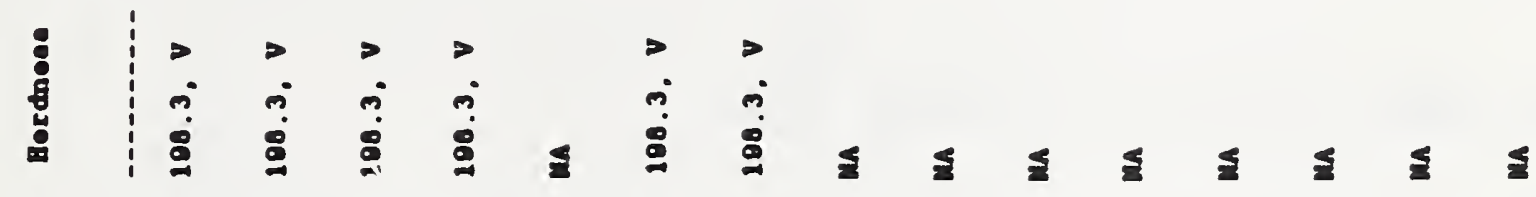

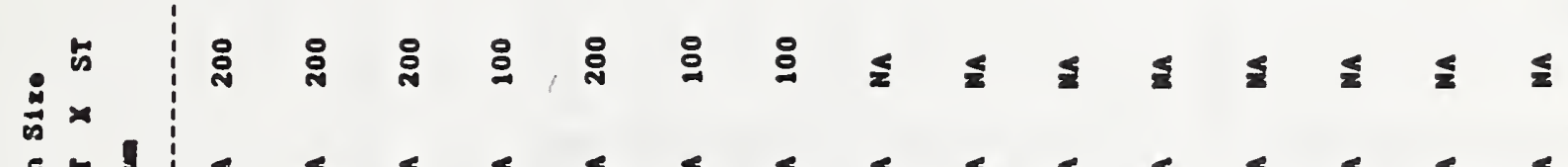

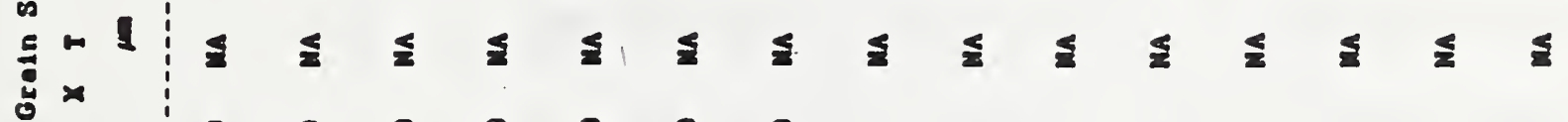
-

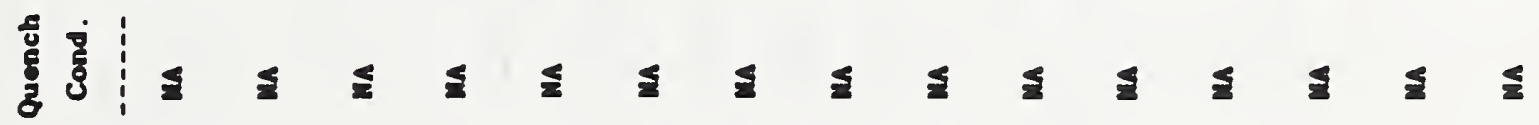

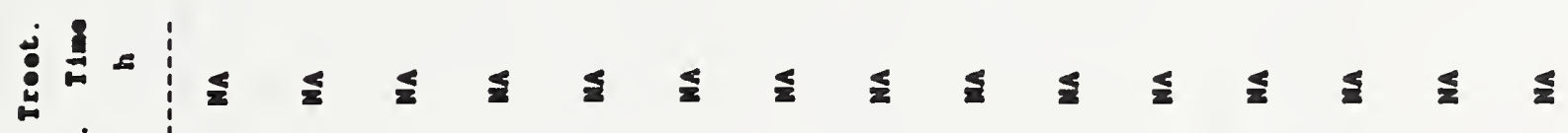

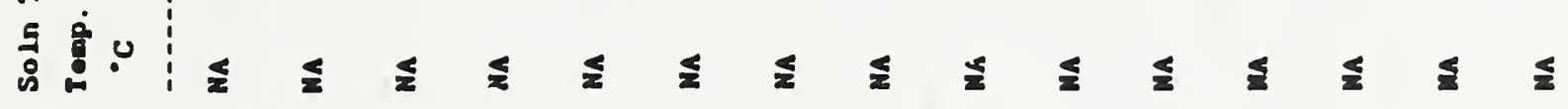

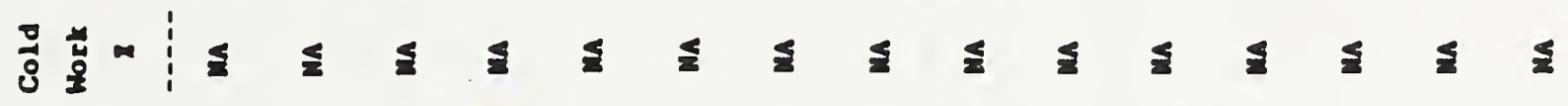

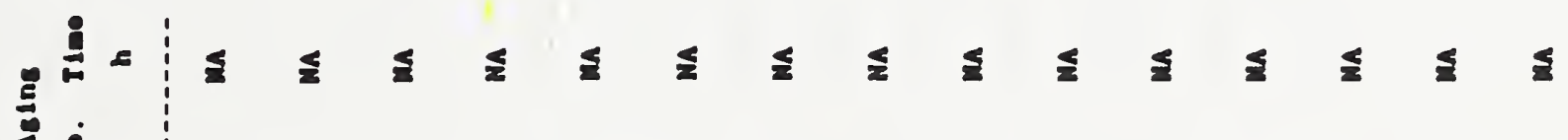

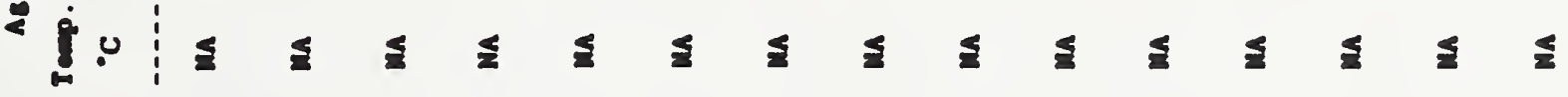

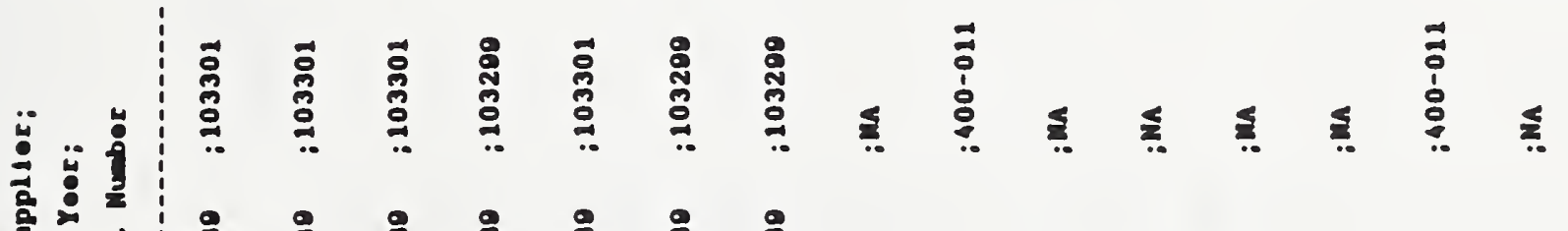

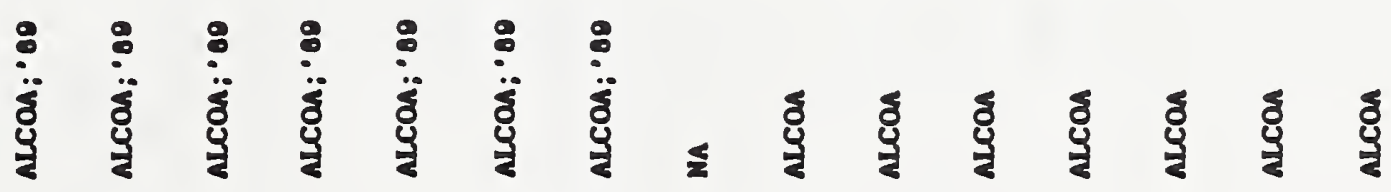

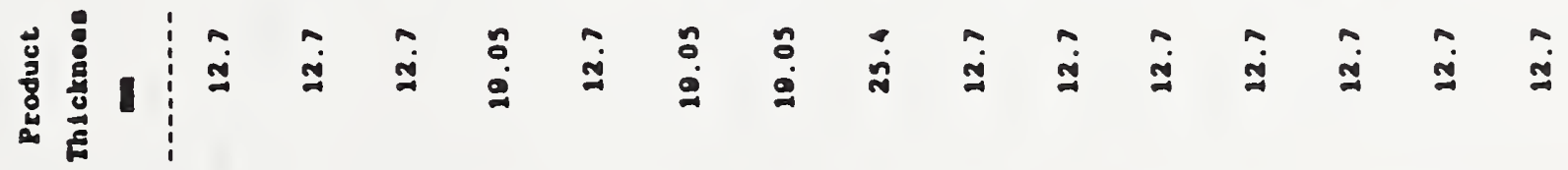

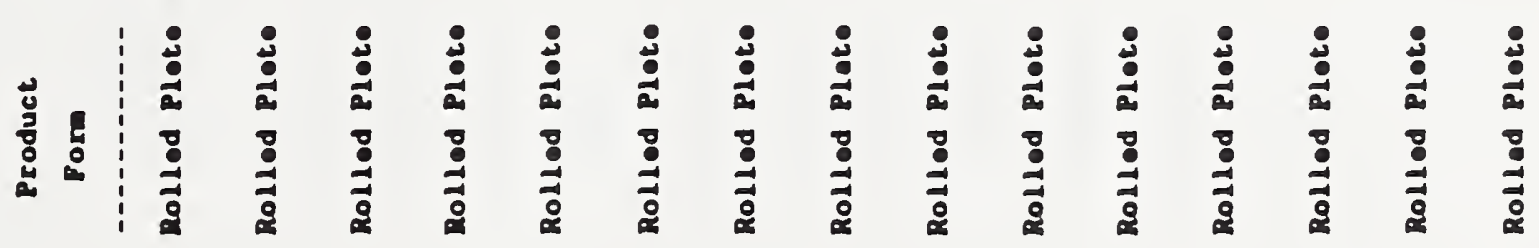

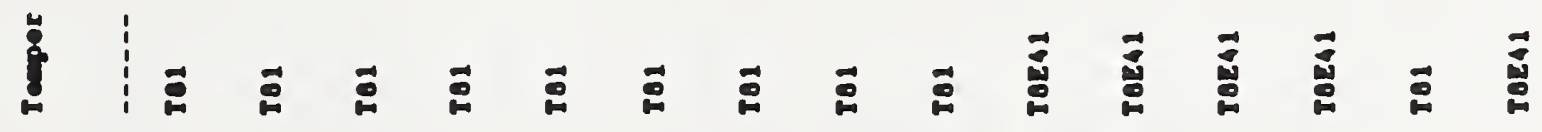

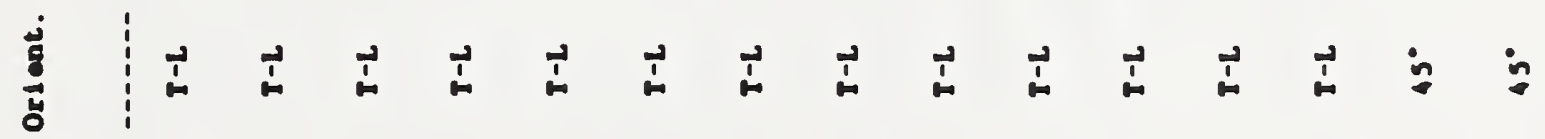

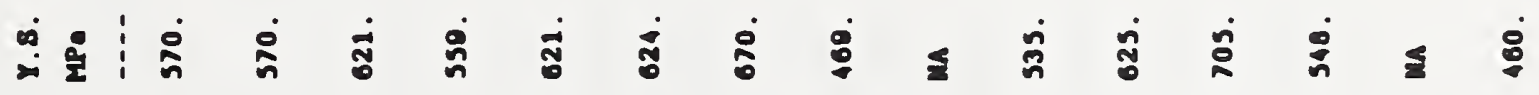

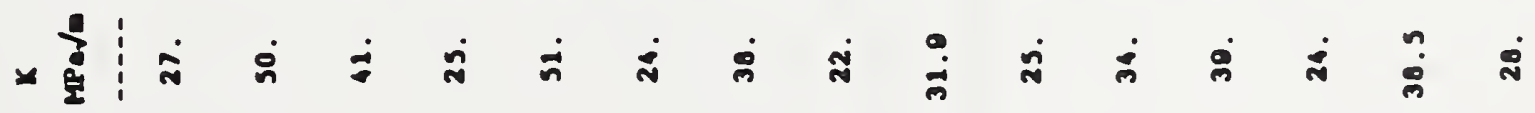

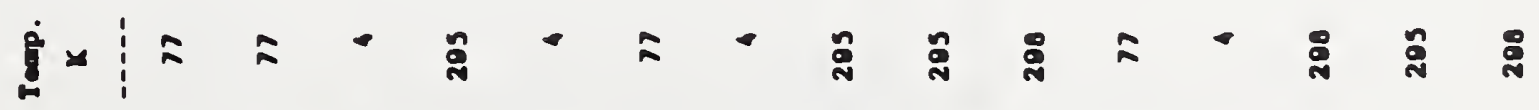

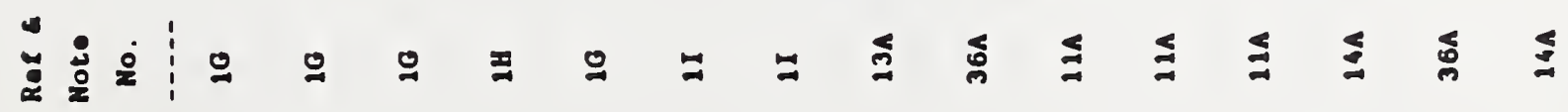


Comments from the Alloy 2090 Data Table

Reference and

Note Number

37B--Value reported is a proposed minimum value.

13A--Value reported are "minimum" properties. 
I

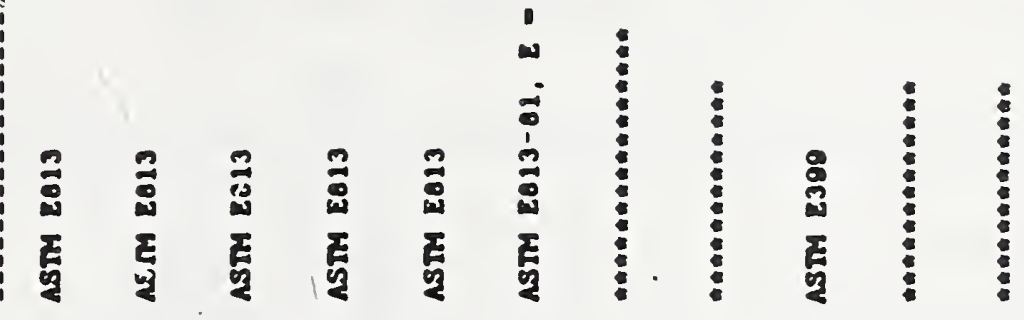

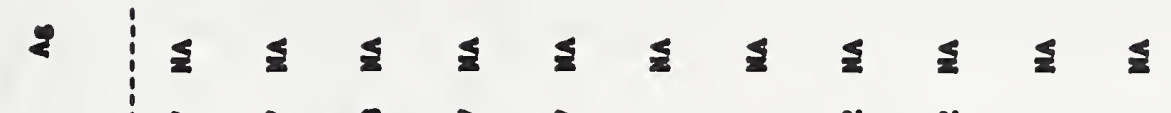

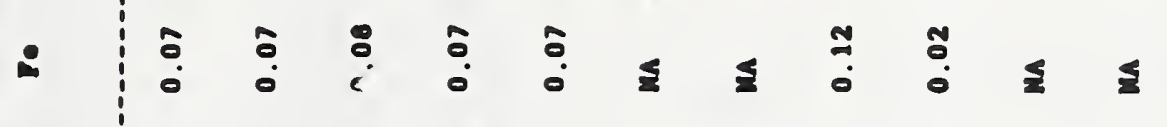

हैं

जै

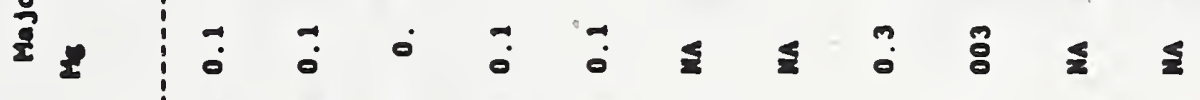

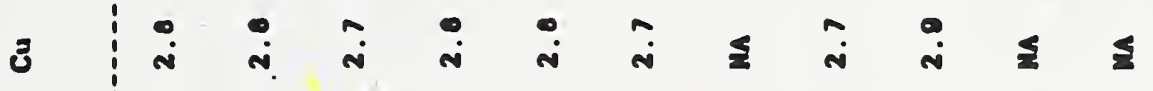

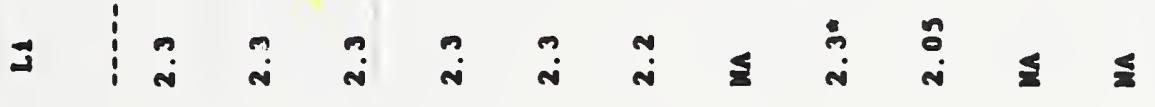

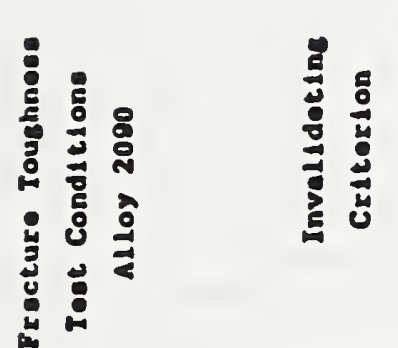

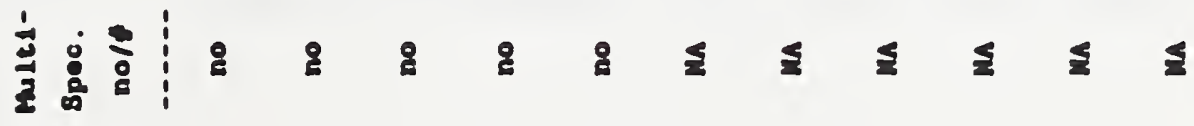

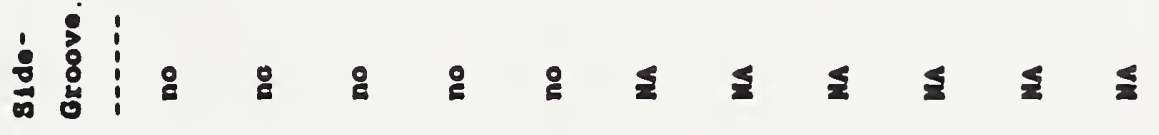

छ்

:

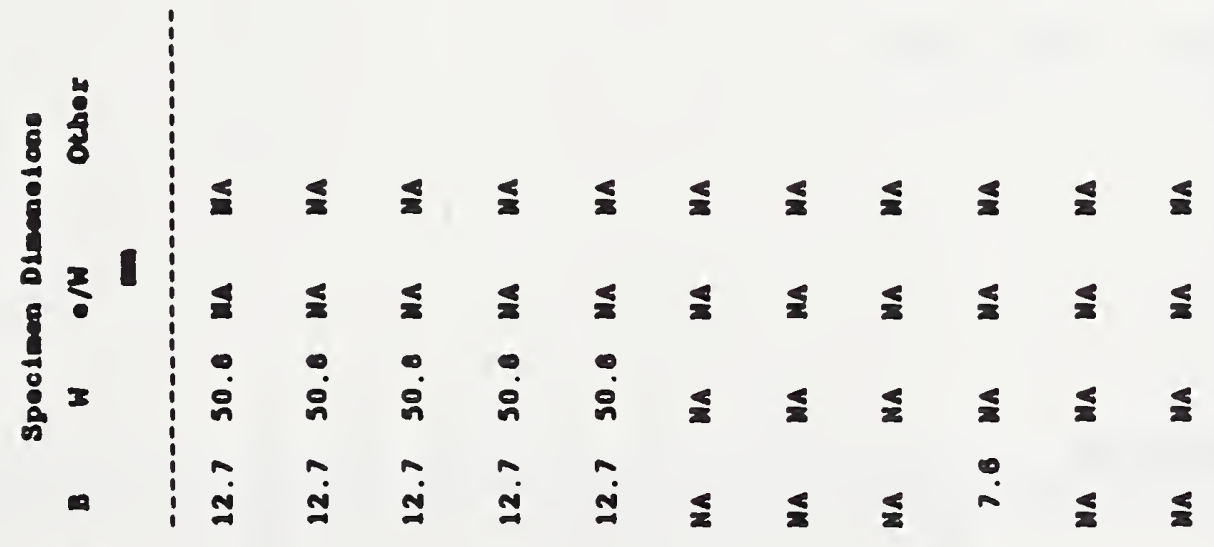

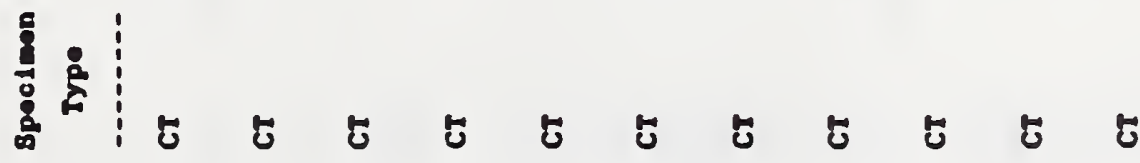

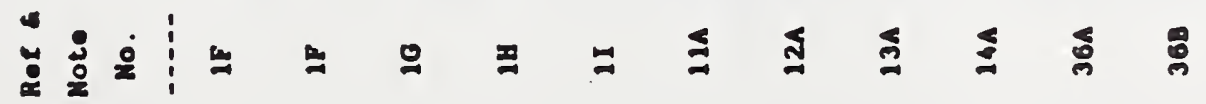


Comments from the Alloy 2090 Test Conditions Table

Reference and

Note Number

11A--Reported composition is based on nominal values.

13A--Reported composition is the average of the minimum and maximum values.

18A--Reported composition is based on nominal values.

Comments from the Alloy WL049 Data Table

Reference and

Note Number

$1 \mathrm{~J}-\mathrm{K}$ - - Values reported are the average of the range of grain sizes.

18A-E--Under the supplier column M.M. = Martin Marietta. 
FRACTURE TOUGHNESS, $\mathrm{ksi}^{\mathrm{i}} \mathrm{in}^{1 / 2}$

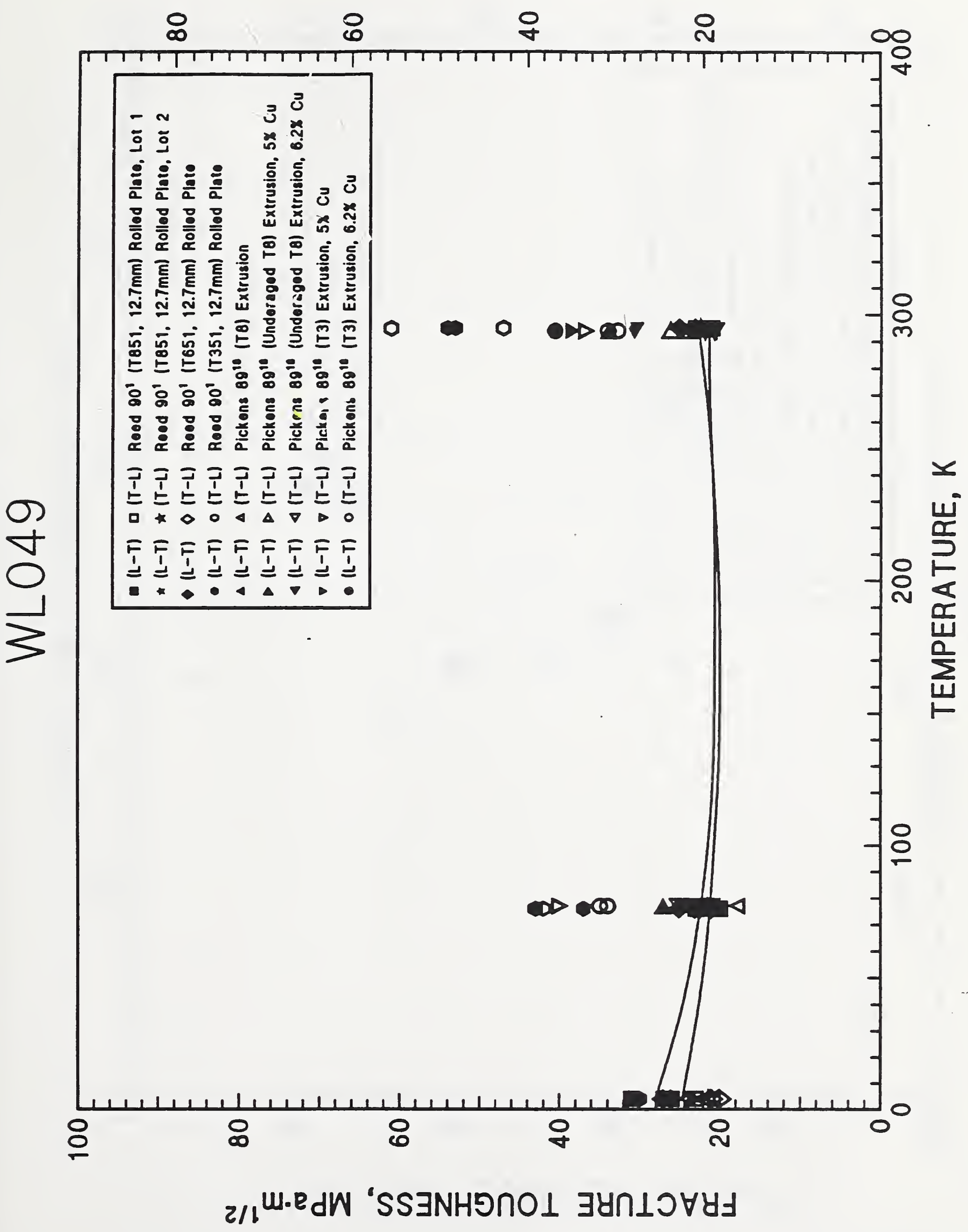


FRACTURE TOUGHNESS, $\mathrm{ksi}^{\mathrm{i}} \mathrm{in}^{1 / 2}$

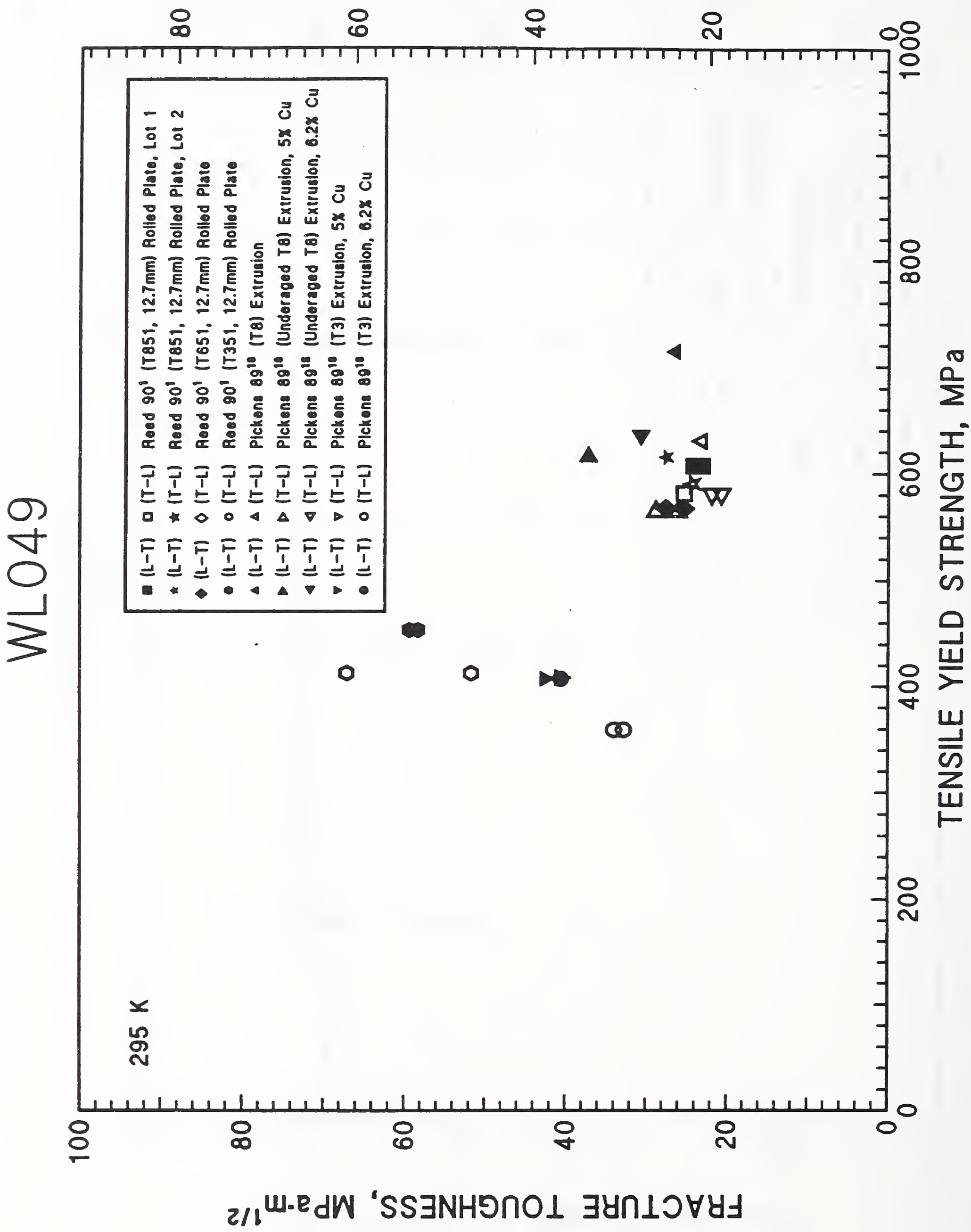


FRACTURE TOUGHNESS, $\mathrm{ksi}^{-1 \mathrm{in}^{1 / 2}}$

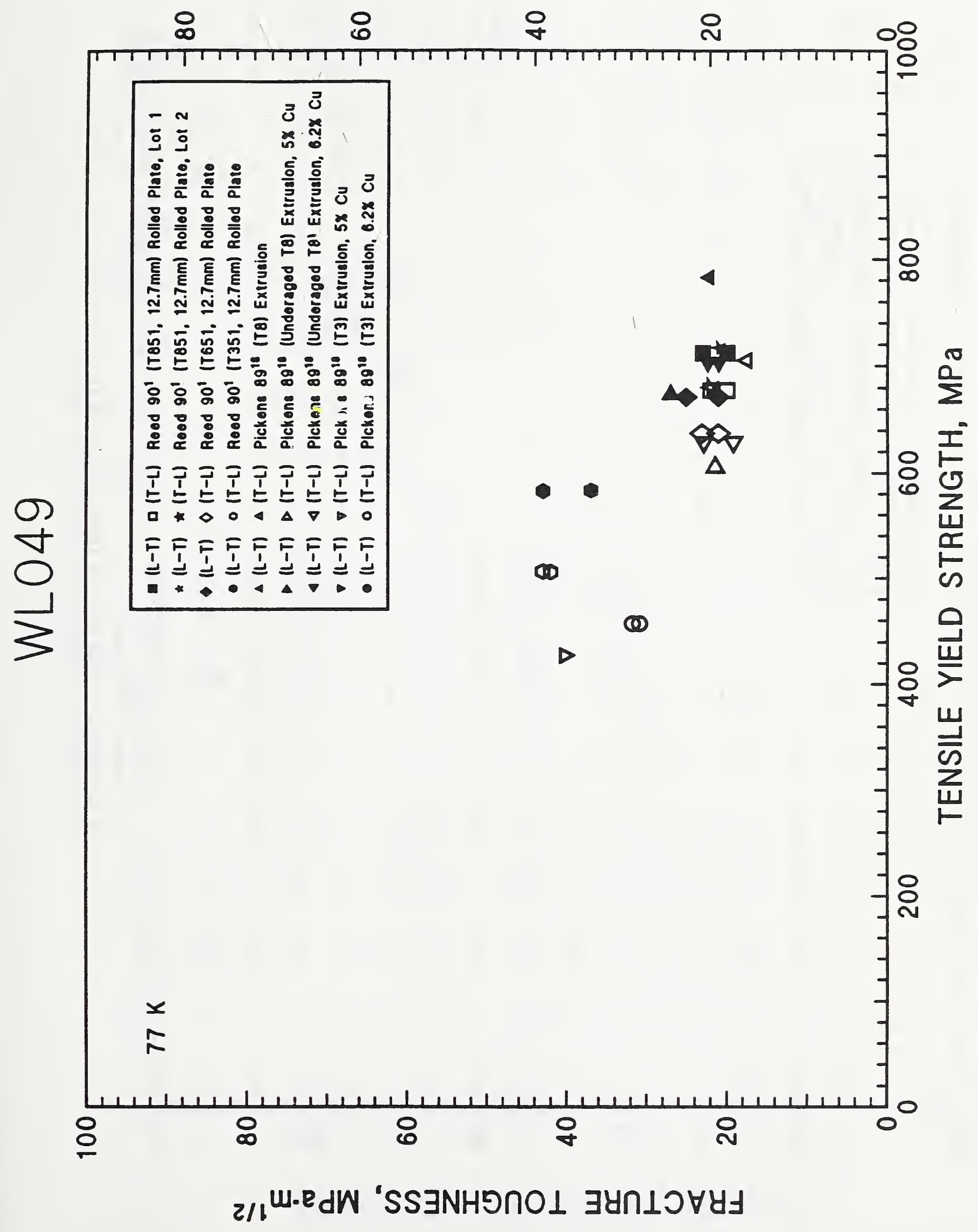


FRACTURE TOUGHNESS, $\mathrm{ksi} \cdot \mathrm{in}^{1 / 2}$

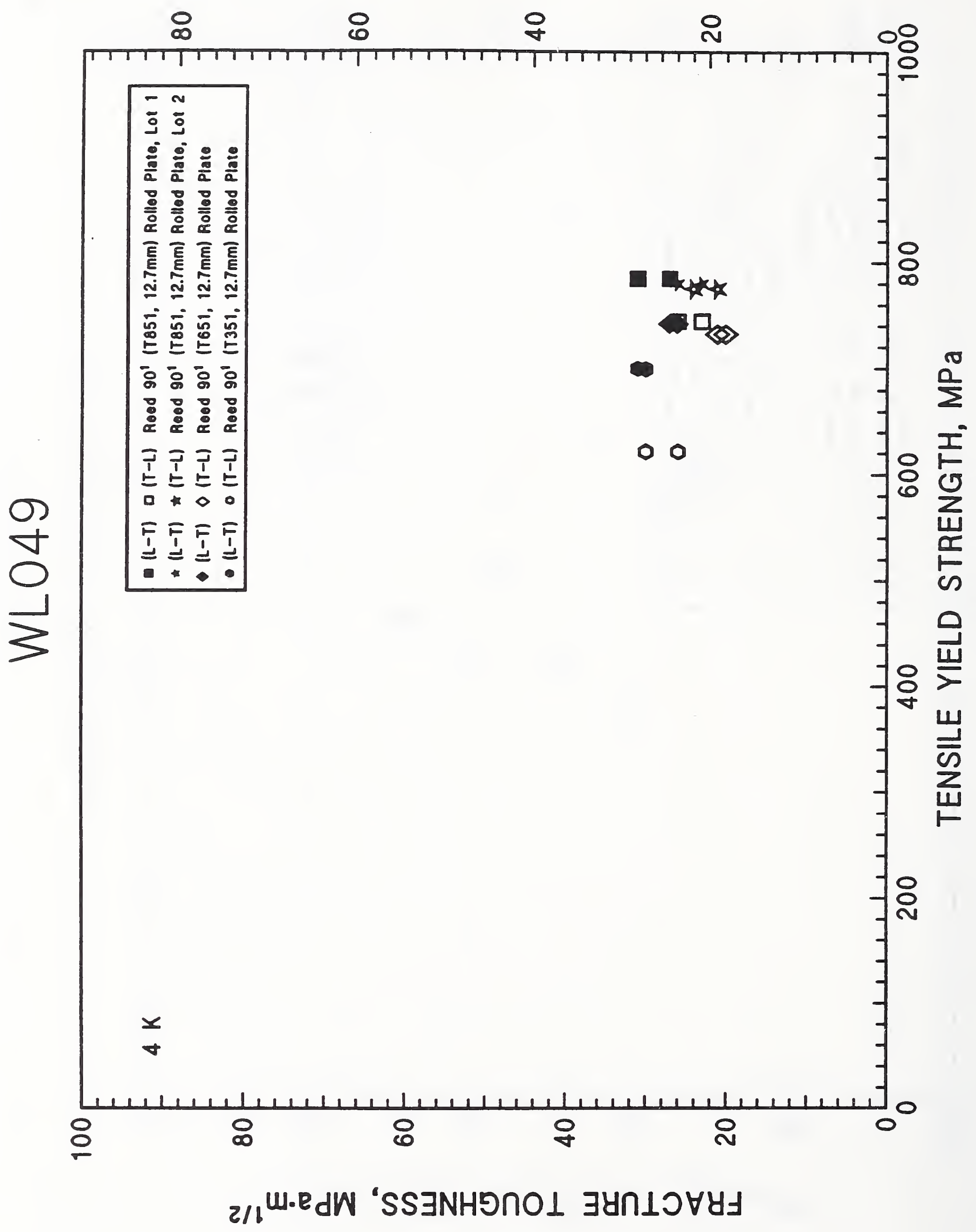




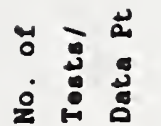

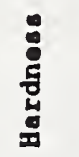

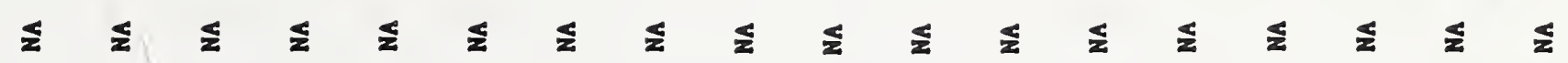

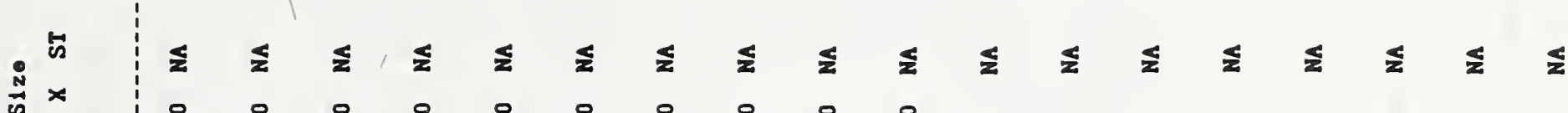
ज小是 ڤ் 竞㝘 通慁

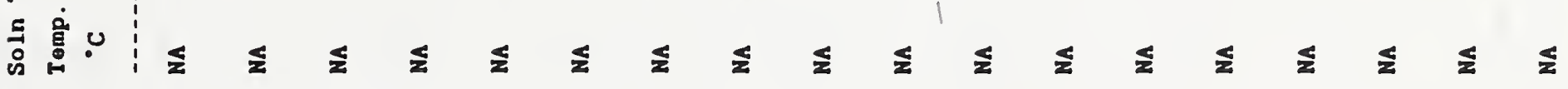

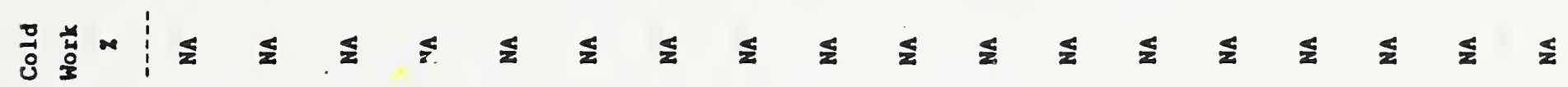

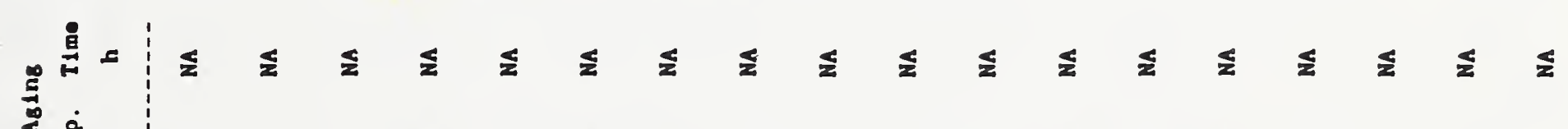

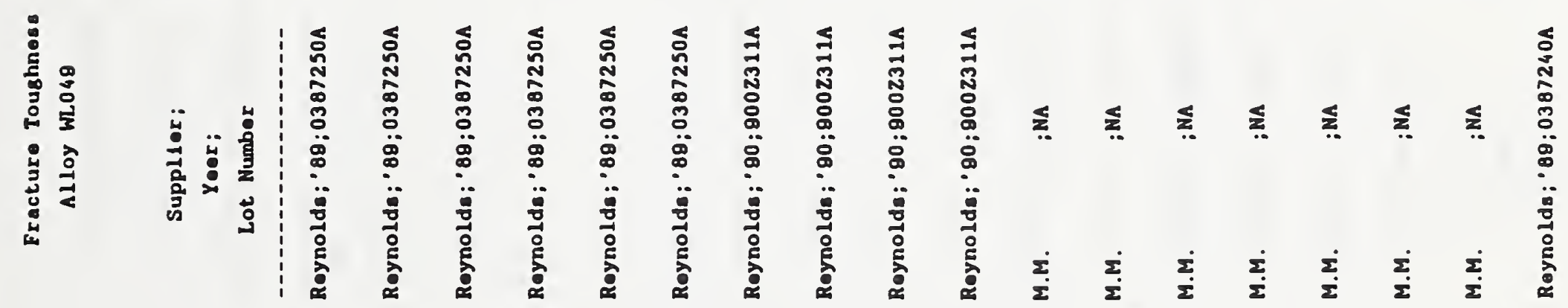

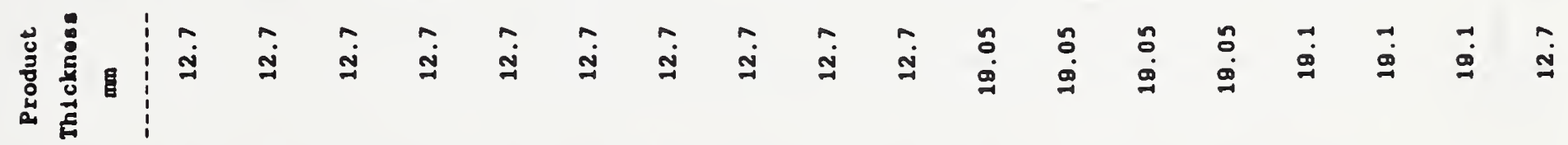

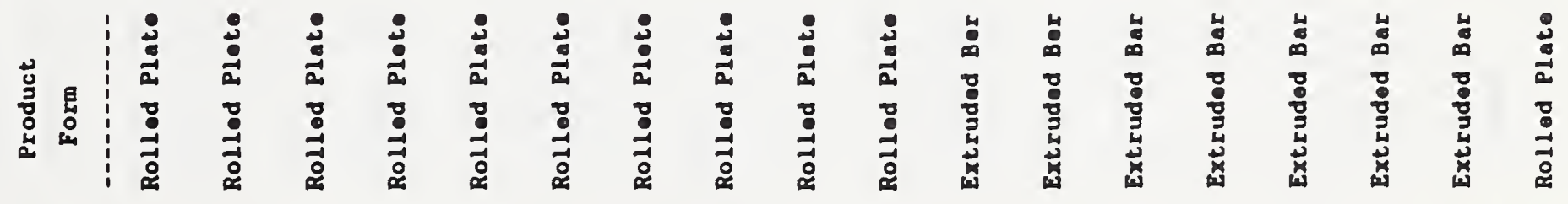
兽 蒄

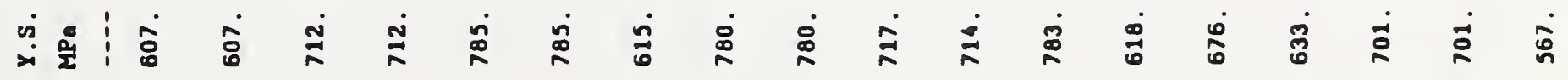
×

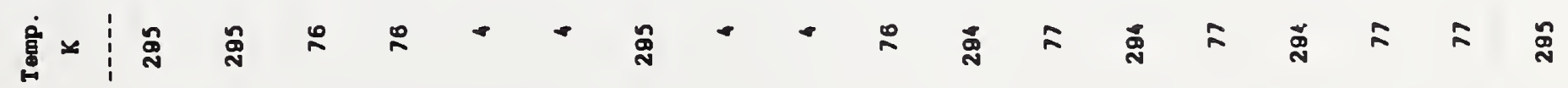
过 


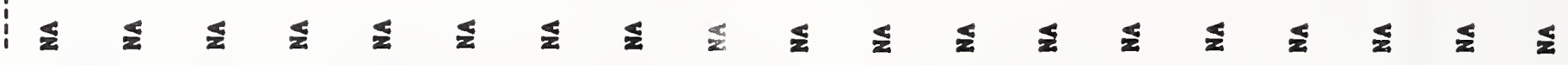
䒴 Е

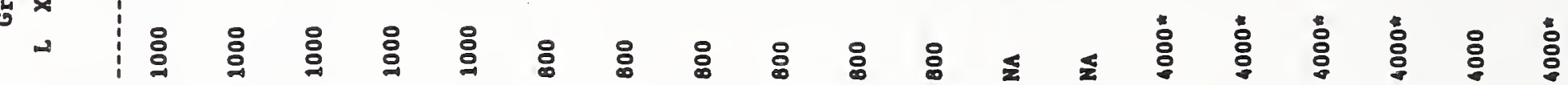

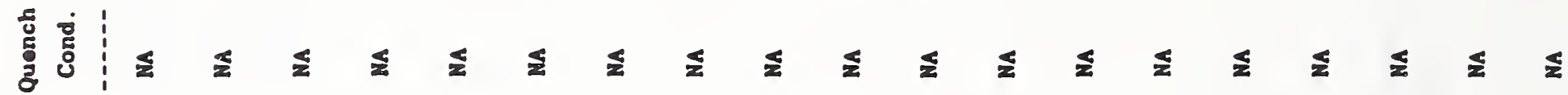

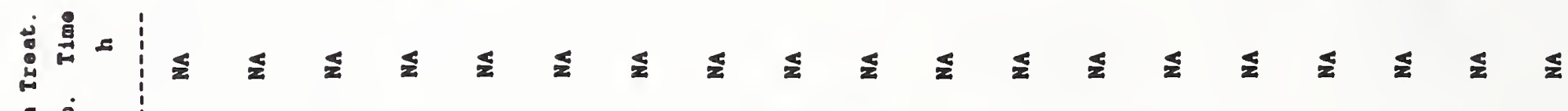

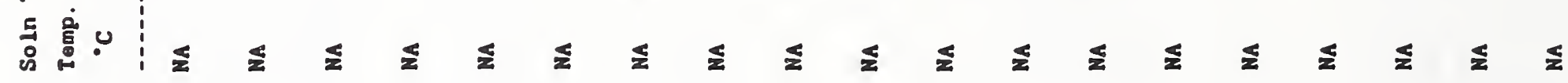

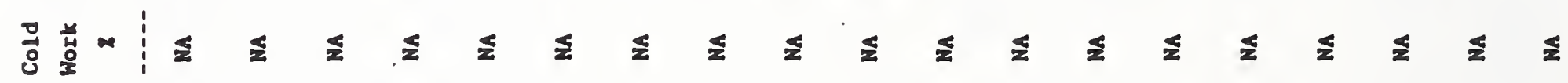

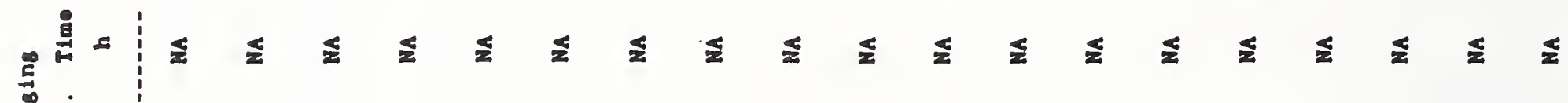
道

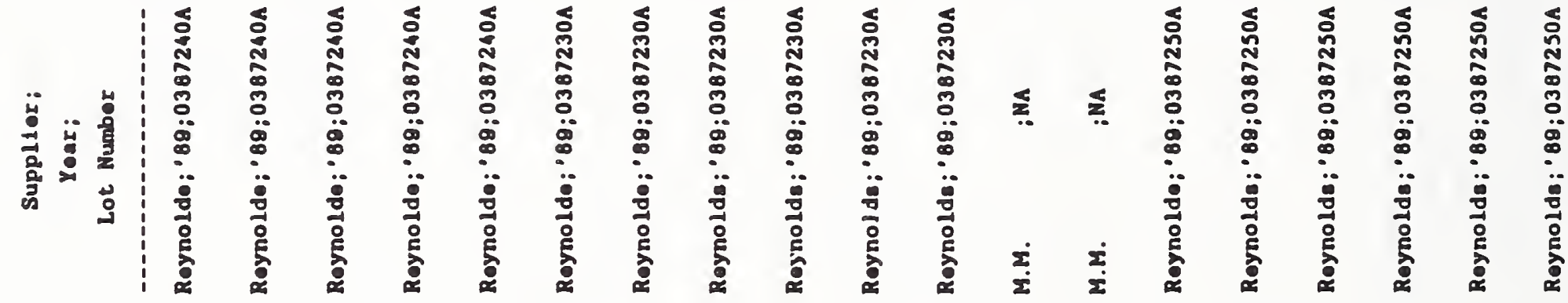

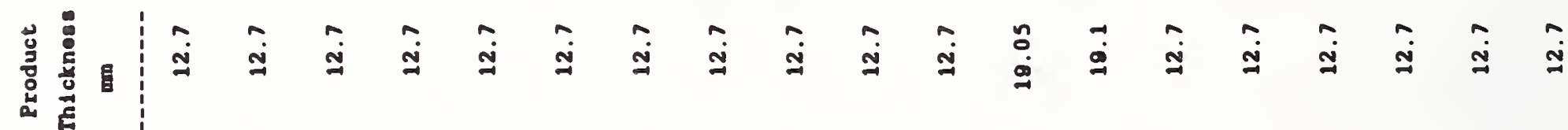

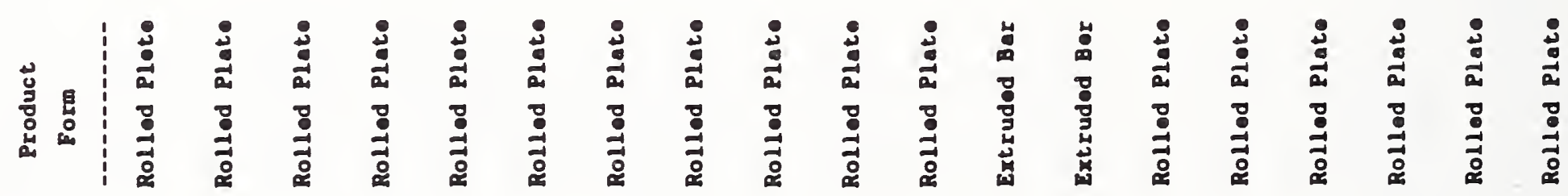

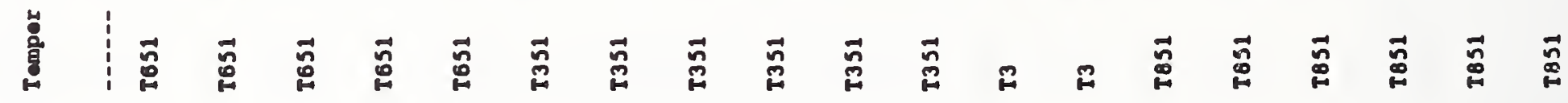
泀

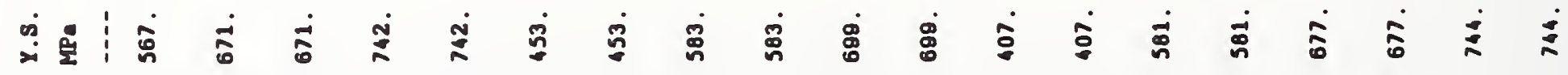

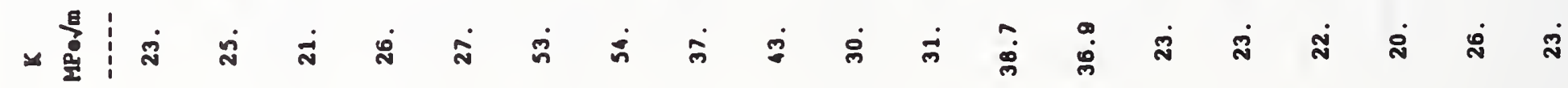
菑ะ

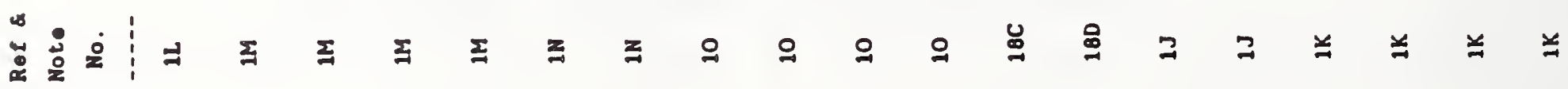




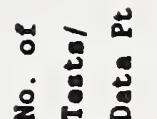

密

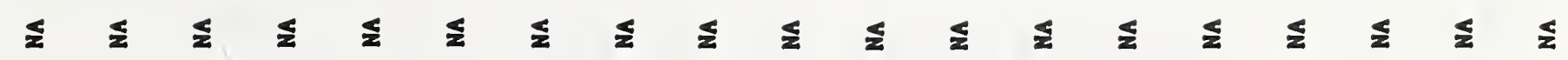

落

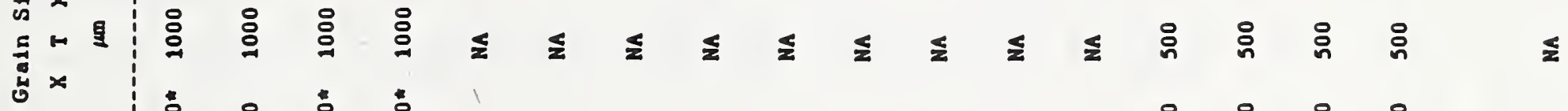
小

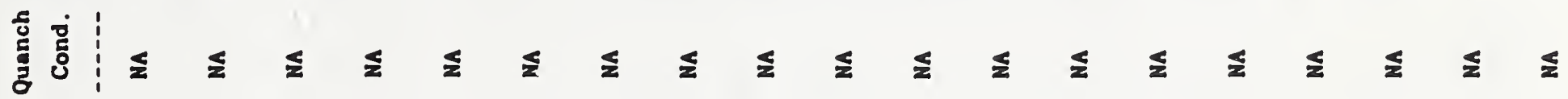

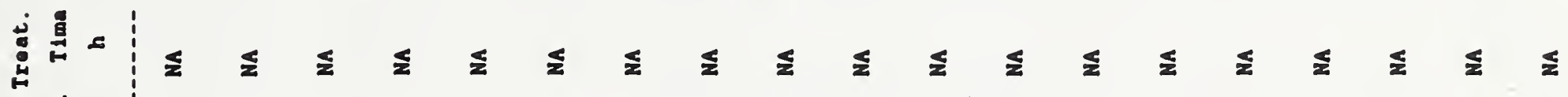

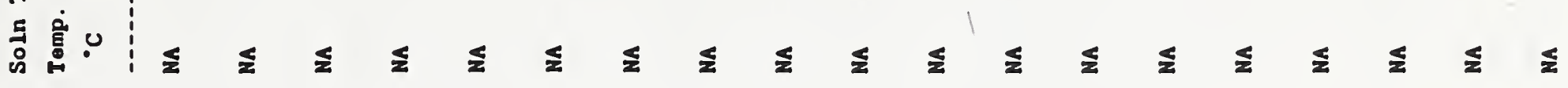
总获

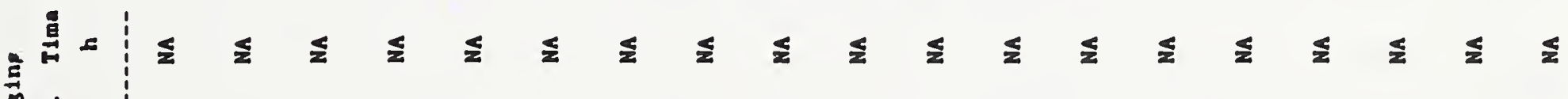

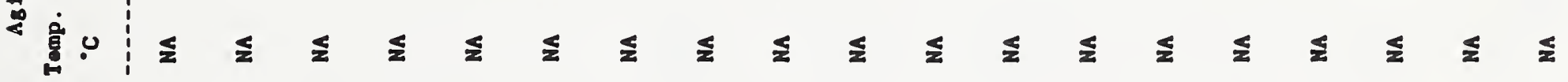

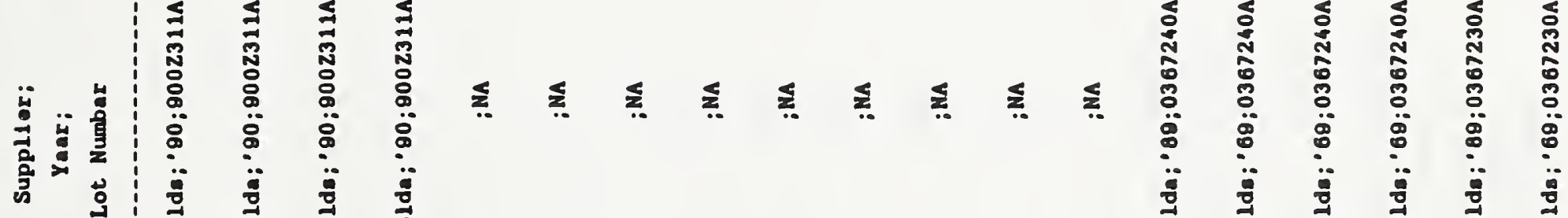

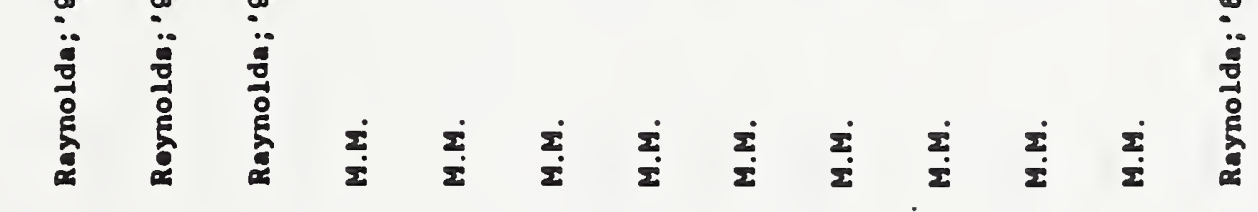

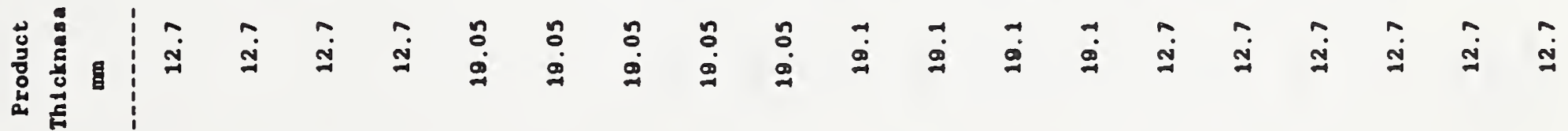

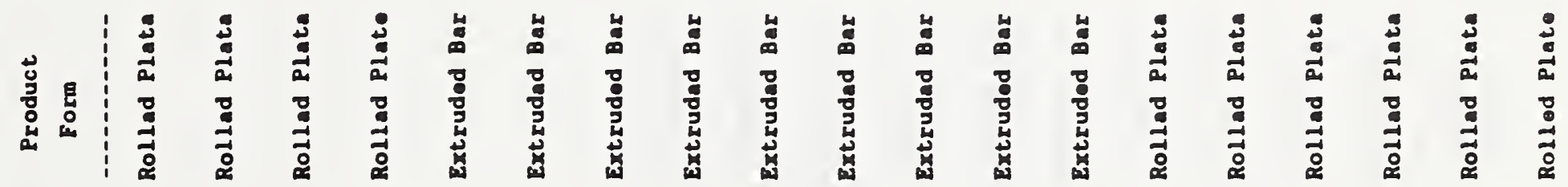

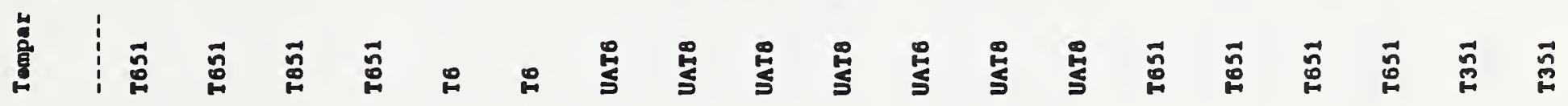

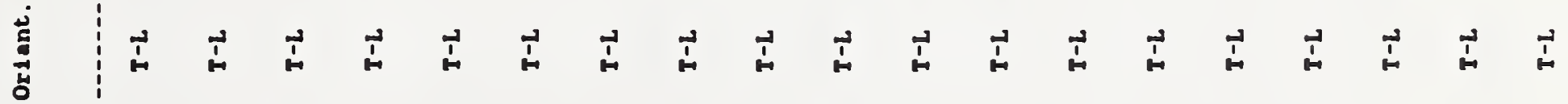

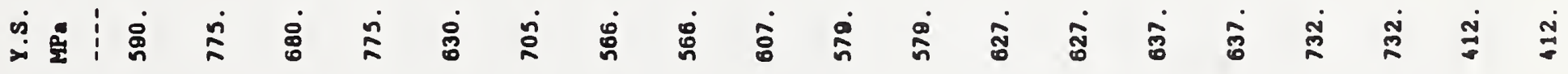

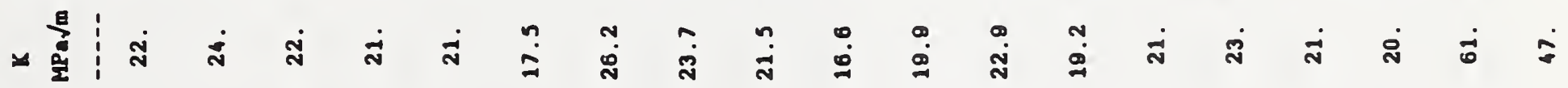

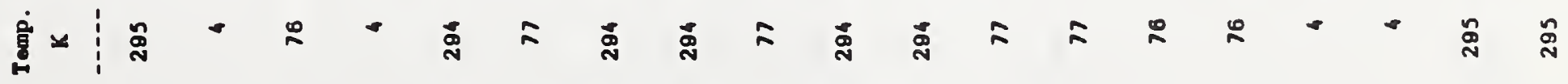

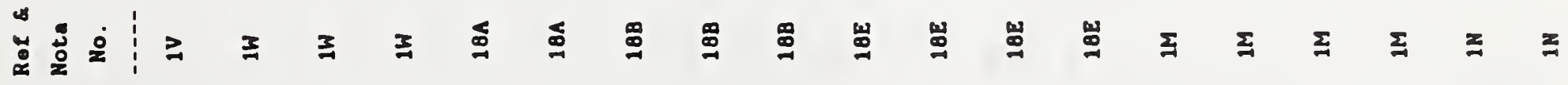




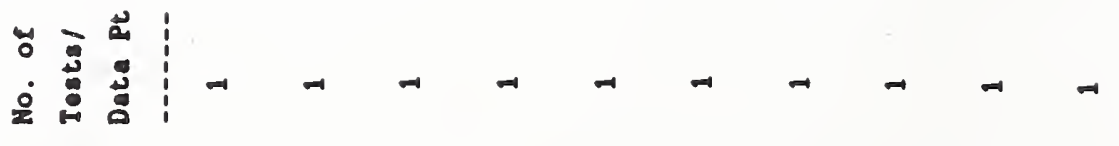

丵

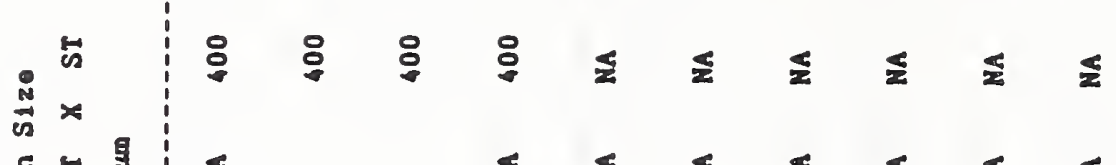

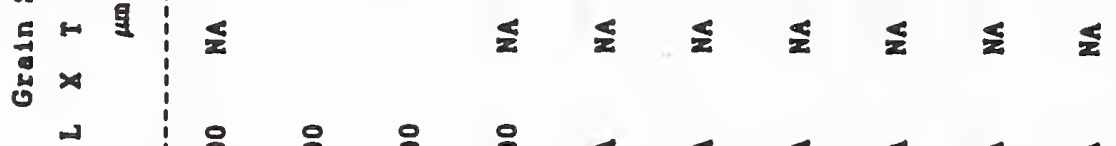

i

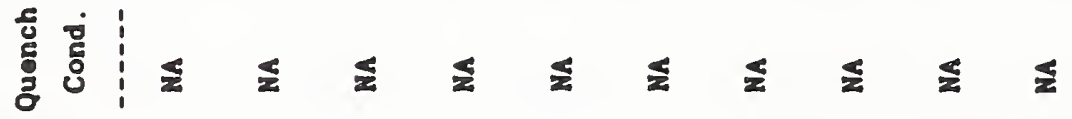
递是

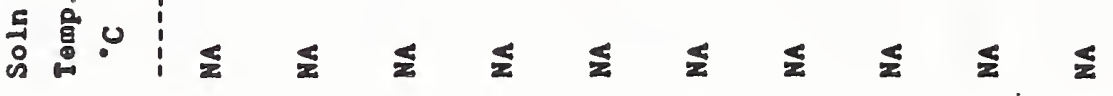

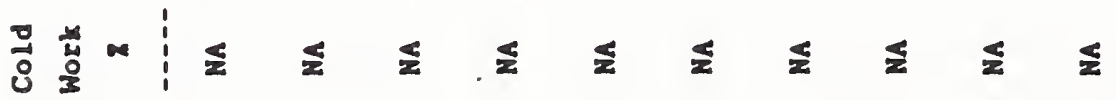

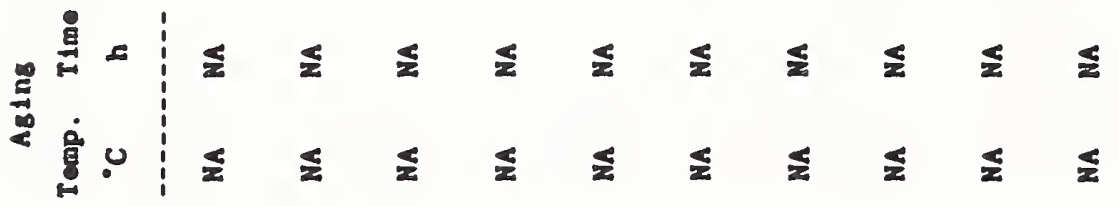

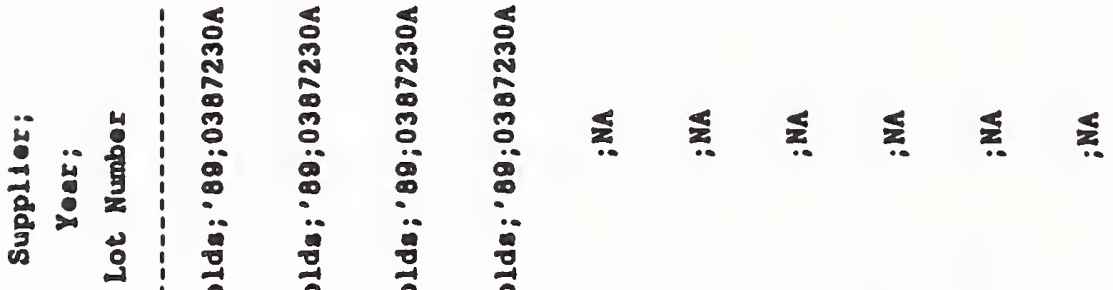

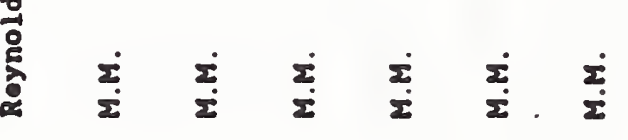

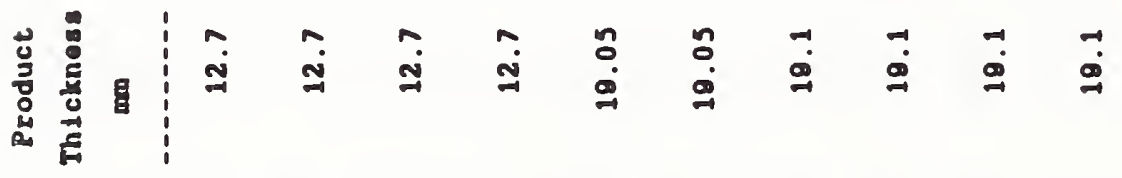

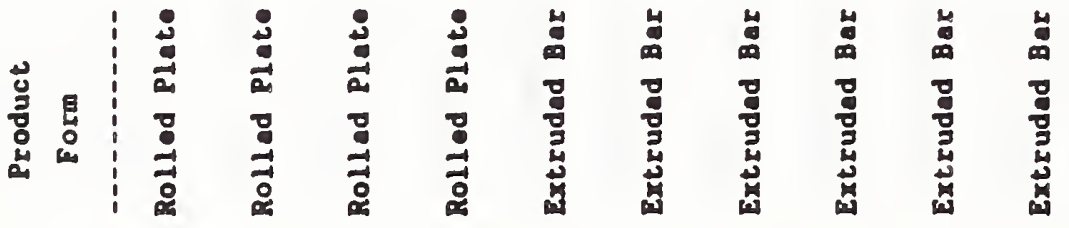
i $\vec{a} \quad \vec{i} \vec{i} \vec{i} \vec{i}$ in $\vec{i}$ in $\vec{i}$ in $\vec{i}$

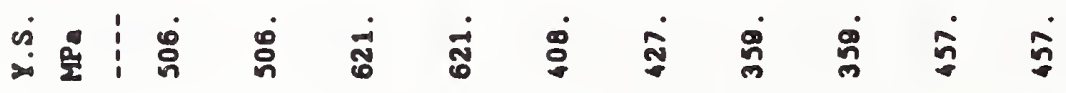
*

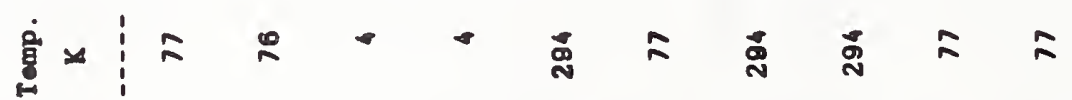

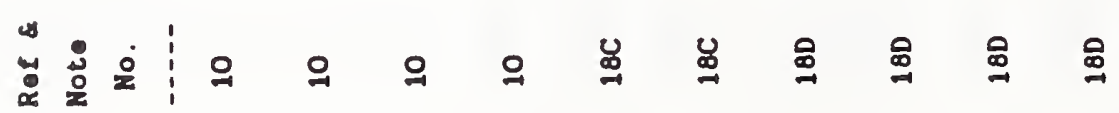




\section{Comments from the Al-Li Alloy WL049 Data Table}

\section{Reference and}

Note Number

1J-K--Values reported are the average of the range of grain sizes.

18A-E--Under the supplier column, M.M. = Martin Marietta. 
离 兽 离

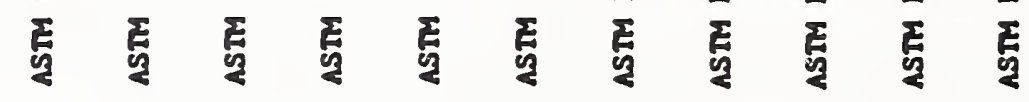

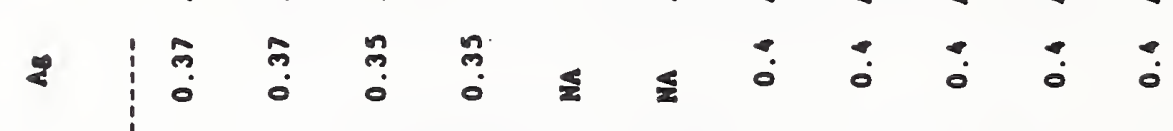
- $\quad \begin{array}{lllllll}0 & 0 & 0 & 0 & 0 & 0 & 0 \\ 0 & 0 & 0 & 0 & 0 & 0 & 0 \\ 0 & 0 & 0 & 0\end{array}$

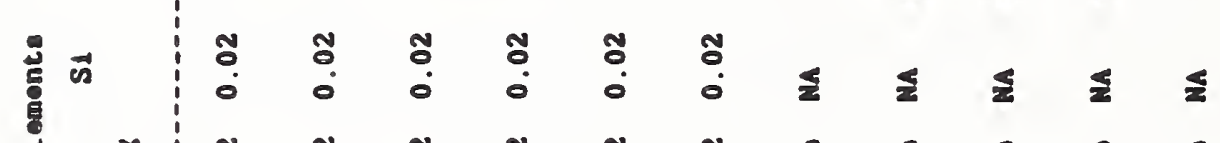

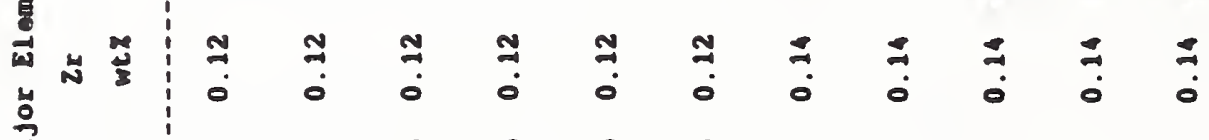

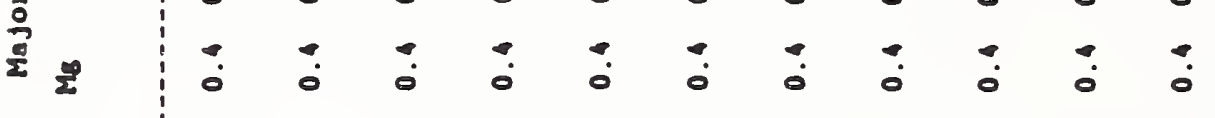

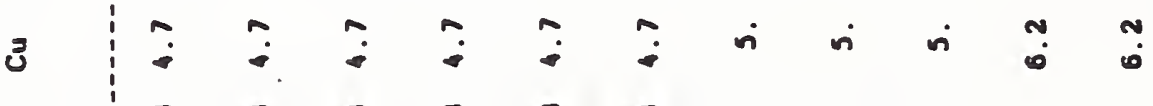

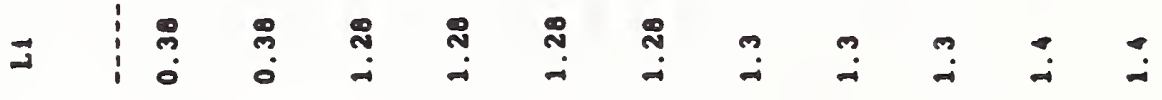

\section{递}

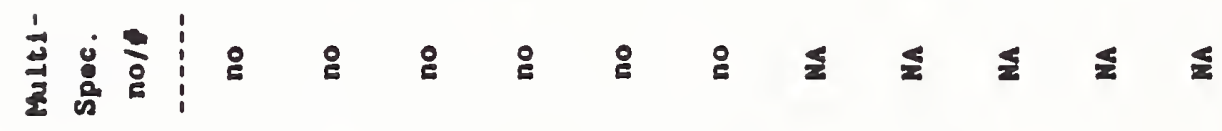
完总 : 总

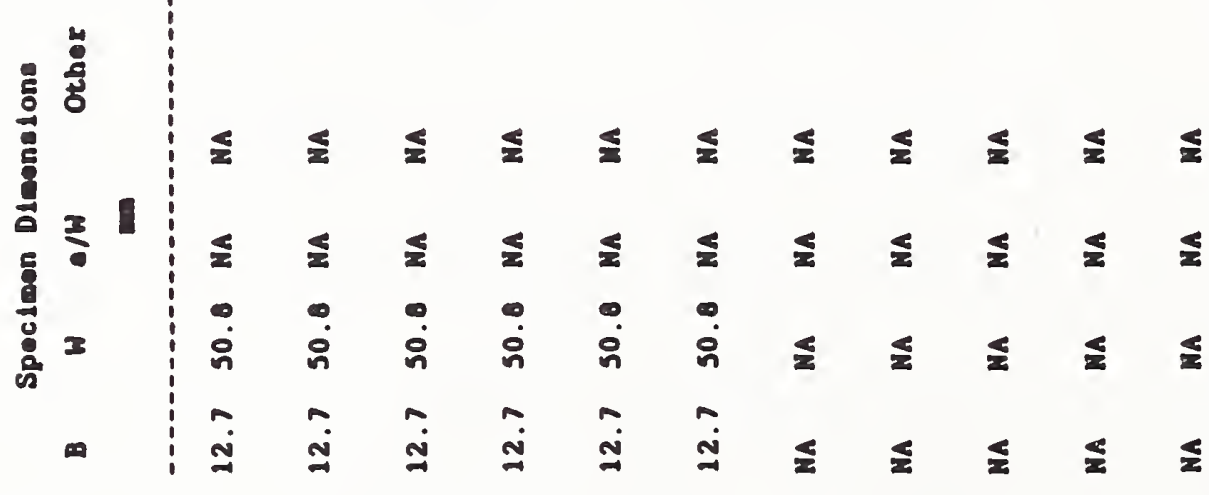
: क

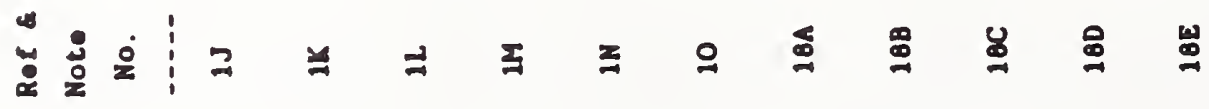


FRACTURE TOUGHNESS, $\mathrm{ksi}^{\mathrm{i}} \mathrm{in}^{1 / 2}$

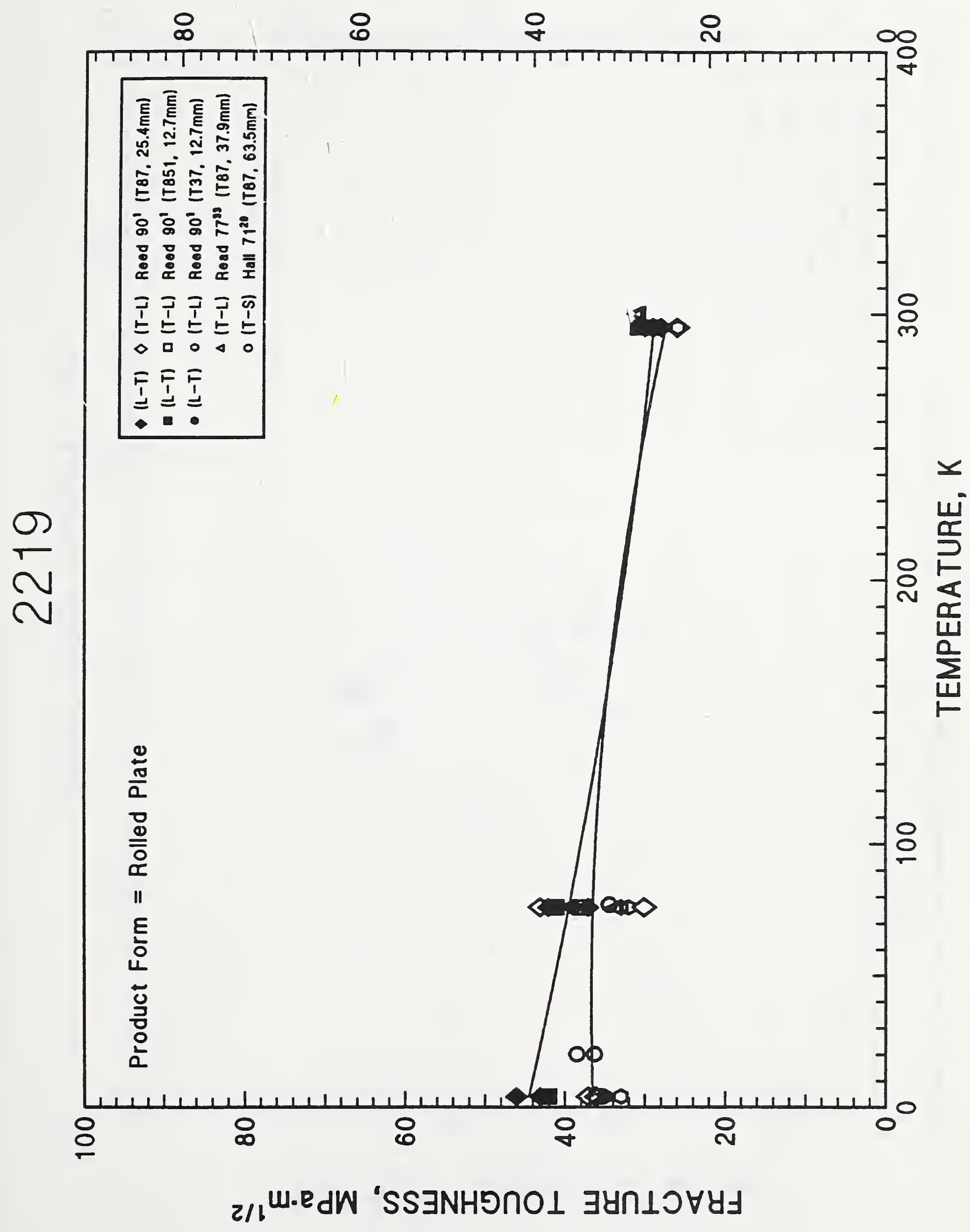


FRACTURE TOUGHNESS, $\mathrm{ksi}^{\mathrm{i}} \mathrm{n}^{1 / 2}$

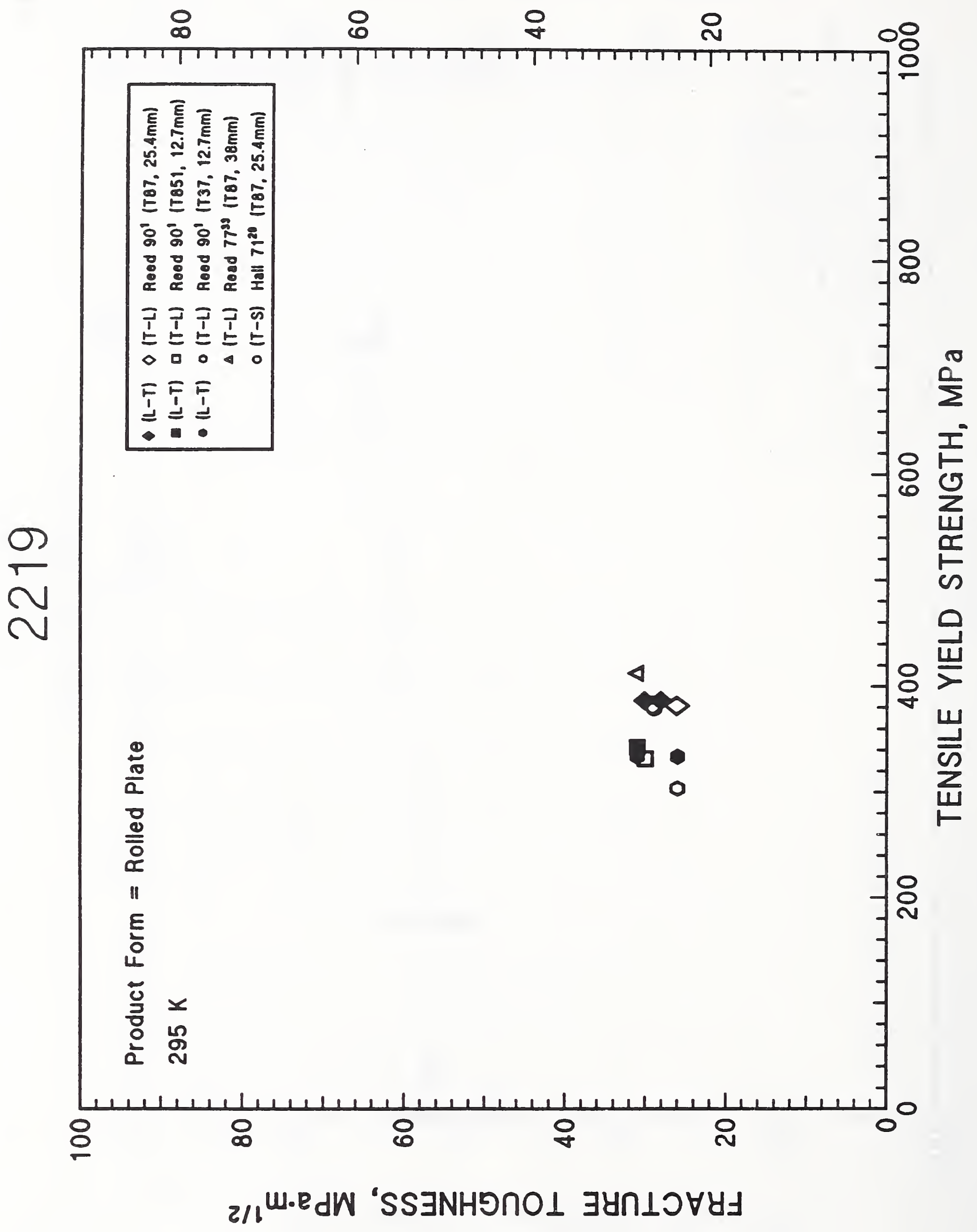


FRACTURE TOUGHNESS, $\mathrm{ksi} \cdot \mathrm{in}^{1 / 2}$

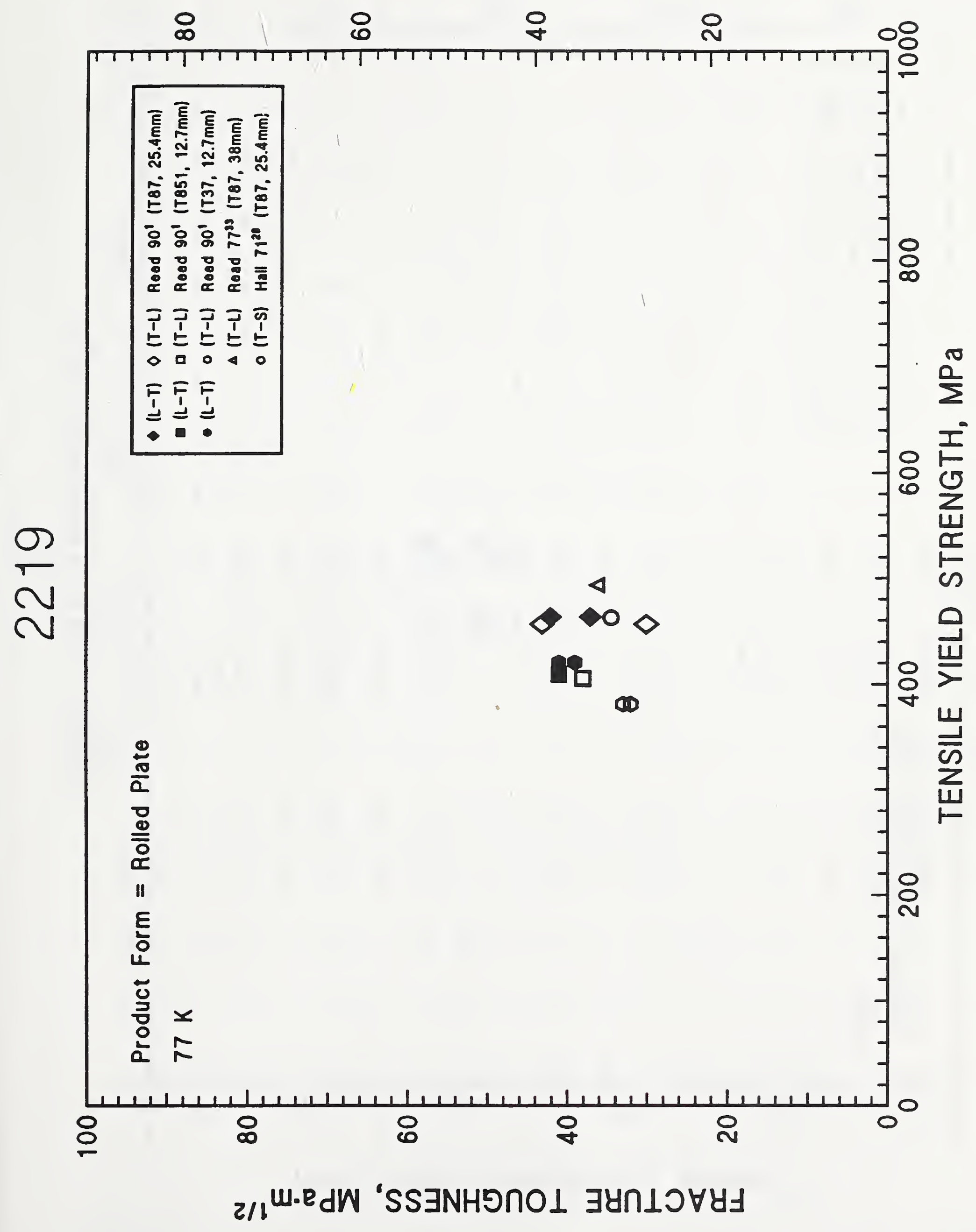


FRACTURE TOUGHNESS, $\mathrm{ksi} \cdot \mathrm{n}^{1 / 2}$

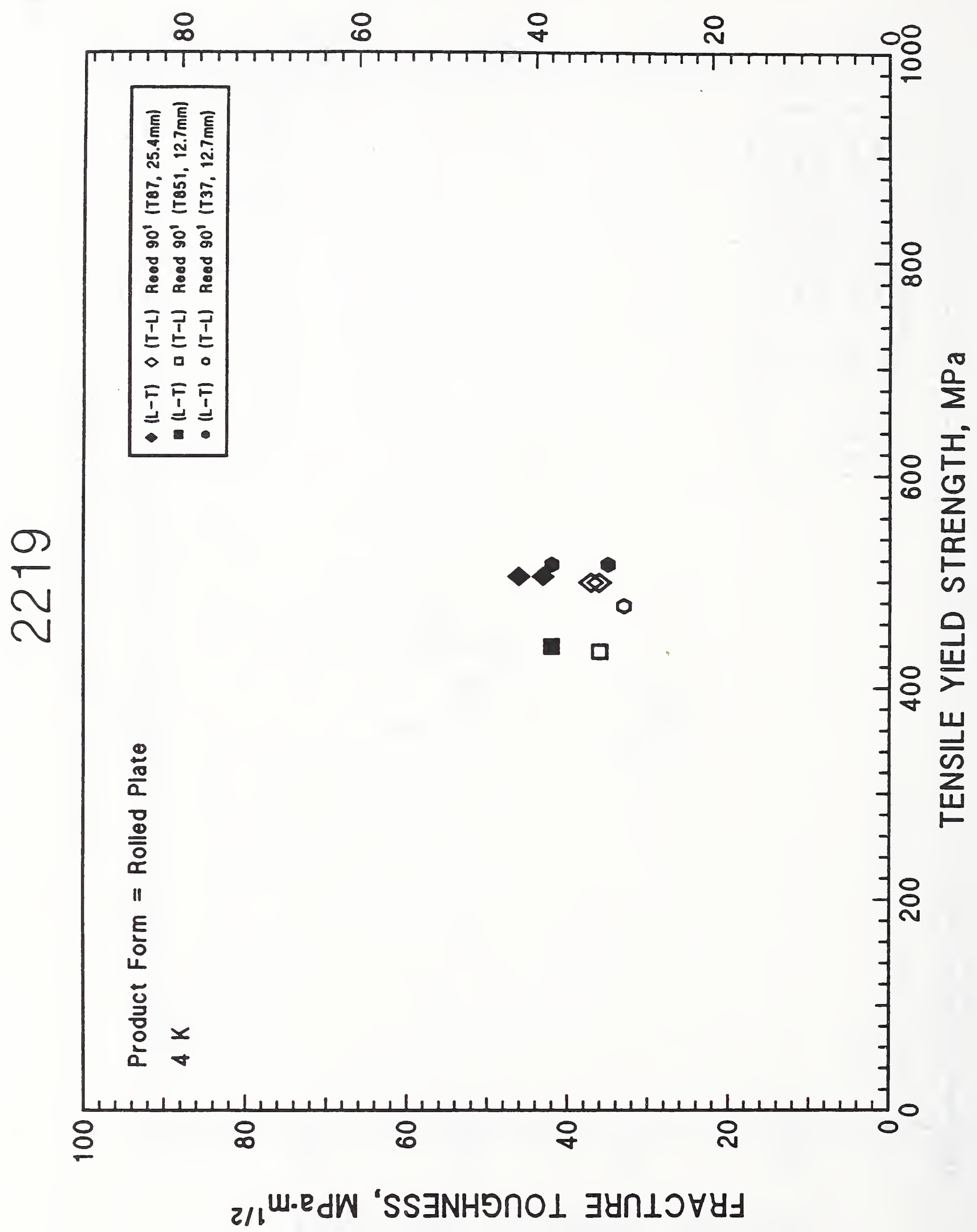




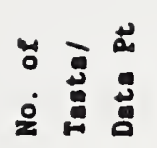

䇋|

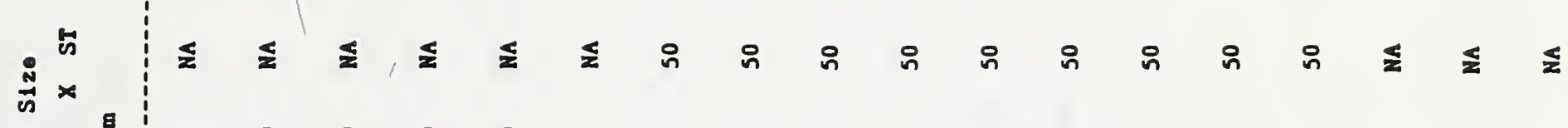

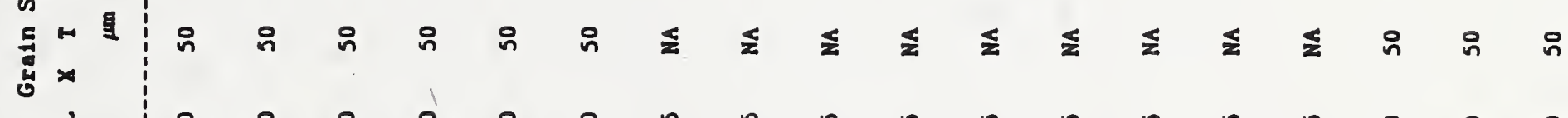
เ

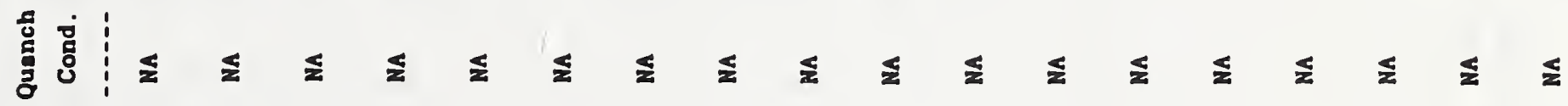

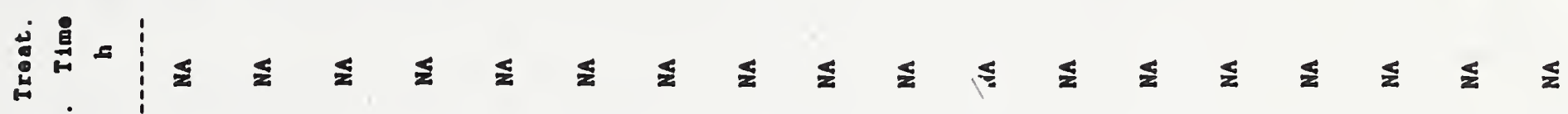

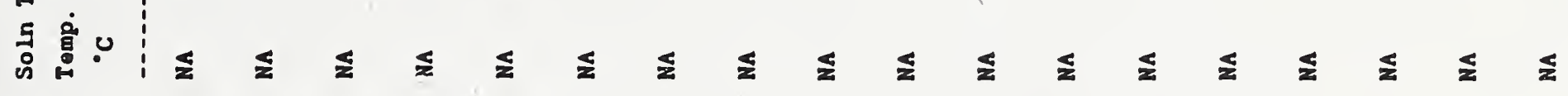
รัํํำ

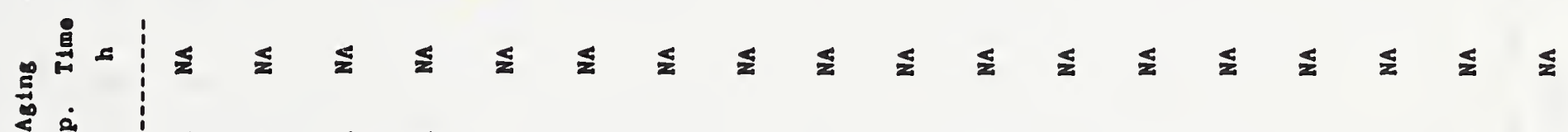
'

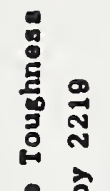

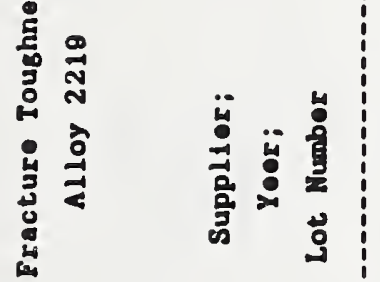

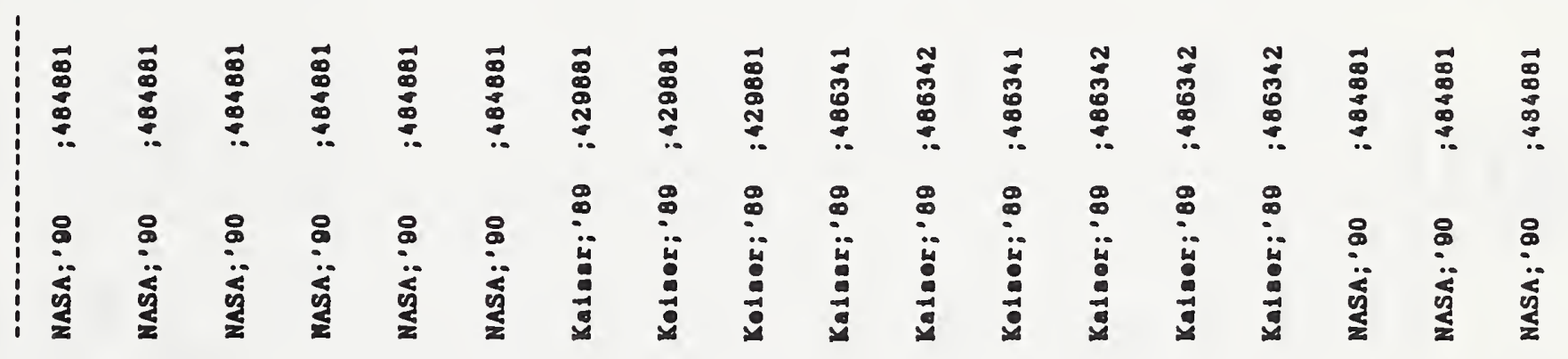

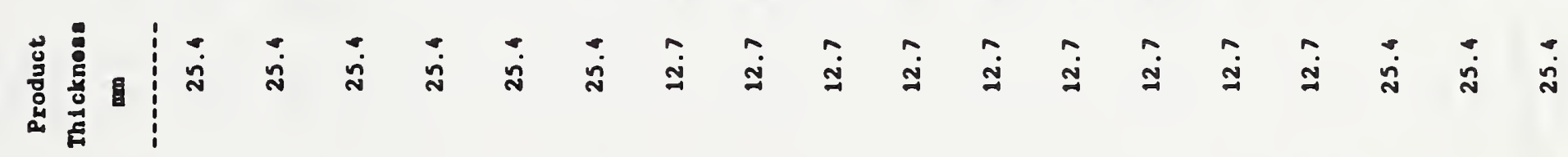

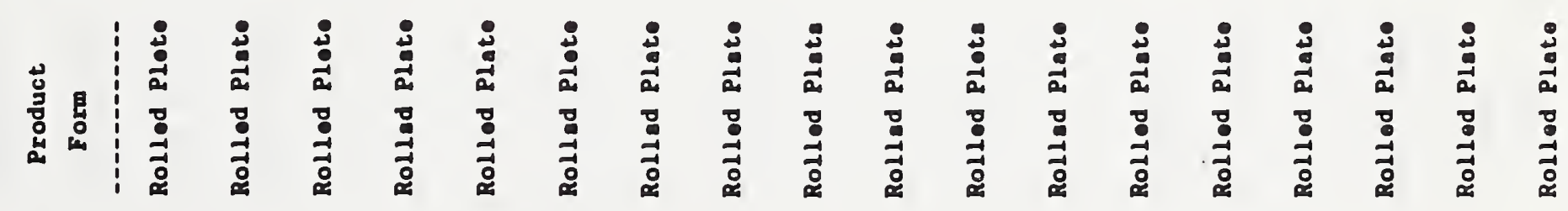

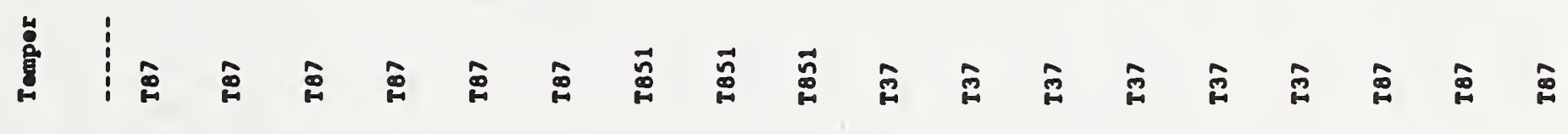

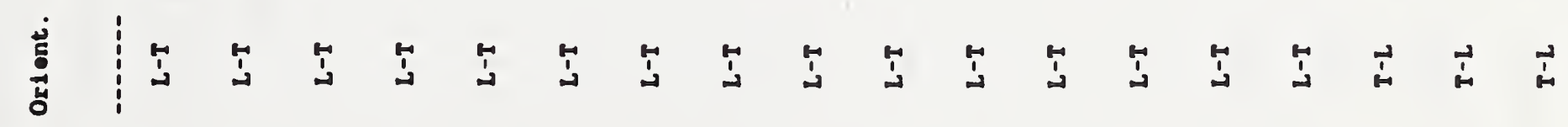

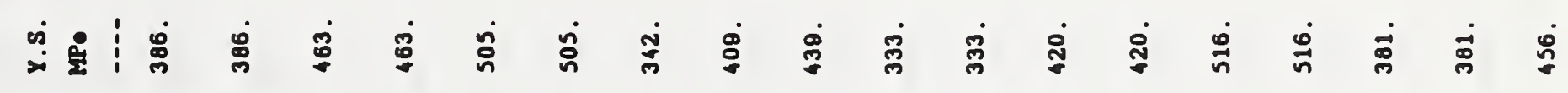

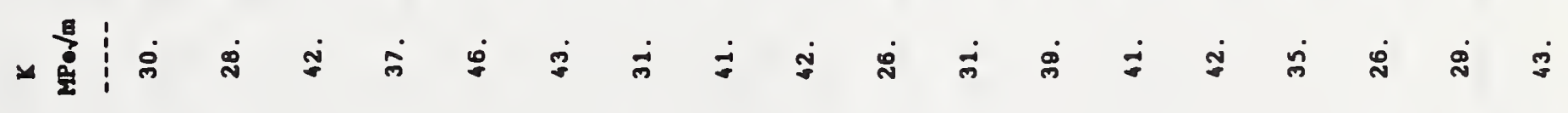

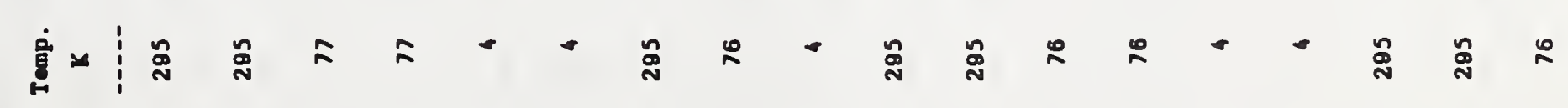

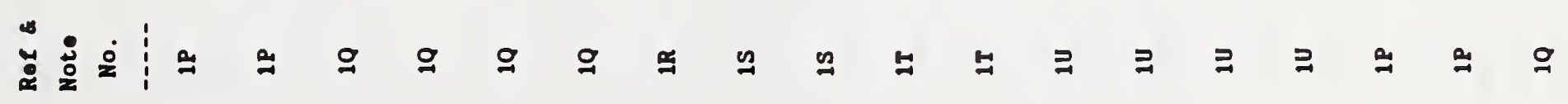




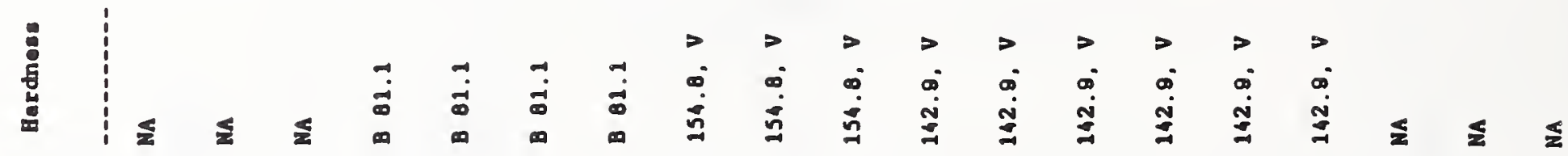
点

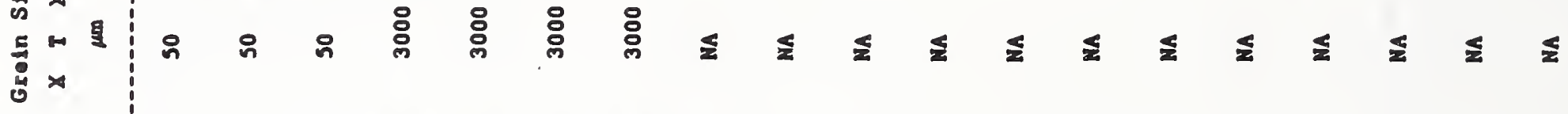
\&

焉 递丵

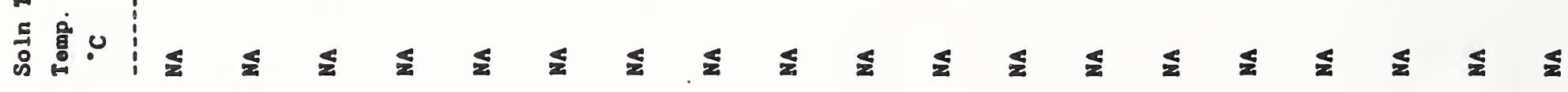

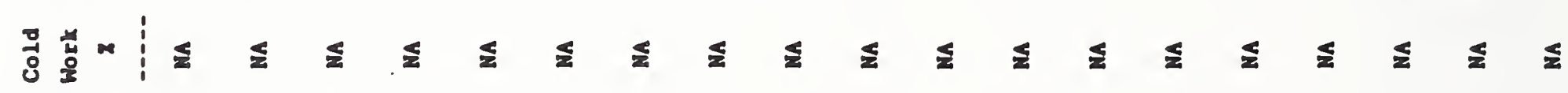

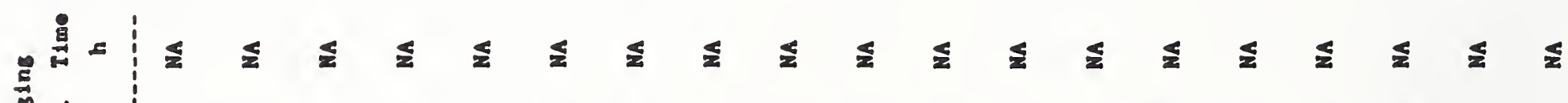

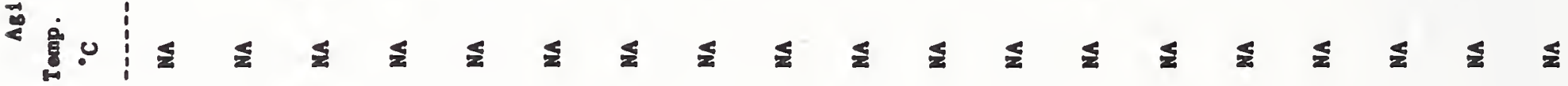

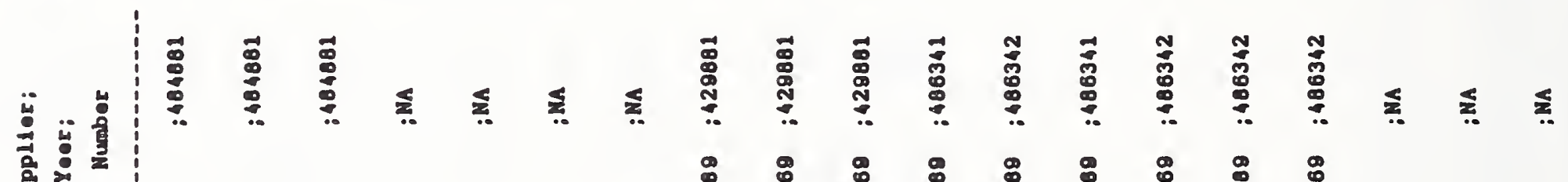
䆛

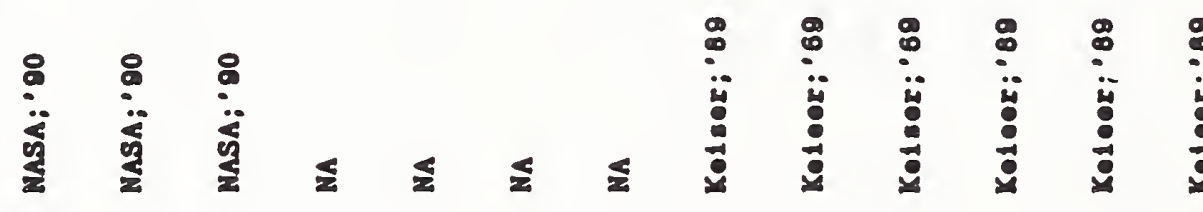

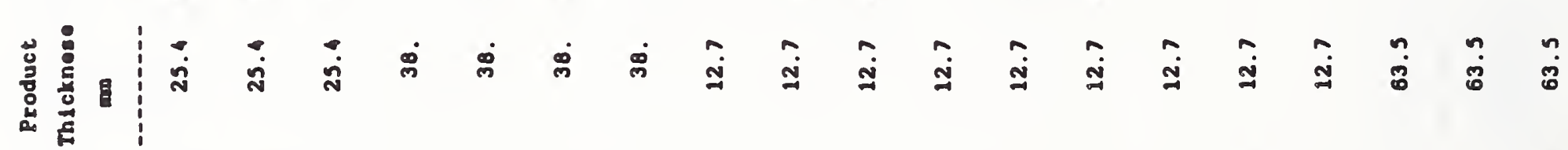

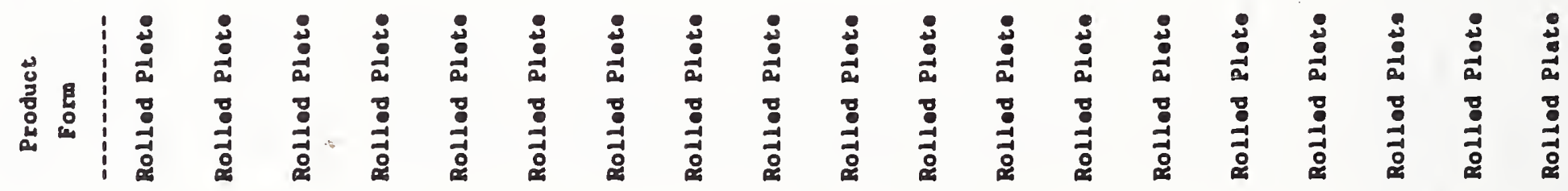

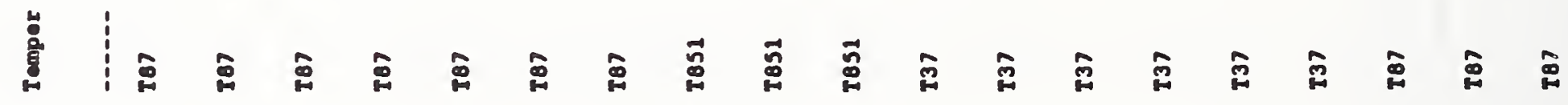

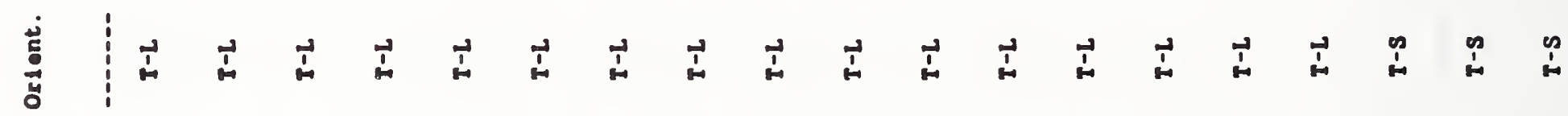

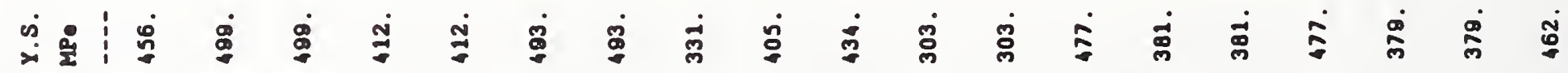
× 息

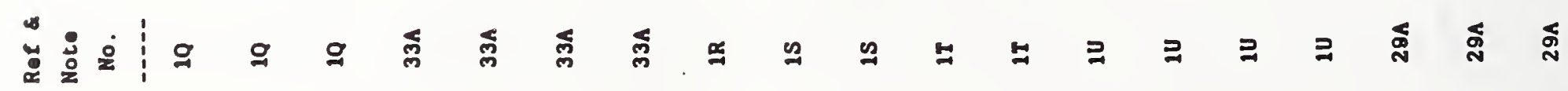




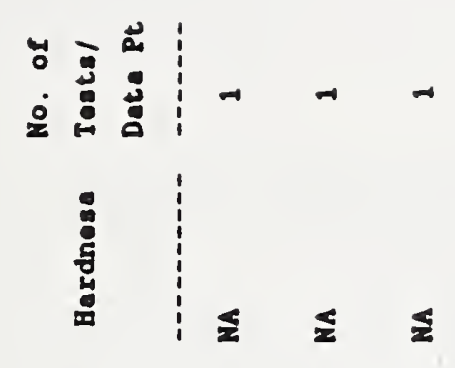

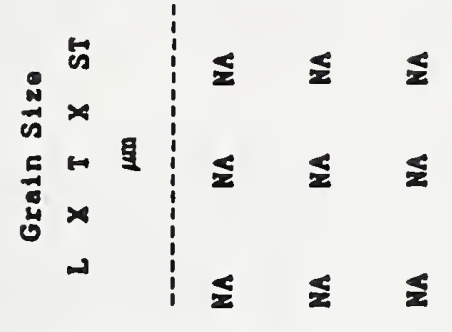

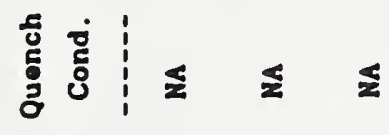

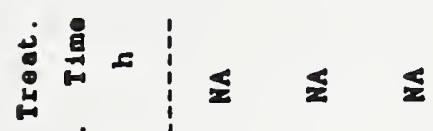

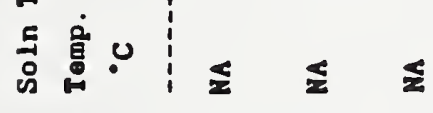

㙜苔以

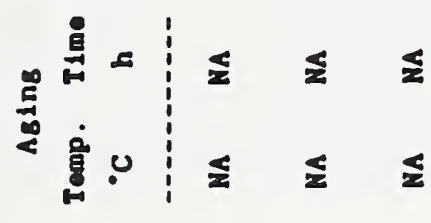

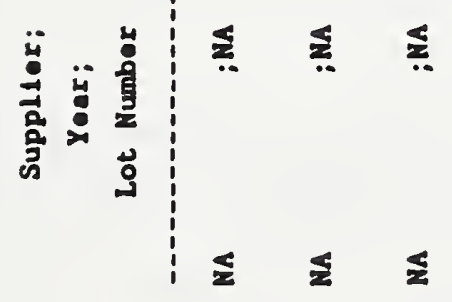

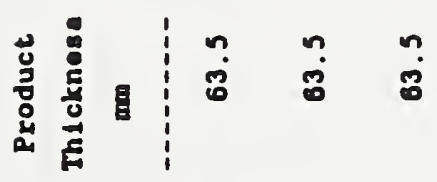

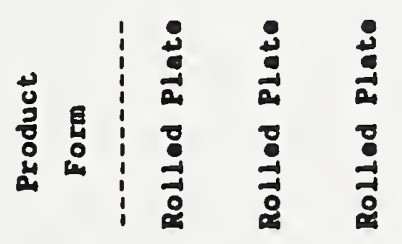

兽:

葡

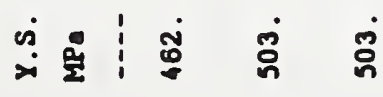

$\times$ 要

密凶:

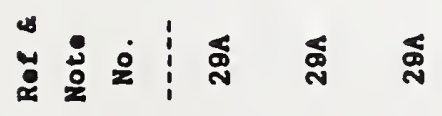




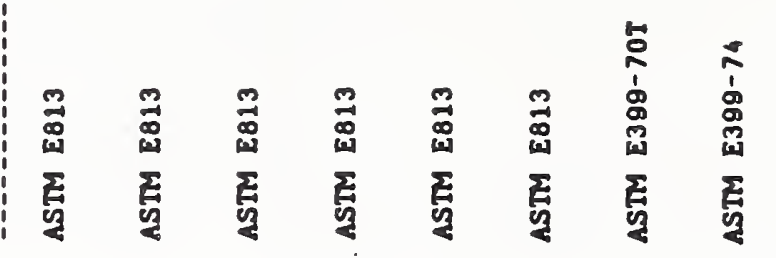

\& $\mid \frac{1}{2} \leq \leqslant \leq \leqslant \leq$

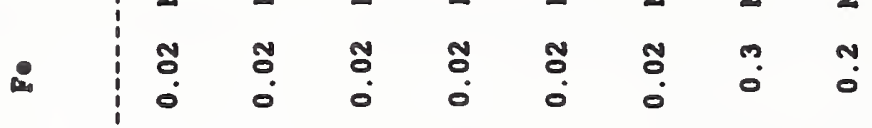

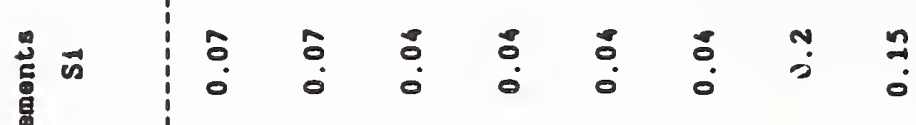

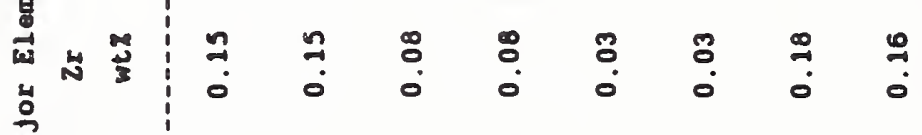

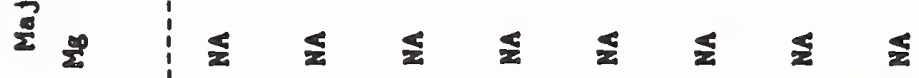
उ $\hat{n}$ iे $\hat{n}$ iे $\hat{n}$ iे $\exists \quad \leq \leqq \leq \leqq \leq$

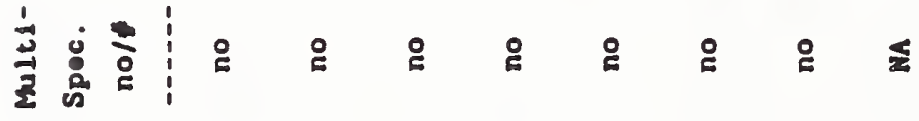
总总

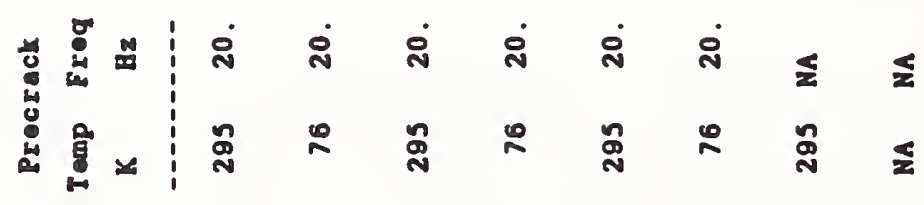

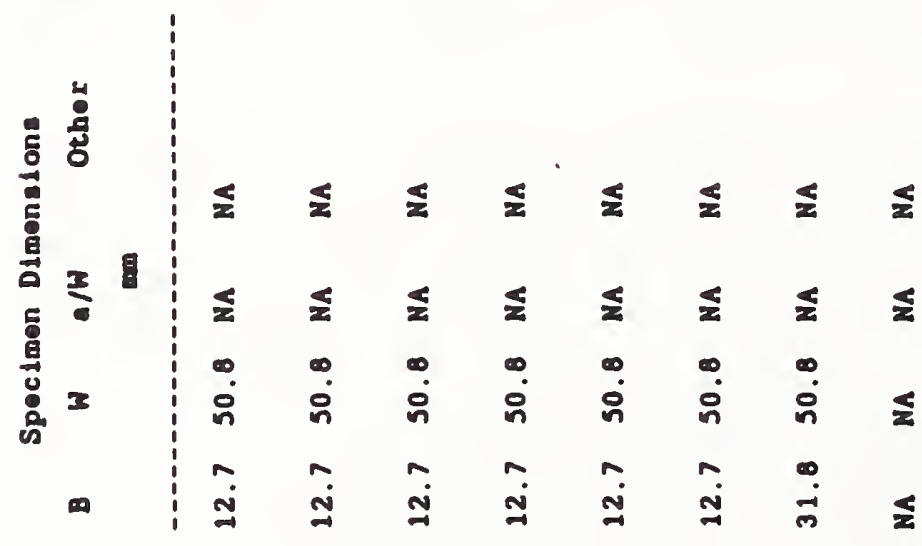

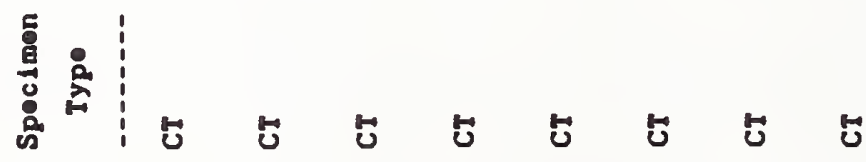

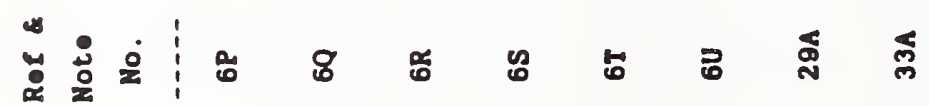




\section{ELASTIC CONSTANTS}

\subsection{Introduction to Graphs}

\subsubsection{Temperature Dependence}

Cryogenic elastic constant data are available only for 2090-T81 (Young's modulus, E, and Poisson's ratio, a) and 2219-T87 (E, à, bulk modulus, B, and shear modulus, G). These data are presented as functions of temperature in four graphs and a table following this discussion. The reason that different values of $\mathrm{E}$ ( 77.7 and $74.7 \mathrm{GPa}$ ) were obtained for $2219-\mathrm{T} 87$ at ambient temperature in the same labcratory is not understood. It is likely that the values reported in the earlier measurements are systematically too high, but the temperature dependence has not been remeasured. (A later measurement at room temperature gave a value of $74.8 \mathrm{GPa}$. ) The value given in MIL-HNBK-5E $E^{35}$ for E for alloy 2219 plate is $72.4 \mathrm{GPa}$. There is considerable disagreement in the literature about the correct value of $E$ at ambien $5 \%$ )

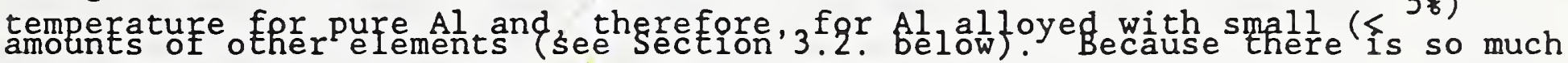
uncertainty in the literature, and because so little cryogenic data are available, a table of ambient-temperature values of elastic constants from various suurces for the Al-Li alloys 8090, 2090, and WL049, and alloy 2219 follows the presentation of the cryogenic data. After a value of $E$ at ambient temperature is chosen, the following equation may be used to estimate values for $4 \mathrm{~K} \leq \mathrm{T} \leq 295 \mathrm{~K}$ :

$$
\begin{aligned}
& E(T)=E(295 \mathrm{~K})\left[1.1+1.20010^{-4} \mathrm{~T}-4.0 \text { o } 10^{-6} \mathrm{~T}^{2}+1.1010^{-8} \mathrm{~T}^{3}\right. \\
&\left.-1.2010^{-11} \mathrm{~T}^{4}\right] .
\end{aligned}
$$

Values derived from Equation (1) should be used with caution because it is based on the one set of measurements available for $2090 .{ }^{37}$

\subsubsection{Effects of Alloying Elements, Cold Work, and Other Factors}

Several sets of measurements are available on the increase in $E$ with alloying additions of $\mathrm{Li} ;{ }^{38,39} \mathrm{Li}$ and $\mathrm{Mg} ;{ }^{38}$ and $\mathrm{Li}$ and $\mathrm{Cu}{ }^{39}$ References 38 and 39 give 66 and $62 \mathrm{GPa}$, respectively, as the ambient temperature value of $E$ for high purity Al. Measured values of $\mathrm{E}$ for $\mathrm{Al}-28 \mathrm{Li}$ were $79 \mathrm{GPa}^{38}$ and $73 \mathrm{GPa}{ }^{39}$ $E$ was found to be $82 \mathrm{GPa}^{39}$ for Al-2024-28Li. The composition of Al-alloy 2024 $(4.5 \mathrm{Cu}, 1.5 \mathrm{Mg}, 0.6 \mathrm{Mn})$ is very similar to the composition of Al-alloy 2019 (5.8-6.8Cu, 0.2-0.4Mn). However, values of $\mathrm{E}$ for pure Al in the literature derived from the single-crystal elastic constants measured by dynamic methods are usually about 108 higher than the values in these two references, ${ }^{38,39}$ averaging around 70 to $72 \mathrm{GPa}$. (Values of $\mathrm{Al}-\mathrm{Li}$ and $\mathrm{Al}-\mathrm{Cu}-\mathrm{Li}$ alloys would be expected to be correspondingly higher.) Reed ${ }^{40}$ presents a table of Al singlecrystal elastic constants from several sources and uses the average of these constants to calculate an E of $70.4 \mathrm{GPa}$. The calculation is based on a formula presented by Hill ${ }^{41}$ in the early 1950s. The discrepancy between values calculated from single-crystal elastic constants using the Hill formula and static measurements of Noble $e^{38}$ was noted by Maller et al., ${ }^{42}$ but the explanation advanced, microplasticity, may not be sufficient to explain such a large disparity in the values. To validate his formula, Hill used a set of 
measurements on elastic constants of four common elements (including Al) whose origin is not well documented. Several dynamic measurements $43,44,45$ not based on single-crystal elastic constants and the Hill formula give about $70 \mathrm{GPa}$ for $E$ of pure Al. This disagrees with values of 66,64 , and $65 \mathrm{GPa}$ obtained by static measurements ${ }^{46}$ on commercially pure Al (99.58) as well as the values quoted above, ${ }^{38,39}$ which are also derived from static measurements.

Differences between static and dynamic measurements should be only about a percent, ${ }^{47}$ and so the discrepancy should not be attributable to dissimilar measurement techniques. The Hill formula is frequently employed in the literature of basic science to calculate polycrystalline elastic constant values from single-crystal measurements. However, to our knowledge, it has not been tested against carefully evaluated measurements on polycrystalline specimens of a wide variety of elements. Furthermore, the disagreement of predicted values of $\mathrm{E}$ with static measurements (commonly used in the aerospace industry) has not been widely recognized.

A calculation by Wawra ${ }^{48}$ for $A I$ gives a directional dependence for $E$ of pure $A l$, such that $E_{111}=73.8 \mathrm{GPa}$ and $E_{100}=63.2 \mathrm{GPa}$, which is approximately the size of the discrepancy in the measurements. Most polycrystalline Al is probably not strongly textured, however, and texture has not been reported with the measurements of $E$. Warwa ${ }^{48}$ also reports a decrease of $E$ of up to $\approx 38$ over a range of cold work from 0 to 1008. Decreasing the purity of the Al from 99.99 to 99.68 increased $E^{48}$ by about 38 to a value of $72.8 \mathrm{GPa}$. These latter effects do not appear large enough to explain the discrepancy.

Varying the aging time of Al-Li alloys also has an effect on E. ${ }^{49}$ Effects were less than 28 for aging temperature of 230,210 , and $190^{\circ} \mathrm{C}$ with aging times of up to $1000 \mathrm{~h}$. This work was carried out on a binary Al-2.5wtoli alloy using an ultrasonic measurement technique. Another recent paper ${ }^{47}$ also presents results of aging treatment and specimen thickness on $E$ and other elastic constants of $2090-\mathrm{T} 8 \mathrm{E} 50$ as a function of the angle from rolling direction. Effects again are small, $\simeq 2-38$, but the anisotropy in $E$ can be as much as 68 at $45^{\circ}$ from the rolling direction. 
YOUNG'S MODULUS, E, $\mathrm{ksi} \times 10^{3}$

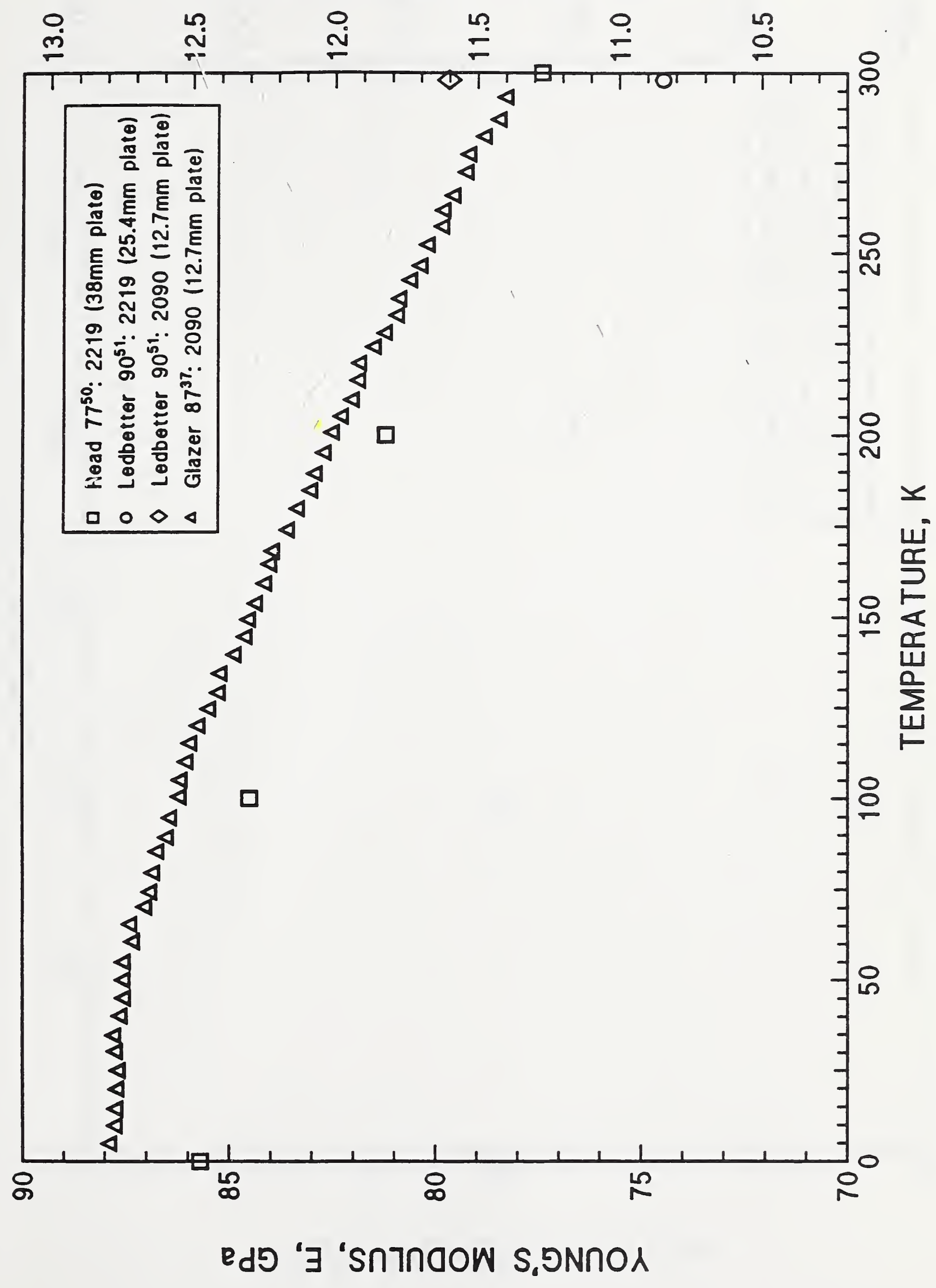


SHEAR MODULUS, G, ksi

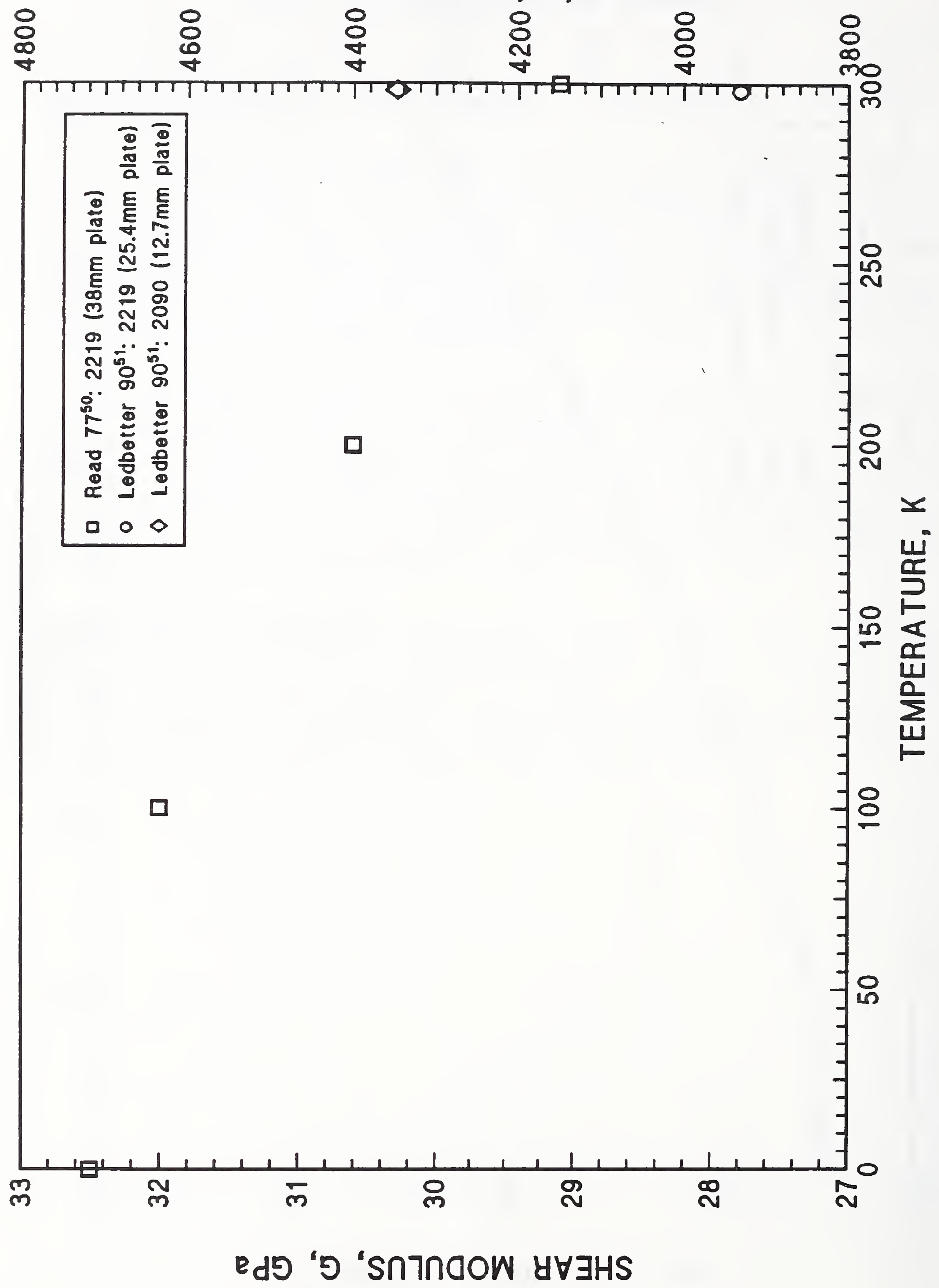




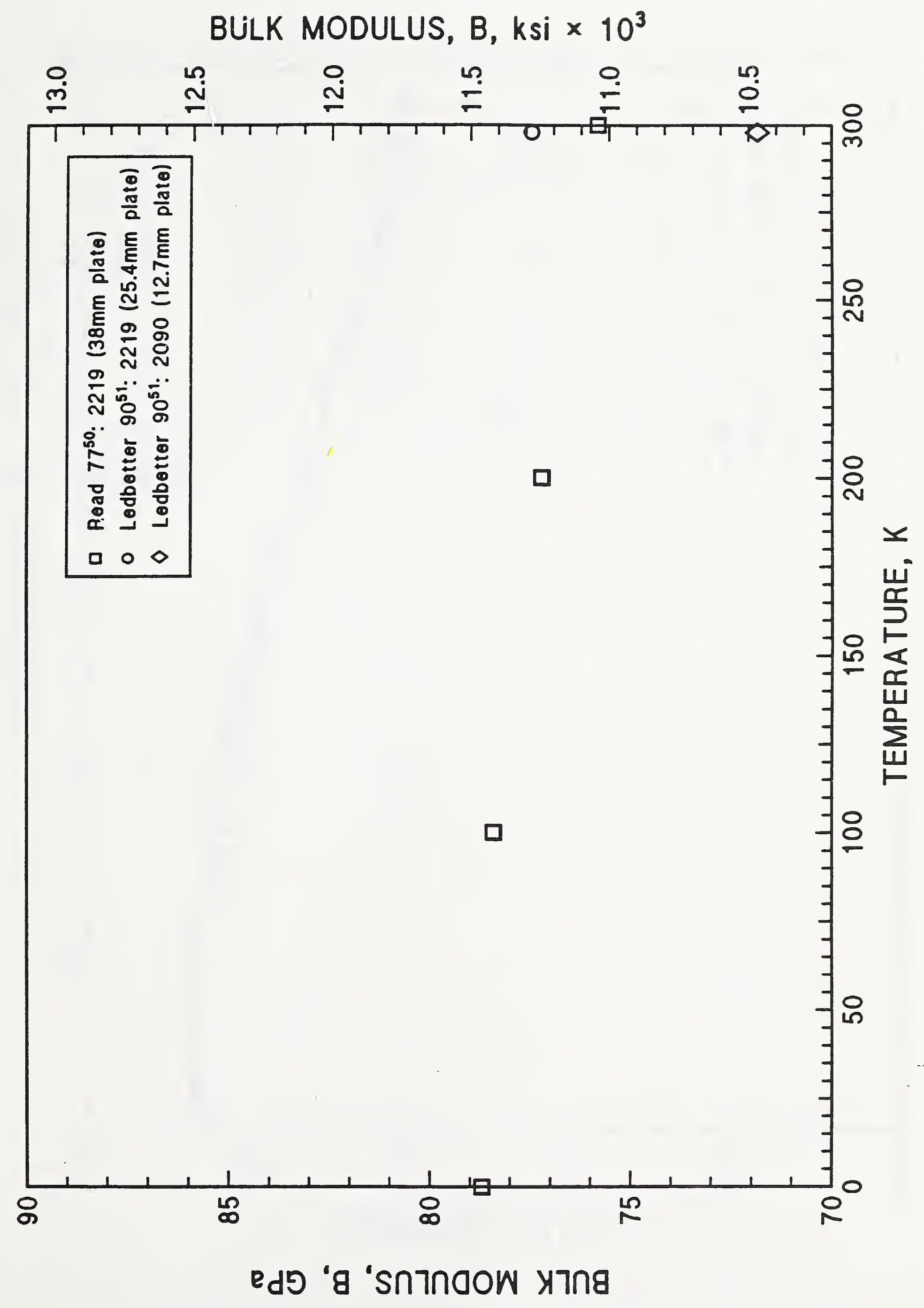




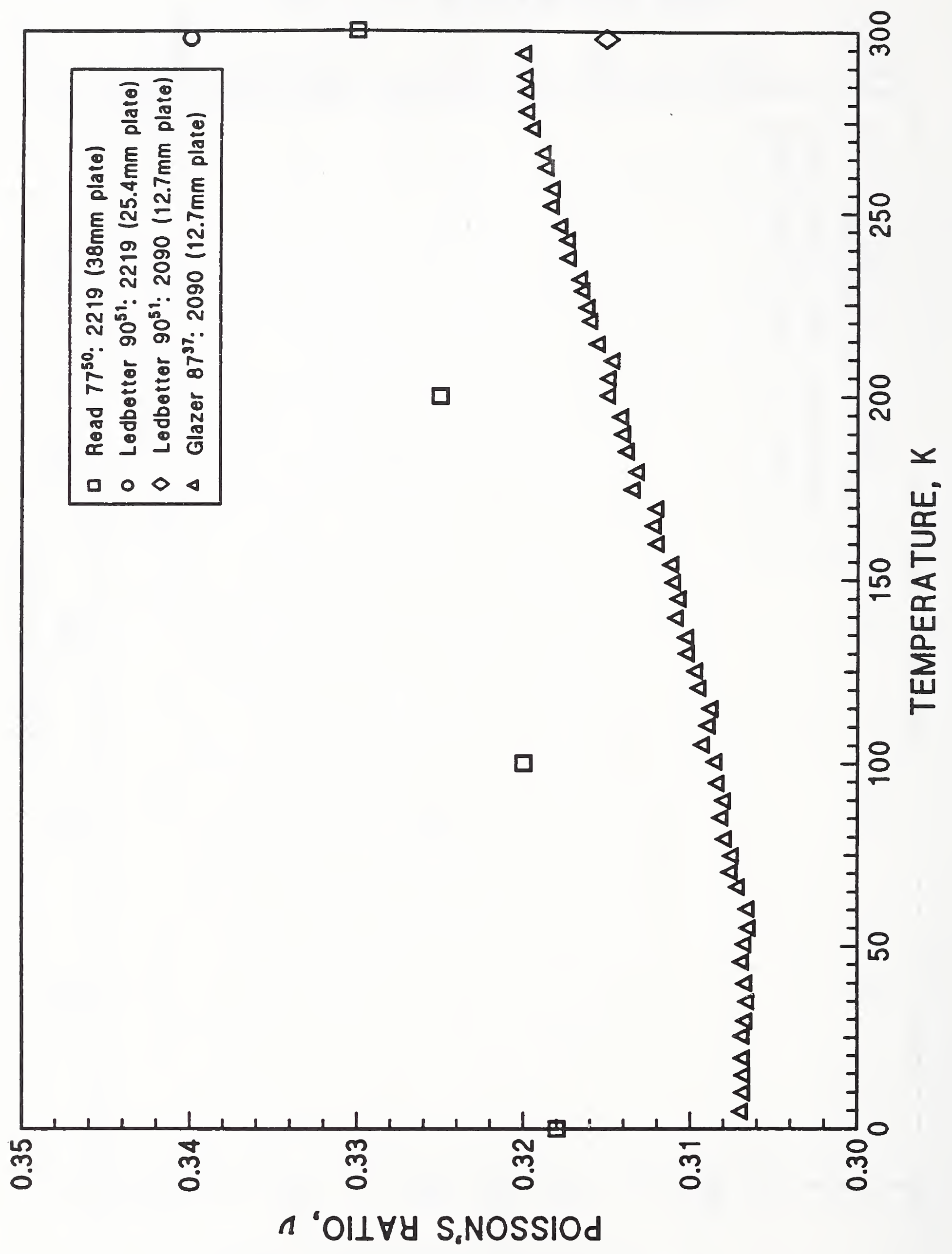


Density and Elastic Constants of Al-Li Alloys and Alloy 2219 at Ambient Temperature.

\begin{tabular}{|c|c|c|c|c|c|c|c|}
\hline Alloy & $\begin{array}{c}\text { Density } \\
\mathrm{kg} / \mathrm{m}^{3} \\
\times 10^{3}\end{array}$ & $\begin{array}{l}\text { Young's } \\
\text { Modulus, } \\
E, G P a\end{array}$ & $\begin{array}{l}\text { Shear } \\
\text { Modulus, } \\
\text { G, GPa }\end{array}$ & $\begin{array}{l}\text { Bulk } \\
\text { Modulus, } \\
\text { B, GPa }\end{array}$ & $\begin{array}{l}\text { Poisson's } \\
\text { Ratio, } \nu\end{array}$ & $\begin{array}{l}\text { Ref. } \\
\text { No. }\end{array}$ & $\begin{array}{c}\text { Method } \\
\text { of } \\
\text { Analysis }\end{array}$ \\
\hline $8090-T 8771$ & - & 79.3 & -. & -. & 0.292 & 5 & 1 \\
\hline $2090-T 81$ & 2.60 & 79.65 & 30.28 & 71.83 & 0.3152 & 51 & 2 \\
\hline $2090-T 81$ & 2.59 & 78.28 & 29.65 & 72.56 & 0.320 & 37 & 2 \\
\hline $2090-T 8 E 50$ & $\ldots$ & 78.60 & .. & .. & .. & 47 & 2 \\
\hline $2090-T 83$ & - & 73.3 & -. & -. & 0.35 & 36 & 1 \\
\hline WL049-T851 & 2.71 & 76.60 & 28.83 & 74.46 & 0.3285 & 51 & 2 \\
\hline WL049-T851 & 2.70 & 77.9 & .. & - & - & 52 & 2 \\
\hline $2219-T 87$ & 2.82 & 74.46 & 27.79 & 77.45 & 0.3398 & 51 & 2 \\
\hline $2219-\mathrm{T} 87$ & -. & 77.4 & 29.1 & 75.8 & 0.330 & 33 & 2 \\
\hline
\end{tabular}

1 Static measurement.

2 Dynamic measurement. 
Elastic Constants of Al-Li Alloys and Alloy 2219 at Low Temperatures.

\begin{tabular}{|c|c|c|c|c|c|c|c|}
\hline Alloy & $\underset{\mathrm{K}}{\operatorname{Temp}}$ & $\begin{array}{l}\text { Young's } \\
\text { Modulus, } \\
\text { E, GPa }\end{array}$ & $\begin{array}{l}\text { Shear } \\
\text { Modulus, } \\
\text { G, GPa }\end{array}$ & $\begin{array}{l}\text { Bulk } \\
\text { Modulus, } \\
\text { B, GPa }\end{array}$ & $\begin{array}{l}\text { Poisson's } \\
\text { Ratio, } \nu\end{array}$ & $\begin{array}{l}\text { Ref. } \\
\text { No. }\end{array}$ & $\begin{array}{l}\text { Method } \\
\text { of } \\
\text { Analysis }\end{array}$ \\
\hline \multirow[t]{4}{*}{2219} & 0 & 85.7 & 32.5 & 78.7 & 0.318 & 50 & 2 \\
\hline & 100 & 84.5 & 32.0 & 78.4 & 0.320 & 50 & 2 \\
\hline & 200 & 81.2 & 30.6 & 77.2 & 0.325 & 50 & 2 \\
\hline & 300 & 77.4 & 29.1 & 75.8 & 0.330 & 50 & 2 \\
\hline 2219 & 298 & 74.5 & 27.8 & 77.5 & 0.340 & 51 & 2 \\
\hline 2090 & 298 & 79.7 & 30.3 & 71.8 & 0.315 & 51 & 2 \\
\hline \multirow[t]{39}{*}{2090} & 5 & 87.8 & .. & - & 0.307 & 37 & 2 \\
\hline & 10 & 87.7 & - & $\ldots$ & 0.307 & 37 & 2 \\
\hline & 15 & 87.7 & $\cdots$ & -- & 0.307 & 37 & 2 \\
\hline & 20 & 87.7 & $\ldots$ & $\ldots$ & 0.307 & 37 & 2 \\
\hline & 25 & 87.6 & $\ldots$ & $\ldots$ & 0.307 & 37 & 2 \\
\hline & 30 & 87.7 & $\ldots$ & $\ldots$ & 0.307 & 37 & 2 \\
\hline & 35 & 87.7 & -. & $\ldots$ & 0.306 & 37 & 2 \\
\hline & 40 & 87.6 & $\cdots$ & $\ldots$ & 0.307 & 37 & 2 \\
\hline & 45 & 87.5 & $\ldots$ & $\ldots$ & 0.307 & 37 & 2 \\
\hline & 50 & 87.5 & $\ldots$ & $\ldots$ & 0.307 & 37 & 2 \\
\hline & 55 & 87.5 & $\ldots$ & - & 0.306 & 37 & 2 \\
\hline & 60 & 87.3 & $\ldots$ & $\ldots$ & 0.306 & 37 & 2 \\
\hline & 65 & 87.3 & $\ldots$ & $\ldots$ & 0.307 & 37 & 2 \\
\hline & 70 & 87.0 & $\ldots$ & $\ldots$ & 0.307 & 37 & 2 \\
\hline & 75 & 86.9 & $\ldots$ & $\cdots$ & 0.307 & 37 & 2 \\
\hline & 80 & 86.8 & $\ldots$ & $\ldots$ & 0.308 & 37 & 2 \\
\hline & 85 & 86.7 & $\cdots$ & - & 0.308 & 37 & 2 \\
\hline & 90 & 86.5 & - & $\ldots$ & 0.308 & 37 & 2 \\
\hline & 95 & 86.4 & - - & $\ldots$ & 0.308 & 37 & 2 \\
\hline & 100 & 86.1 & - & $\cdots$ & 0.308 & 37 & 2 \\
\hline & 105 & 86.1 & $\ldots$ & $\ldots$ & 0.309 & 37 & 2 \\
\hline & 110 & 86.0 & - & $\ldots$ & 0.309 & 37 & 2 \\
\hline & 115 & 85.9 & .. & $\ldots$ & 0.309 & 37 & 2 \\
\hline & 120 & 85.7 & -- & $\cdots$ & 0.309 & 37 & 2 \\
\hline & 125 & 85.4 & - & -. & 0.310 & 37 & 2 \\
\hline & 130 & 85.2 & -. & $\ldots$ & 0.310 & 37 & 2 \\
\hline & 135 & 85.2 & -- & -. & 0.310 & 37 & 2 \\
\hline & 140 & 84.8 & -- & $\ldots$ & 0.311 & 37 & 2 \\
\hline & 145 & 84.5 & $\ldots$ & $\ldots$ & 0.311 & 37 & 2 \\
\hline & 150 & 84.5 & $\ldots$ & - - & 0.311 & 37 & 2 \\
\hline & 155 & 84.3 & $\ldots$ & -. & 0.311 & 37 & 2 \\
\hline & 160 & 84.1 & $\ldots$ & $\ldots$ & 0.312 & 37 & 2 \\
\hline & 165 & 84.0 & -- & $\ldots$ & 0.312 & 37 & 2 \\
\hline & 170 & 83.9 & - & $\ldots$ & 0.312 & 37 & 2 \\
\hline & 175 & 83.5 & - & $\ldots$ & 0.313 & 37 & 2 \\
\hline & 180 & 83.3 & $\ldots$ & - & 0.313 & 37 & 2 \\
\hline & 185 & 83.0 & $\ldots$ & $\ldots$ & 0.314 & 37 & 2 \\
\hline & 190 & 82.9 & - & - - & 0.314 & 37 & 2 \\
\hline & 195 & 82.7 & -- & $\ldots$ & 0.314 & 37 & 2 \\
\hline
\end{tabular}

1 Static measurement.

2 Dynamic measurement. 


\section{THERMAL PROPERTIES}

\subsection{Specific Heat \\ 4.1.1. Introduction to Graph}

The available specific heat data from cryogenic temperatures to the melting point are presented in the figure and table. Measurements are available only on alloys 80 p 0 and 2090 between 123 and $598 \mathrm{~K}$. Some of these data were obtained by differential scanning calorimetry to indicate the dissolution temperature of precipitat 3 s produced by various aging treatments and the formation of subsequent phases. These are shown in a smoothed form, $53,54,55$ or are omitted ${ }^{53}$ above $400 \mathrm{~K}$. As shown by Papazian, ${ }^{54}$ changes in the aging treatment move the position of the peaks and valleys along the curve to higher and lower temperatures. Taylor ${ }^{55}$ identified the peak at $\approx 510 \mathrm{~K}$ in his specific heat data as the melting point of Li. However, a peak at this position is not observed in the other specific heat measurements of alloy 2090 , and it seems more probable that peaks can be identified with the aging treatment. Consult the original references, which specify aging treatments, for specific heat data on alloys 8090 and 2090 with the fine structure in the curves (important only above $400 \mathrm{~K}$ ).

At present, there are no specific heat data for alloys wh049 or 2219 in the cryogenic temperature range. The curve for the specific heat of alloy 2219 vs. temperature presented in Figure 3.2.6.0. of MIL-HDBK 5E appears to be based upon data from Al-alloy 2024.2,56,57 The composition of alloy 2024 (4.5Cu, $1.5 \mathrm{Mg}$, and $0.6 \mathrm{Mn})$, is similar to the composition of alloy 2219 (5.8-6.8Cu, and $0.2-0.4 \mathrm{Mn}$ ). These data, labeled 2024(2219), are also given in the figure.

The specific heat of an alloy can be approximated, near ambient temperature, by a linear combination of the specific heats of the constituent elements. ${ }^{58}$ Because the specific heat of $\mathrm{Li}$ is about 4 times larger than the specific heat of $\mathrm{Al}$, and about 9 times larger than that of $\mathrm{Cu}$, the specific heats of alloys 8090 and 2090 should be about $10 \%$ higher than that of alloy 2219. This is similar to what is shown in the specific heat figure for the data of Sato ${ }^{53}$ on alloy 8090 and Papazian ${ }^{54}$ on alloy 2090 . However, the higher temperature data on alloy $8090^{4}$ appear quite similar to those of alloy 2024(2219), and, therefore, are probably too low. Variations in aging conditions and chemistry for individual heats can result in changes in the fine structure of a specific heat curve for Al-Li alloys, especially above ambient temperatures. This could account for this apparent discrepancy, and perhaps, also for one unexpectedly high value of specific heat ${ }^{12}$ at $100^{\circ} \mathrm{C}$. More measurements of the specific heat on current production heats of Al-Li alloys would be very desirable. 


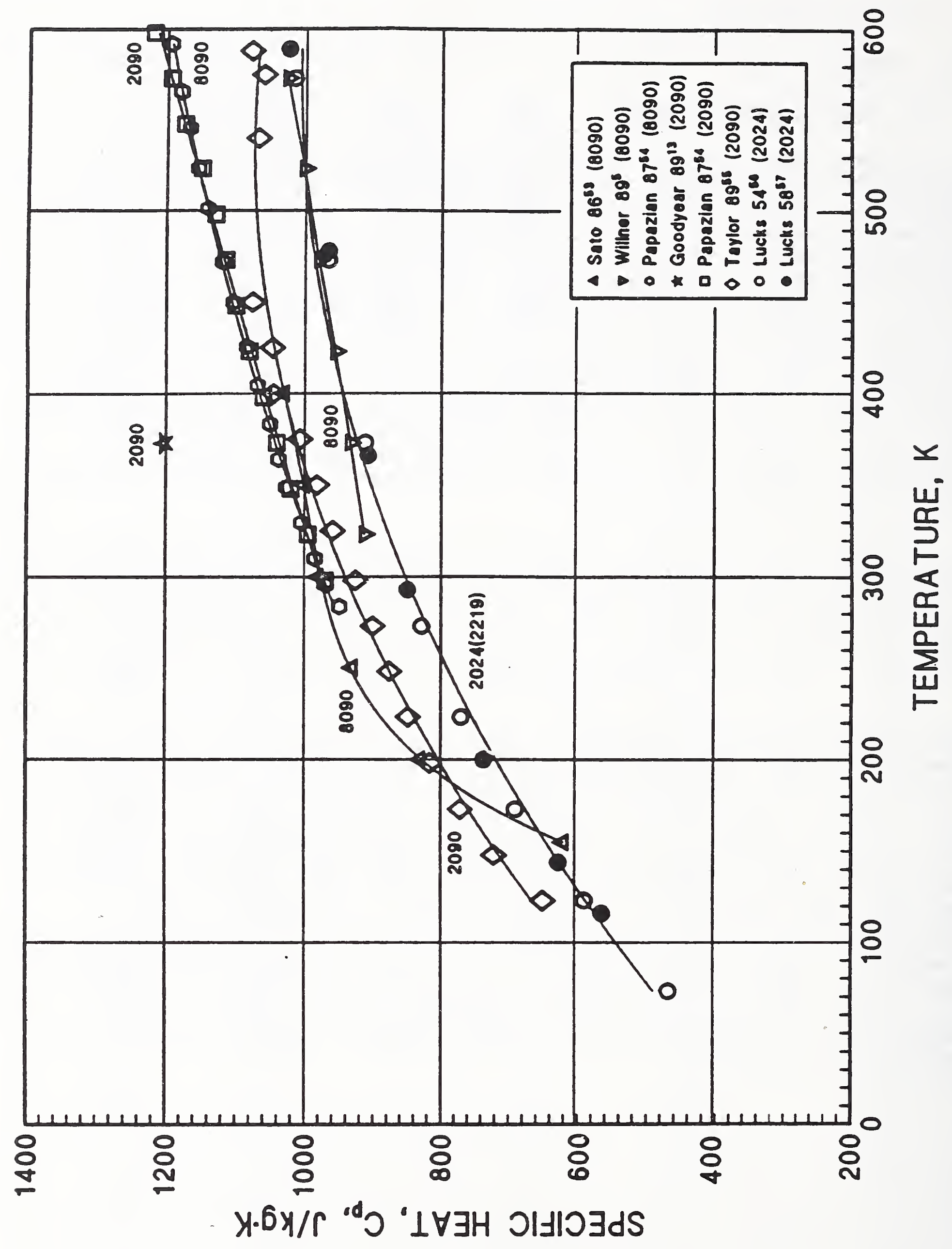


Specific Heat of Al-Li Alloys and Alloy 2219.

\begin{tabular}{|c|c|c|c|c|c|c|c|c|}
\hline Alloy & $\underset{\mathrm{K}}{\text { Temp., }}$ & $\begin{array}{c}\mathrm{C}_{\mathrm{P}} \cdot \\
\mathrm{J} / \mathrm{kg} \cdot \mathrm{K}\end{array}$ & $\begin{array}{l}\text { Ref. } \\
\text { No. }\end{array}$ & & Alloy & $\underset{\mathrm{K}}{\text { Temp., }}$ & $\begin{array}{c}\mathrm{C}_{\mathrm{P}^{\prime}} \\
\mathrm{J} / \mathrm{kg} \cdot \mathrm{k}\end{array}$ & $\begin{array}{l}\text { Ref. } \\
\text { No. }\end{array}$ \\
\hline \multirow[t]{6}{*}{8090} & 155 & 620 & 54 & & 2090 & 123 & 649 & 56 \\
\hline & 200 & 830 & 54 & & & 148 & 720 & 56 \\
\hline & 250 & 930 & 54 & 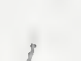 & & 173 & 770 & 56 \\
\hline & 300 & 980 & 54 & & & 198 & 815 & 56 \\
\hline & 350 & 1000 & 54 & & & 223 & 847 & 56 \\
\hline & 400 & 1030 & 54 & & & 248 & 875 & 56 \\
\hline \multirow[t]{8}{*}{8090} & 323 & 913 & 5 & & & 273 & 900 & 56 \\
\hline & 373 & 934 & 5 & & & 298 & 925 & 56 \\
\hline & 423 & 956 & 5 & & & 325 & 958 & 56 \\
\hline & 473 & 980 & 5 & & & 350 & 981 & 56 \\
\hline & 523 & 1002 & 5 & & & 375 & 1006 & 56 \\
\hline & 573 & 1027 & 5 & & & 400 & 1045 & 56 \\
\hline & 623 & 1047 & 5 & & & 425 & 1046 & 56 \\
\hline & 673 & 1070 & 5 & & & 450 & 1075 & 56 \\
\hline \multirow[t]{16}{*}{8090} & 284 & 949 & 55 & & & 540 & 1068 & 56 \\
\hline & 296 & 969 & 55 & & & 575 & 1060 & 56 \\
\hline & 310 & 985 & 55 & & & 588 & 1078 & 56 \\
\hline & 329 & 1005 & 55 & & $2024(2219)$ & 73 & 469 & 57 \\
\hline & 349 & 1026 & 55 & & & 123 & 590 & 57 \\
\hline & 364 & 1038 & 55 & & & 173 & 690 & 57 \\
\hline & 383 & 1051 & 55 & & & 223 & 770 & 57 \\
\hline & 404 & 1069 & 55 & & & 273 & 828 & 57 \\
\hline & 426 & 1085 & 55 & & & 373 & 912 & 57 \\
\hline & 450 & 1104 & 55 & & & 473 & 967 & 57 \\
\hline & 472 & 1120 & 55 & & & 573 & 1017 & 57 \\
\hline & 501 & 1141 & 55 & & $2024(2219)$ & 116 & 565 & 58 \\
\hline & 523 & 1155 & 55 & & & 144 & 628 & 58 \\
\hline & 546 & 1168 & 55 & & & 200 & 736 & 58 \\
\hline & 566 & 1181 & 55 & & & 293 & 849 & 58 \\
\hline & 592 & 1195 & 55 & & & 366 & 908 & 58 \\
\hline 2090 & 373 & 1203 & 13 & & & 478 & 966 & 58 \\
\hline \multirow[t]{13}{*}{2090} & 298 & 970 & 55 & & & 589 & 1025 & 58 \\
\hline & 323 & 995 & 55 & & & & & \\
\hline & 348 & 1020 & 55 & & & & & \\
\hline & 373 & 1040 & 55 & & & & & \\
\hline & 398 & 1060 & 55 & & & & & \\
\hline & 423 & 1080 & 55 & & & & & \\
\hline & 448 & 1100 & 55 & & & & & \\
\hline & 473 & 1115 & 55 & & & & & \\
\hline & 498 & 1130 & 55 & & & & & \\
\hline & 523 & 1150 & 55 & & & & & \\
\hline & 548 & 1175 & 55 & & & & & \\
\hline & 573 & 1195 & 55 & & & & & \\
\hline & 598 & 1220 & 55 & & & & & \\
\hline
\end{tabular}




\subsection{Thermal Conductivity}

\subsubsection{Introduction to Graph}

Thermal conductivity data for alloys 8090, 2090, and 2219 between 4 and $573 \mathrm{~K}$ are given in the accompanying thermal conductivity figure and table. No data on WL049 are currently available. The solid lines shown in the figure represent the fit of second-order polynomials to the data for alloy $8090,{ }^{4}$ alloy $2090,53,59$ and alloy $2219 .{ }^{60}$ The data of $R u l e^{59}$ appear to be anomalously low. However, thermal conductivity of Al alloys at low temperatures is composition and cold-work sensitive. ${ }^{61}$ 


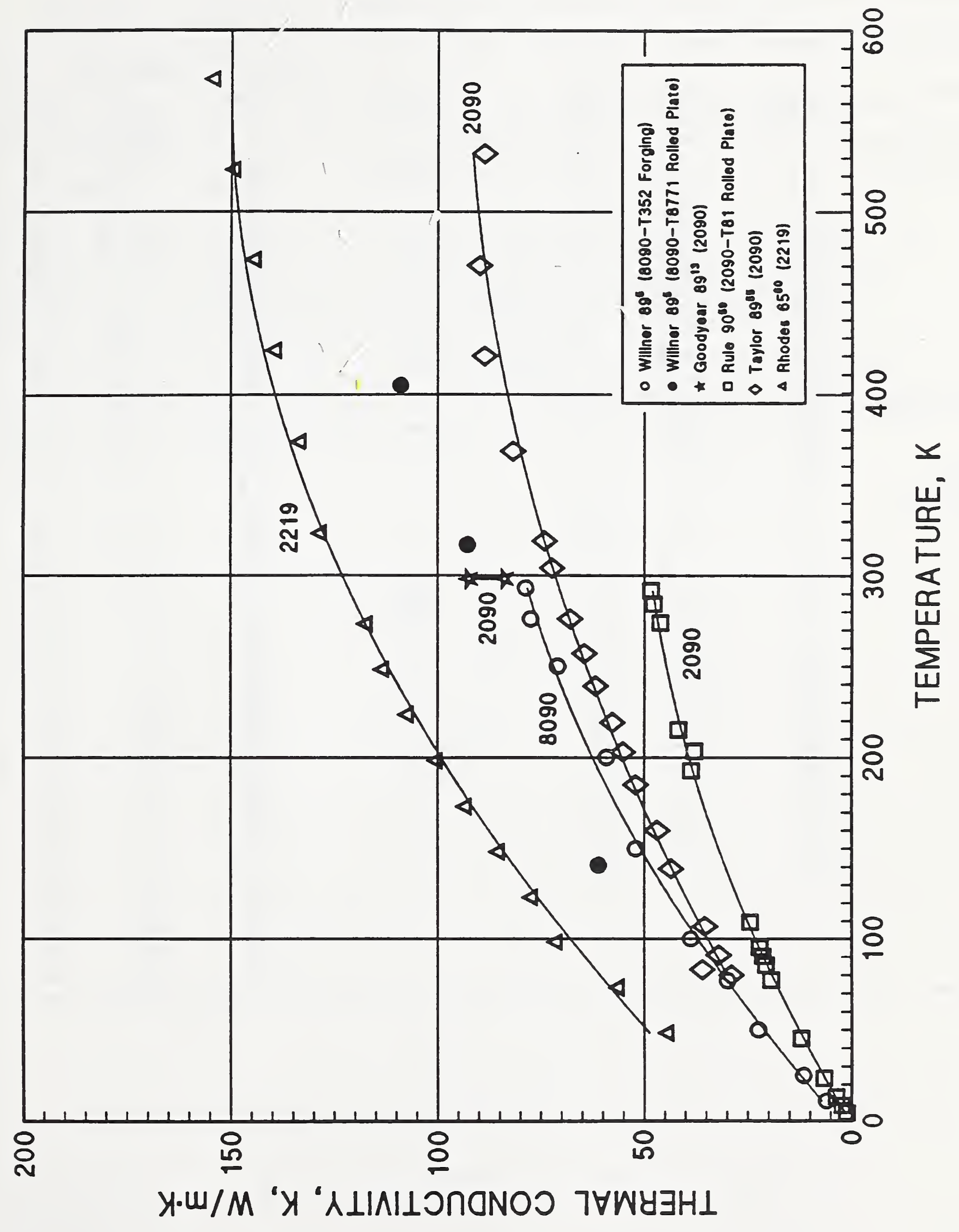


Thermal Conductivity of Al-Li Alloys and Alloy 2219.

\begin{tabular}{|c|c|c|c|c|c|c|c|}
\hline Alloy & $\underset{\mathrm{K}}{\operatorname{Temp}}$ & $\begin{array}{c}\mathrm{K} \\
\mathrm{W} / \mathrm{m} \cdot \mathrm{K}\end{array}$ & $\begin{array}{l}\text { Ref. } \\
\text { No. }\end{array}$ & Alloy & $\underset{K}{\text { Temp. }}$ & $\begin{array}{c}\mathrm{K} \\
\mathrm{W} / \mathrm{m} \cdot \mathrm{K}\end{array}$ & $\begin{array}{l}\text { Ref. } \\
\text { No. }\end{array}$ \\
\hline \multirow[t]{10}{*}{$8090-\mathrm{T} 352$} & 11 & 6.1 & 5 & \multirow[t]{18}{*}{2090} & 80 & 28.8 & 56 \\
\hline & 25 & 11.6 & 5 & & 83 & 35.8 & 56 \\
\hline & 50 & 22.5 & 5 & & 91 & 31.9 & 56 \\
\hline & 77 & 29.9 & 5 & & 107 & 35.2 & 56 \\
\hline & 100 & 38.8 & 5 & & 139 & 43.4 & 56 \\
\hline & 150 & 52.1 & 5 & & 160 & 46.7 & 56 \\
\hline & 200 & 59.2 & 5 & & 185 & 51.9 & 56 \\
\hline & 250 & 71.0 & 5 & & 203 & 55.0 & 56 \\
\hline & 276 & 77.5 & 5 & & 219 & 57.6 & 56 \\
\hline & 293 & 78.7 & 5 & & 239 & 61.7 & 56 \\
\hline \multirow[t]{3}{*}{$8090-T 8771$} & 141 & 61.1 & 5 & & 257 & 64.4 & 56 \\
\hline & 317 & 92.8 & 5 & & 276 & 67.8 & 56 \\
\hline & 404 & 109. & 5 & & 304 & 72.2 & 56 \\
\hline 2090 & 298 & 87.9 & 13 & & 319 & 74.0 & 56 \\
\hline \multirow[t]{20}{*}{$2090-T 81$} & 4 & 1.1 & 60 & & 368 & 81.6 & 56 \\
\hline & 8 & 2.2 & 60 & & 420 & 88.5 & 56 \\
\hline & 13 & 3.6 & 60 & & 470 & 89.7 & 56 \\
\hline & 23 & 6.6 & 60 & & 532 & 88.5 & 56 \\
\hline & 45 & 12.1 & 60 & \multirow[t]{16}{*}{2219} & 48 & 44 & 61 \\
\hline & 77 & 19.4 & 60 & & 73 & 56 & 61 \\
\hline & 85 & 20.6 & 60 & & 98 & 71 & 61 \\
\hline & 90 & 21.4 & 60 & & 123 & 77 & 61 \\
\hline & 95 & 22.1 & 60 & & 148 & 85 & 61 \\
\hline & 109 & 24.4 & 60 & & 173 & 93 & 61 \\
\hline & 193 & 38.6 & 60 & & 198 & 100 & 61 \\
\hline & 203 & 37.9 & 60 & & 223 & 107 & 61 \\
\hline & 215 & 41.7 & 60 & & 248 & 113 & 61 \\
\hline & 274 & 46.1 & 60 & & 273 & 117 & 61 \\
\hline & 284 & 47.7 & 60 & & 323 & 128 & 61 \\
\hline & 292 & 48.4 & 60 & & 373 & 133 & 61 \\
\hline & & & & & 423 & 139 & 61 \\
\hline & & & & & 473 & 144 & 61 \\
\hline & & & & & 523 & 149 & 61 \\
\hline & & & & & 573 & 154 & 61 \\
\hline
\end{tabular}




\subsection{Mean Thermal Expansion}

\subsubsection{Introduction to Graph}

The figure on mean thermal expansion presents the data available on the property, defined as

$$
\Delta L / L \cdot \Delta T=[L(293 \mathrm{~K})-\mathrm{L}(\mathrm{T})] /[\mathrm{L}(293 \mathrm{~K})(293 \mathrm{~K}-\mathrm{T})] .
$$

Only data for alloy 2219-T87 are available over a wide temperature range, from 18 to $573 \mathrm{~K}$. The values presented for alloys 8090 and 2090 are averages obtained over the temperature range indicated in the graph. Near $293 \mathrm{~K}$, the quantity $\triangle \mathrm{L} / \mathrm{L} \cdot \Delta \mathrm{T}$ becomes less accurate, because a smal? er length change is measured. Mean thermal expansion data for alloy 2219 near $293 \mathrm{~K}$ were eliminated if a wide degree of $\mathrm{s}^{\prime}$ atter was evident. Although only one set of thermal expansion data for alloy 2219 is available, that data set is in fair agreement with several sets of data for alloy $6061(0.6 \mathrm{Si}, 0.27 \mathrm{Cu}, 1.0 \mathrm{Mg}$, $0.2 \mathrm{Cr}$ ) over a similar temperature range. The data are also presented in the thermal expansion table that follows the graph. 


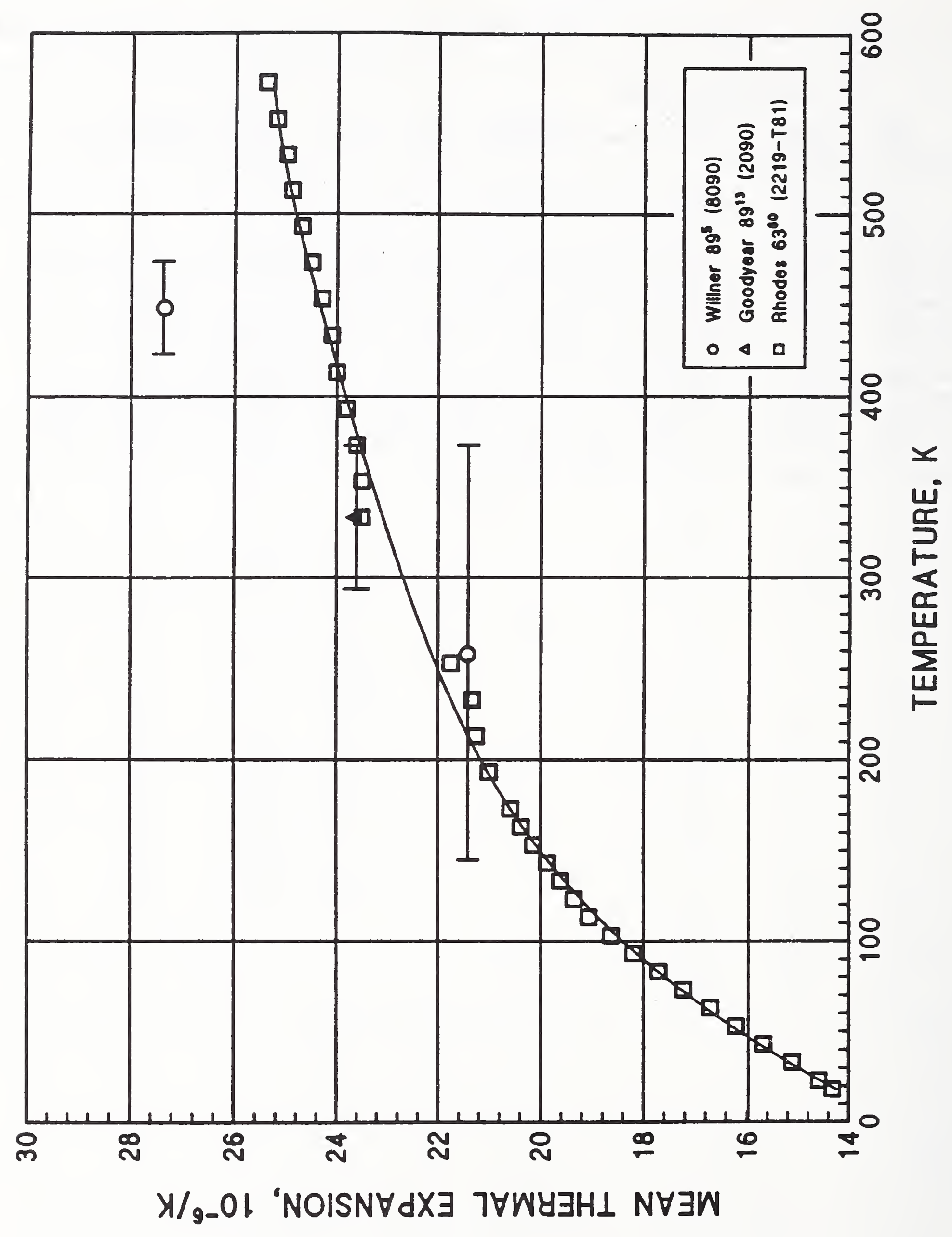


Mean Thermal Expansion of Al-Li Alloys and Alloy 2219.

\begin{tabular}{|c|c|c|c|}
\hline Alloy & $\underset{K}{\operatorname{Temp}}$ & $\begin{array}{c}\frac{1}{\mathrm{~L}} \frac{\Delta \mathrm{L}}{\Delta \mathrm{T}} \\
10^{-5_{\mathrm{K}}-1}\end{array}$ & $\begin{array}{l}\text { Ref. } \\
\text { No. }\end{array}$ \\
\hline 8090 & $\begin{array}{l}258 \\
448\end{array}$ & $\begin{array}{l}27.4 \\
21.4\end{array}$ & $\begin{array}{l}5 \\
5\end{array}$ \\
\hline 2090 & 333 & 23.6 & 13 \\
\hline \multirow[t]{34}{*}{$2219-T 81$} & 18 & 14.3 & 61 \\
\hline & 23 & 14.6 & 61 \\
\hline & 33 & 15.1 & 61 \\
\hline & 43 & 15.7 & 61 \\
\hline & 53 & 16.2 & 61 \\
\hline & 63 & 16.7 & 61 \\
\hline & 73 & 17.2 & 61 \\
\hline & 83 & 17.7 & 61 \\
\hline & 93 & 18.2 & 61 \\
\hline & 103 & 18.6 & 61 \\
\hline & 113 & 19.1 & 61 \\
\hline & 123 & 19.4 & 61 \\
\hline & 133 & 19.6 & 61 \\
\hline & 143 & 19.9 & 61 \\
\hline & 153 & 20.1 & 61 \\
\hline & 163 & 20.4 & 61 \\
\hline & 173 & 20.6 & 61 \\
\hline & 193 & 21.0 & 61 \\
\hline & 213 & 21.3 & 61 \\
\hline & 233 & 21.3 & 61 \\
\hline & 253 & 21.8 & 61 \\
\hline & 333 & 23.5 & 61 \\
\hline & 353 & 23.5 & 61 \\
\hline & 373 & 23.6 & 61 \\
\hline & 393 & 23.8 & 61 \\
\hline & 413 & 24.0 & 61 \\
\hline & 433 & 24.1 & 61 \\
\hline & 453 & 24.3 & 61 \\
\hline & 473 & 24.5 & 61 \\
\hline & 493 & 24.7 & 61 \\
\hline & 513 & 24.9 & 61 \\
\hline & 533 & 25.0 & 61 \\
\hline & 553 & 25.2 & 61 \\
\hline & 573 & 25.4 & 61 \\
\hline
\end{tabular}




\section{ACKNOWLEDGEMENTS}

We thank Troy Tack, Bob Ritchie, K.T. Venkateswara Rao, Steve James, Dennis Rule, and Hassell Ledbetter for providing us with preprints and data. We would also like to thank the many authors who have been so cooperative in answering our many questions. 


\section{REFERENCES}

1. Reed, R. P., Purtscher, P. T., McColskey, J. D., Walsh, R. P., Berger, J. R., Drexler, E. S., Santoyo, R. L., and Simon, N. J., "Aluminum Alloys for ALS Cryogenic Tanks: Comparative Measurements of Cryogenic Mechanical Properties of Al-Li Alloys and Alloy 2219," submitted for publication as NISTIR 3979, Natiunal Institute of Standards and Technology, Boulder, CO.

2. Metallic Materials and Elements for Aerospace Vehicle Structure, Vol. 1," Department of Defense, Washington, SC, MIL-HNBK-5E (1987).

3 Wan, C. C., Carter, R. V., Henderson, G. W., and Uht, J. C., "Tensile Properties of $8090 \mathrm{Al}-\mathrm{Li}$ Alloy at Elevated and Cryogenic Temperatures," The Aerospace Corp., El Segundo, CA, Report No. ATR$89(8486)-1,48$ pp. (1989).

4. Venkateswara Rao, K.T., Yu, W., and Ritchie, R.O., "Cryogenic Toughness of Commercial Aluminum-Lithium Alloys: Role of Delamination Toughening," Lawrence Berkeley Laboratory, Berkeley, CA, Report No. LBL-224969, 36 pp. (1988).

5. Willner, E., "Aluminum-Lithium Alloy $8090, "$ Structural and Materials Engineering Bulletin, Lockheed Missiles and Space Company, 27 pp. (1989).

6. Jata, K. V., and Starke, E. A., Jr., "Fracture Toughness of Al-Li-X Alloys at Ambient and Cryogenic Temperatures," Scripta Metallurgica, 22, 1553-1556 (1988).

7. Grimes, R., Miller, W. S., and Reynolds, M. A., "The Status of Alcan's Aluminum-Lithium Alloy Programme," in Aluminum-Lithium Alloys: Design, Development and Application Update, Eds. Kar, R. J., Agrawal, S. P., and Quist, W. E., ASM International, Metals Park, OH, 41-55 (1988).

8. Peel, C. J., Evans, B., and McDarmaid, D., "Current Status of UK Lightweight Lithium-containing Aluminum Alloys," in Aluminum-Lithium Alloys III, Institute of Metals, London, England, 26-36 (1986).

9. Lockheed Missiles and Space Company, Inc., "Aluminum-Lithium Alloy 8090, Sheet and Plate," Lockheed Missiles and Space Company, Report No. LAC 07-4774 D, 14 pp. (1989).

10. Welpmann, K., Lee, Y. T., and Peters, M., "Low Temperature Deformation Behavior of 8090," in Aluminum-Lithium Alloys V, Eds. Starke, E. A., Jr., and Sanders, T. H., Jr., Materials and Components Engineering Publications, Birmingham, England, 1513-1522 (1989).

11. Glazer, J., Verzasconi, S. L., Dalder, E.N.C., Yu, W., Emigh, R. A.,Ritchie, R. O., and Morris, J. W., Jr., "Cryogenic Mechanical Properties of Al-Cu-Li-Zr Alloy 2090," in Advances in Cryogenic Engineering Materials, Vol. 32, Eds. Reed, R. P., and Clark, A. F., Plenum Press, NY, 397-404 (1986). 
12. Venkateswara Rao, K. T., and Ritchie, R. O., "Fracture-Toughness Behavior of 2090-T83 Aluminum-Lithium Alloy Sheet at Ambient and Cryogenic Temperatures," Scripta Metallurgica, 23, 1129-1134 (1989).

13. Goodyear, M. D., "ALCOA Alloy 2090," Aluminum Company of America, Alcoa Center, PA, ALCOA Green Letter GL 226, 103 pP. (1989).

14. Venkateswara Rao, K. T., and Ritchie, R. O., "Mechanical Properties of Commercial Aluminum-Lithium Alloys Part I: Fracture Toughness and Microstructure," Material Science and Technology, 5 , 882-895 (1989).

15. Venkateswara Rao, K. T., Hayashigatani, H. F., Yu, W., and Ritchie, R. 0., "On the Fracture Toughness of Aluminum-Lithium Alloy 2090-T8E41 at Ambient and Cryogenic Temperatures," Scripta Metallurgica, 22, 93-98 (1988).

16. Glazer, J., Verzasconi, S. L., Sawtell, R. R., and Morris, J. W., Jr., Mechanical Behavior of Aluminum-Lithium Alloys at Cryogenic Temperatures," Metallurgical Transactions A, 18A, 1695-1701 (1987).

17. Tobler, R. L., Han, J. K., and Reed, R. P., "Fatigue Resistance of a 2090-T8E41 Aluminum Alloy at Cryogenic Temperatures," in Cryogenic Materials '88: Vol. 2. Structural Materials, Eds. Reed, R. P., Xing, Z. S., and Collings, E. W., International Cryogenic Materials Conference, Boulder, CO, 703-712 (1988).

18. Pickens, J. R., Heubaum, F. H., and Tack, W. T., "Weldalite 049: An Advanced Cryogenic Aluminum Alloy," Unpublished data, Martin Marietta Corporation (1989).

19. Tack, W. T., and Loechel, I. W., "Weldalite 049: Applicability of A New High Strength, Weldable Al-Li-Cu Alloy," in Aluminum-Lithium Alloys V, Eds. Starke, E. A., Jr. and Sanders, T. H., Jr., Materials and Component Engineering Publication, Birmingham, England, 1457-1467 (1989).

20. Pickens, J. R., Heubaum, F. H., Langan, T. J ., and Kramer, L. S., "Al- -4.5-6.3 Cu--1.3Li--0.4Ag--0.4Mg--0.14Zr Alloy Weldalite 049," in Aluminum-Lithium Alloys V, Eds. Starke, E. A., Jr., and Sanders, T. H., $\mathrm{Jr}$., Materials and Component Engineering Publications, Birmingham, England, 1397-1414 (1989).

21. Kaufman, J. G., Bogardus, K. O., and Wanderer, E. T., Tensile Properties and Notch Toughness of Aluminum Alloys at $-452^{\circ} \mathrm{F}$ in Liquid Helium," in Advances in Cryogenic Engineering, 13, 294-308 (1968).

22. Carman, C. M., Forney, J. W., and Katlin, J. M., "Plane Strain Fracture Toughness of 2219-T87 Aluminum Alloy at Room and Cryogenic Temperatures, NASA, Report No. CR-54297 (1966).

23. Denaburg, C. R., "Low Temperature Mechanical Properties of Aluminum Alloy 2219-T87, 0.040 Inch Thick Sheet through 5.00 Inch Thick Plate," NASA--George C. Marshall Space Center, Report No. TMX-53332 (1965). 
24. Kaufman, J. G., Nelson, F. G., and Johnson, E. W., "The Properties of Aluminum Alloy 2219 Sheet Plate, and Welded Joints at Low Temperatures," in Advances in Cryogenic Engineering, Vol. 8, Ed. Timmerhaus, K. D., Plenum Press, New York, NY, 661-670 (1963).

25. Hall, I. R., and Bixler, W. D., "Subcritical Crack Growth of Selected Aerospace Pressure Vessel Materials," :ASA, Report No. CR-120834 (1972).

26. Witzel1, W. E., "Crack Growth Behavior of 2219-T87 Aluminum Alloy from 20 $\mathrm{K}\left(-423^{\circ} \mathrm{F}\right)$ to $422 \mathrm{~K}\left(300^{\circ} \mathrm{F}\right)$," Convair Aerospace, Division of General Dynamics, Report No. NAS-73011 (1973).

27. Masters, J. N., Haese, W. P., and Finger, R. W., "Investigation of Deep Flaws in Thin Walled Tanks," NASA, Report No. CR-12606 (1969).

28. Tiffany, C. F., Lorenz, P. M., and Shah, R. C., "Extended Loading of Cryogenic Tanks," NASA, Report No. CR-72252 (1966).

29. Tiffany, C. F., Lorenz, P. M., and Hall, L. R., "Investigation of Plane-Strain Flaw Growth in Thick Walled Tanks," NASA, Report No. CR-54837 (1966).

30. Hall, L. R., and Finger, R. W., "Investigation of Flaw Geometry and Loading Effects on Plane Strain Fracture in Metallic Structures," NASA, Report No. CR-72659 (1971).

31. Masters, J. N., Bixler, W. D., and Finger, R. W., "Fracture Characteristics of Structural Aerospace Alloys Containing Deep Surface Flaws," NASA, Report No. CR-134587 (1973).

32. Shah, R. C., "Effects of Proof Loads and Combined Mode Loadings on Fracture and Flaw Growth Characteristics of Aerospace Alloys," NASA--Lewis Research Center, Cleveland, OH, Report No. CR-134611, 274 PP. (1974).

33. Masters, J. N., Engstrom, W. L., and Bixler, W. D., "Deep Flaws in Weldaments of Aluminum and Titanium," NASA, Report No. CR-134649 (1974).

34. Read, D. T., and Reed, R. P., "Effects of Specimen Thickness on Fracture Toughness of an Aluminum Alloy," International Journal of Fracture, 13 , 201-213 (1977).

35. Schwanbeck, C. A., "Effect of Nuclear Radiation on Materials at Cryogenic Temperature," NASA, Report No. CR-54881 (1965).

36. James, R. S., and Bucci, R. J., "Lessons Learned: Aluminum-Iithium Alloy Development, "Unpublished data, Aluminum Company of America, Alcoa Center, PA, 62 pp. (1989).

37. Glazer, J., Morris, J. W., Jr., Kim, S. A., Austin, M. W., and Ledbetter, H. M., "Temperature Variation of the Elastic Constants of Aluminum Alloy 2090-T81," AIAA Journal, 25, 1271-1272 (1987). 
38. Noble, B., Harris, S. J., and Dinsdale, K., "The Elastic Modulus of Aluminum-Lithium Alloys," Journal of Material Science, 17, 461-468 (1982).

39. Webster, D., "Toughness and Ductility of Aluminum-Lithium Alloys Prepared by Powder Metallurgy and Ingot Metallurgy," in Aluminum-Lithium Alloys I, Eds. T. H. Sanders, Jr. and E. A. Starke, Jr., The Metallurgical Society of the AIME, New York, NY, 228-239 (1981).

40. Reed, R. P., "Materials at Low Temperatures: Aluminum. 2. A Review of Deformation Properties of High-Purity Aluminum and Dilute Aluminum Alloys," Cryogenics, 12, 259-291 (1972).

41. Hill, R., "The Elastic Behavior of a Crystalline Aggregate," Proceedings of the Physical Society, Section A, 65, 349-354 (1952).

42. Maller, W., Bubeck, E., and Gerold, V., "Elastic Constants of Al-Li Solid

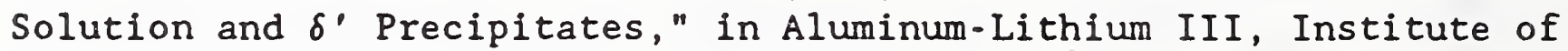
Metals, London, England, 435-441 (1986).

43. Stokes, H. J., "Apparatus for the Measurement of Young's Modulus, between -200 and $700^{\circ} \mathrm{C}$ by the Transverse Vibration in Vacuum," Journal of Scientific Instruments, 37, 117-120 (1960).

44. Senoo, M., Nishimura, T., Matsumuro, A., and Ishigai, S., "Measurement of the Elastic Constants of Polycrystals in a Cylindrical Specimen by the Resonance Method (Elastic Anisotropy of an Axisymmetrical Specimen and Measurements at Low and High Temperature)," JSME International Journal, 30, 747-753 (1987).

45. Girard, F., and Vidal, G., "Nouvelle Méthode de Mesure à Chaud du Coefficient de Poisson des Métaux et Alliages," Memoires Scientifiques Rev. Metallurg., 57, 118-123 (1960).

46. Dudzinski, N., Murray, J. R., and Chalmers, B., "The Young's Modulus of Some Aluminum Alloys," The Journal of the Institute of Metals, 74, 291-314 (1948).

47. Rooney, W. D., Papazian, J. M., Balmuth, E. S., Davis, R. C., and Adler, P. N., "Elastic Anisotropy in Al-Li Alloys," in Aluminum-Lithium Alloys 5, Eds. T. H. Sanders, Jr. and E. A. Starke, Jr., Materials and Component Engineering Publications Ltd., Birmingham, England, 799-808 (1989).

48. Wawra, H. H., "Einfluss der Werkstoffvorbehandlung auf die Elastizitatseigenschaften vol Aluminiumwerkstoffen," Aluminum, 46, 805-811 (1970).

49. Broussaud, F., and Thomas, M., "Influence of $\delta$ ' Phase Coalescence on Young's Modulus in an Al-2.5wtzLi Alloy," in Aluminum-Lithium Alloys III, Institute of Metals, London, England, 442-447 (1986).

50. Read, D. T., and Ledbetter, H. M., "Temperature Dependence of the Elastic Constants of Precipitation-Hardened Aluminum Alloys 2014 and 2219," 
Journal of Engineering Materials and Technology, 99, 181-184 (1977).

51. Ledbetter, H. M., private communications, National Institute of Standards and Technology, Boulder, CO (1990).

52. Pickens, J. R., "Weldalitz 049: U1ta-High-Strength Weldable Al-Li Alloy, Technical Data Package, Martin Marietta Laboratories, Baltimore, MD, Pp. 44 (1990).

53. Sato, T., Takahashi, T., "Precipitation Phenomena and Mechanical Properties in an Al-Li-Cu-Mg-Zr Alloy," Journal of the Japanese Institute for Light Metals, 36, 728-736 (1986).

54. Papazian, J. M., Bott, G. C., and Shaw, P., "Influence of Forming in the T3 Condition on Properties of 2090-T8X, 2091-T8X, and 8090-T8X, "Journal de Physique, Colloque $3, \underline{48-C 3}, 231-237$ (1987).

55. Taylor, R. E., Groot, H., and Larimore, J., "Thermal Conductivity and Specific Heat of Aluminum-Lithium Alloy 2090," Thermophysical Properties Research Laboratory, Purdue University, West Lafayette, Indiana, Report No. TPRL 878,14 pp. (1989).

56. Lucks, C. F., Matolich, J., and Van Valzor, J. A., "The Experimental Measurement of Thermal Conductivities, Specific Heats, and Densities of Metallic, Transparent, and Protective Materials, Part III," Battelle Memorial Institute, Columbus, OH, Report No. TR 6145, 72 pp. (1954).

57. Lucks, C. F., and Deem, H. W., "Thermal Properties of Thirteen Metals," ASTM Special Technical Publication No. 227, American Society for Testing and Materials, Philadelphia, PA (1958).

58. Corruccini, R. J., "Properties of Materials at Low Temperatures, Part I," Chemical Engineering Progress, 53, 262-267 (1957).

59. Rule, D. L., "Thermal Conductivity of Aluminum-Lithium Alloy 2090-T81 from 4.2 to $300 \mathrm{~K}, "$ private communication, National Institute of Standards and Technology, Boulder, CO (1990).

60. Rhodes, B. L., Moeller, C. E., and Sauer, H. J., "An Apparatus for Determining Thermal Conductivity of Solids from 20 to $600 \mathrm{~K}$," Cryogenics, 5, 17-20 (1965).

61. Hust, J. G., and Lankford, A. B., "Thermal Conductivity of Aluminum, Copper, Iron, and Tungsten for Temperatures from $1 \mathrm{~K}$ to the Melting Point," National Bureau of Standards, Boulder, CO, NBSIR 84-3007 (1984). 
BL-114A

$(5-90)$
U.S. DEPARTMENT OF COMMERCE NATIONAL INSTITUTE OF STANDARDS AND TECHNOLOGY

\section{BIBLIOGRAPHIC DATA SHEET}

1. PUEUCATION OR REPORT NUMBER NISTIR 3971

2. PERFORMING ORQAMIZATION REPOAT MUMBEA B91-0236

3. PUELCATION DATE

December 1991

\section{TITLE AND SUBTITLE}

Review of Cryogenic Mechanical and Thermal Properties of Al-Li Alloys and Alloy 2219

5. AUTHOR(S)

N.J. Simon, E.S. Drexler, and R.P. Reed

6. PERFORMING ORQANIZATION (IF JOINT OR OTHER THAN NIST, SEE INSTAUCTIONS)

U.S. DEPAATMENT OF COMMERCE

MATIONAL INSTITUTE OF STANDARDS AND TECHNOLOOY

BOULDER, COLORADO $80303-3328$

7. CONTRACT/GRANT MUMBEA

8. TYPE OF REPORT AND PEAIOD COVEAED

9. SPONSORING ORGANIZATION MAME AND COMPLETE ADDRESS (STREET, CITY, STATE, ZIP)

Air Force System Command

Astronautics Laboratory

Edwards Air Force Base, CA

10. SUPPLEMENTARY NOTES

11. ABSTRACT (A 200-WORD OA LESS FACTUAL SUMMAAY OF MOST SIGMIFICANT INFOAMATION. IF DOCUMENT INCLUDES A SIGNIFICANT BIBLOGRAPHY OR UTERATURE SURVEY, MENTION IT MERE,

The review of cryogenic mechanical and thermal properties presented here is part of a broader National Institute of Standards and Terhnology (NIST) program to assess new high-strength Al-Li alloys for use in the cryogenic tankagi of the Advanced Launch System (ALS). The purpose of the NIST program has been to assess the relative suitability of high-strength Al-Li alloys and alloy 2219 for use in ALS cryogenic tanks. In this report, the cryogenic data on Al-Li alloys 8090, 2090, WL049, and Al alloy 2219 have been summarized. Properties covered in this survey are tensile strength, yield strength, elongation, fracture toughness, elastic constants, specific heat, thermal conductivity, and thermal expansion.

12. KEY WORDS (6 TO 12 ENTRIES; ALPHABETICAL ORDER; CAPITALIZE ONLY PROPER MAMES; AND SEPARATE KEY WORDS BY SEMICOLONS)

alloy 2219; aluminum alloys; cryogenic properties; elastic constants; 1ithium alloys; mechanical properties; physical properties

\section{AVAILABILTY}

$X$ UNUMITED

FOR OFFICIAL DISTRIBUTION. DO NOT RELEASE TO NATIONAL TECHMICAL INFORMATION SERVICE (MTIS).

ORDER FROM SUPEAINTENDENT OF DOCUMENTS, U.S. GOVERMMENT PRINTING OFFICE, WASHINGTON, DC 20402.

ORDER FROM NATIOMAL TECHNICAL INFORMATION SERVICE (NTIS), SPR!NGFIELD, VA 22161.

14. NUMBER OF PRINTED PAGES

15. PAICE

A09

ELECTRONIC FORM 
